\title{
Effects of blast loading on seismically detailed reinforced concrete columns
}

\author{
by
}

Conrad Kyei

A thesis submitted to the Faculty of Graduate and Postdoctoral Affairs in partial fulfillment of the requirements for the degree of

Master of Applied Science

in

Civil Engineering

Carleton University

Ottawa, Ontario

(C) 2014, Conrad Kyei 


\section{Abstract}

The rise in the number of terrorist attacks over the past few decades has led to growing concerns about the performance of buildings designed by well-established conventional design methods under blast loading. The concerns arise from the response of buildings and loss of lives in some of the more popular terrorist attacks such as those involving the Alfred P. Murrah Building, the Khobar Towers, and Marriott Hotel in Islamabad. Whereas most damage during these attacks was to non-structural elements such as infill wall systems and window glass, the collapse of the Alfred P. Murrah Building revealed that failure of load-bearing members can lead to widespread buildings failure. Thus, it has become imperative to investigate the performance of load-bearing building members to blast loading. More specifically, to quantify the blast resistance offered by buildings designed and detailed for other load types such as wind and earthquake.

The effect of seismically detailed reinforced concrete columns on their blast resistance was investigated. Reinforced concrete columns not forming part of the seismic force resisting system were detailed according to CSA A23.3-04 - Design of Concrete Structures. The detailed reinforced concrete columns were subjected to blast loading in a numerical study using the high fidelity physics based finite element code (LS-DYNA). The numerical study was undertaken to investigate the effects of columns designed for different levels of seismicity in the National Building Code of Canada (NBCC) on their blast resistance.

The results of the numerical study show that the lateral reinforcement detailing has a significant effect on the behaviour of columns under blast loading. When the reinforced concrete columns were detailed for high levels of seismicity by reducing the lateral reinforcement spacing in the plastic hinge region, the maximum lateral displacement was observed to reduce significantly in comparison with columns detailed with lateral reinforcement spaced for conventional design. 
Also, reducing the lateral reinforcement spacing at mid-height of the column, where plastic hinge formations is expected under blast loading, further reduced the maximum lateral displacement. The closely spaced lateral reinforcement in the seismically-detailed columns was observed to increase the blast resistance, especially to close-in blast loading. The effect of axial loading was also investigated in the numerical study. As the axial load ratio increased, the blast resistance of the concrete columns increased. However, at high, axial load ratios, the columns suffered concrete crushing in the compression zone leading to higher lateral displacements and instability. At higher scaled distances, increasing axial load ratios resulted in reduced maximum lateral displacements; with the seismically-detailed columns not offering any significant advantage over the conventionally-detailed columns. 


\section{Acknowledgements}

Every human endeavor worth pursuing is never accomplished solely by the efforts of a single individual.

I would like to express my gratitude to certain specific individuals who have made this effort much more bearable. Firstly, to my supervisor, Dr. Braimah, who guided me every step of the way. To my parents, who have been a constant source of encouragement and provided support in various forms throughout the duration of my studies. And to a special friend, Matilda OwusuMensah, I am grateful for all you have done.

I am also very grateful for all who have in various ways, big or small, helped in bringing this work to fruition. 


\section{Table of Contents}

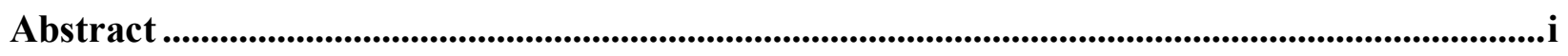

Ackno wledgements .................................................................................................................. iii

Table of Contents .......................................................................................................................iv

List of Tables ............................................................................................................................. viii

List of Figures.............................................................................................................................................................ix

List of Abbreviations and Symbols ....................................................................................................xiv

1 Chapter: Introduction ........................................................................................................1

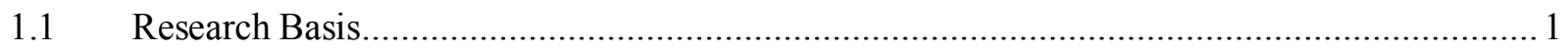

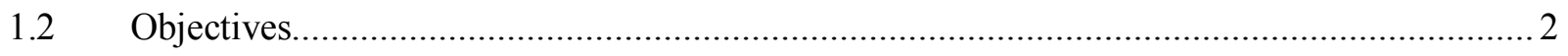

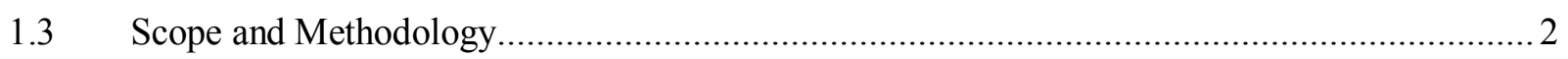

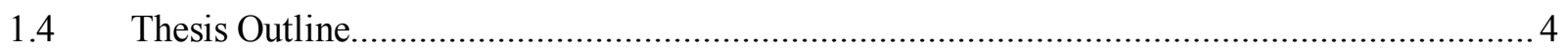

2 Chapter: Literature Review..............................................................................................................5

2.1 Nature of explosions and mechanism of blast waves...........................................................

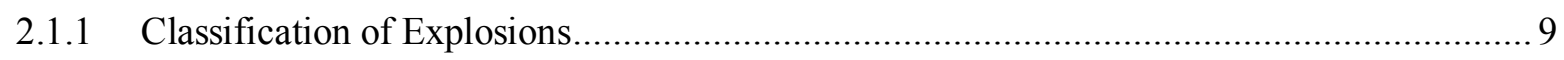

2.1.2 Blast Scaling Laws …………………………………......................................... 10

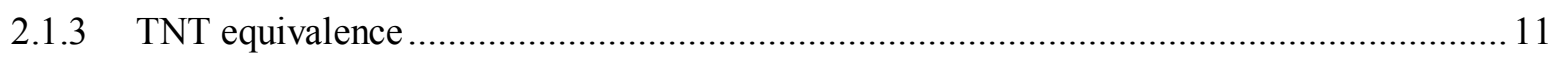

2.1.4 Blast load interaction with structures .................................................................... 11

2.2 Estimating Structural response to blast loads ................................................................ 12

2.2.1 Equivalent Single Degree of Freedom Analysis .............................................................. 13

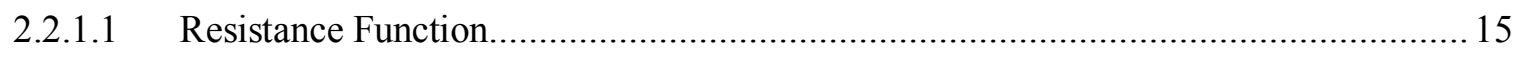

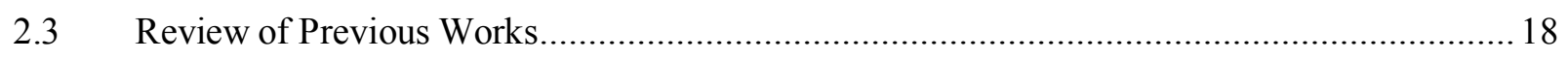

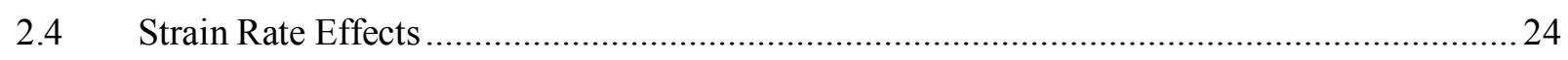

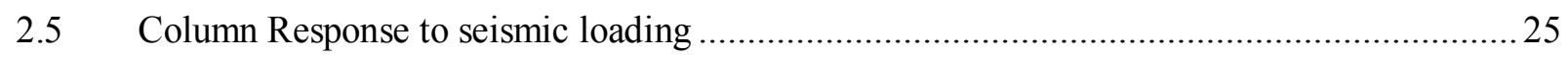




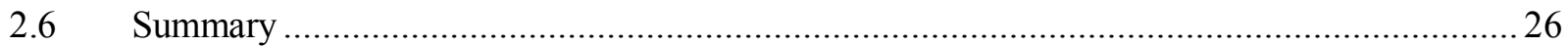

3 Chapter: Detailing of Transverse Reinforcement ........................................................29

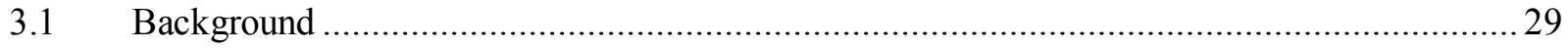

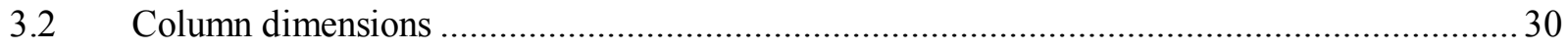

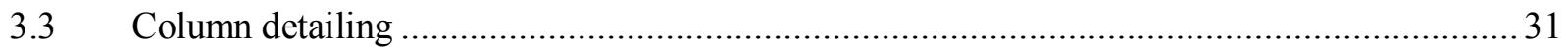

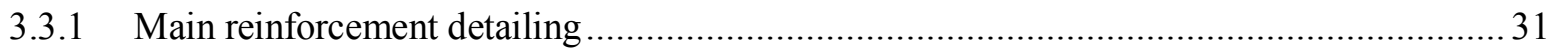

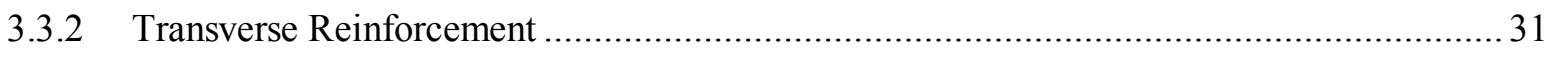

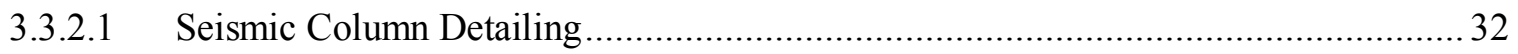

3.3.2.1.1 Transverse reinforcement spacing in plastic hinge length ................................ 32

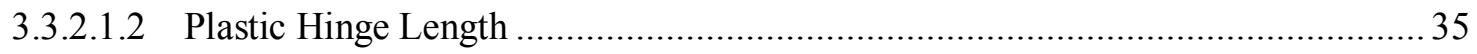

3.3.2.1.3 Transverse reinforcement spacing outside plastic hinge length ......................... 37

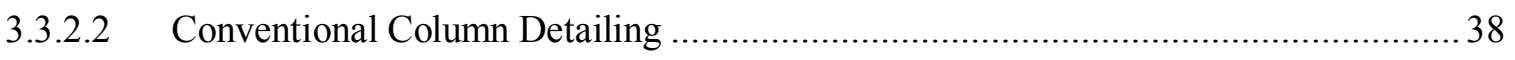

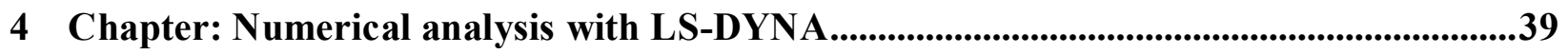

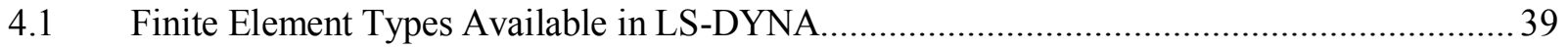

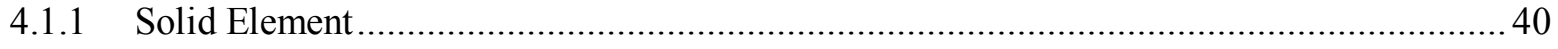

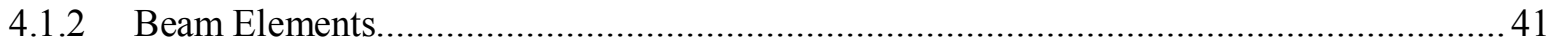

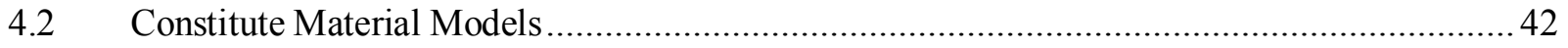

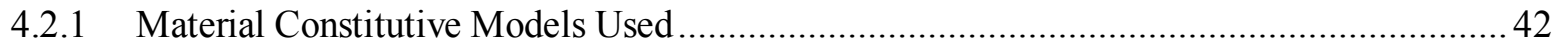

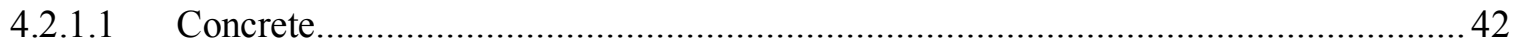

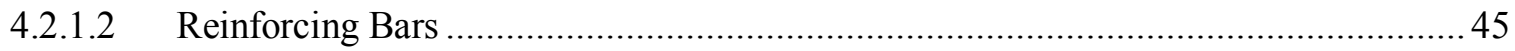

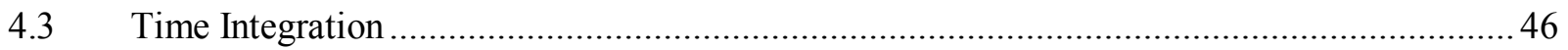

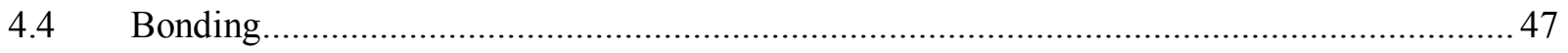

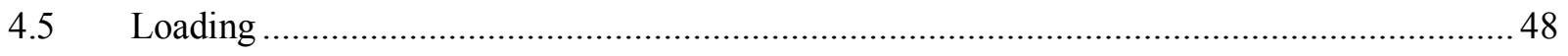

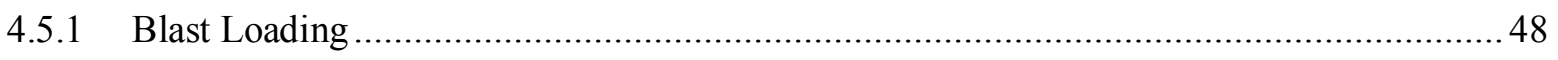

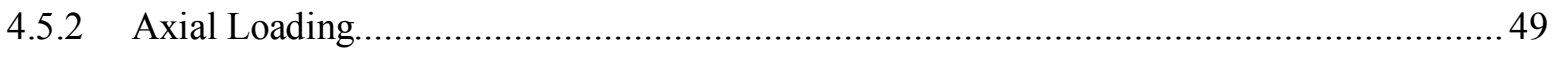




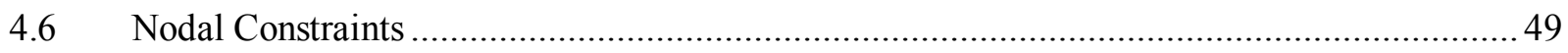

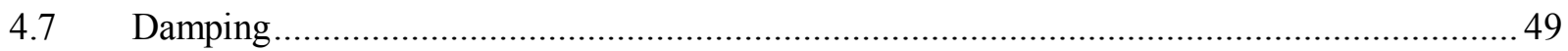

5 Chapter: Experimental program and validation of LS-DYNA model ............................51

$5.1 \quad$ Description of experimental program ....................................................................... 51

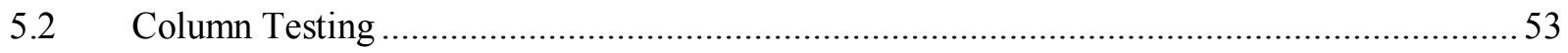

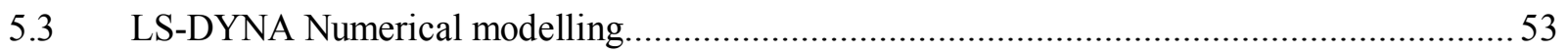

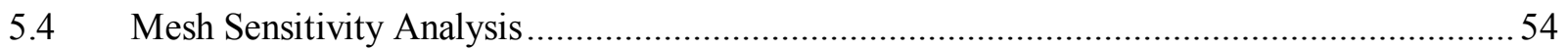

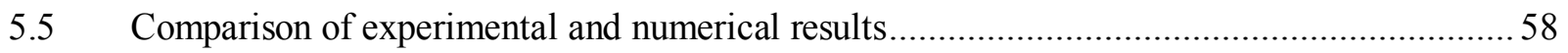

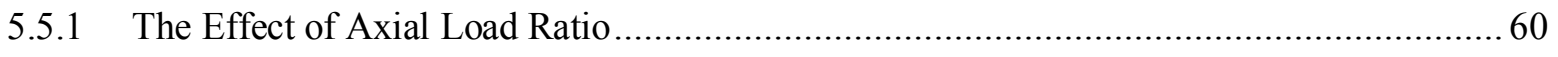

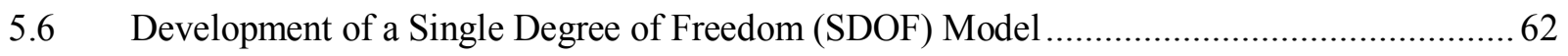

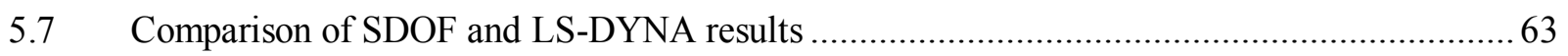

6 Chapter: Parametric Analysis of Reinforced Concrete Columns under Blast Loading .68

6.1 Effect of different charge masses at the same scaled distance ........................................ 72

6.2 Effect of reinforcement detailing on column response …................................................ 77

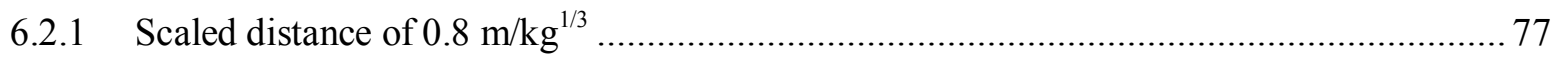

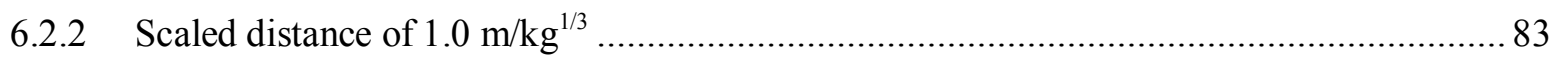

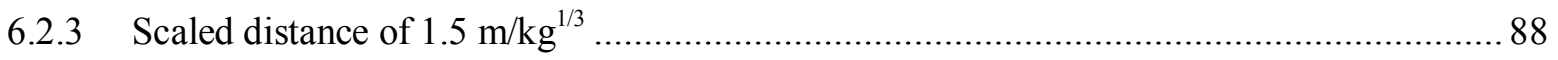

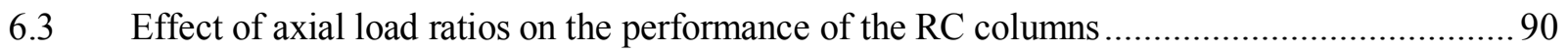

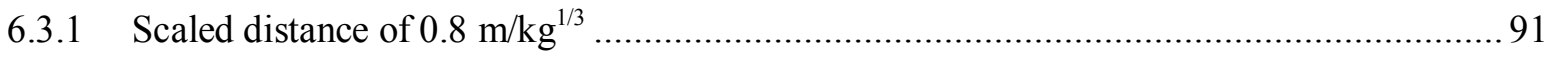

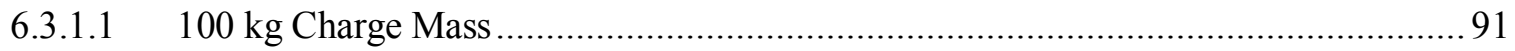

6.3.1.1.1 Conventionally detailed Column ......................................................... 91

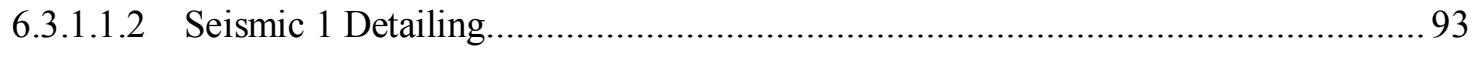

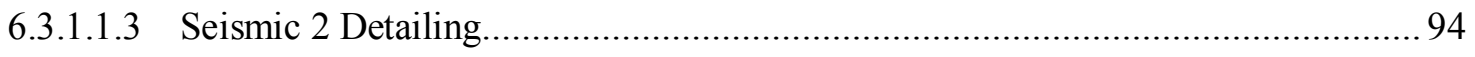

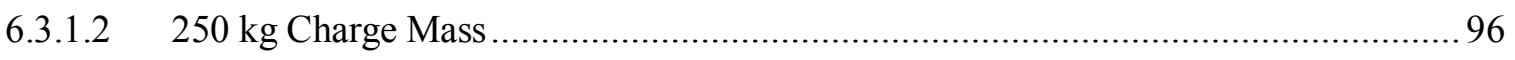

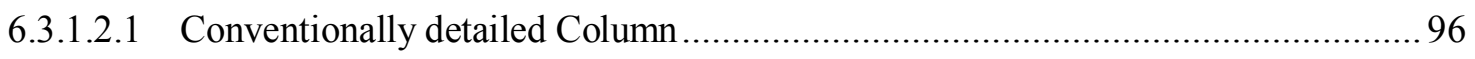




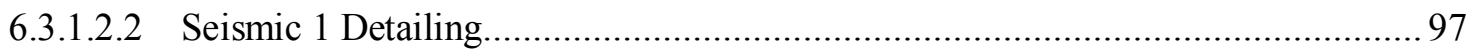

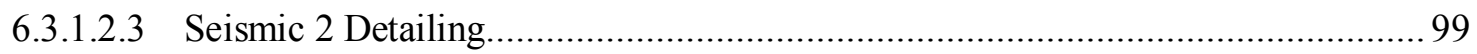

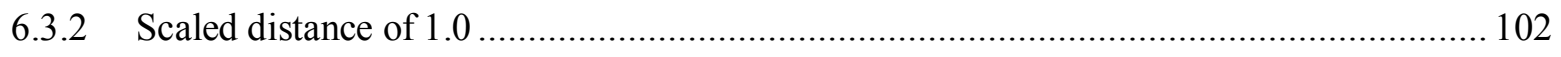

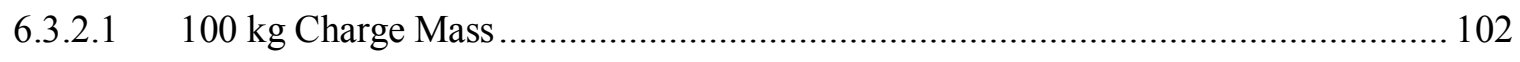

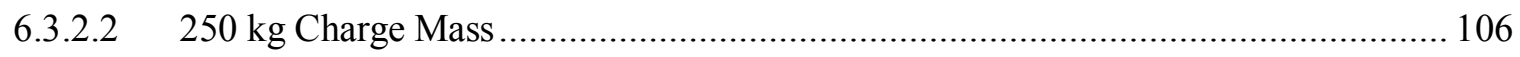

7 Chapter: CONCLUSION AND RECOMMENDATIONS ...................................................111

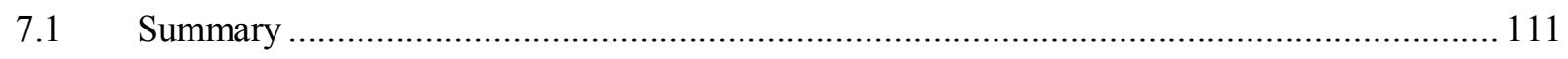

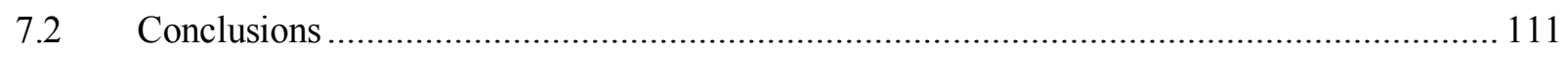

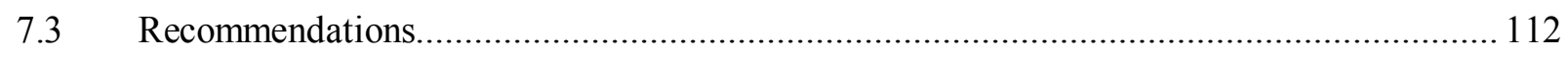

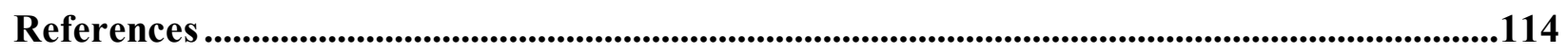

APPENDIX A: Implementation of the SDOF Numerical Model...............................................122

APPENDIX B: Sample LS-DYNA input keycards used in numerical analysis ......................136 


\section{List of Tables}

Table 3-1: Parameters used for detailing of RC columns for numerical work .............................. 31

Table 4-1: Concrete Material Models in LS-DYNA (LSTC 2013)...........................................43

Table 4-2: Steel Material Models in LS-DYNA (LSTC 2013) ...................................................46

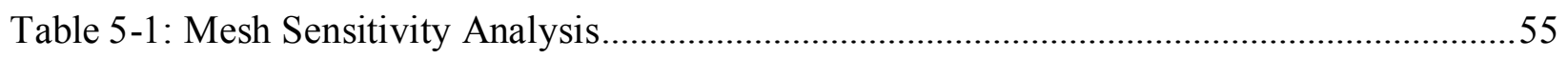

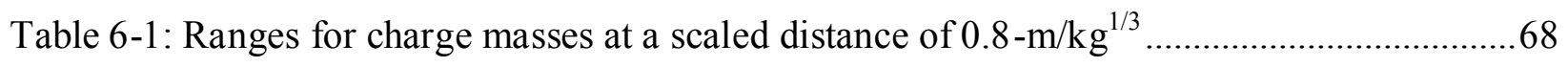

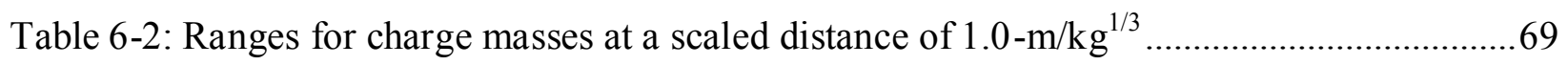

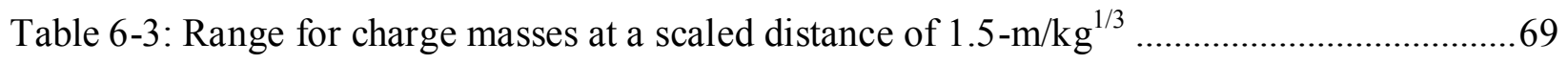

Table 6-4: Applied axial loads for different axial load ratios .................................................... 70

Table 6-5: Summary of maximum displacements for different charge masses with increasing

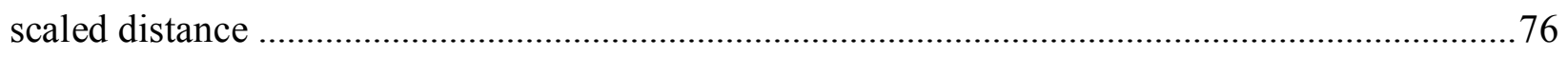

Table 6-6: Summary of the maximum displacements and corresponding rotations for the scaled

distance of $0.8 \mathrm{~m} / \mathrm{kg}^{1 / 3}$ using different charge masses.

Table 6-7: Summary of the maximum displacements and corresponding rotations for the scaled

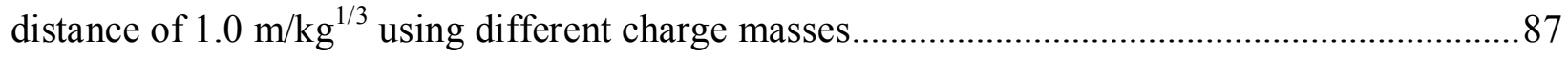

Table 6-8: Summary of the maximum displacements and corresponding rotations for the scaled distance of $1.5 \mathrm{~m} / \mathrm{kg}^{1 / 3}$ using different charge masses and an axial load ratio of $0.0 \ldots \ldots \ldots \ldots \ldots \ldots . . . . . . . . .88$

Table 6-9: Summary of displacements for $250 \mathrm{~kg}$ charge mass at $\mathrm{z}=0.8 \mathrm{~m} / \mathrm{kg}^{1 / 3} \ldots \ldots \ldots \ldots \ldots \ldots . . . . . . .101$

Table 6-10: Summary of displacements for $100 \mathrm{~kg}$ charge mass at $\mathrm{z}=1.0 \mathrm{~m} / \mathrm{kg}^{1 / 3} \ldots \ldots \ldots \ldots \ldots \ldots . . . . . .104$

Table 6-11: Summary of displacements for $250 \mathrm{~kg}$ charge mass at $\mathrm{z}=1.0 \mathrm{~m} / \mathrm{kg} 1 / 3 \ldots \ldots \ldots \ldots \ldots . . . .109$ 


\section{List of Figures}

Figure 2-1: Typical Blast Pressure-Impulse Time Curve.........................................................

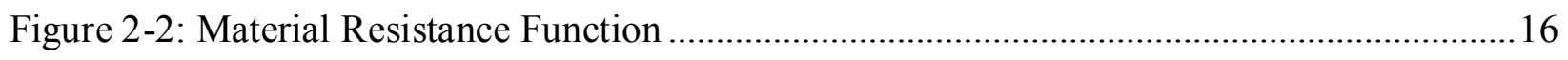

Figure 2-3: Lateral deformations due to: (a) Flexure (b) bond slip (c) shear (after Sezen 2000)..25

Figure 4-1: General shape of the concrete model yield surface in three dimensions (Murray et al. 2007)

Figure 4-2: General shape of the concrete model yield surface in two dimensions in the meridonal plane (Murray et al. 2007)

Figure 5-1: Reinforcement detailing for seismic and conventional columns used in experimental

work

Figure 5-2: The experimental setup for blasting testing of the RC columns .53

Figure 5-3: Finite element meshes sizes used for mesh sensitivity analysis

Figure 5-4: Comparison of displacement-time histories for various mesh sizes and experimental

results. .56

Figure 5-5: Comparison of damaged profiles of numerical and experimental RC columns for

mesh sensitivity analysis

Figure 5-6: Comparison of damaged profile of seismically detailed column in numerical simulation and experimental test

Figure 5-7: Comparison of displacement-time histories of seismically detailed experimental column and corresponding numerical models .....

Figure 5-8: Comparison of damaged profiles of numerical and experimental RC columns .61 Figure 5-9: Graphic User Interface showing the output results of the developed equivalent SDOF numerical model. 
Figure 5-10: Comparison of SDOF model with LS-DYNA model at $\mathrm{z}=0.8 \mathrm{~m} / \mathrm{kg}^{1 / 3} \mathrm{using}$ a 100

kg TNT charge mass .65

Figure 5-11: Comparison of SDOF model with LS-DYNA model at $\mathrm{z}=0.8 \mathrm{~m} / \mathrm{kg}^{1 / 3}$ using a 250

kg TNT charge mass .65

Figure 5-12: Comparison of SDOF model with LS-DYNA model at $\mathrm{z}=1.0 \mathrm{~m} / \mathrm{kg}^{1 / 3} \mathrm{using}$ a 100

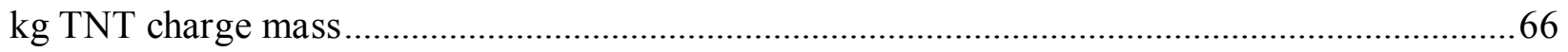

Figure 5-13: Comparison of SDOF model with LS-DYNA model at $\mathrm{z}=1.0 \mathrm{~m} / \mathrm{kg}^{1 / 3} \mathrm{using}$ a 250

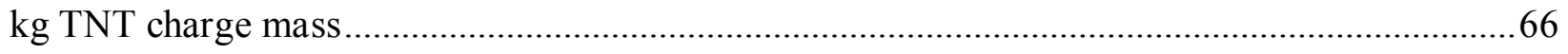

Figure 5-14: Comparison of SDOF model with LS-DYNA model at $\mathrm{z}=1.5 \mathrm{~m} / \mathrm{kg}^{1 / 3} \mathrm{using}$ a 100

kg TNT charge mass

Figure 5-15: Comparison of SDOF model with LS-DYNA model at $\mathrm{z}=1.5 \mathrm{~m} / \mathrm{kg}^{1 / 3} \mathrm{using}$ a 250

kg TNT charge mass

Figure 6-1: Three different RC column detailing used for numerical analysis

Figure 6-2: Pressure and impulse time histories for four different charges masses at $z=1.0$ $\mathrm{m} / \mathrm{kg}^{1 / 3}$ .72

Figure 6-3: Displacement-time history plots for different charge masses at a scaled distance of $0.8 \mathrm{~m} / \mathrm{kg}^{1 / 3}$

Figure 6-4: Displacement-time history plots for different charge masses at a scaled distance of $1.0 \mathrm{~m} / \mathrm{kg}^{1 / 3}$

Figure 6-5: Displacement-time history plots for different charge masses at a scaled distance of $1.5 \mathrm{~m} / \mathrm{kg}^{1 / 3}$ .75

Figure 6-6: Displacement Time History at $\mathrm{z}=0.8 \mathrm{~m} / \mathrm{kg}^{1 / 3}$ using a $100 \mathrm{~kg}$ charge mass . .77

Figure 6-7: Displacement Time History at $\mathrm{z}=0.8 \mathrm{~m} / \mathrm{kg}^{1 / 3}$ using a $250-\mathrm{kg}$ charge mass. .78 
Figure 6-8: Displacement Time History at $\mathrm{z}=0.8 \mathrm{~m} / \mathrm{kg}^{1 / 3} \mathrm{using}$ a $500 \mathrm{~kg}$ charge mass .79

Figure 6-9: Laterally deformed conventional columns under $500 \mathrm{~kg}$ charge mass, $\mathrm{z}=0.8 \mathrm{~m} / \mathrm{kg}^{1 / 3}$

$\mathrm{ALR}=0.0$

Figure 6-10: Laterally deformed seismic 1 column under $500 \mathrm{~kg}$ charge mass, $\mathrm{z}=0.8 \mathrm{~m} / \mathrm{kg}^{1 / 3} . .80$

Figure 6-11: Velocity Time History for $500 \mathrm{~kg}$ charge mass on conventional column at $\mathrm{z}=0.8$ $\mathrm{m} / \mathrm{kg}^{1 / 3}$

Figure 6-12: Displacement Time History at $\mathrm{z}=0.8 \mathrm{~m} / \mathrm{kg}^{1 / 3} \mathrm{using}$ a $1000 \mathrm{~kg}$ charge mass ..........82

Figure 6-13: Displacement Time History at $\mathrm{z}=1.0 \mathrm{~m} / \mathrm{kg}^{1 / 3} \mathrm{using}$ a $100 \mathrm{~kg}$ charge mass ............84

Figure 6-14: Displacement Time History at $\mathrm{z}=1.0 \mathrm{~m} / \mathrm{kg}^{1 / 3}$ using a $250 \mathrm{~kg}$ charge mass .............84

Figure 6-15: Displacement Time History at $\mathrm{z}=1.0 \mathrm{~m} / \mathrm{kg}^{1 / 3} \mathrm{using}$ a $500 \mathrm{~kg}$ charge mass ............85

Figure 6-16: Displacement Time History at $\mathrm{z}=1.0 \mathrm{~m} / \mathrm{kg}^{1 / 3} \mathrm{using}$ a $1000 \mathrm{~kg}$ charge mass ..........85

Figure 6-17: Damage profile columns under $1000 \mathrm{~kg}$ charge mass, $\mathrm{z}=1.0 \mathrm{~m} / \mathrm{kg}^{1 / 3} \ldots \ldots \ldots \ldots \ldots \ldots . . . . . . .6$

Figure 6-18: Damage profile columns under $1000 \mathrm{~kg}$ charge mass, $\mathrm{z}=1.5 \mathrm{~m} / \mathrm{kg}^{1 / 3} \ldots \ldots \ldots \ldots \ldots \ldots . . . . . . . . .19$

Figure 6-19: Displacement time history plot for a conventionally detailed RC column at $\mathrm{z}=0.8$ $\mathrm{m} / \mathrm{kg}^{1 / 3}$ using a $100 \mathrm{~kg}$ charge mass at different ALRs

Figure 6-20 Damage profile of conventional column under a blast load from a $100 \mathrm{~kg}$ charge

mass at $\mathrm{z}=0.8 \mathrm{~m} / \mathrm{kg}^{1 / 3}, \mathrm{ALR}=0.2$

Figure 6-21: Displacement time history plot for $\mathrm{RC}$ column with seismic 1 detailing at $\mathrm{z}=0.8$ $\mathrm{m} / \mathrm{kg}^{1 / 3}$ using a $100 \mathrm{~kg}$ charge mass at different ALRs

Figure 6-22: Damage profile of seismic 1 column under a blast load from a $100 \mathrm{~kg}$ charge mass at $\mathrm{z}=0.8 \mathrm{~m} / \mathrm{kg} 1 / 3, \mathrm{ALR}=0.2$

Figure 6-23: Displacement time history plot for $\mathrm{RC}$ column with seismic 2 detailing at $\mathrm{z}=0.8$ $\mathrm{m} / \mathrm{kg}^{1 / 3}$ using a $100 \mathrm{~kg}$ charge mass at different ALRs .95 
Figure 6-24: Damage profile of seismic 2 column under a blast load from a $100 \mathrm{~kg}$ charge mass at $\mathrm{z}=0.8 \mathrm{~m} / \mathrm{kg} 1 / 3, \mathrm{ALR}=0.2$

Figure 6-25: Displacement time history plot for a conventionally detailed $\mathrm{RC}$ column at $\mathrm{z}=0.8$ $\mathrm{m} / \mathrm{kg}^{1 / 3}$ using a $250 \mathrm{~kg}$ charge mass at different ALRs .96

Figure 6-26: Damage profile for a conventional column under a blast load from a $250 \mathrm{~kg}$ charge mass at $\mathrm{z}=0.8 \mathrm{~m} / \mathrm{kg}^{1 / 3}, \mathrm{ALR}=0.1$

Figure 6-27: Damage profile for a seismic 1 column under a blast load from a $250 \mathrm{~kg}$ charge mass at $\mathrm{z}=0.8 \mathrm{~m} / \mathrm{kg} 1 / 3$ with varying ALR values .98

Figure 6-28: Displacement time history plot for $\mathrm{RC}$ column with seismic 1 detailing at $\mathrm{z}=0.8$ $\mathrm{m} / \mathrm{kg}^{1 / 3}$ using a $250 \mathrm{~kg}$ charge mass at different ALRs

Figure 6-29: Damage profile for a seismic 2 column under a blast load from a $250 \mathrm{~kg}$ charge mass at $\mathrm{z}=0.8 \mathrm{~m} / \mathrm{kg} 1 / 3$ with varying ALR values

Figure 6-30: Displacement time history plot for $\mathrm{RC}$ column with seismic 2 detailing at $\mathrm{z}=0.8$ $\mathrm{m} / \mathrm{kg}^{1 / 3}$ using a $250 \mathrm{~kg}$ charge mass at different ALRs

Figure 6-31: Displacement time history plot for a conventionally detailed $\mathrm{RC}$ column at $\mathrm{z}=1.0$ $\mathrm{m} / \mathrm{kg}^{1 / 3}$ using a $100 \mathrm{~kg}$ charge mass at different ALRs

Figure 6-32: Displacement time history plot for $\mathrm{RC}$ column with seismic 1 detailing at $\mathrm{z}=1.0$ $\mathrm{m} / \mathrm{kg}^{1 / 3}$ using a $100 \mathrm{~kg}$ charge mass at different ALRs

Figure 6-33: Displacement time history plot for $\mathrm{RC}$ column with seismic 2 detailing at $\mathrm{z}=1.0$ $\mathrm{m} / \mathrm{kg}^{1 / 3}$ using a $100 \mathrm{~kg}$ charge mass at different ALRs

Figure 6-34: Damage profile for three column types under a blast load from a $100 \mathrm{~kg}$ charge mass at $\mathrm{z}=1.0 \mathrm{~m} / \mathrm{kg} 1 / 3$ recorded at 60 milliseconds .105 
Figure 6-35: Displacement time history plot for a conventionally detailed $\mathrm{RC}$ column at $\mathrm{z}=1.0$ $\mathrm{m} / \mathrm{kg}^{1 / 3}$ using a $250 \mathrm{~kg}$ charge mass at different ALRs 106

Figure 6-36: Displacement time history plot for $\mathrm{RC}$ column with seismic 1 detailing at $\mathrm{z}=1.0$ $\mathrm{m} / \mathrm{kg}^{1 / 3}$ using a $250 \mathrm{~kg}$ charge mass at different ALRs . 107

Figure 6-37: Displacement time history plot for $\mathrm{RC}$ column with seismic 2 detailing at $\mathrm{z}=1.0$ $\mathrm{m} / \mathrm{kg}^{1 / 3}$ using a $250 \mathrm{~kg}$ charge mass at different ALRs

Figure 6-38: Damage profile for three column types under a blast load from a $250 \mathrm{~kg}$ charge mass at $\mathrm{z}=1.0 \mathrm{~m} / \mathrm{kg} 1 / 3$ recorded at 60 milliseconds .108 


\section{List of Abbreviations and Symbols}

$A_{\text {ch }} \quad$ Cross-sectional area of concrete core

Ag $\quad$ Gross area of section

ALR Axial load ratio

$\mathrm{A}_{\mathrm{sh}} \quad$ Total cross-sectional area of transverse reinforcement within spacing, s, and perpendicular to the dimension $\mathrm{h}_{\mathrm{c}}$

$\mathrm{A}_{\mathrm{st}} \quad$ Total area of longitudinal reinforcement

D Damage parameter (L)S-DYNA Mat_CSCM_159

$d_{b} \quad$ Diameter of main reinforcement bar

$d_{t} \quad$ Diameter of transverse reinforcement

$\mathrm{f}_{\mathrm{c}}{ }^{\prime} \quad$ Specified compressive strength of concrete

$\mathrm{F}_{\mathrm{e}} \quad$ Equivalent Load

FEMA Federal Emergency Management Agency

$\mathrm{F}_{\mathrm{T}} \quad$ Magnitude of blast load at a given time instance

$\mathrm{f}_{\mathrm{yh}} \quad$ Specified yield strength of hoop reinforcement

$\mathrm{h}_{\mathrm{c}} \quad$ Dimension of concrete core of rectangular section measured perpendicular to the direction of the hoop bars to outside of peripheral hoop (Clause 21 (CSA 2004)).

$\mathrm{H}_{\mathrm{EXP}}{ }^{\mathrm{d}} \quad$ Heat of detonation of explosive being converted to TNT

$\mathrm{h}_{\mathrm{x}} \quad$ Maximum horizontal centre-to-centre spacing between longitudinal bars on all faces of the column that are laterally supported by seismic hoops or crosstie legs

$\mathrm{K}_{\mathrm{e}} \quad$ Equivalent Stiffness

$\mathrm{K}_{\mathrm{L}} \quad$ Load transformation factor 


\begin{tabular}{|c|c|}
\hline $\mathrm{K}_{\mathrm{M}}$ & Mass transformation factor \\
\hline $1_{\mathrm{o}}$ & $\begin{array}{l}\text { Minimum length measured from the face of the joint along axis of the structural } \\
\text { member, over which transverse reinforcement needs to be provided }\end{array}$ \\
\hline $\mathrm{M}_{\mathrm{e}}$ & Equivalent Mass \\
\hline NBCC & National Building Code of Canada \\
\hline $\mathrm{n}_{1}$ & $\begin{array}{l}\text { Total number of longitudinal bars in column cross-section that are laterally } \\
\text { supported by corner of hoops or by hooks of seismic crossties }\end{array}$ \\
\hline $\mathrm{M}_{\mathrm{T}}$ & Total lumped mass \\
\hline$P_{f}$ & Maximum factored axial load for earthquake loading cases \\
\hline$P_{r}$ & Reflected overpressure \\
\hline$P_{r, \max }$ & Maximum axial load resistance \\
\hline $\mathrm{P}_{\text {ro }}$ & Factored axial load resistance at zero eccentricity \\
\hline $\mathrm{P}_{\mathrm{so}}$ & Incident overpressure \\
\hline $\mathrm{R}$ & Distance of target from source of detonation (standoff distance) \\
\hline $\mathrm{R}_{1}$ & Corresponding force at $y_{1}$ \\
\hline $\mathrm{R}_{\mathrm{m}}$ & Maximum resistance corresponding to $\mathrm{y}_{2}$ and $\mathrm{y}_{\mathrm{m}}$ \\
\hline s & $\begin{array}{l}\text { Spacing of transverse reinforcement measured along the longitudinal axis of the } \\
\text { structural member }\end{array}$ \\
\hline $\mathrm{t}_{\mathrm{a}}$ & Time of arrival \\
\hline $\mathrm{t}_{\mathrm{d}}^{+}$ & Positive phase duration \\
\hline$t_{d}{ }^{-}$ & Negative phase duration \\
\hline TNT & Trinitrotoluene \\
\hline
\end{tabular}


Charge mass

$\mathrm{W}_{\mathrm{eff}} \quad$ Equivalent mass of TNT

$\mathrm{W}_{\mathrm{EXP}} \quad$ mass of explosive being converted to TNT

$\mathrm{y}_{1} \quad$ Displacement at elastic yield

$\mathrm{y}_{2}$ Displacement at transition point between elasto-plastic and plastic phase

$\mathrm{y}_{\mathrm{m}} \quad$ Maximum displacement of resistance function

Z Scaled distance

$\alpha_{1} \quad$ Ratio of average stress in rectangular compression block to the specified concrete compression strength

$\phi_{\mathrm{c}} \quad$ Material resistance factor for concrete 


\section{Chapter: Introduction}

Explosions, whether accidental or planned, can potentially cause significant damage to the built environment. Up until about the last fifty years, blast design was only considered for chemical facilities and military installations. This was generally due to the high risk of accidental explosions that existed in these types of facilities.

The rise in the number of terrorist attacks over the past few decades has, however, led to growing concerns about the performance of buildings designed for aesthetics and economy under blast loading. The Federal Emergency Management Agency (FEMA) in the United States reports that approximately one in every two terrorist attacks involves the use of explosives (FEMA 2003). After the terrorists attacks on the Alfred P. Murrah Building in Oklahoma City and the World Trade Centre in New York City (Fujikura 2007), various forms of mitigation measures are now being sought to protect critical infrastructures against blast loading. The blast mitigation measures vary from retrofitting of the existing building façades against potential blast loading to the full blast resistant design of critical structural components in buildings.

\subsection{Research Basis}

Structures designed to resist one load type can often have the capacity to resist a different load type (Hayes et al. 2005). Retrofitting an existing building against blast loads or designing structural components with adequate blast resistance can be expensive. Seismic design is, however, an integral part of conventional structural design. Thus, buildings designed to meet strength and ductility requirements, depending on the seismicity of a particular region and the importance of the building (MacGregor and Bartlett 2000) could potentially have inherent capacity to resist blast loading. The literature available shows there has been limited research 
carried out to investigate the performance of seismically designed and detailed structural elements, in accordance with the National Building Code of Canada (NBCC) (NRC 2005), under blast loading. The research work presented in this thesis seeks to investigate the behaviour of reinforced concrete (RC) columns, designed and detailed for seismic loading in accordance with the NBCC, when subjected to blast loading.

\subsection{Objectives}

The main objectives for the research presented in this thesis are as follows:

- The development of a finite element (LS-DYNA) model for studying the behaviour of seismically detailed RC columns subjected to blast loading

- To study the effect of axial loads on the blast resistance of RC columns

- Investigate the different failure modes of RC columns under blast loading

- To study the effects of varying scaled distances of the explosive charges on the behaviour of RC columns

- Comparison of the results of a single-degree-of-freedom (SDOF) analysis with the LSDYNA numerical simulation.

\subsection{Scope and Methodology}

Field testing to investigate the effect of blast loading on structural elements is very expensive. Unlike conventional research on structural elements which is often carried out under laboratory conditions, experimental testing involving explosives, especially substantial amounts of explosives, can only be carried out in a remote field site. Usually, the testing in Canada is carried 
out at military bases in Ontario or Alberta. The cost involved in field testing includes access to the test site, transportation of specimens, rental of heavy equipment etc. Numerical simulations, on the other hand, afford the researcher the ability to investigate the effects of various parameters at a significantly lower cost. The general purpose high-fidelity physics based finite element package, LS-DYNA, was used to model and study the effects of blast loading on RC columns detailed for various levels of seismicity. The RC columns investigated in this thesis do not form part of the seismic force resisting system (SFRS) but are detailed with enough ductility for a given magnitude of earthquake in a specific seismic zone. The RC columns were modelled with various reinforcement details representative of both conventional and seismic detailing rules and a comparison of their behaviour and response were investigated. Prior to the comparison, the numerical model was validated with experimental results obtained from live explosion field tests. Most numerical works involving blast loading on structures do not consider the effect of axial loading. Axial load ratios representative of the axial load levels on lower floor columns in lowrise, mid-rise and high-rise buildings, in comparison to their capacities, were incorporated in the modelling. This afforded a study of the behaviour of the RC columns under the combined effect of the axial loads and blast loading on the columns.

The use of a complex finite element program such as LS-DYNA can be very computationally costly. Thus many blast engineering designers use an SDOF system in analysis and design of structural elements subjected to blast loading as an initial estimate of their performance. An SDOF analysis code was written to determine quick and approximate estimates of column response parameters under blast loading. Results from the SDOF analysis were compared to results of the numerical LS-DYNA simulations. 


\subsection{Thesis Outline}

Chapter 1 presents the state of research on blast resistant design and analysis and motivation for the thesis. This is followed out by the objectives of the research, scope of work and methodology used in the thesis. The chapter then ends with a thesis outline that summarizes all the individual chapters making up the thesis.

Chapter 2 reviews literature of previous research work on the effects of blast loading on structures. It also introduces the concept of explosion, explosion effects, and blast wave evolution and interaction with structural elements.

Chapter 3 outlines the design and detailing guidelines provided by the Cement Association of Canada's Concrete Design hand book. The detailing rules are in accordance to the CSA Standard A23.3-04 with special emphasizes on Clause 21.

Chapter 4 focuses on the numerical model developed in LS-DYNA. It details the considerations that went into selection of finite element types, the constitutive material models, mesh sensitivity analysis, and the application of loads.

Chapter 5 discusses the validation of the numerical model with experimental data available from previous field testing as well as a comparison of LS-DYNA results with SDOF results.

Chapter 6 presents a parametric analysis of the results obtained from the numerical blast loading simulations on both seismically detailed and conventionally detailed RC columns.

Finally Chapter 7 presents some conclusions arrived at from the research and proposed recommendations for future work based on the findings reported in this thesis. 


\section{Chapter: Literature Review}

Blast loading on critical infrastructures can be from accidental or planned explosions. Accidental explosions can occur during manufacture, transport or storage of explosives and hazardous materials and include examples such as the Halifax explosion in 1917 (Kitz 1989) which involved two cargo ships and the explosion of a chemical plant in Flixborough (Høiset et al. 2000) in 1974. Accidental explosions can have devastating effects on proximate structures and result in countless fatalities. As recent as 2008, the explosion of an industrial gas facility in Toronto led to an approximate cost of $\$ 1.9$ million in damages to homes and infrastructure (Kinastowski 2009) while the explosion of the ammonium nitrate plant in West Texas of April 17, 2013 (TDPS 2013) resulted in 15 deaths and damage to over 150 buildings.

Terrorist attacks involving the use of explosions have also been a major concern for engineers in recent years. Following terrorist bombings of the Alfred P. Murrah Building in the United States (April 1995), the Khobar Towers Bombing in Saudi Arabia (June 1996), the Australian Embassy in Jakarta (September 2004), the Marriott Hotel in Pakistan (September 2008) and several other terrorist bombings worldwide, there is renewed interest in design and retrofit of critical infrastructure to resist blast loading (Stewart 2006; Yusof et al. 2010).

Most of the earlier research in the field of blast load effects on structures was carried out by military and government agencies (FEMA 2003; U. S. Army Corps of Engineers 2008) and in most cases were classified and targeted to hardened structures. Some of this research has now been declassified and proposed for design of conventional structures. However, a lot more of such research works remain classified and inaccessible to engineers and researchers, especially outside of the USA (Carriere 2006). 
The design of blast resistant conventional structures has, therefore, become significantly more important in recent years in light of the increase in global terrorism. Conventional design principles aim at ensuring controlled damage of structures as well as safety of lives. The failure of critical structural components, such as RC columns, can have devastating effects on the structure as a whole. RC columns form an integral part of the load carrying components (load path) in a building. In conventional design, RC columns predominantly transmit gravity loads from top floors of the building to the foundations. The total or partial loss of capacity of an $\mathrm{RC}$ column results in the redistribution of loads to adjacent structural components. The redistributed loading can result in the overload of the adjacent structural components beyond their load carrying capacities and can lead to their partial or total collapse. The total or partial collapse of the column and the tributary beams and floors, referred to as progressive collapse, is a common failure phenomenon associated with structures subjected to blast loading (Byfield 2006; Li and Hao 2013; Shi et al. 2010). Thus, the preventative design principles against progressive collapse is to ensure RC columns are designed and detailed with adequate strength and ductility, especially at the lower stories.

In hazard mitigation, it is common to investigate the performance of a structural component to a loading condition that it was not originally designed for, with the aim of reducing high mitigation costs while also relying on well-known and established design principles (Hayes et al. 2005). Under blast loading, an RC column is subjected to lateral deformations in addition to the gravity loading acting on it from top floors. RC columns also undergo lateral deformations when subjected to cyclical loading in the event of an earthquake. Many researchers (Bao and Li 2010; Flores 2004; Fujikura and Bruneau 2011; Hayes et al. 2005; Williams and Williamson 2011) have done various works on seismically detailed $\mathrm{RC}$ components subjected to blast and reported 
improved performances over conventionally designed $\mathrm{RC}$ components. The research presented in this thesis focuses on the performance of RC columns detailed in accordance with the Canadian seismic detailing rules outlined clause 21 of CSA A23.3-04 (CSA, 2004).

This chapter reviews explosion mechanisms and the nature of explosives. The chapter also presents a review of some research works on the effects of blast loading on structures with emphasis on the behaviour of RC columns. Methodologies available for calculating blast loading on structures are also reviewed. The chapter further presents a description of the behaviour of RC columns under seismic loading which influences their reinforcement detailing.

\subsection{Nature of explosions and mechanism of blast waves}

Conventional load types in structural design manuals do not include blast loading. The concept of explosions and blast loading is, therefore, not very widely understood by the structural engineering community.

The chemical reaction associated with a chemical explosion results in a rapid dissociation of the explosive material and the release of high amounts of heat, light, and energy (FEMA 2003). The chemical reaction also results in an increase in pressure, above the atmospheric pressure, known as overpressure. To restore the atmospheric pressure and temperature equilibrium, the localized high pressure air rapidly expands, forming a blast wave preceded by a thin shock front. The shock front (blast wave) may have enough impetus to cause damage to structures in its path (U. S. Army Corps of Engineers 2008).

When the blast wave reaches a point in space, the atmospheric pressure instantaneously increases to the incident overpressure and then exponentially decays back to atmospheric, within a few tens of milliseconds, as the blast wave passes the point. Thus, blast loading on structures is 
typically a very short duration impulsive load. The rapid reduction in overpressure also results in negative pressure (suction pressure) which gradually rises to atmospheric pressure (equilibrium pressure).

Figure 2-1 shows a typical blast pressure profile at a point remote from the centre of explosion. The time of arrival $\left(t_{a}\right)$ is the time it takes the blast wave to reach the point of interest. The atmospheric pressure rises instantaneously to the peak incident overpressure $\left(\mathrm{P}_{\mathrm{so}}\right)$. The time during which the overpressure is greater than atmospheric $\left(\mathrm{P}_{\mathrm{o}}\right)$ is the positive phase of the blast pressure profile with a duration $\mathrm{t}_{\mathrm{d}}{ }^{+}$while the time during which the overpressure is below atmospheric is the negative phase of the blast profile with a corresponding duration $t_{d}$.

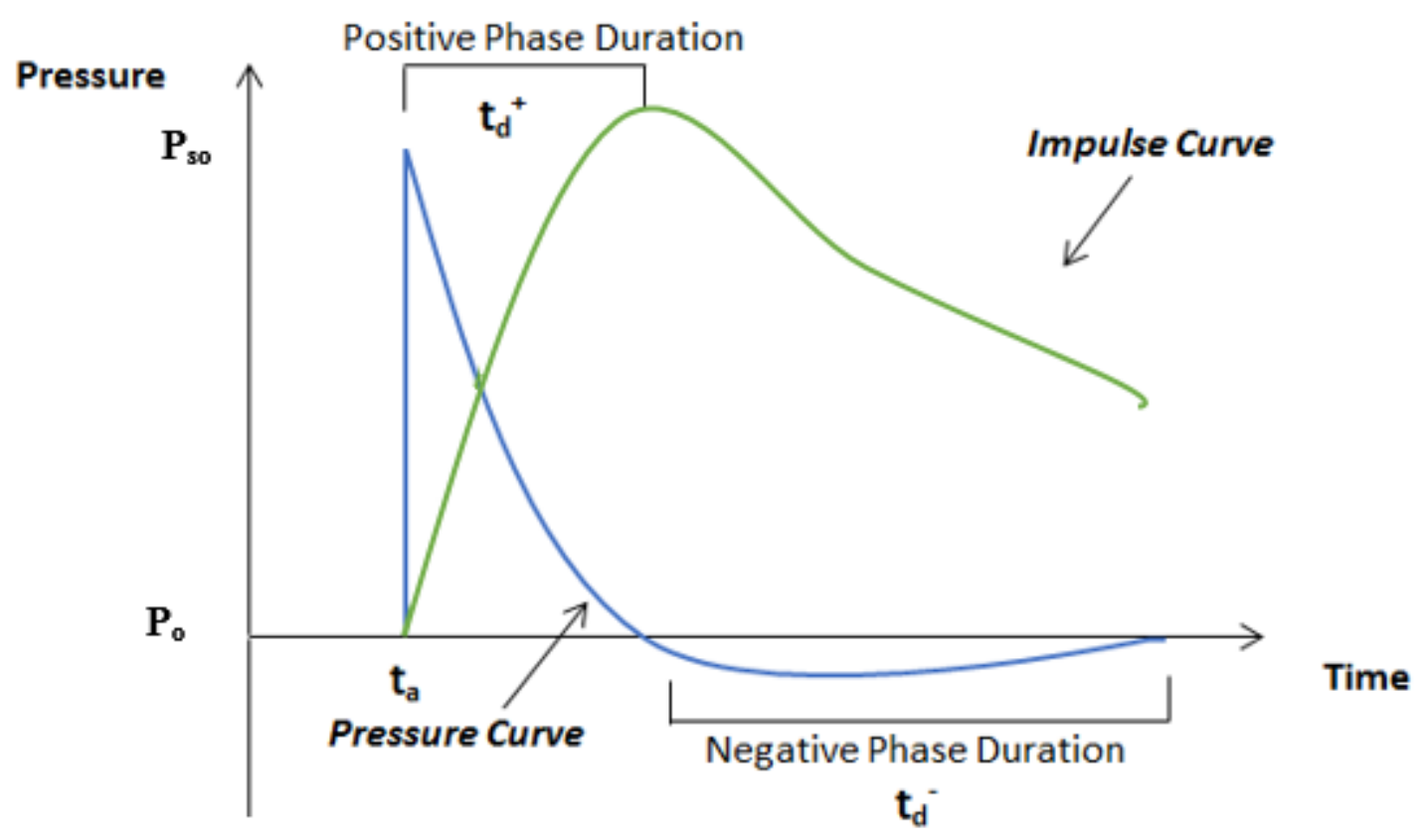

Figure 2-1: Typical Blast Pressure-Impulse Time Curve 
When the incident blast wave strikes a surface denser than the medium the blast wave is traveling in, it is reflected and exerts a pressure on the surface, the reflected pressure $\left(\mathrm{P}_{\mathrm{r}}\right)$, which is higher than the peak incident overpressure at the point in the absence of reflecting surface. The maximum reflected overpressure occurs at an angle of incidence of $90^{\circ}$ (FEMA 2003). The peak value of the blast pressure is a function of the charge mass $(W)$, the standoff distance of the structure (target) from detonation source $(R)$ and the angle of incidence to the reflecting surface. FEMA (2003) reports that the peak reflected pressure can be as high as 12 times the peak incident pressure.

The area under the blast pressure-time history plot (integral of the pressure-time profile) gives the impulse of the blast load (Figure 2-1). Equation [2-1] presents the impulse under the blast pressure-time curve. The incident impulse $\left(I_{s o}\right)$ is the area under the incident pressure curve while the reflected impulse $\left(I_{r}\right)$ is the area under the reflected pressure curve.

$I=\int P(t) d t$

[2-1]

The impulse is a measure of the amount of energy released in an explosion. The impulse represents the potential energy transferred to a structure in the event of an explosion (FEMA 2003).

\subsubsection{Classification of Explosions}

Explosions can be classified based on several factors such as the explosive material, the prevailing exposure conditions and also of the location of the explosive charge mass relative to the target structure. If the explosive detonates such that generated blast wave impinges on the structure without a prior reflection of the waves, it is referred to as a free air-burst. On the other hand, if the blast waves are reinforced by reflection before it strikes the target surface, it is referred to as air-burst. Both free air-burst and air-burst occur above the ground surface and are 
thus referred to as spherical air-burst. Conversely, hemispherical air-burst refers to explosions in which the explosive is located on the ground surface and expands hemispherically (PEC and BakerRisk 2008; U. S. Army Corps of Engineers 2008).

\subsubsection{Blast Scaling Laws}

Most of the data available for blast analysis comes from experimental testing involving various explosive types and quantities of explosives. The amount of explosives used in the testing is usually limited necessitating the extrapolation of test results to capture the behaviour of structural components subjected to blast loading from larger quantities of explosives. Scaling laws have, thus, been developed to enable the comparison of all blast test results.

The Hopkinson-Cranz scaling law or the cube-root scaling law is the most commonly used scaling law in explosion effects analysis and design (Smith and Hetherington 1994). Another scaling law - Sachs scaling law (Sachs 1944) relates different explosive charge masses in different atmospheric conditions, with variations in pressure and temperature and varying altitudes (Hargather 2008). The cube-root scaling law is based on the notion that the detonation of an explosive of a particular charge weight, $W_{l}$, at a set stand-off distance, $R_{1}$, from a target will produce blast wave parameters such that the incident pressure, blast duration and impulse, will be similar to the blast wave parameters produced by another charge weight, $W_{2}$, at a corresponding scaled distance, $R_{2}$, detonated in the same atmospheric conditions in accordance with equation [2-2] (Hargather 2008; Kleine et al. 2003).

$$
\begin{aligned}
& \frac{R_{1}}{R_{2}}=\left(\frac{W_{1}}{W_{2}}\right)^{\frac{1}{3}} \\
& \frac{R_{1}}{\left(W_{1}\right)^{1 / 3}}=\frac{R_{2}}{\left(W_{2}\right)^{1 / 3}}=Z
\end{aligned}
$$


Equation [2-3], a rearranged form of equation [2-2], defines the scaled distance $(z)$ as a ratio of the stand-off distance to the cube-root of the charge weight of the explosive (Baker 1973). With little or no variation in attitudes, the Hopkinson-Cranz scaling law can be used to scale different charge masses to result in the same overpressure at the different corresponding standoff distances.

\subsubsection{TNT equivalence}

Different explosive materials release different amounts of energy per unit mass (energy density) upon detonation. The nature of the shockwave produced and the magnitude of the pressure generated from an explosion is thus dependent on the type of explosive involved. This creates a potential difficulty in blast load analysis as various explosive materials generate unique blast wave parameters in an explosion and would require knowledge of explosion behaviour and characteristics of a large number of explosives (Cooper 1994; Held 1983). Trinitrotoluene (TNT) is, therefore, used as the standard explosive to which all other explosives are compared and their equivalence to TNT established (PEC and BakerRisk 2008). TNT equivalence is used to represent the mass of TNT that will produce the same amount of energy or explosion effects as a unit mass of a particular explosive in an explosion (Sochet 2010). TNT conversion factors have been determined for different explosive materials and tabulated in a number of blast design guides (PEC and BakerRisk 2008). For the purpose of this thesis, all explosive charge materials other than TNT are converted to TNT equivalent masses.

\subsubsection{Blast load interaction with structures}

Shockwaves from an explosion exert very high pressures on target structures in close proximity to the explosion. When the blast waves encounter a structure, the front face experiences reflected pressure and depending on the size of the structure relative to the blast loading (standoff distance 
and magnitude of incident blast pressure) the shock wave diffracts around the structure. The side walls, roof and back face of the structure experience incident blast pressure together with dynamic blast wind loading (FEMA 2003).

Generally, when the blast wave engulfs a structure, it exerts a crushing force on all sides of the target structure. The crushing forces on the side wall exert a net zero resultant force on the structure while the resultant of the reflected pressure on the front face and incident pressure on back face results in a net drag force in the direction of the blast wave.

\subsection{Estimating Structural response to blast loads}

The blast waves generated from an explosion exert a transient dynamic load on the target structure. The short duration impulsive load and the resulting inertial force generated due to the acceleration of the target are resisted by the internally generated strain energy (Humar 2012). The response of structural elements subjected to blast loading can be investigated through field testing or numerical modelling. The numerical modelling techniques often employed consist of non-linear dynamic finite element analysis or simplified methods such as the single-degree-offreedom (SDOF) analysis. Non-linear finite element numerical modelling techniques provide a less expensive method of performing an extensive parametric analysis of a specific problem which is difficult to accomplish with live-testing due to the high costs of testing. Non-linear finite element analysis, however, also presents its own set of challenges (Belytshko et al. 2014). Some of those challenges being:

- The selection of a suitable problem-specific mesh.

- The ability to examine stability of the solution procedure.

- The possible sources of errors based on modelling assumptions. 
A simplified method, such as the SDOF analysis, is often used to estimate initial structural response while detailed finite element analysis is employed for detailed design (Bao and Li 2010; Biggs 1964; Nassr et al. 2012).

\subsubsection{Equivalent Single Degree of Freedom Analysis}

Equation [2-4] represents the general equation of motion of a structural system with mass $\mathbf{m}$, damping coefficient $\mathbf{c}$, and stiffness $\mathbf{k}$ when subjected to an external load $\mathbf{F}(\mathbf{t})$. $\ddot{\mathbf{u}}, \dot{\mathbf{u}}$ and $\mathbf{u}$ represent the acceleration, velocity and displacement respectively.

$\mathbf{m u ̈}+\mathbf{c u}+\mathbf{k u}=\mathbf{F}(\mathbf{t})$

In numerical analysis, the equation of motion is solved to obtain the structural response parameters such as displacements, velocities and accelerations. Many commercial finite element software packages model structural elements by meshing techniques that result in multiple degrees of freedom. The equation of motion represented by equation [2-2] is presented in matrix format with an equation each corresponding to the number of degrees of freedom of the structural element. Solutions to the matrix equation of motion yields the response of the structural element at the various nodes of the of the finite element mesh. In the analysis of reinforced concrete elements subjected to blast loading, for instance, material non-linearity of the composite material and the blast load function tend to compound the complexity of the solution. An alternative numerical method which lends itself to easy hand calculations is the reduction of the analysis of a complex system with infinite number of degrees of freedom to an equivalent (SDOF) system. For structural systems subjected to dynamic loadings, such as blast loads, a mathematical model can be used to completely define the time response of a single independent coordinate of the structural element (Paultre 2010). In this mathematical model, an independent coordinate system is required to define the system at any given instant. For design purposes, it is 
practical to adopt appropriate methods which help idealize the numerical model into an equivalent simplified model whose solution can be obtained easily with minimal effort (Biggs 1964). For a quick approximate solution blast designers consider an equivalent SDOF system.

In order to convert a structural model with infinite number of degrees-of-freedom to an equivalent SDOF system, the work done by loads on the structural system have to be conserved between the structural model and the equivalent SDOF model. Similarly the strain energy in the structural element and the equivalent SDOF model must be the same. This equivalence is expressed in the main components of the equivalent system: $\mathbf{M}_{\mathbf{e}}$ (effective mass), $\mathbf{K}_{\mathbf{e}}$ (equivalent stiffness) and $\mathbf{F}_{\mathbf{e}}$ (effective load). Once the equation of motion has been formulated, its solution by any of the well-established numerical integration methods can then be obtained.

To ensure that the response parameters obtained from the equivalent SDOF system closely approximate the actual results, the equivalent SDOF is chosen such that the maximum deflection corresponds to the deflection of a significant location in the real structure (Biggs 1964).

The constants of the equivalent SDOF are computed based on the resulting deformed shape under static loading. Transformation factors are then used to change the real system into the equivalent SDOF.

The effective mass is computed by equation [2-5]:

$\mathbf{M}_{\mathbf{e}}=\mathbf{k}_{\mathbf{M}} \times \mathbf{M}_{\mathbf{T}}$

where $\mathbf{k}_{\mathbf{M}}$ is the mass transformation factor and $\mathbf{M}_{\mathbf{T}}$ is the total mass of the structural component. The equivalent load and equivalent resistance are similarly computed by equation [2-6] and equation [2-7] respectively:

$F_{e}=k_{L} \times F_{t}$

$\mathbf{K}_{\mathbf{e}}=\mathbf{k}_{\mathbf{L}} \times \mathbf{k}$ 
where $\mathbf{k}_{\mathbf{L}}$ is the load transformation factor, $\mathbf{k}$ represents the stiffness of the system at a given time $\mathbf{t}$ and $\mathbf{F}_{\mathbf{t}}$ is the total force acting on the structural component at a given time, $\mathbf{t}$. The equivalent factors have been tabulated in several blast design manuals as well as Biggs (1964).

Review of research work revealed that various damping ratios ranging from $1 \%$ to $5 \%$ have been used in SDOF blast analysis (Andersson and Karlsson 2012; Carlsson and Kristensson 2012; Rezaei 2011). Carlsson and Kristensson (2012) performed SDOF analysis of concrete structures and used damping ratios ranging from $3 \%$ to $5 \%$. In their respective research works, Andersson and Karlsson (2012) studied the structural response of concrete beams subjected to blast loading while Rezaei (2011) studied the response of RC elements to high-velocity impact loading. Both research works used a damping ratio of $5 \%$ for their research works (Andersson and Karlsson 2012; Rezaei 2011). PEC and BakerRisk (2008), however, suggests the use of a smaller damping ratio of about $1 \%$. PEC and BakerRisk (2008) suggests that due to the very short duration of the blast load, the peak response usually occurs in the first cycle. Thus, there is not much time for damping to be effective. Thus, using a smaller damping ratio gives a conservative estimate of the blast loading response parameters for the single-degree-of-freedom system.

\subsubsection{Resistance Function}

The force that tends to restore a structure to its unloaded position defines the resistance of the structure. The resistance is dependent on the distribution of the applied loading, the geometry of the structural component as well as the support condition (U. S. Army Corps of Engineers 2008). A force-displacement curve, often referred to as a resistance function is not a single value but depends on displacement-response history (Humar 2012). At each time step the response 
parameters of displacement, velocity and acceleration determine whether structural component has yielded and transitioned into elastic, elasto-plastic or plastic phase due to the formation of plastic hinges at points of maximum stress (U. S. Army Corps of Engineers 2008). This is then used to establish the structural component resistance value at subsequent time steps. A typical resistance-function is presented in Figure 2-2.

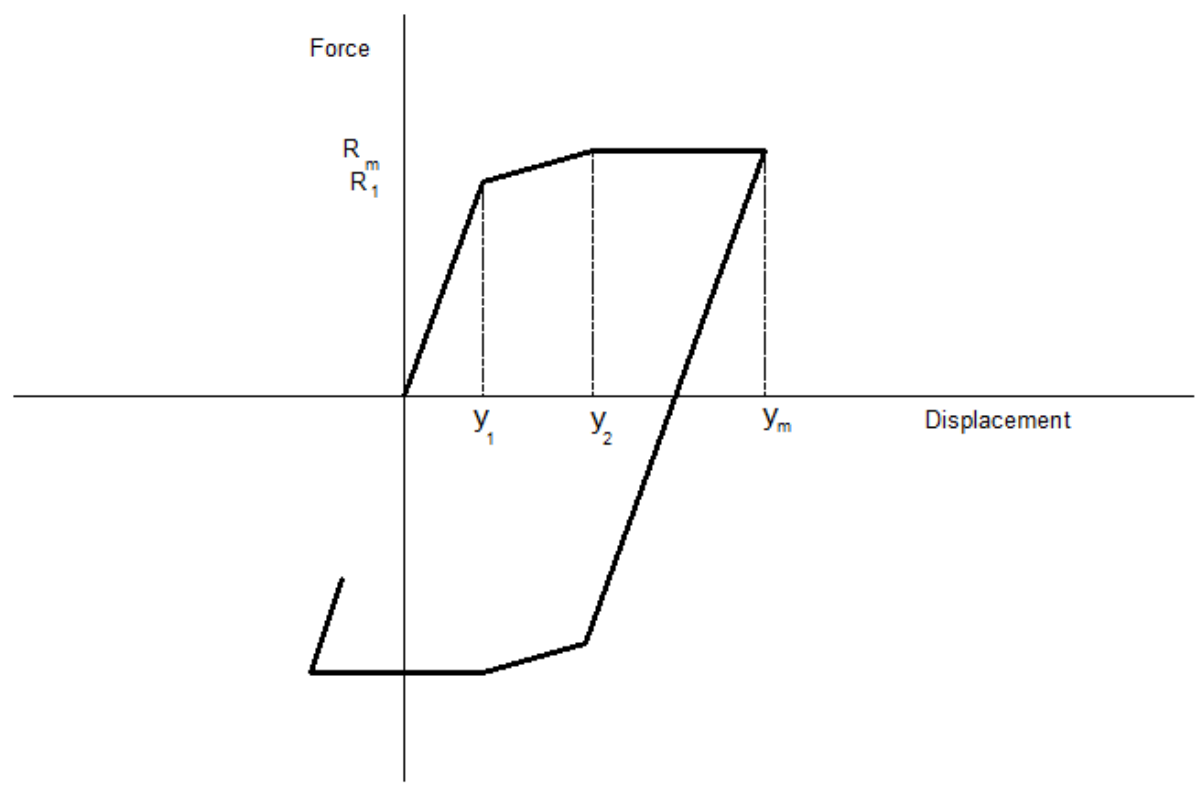

Figure 2-2: Material Resistance Function

The applied loading initially results in elastic flexural response until yielding occurs. Yielding is associated with the formation of plastic hinges at regions of maximum moments. This corresponds to fixed ends of structural components if the structure has fixed supports. Figure 2-2 shows that the structure remains elastic until it undergoes a displacement, $\boldsymbol{y}_{\mathbf{1}}$, the corresponding force at this displacement is given by $\mathbf{R}_{\mathbf{1}}$. The equivalent stiffness for this elastic section is given by Equation [2-8].

$\mathbf{k}_{\mathbf{e}}=\frac{\mathbf{R}_{1}}{\mathbf{y}_{1}}$ 
The structure then transitions through an elasto-plastic phase, where an increase in loading is resisted by a less stiff system, until its displacement reaches $\mathbf{y}_{2}$. The stiffness of the system within the elasto-plastic range, $\mathbf{k}_{\mathbf{e p}}$, is computed by equation [2-9].

$\mathbf{k}_{\mathrm{ep}}=\frac{\mathbf{R}_{\mathrm{m}}-\mathbf{R}_{\mathbf{1}}}{\mathbf{y}_{2}-\mathbf{y}_{1}}$

Beyond $\mathbf{y}_{2}$, the structure forms a mechanism and becomes perfectly plastic with an accompanying zero stiffness. When the velocity reverses direction, at maximum displacement $\left(\mathbf{y}_{\mathbf{m}}\right)$, the structure returns to the elastic range (PEC and BakerRisk 2008). Thus, in the solution of the equivalent SDOF, the resistance is evaluated at each time step based on the already computed structural response values.

The following are some of the simplifications that limit the use of the equivalent SDOF model for detailed structural response analysis.

- The equivalent SDOF blast analysis is performed with the assumption that the blast loading is distributed uniformly over the target area of the structural component (PEC and BakerRisk 2008; U. S. Army Corps of Engineers 2008). This, however, is not always the case especially with close-in explosions.

- The first mode shape is assumed to govern the dynamic response of the structural component (Biggs 1964; Nassr et al. 2012). This tends to be a good assumption when most of deflections occur during the plastic response phase which is dominated by the first mode shape and the blast loading is also uniform. Deflections in the elastic range tend to be affected much more by higher modes (PEC and BakerRisk 2008).

- The equivalent SDOF model, in general, gives an estimate of the dynamic response parameters of the given structural component. The equivalent SDOF model can be 
modelled with a much more complex resistance function to factor in material specific behaviours such as flexure, compression and axial loading. Yet, even more complex behaviours such as breach and scabbing can only be modelled with a detailed finite element analysis (Nassr et al. 2012; PEC and BakerRisk 2008).

\subsection{Review of Previous Works}

Research work in the field of blast load effect on buildings has, until recently, been focused on military structures, designed to resist explosions, and buildings in industries with high explosion risk. The United States Department of Defense (US DoD), for instance, developed a manual for the design and analysis of structures to resist the effects of accidental explosions (U. S. Army Corps of Engineers 2008). The design guidelines are for hardened structures that are usually more expensive to construct in comparison with conventional structures. Thus, adapting the design requirements for conventional structures can potentially lead to great savings and safeguard of lives.

Significant amount of research has gone into investigating the blast resistance of non-structural components making up the façade of buildings such as windows (Norville and Conrath 2006; Pritchard 1981) and masonry infill walls (Davidson et al. 2004, 2005; Fitzmaurice et al. 2006; Myers et al. 2004). Damage of non-structural components can cause devastating effects on human lives as well as property if no mitigation measures are put in place. For instance, glass shards resulting from explosions can cause serious injuries to inhabitants of the building; especially those close to glass windows. Norville et al. (2006) investigated different laminated glass thicknesses under blast loading that can potentially mitigate glass shard related injuries. 
Davidson and Fisher (2005) reported improved performance of unreinforced masonry walls by using low-strength, high-elongation, and thin-membrane elastomeric polymers.

A lot more research work has, however, concentrated on structural components such as slabs (Low and Hao 2002; Mosalam and Mosallam 2001; Ngo et al. 2007; Zhou et al. 2008), beams (Kamali 2012; Magnusson 2007) and columns (Astarlioglu et al. 2013; Bao and Li 2010; Carriere et al. 2009; Elsanadedy et al. 2011; Morrill and Malvar 2004; Roller et al. 2013; Sezen and Moehle 2004; Shi et al. 2010; Wu et al. 2011a). For instance, a case study of the attack on the Alfred P. Murray Building (Lew 2002), showed extensive damage of the building was due to the collapse of significant structural load-bearing columns at the lower story of the building. This has led some researchers (Ettouney et al. 1996; Luccioni et al. 2004; Remennikov 2003) to focus on the effects of blast loading to an entire building. The Commission on Engineering and Technical Systems (CETS 2000) as part of a research to improve the safety of U.S. embassies, constructed a full-scale prototype of a concrete structure to study the behaviour of glass windows, walls, and structural elements under blast loading. This, however, is very impractical as such a project is associated with high costs.

Due to the very high cost of live explosive testing, a lot of researchers have had to rely on a combination of limited experimental tests coupled with numerical modelling to predict the behaviour of structural components under blast loading. This helps to reduce the cost of research while affording flexibility in conducting complex analysis and evaluating element behaviours that are difficult to capture in live explosion testing.

It is also currently impractical to perform a realistic numerical simulation in which the actual reinforced concrete (RC) building components are modelled with all the associated detailing. This is due to the very expensive computational cost associated with such a global numerical 
assessment of an entire building. Luccioni et al. (2004) performed a numerical analysis of a building that had been subjected to blast loading and compared the results with the damage sustained by the actual building in a terrorists attack in Argentina. The columns, beams and slabs were modelled using three-dimensional (3D) solid elements while the exterior and interior walls were modelled with shell elements. The concrete material was modelled as a homogenized elasto-plastic material with strength equivalent to that of the actual columns. A comparison of the numerical simulation to the actual damaged building showed similarity in damage patterns. The RC structural components were modelled without any emphasis on the reinforcement detailing. The extent to which the reinforcement detailing influenced the response of the structural components to blast loading was, thus, not investigated and reported.

With the high impulsive loading associated with explosions, the potential localized damage of individual structural components becomes a subject of great concern. The failure of load carrying structural components, such as columns, can result in the partial or total collapse of the building structure. On May 16, 1968, the Ronan-Point apartment suffered extensive collapse of a part of the building due to a gas explosion that led to collapse of a load bearing wall on the $18^{\text {th }}$ floor of the structure. With no alternate loading path, the floors above and below the $18^{\text {th }}$ floor collapsed (Li and Hao 2013). Corley et al. (1996) documents how the 9-storey reinforced concrete Alfred P. Murrah building suffered progressive collapse. The blast load destroyed critical load carrying columns resulting in the collapse of the floors above. Corley et al. (1996) reports that only about $4 \%$ of the total building area was damaged as a result of the direct effects of the blast loading while approximately $42 \%$ of the total building area was damaged due to the combined effects of the blast loads and progressive collapse. A lot of research has, therefore, been conducted on the 
response and behaviour of individual $\mathrm{RC}$ columns in an attempt to understand the failure mechanisms of reinforced concrete columns under blast loading.

Researchers have focused on retrofitting and strength enhancement schemes to improve the performance of RC columns. Crawford (2013) studied the use of fibre reinforced polymer (FRP) sheets to enhance the strength of RC columns and reported decreased lateral column deflections and improved axial load capacity. The FRP-wrapped columns were more ductile and also exhibited enhanced shear strength, as the concrete core was protected from damage, than the non-FRP wrapped columns. The research was focused on the use of FRP to improve the load carrying capacity of RC columns and did not focus on the use transverse reinforcement spacing to achieve improved RC column load carrying capacity. Roller et al. (2013) investigated concrete strengthening schemes such as reinforced polymer wrapping and high compressive strength concretes. Roller et al. (2013) tested the residual capacity of scaled-down models of RC columns subjected to close-in explosions in a two-stage approach. The RC columns were initially subjected to blast loading ignoring axial loading on the columns. The laterally deformed RC columns were then subsequently subjected to axial loading to determine their residual capacities. The hardening and retrofitting measures employed resulted in decreased lateral displacements in comparison to the larger displacements measured in the conventional RC columns. Roller et al. (2013), however, did not consider the combined effect of simultaneously subjecting the RC columns to blast loading and axial compression. The effect of reinforcement detailing on the performance of the RC columns was also not investigated. Elsanadedy et al. (2011) also investigated the effect of blast loads on carbon fibre reinforced polymer (CFRP) wrapped circular RC columns at different stand-off distances. The RC columns were wrapped with $1 \mathrm{~mm}$ thick CFRP layers to increase concrete confinement and provide shear enhancement as well as 
improved flexural capacity of the columns. The retrofitted RC columns recorded improved performance over the non-retrofitted columns with exponential decrease in lateral deformation as the scaled distance increased. Elsanadedy et al. (2011) did not consider the effect of varying axial loads on the columns.

$\mathrm{Wu}$ et al. (2011b) investigated the effect of contact explosion on composite columns. The composite columns consisted of a structural steel section embedded in a RC column. The purpose of the study was to evaluate the residual axial compression capacity of the composite column after it had been subjected to blast loading. The damaged profile was compared with results of a finite element analysis using LS-DYNA and showed good correlation. A parametric study was then conducted on different composite RC columns by varying the column depth, column height, structural steel ratio and the axial load ratio on the composite RC column. Increased column depth and structural steel ratio led to increased impulse load resistance. The column height, however, was determined to have had no effect on the residual column capacity. Also, an increased axial load ratio was reported to increase the moment capacity of the columns. This research focused on investigating the improved performance provided by the embedded steel section.

Several researchers have also investigated the effect of seismic detailing on the performance of RC columns subjected to blast loading. Bao and Li (2010) performed experimental tests on RC columns considering the combined effect of axial gravity loads and lateral blast loads on the RC columns. Bao and Li (2010) also correlated the experimental results with a numerical parametric study considering the effects of axial loads, transverse bar spacing and longitudinal bars. The gravity axial loads were applied prior to blast loading and sustained during and after the blast loading. The presence of axial load resulted in reduced lateral displacements. Yet beyond a 
certain critical displacement the columns lost their moment capacities. Secondary effects caused rapid increase in lateral deflections, strength degradation and buckling of longitudinal reinforcement. Increasing the amount of transverse reinforcement also increased the shear capacity ensuring columns failed in flexure rather than in shear while also preventing buckling of longitudinal bars. Bao and $\mathrm{Li}$ (2010) also observed that increasing transverse reinforcement required commensurately higher failure loads. Higher amounts of longitudinal reinforcement increased the moment and axial load capacity of the columns. However, the presence of a high amount of longitudinal reinforcements resulted in sudden shear failure. Bao and Li (2010) limited their research on close-in explosions and used a fixed standoff distance of $5 \mathrm{~m}$ for the numerical work. Wu et al. (2011a) also tested reinforced concrete columns detailed for seismic resistance in accordance with ACI code to study the residual capacity of RC columns subjected to contact explosions and axial loads. Wu et al. (2011a) also limited their research to close-in explosions and did not investigate the performance of the $\mathrm{RC}$ columns under varying blast loading standoff distances.

Many researchers (Fujikura and Bruneau 2011; Williams and Williamson 2011; Williamson et al. 2010; Winget et al. 2005) have also studied the performance of bridge piers under blast loading. Fujikura et al. (2008) studied the effects of blast loading on multi-hazard bridge piers; designed for both seismic and blast loading. The research was conducted on $1 / 4$ scaled bridge piers made of concrete-filled Steel Tubes (CFST). The results were compared to an equivalent SDOF system with elasto-plastic behaviour, with the CFST columns showing ductile behaviour under blast loading.

Fujikura and Bruneau (2011) went on further to investigate the performance of seismically ductile RC bridge columns and conventional RC bridge columns retrofitted with steel jackets. 
The research did not consider the effects of axial loads on the columns. Both type of columns failed in shear and were found to be lacking adequate ductility under blast loading.

Parisi and Augenti (2012) assessed the blast resistance of a seismic-designed RC framed building. The building was designed according to Eurocode 8 and compared with another designed for only gravity loading. Under close-in explosion, the seismic-designed RC frame did not provide sufficient structural robustness against progressive collapse but suffered significantly less damage in comparison with the $\mathrm{RC}$ frame column designed for gravity load only.

\subsection{Strain Rate Effects}

The behaviour of structural components under dynamic loading can be very different than under static loading. Under dynamic loading, the rate of application of the load can significantly affect the response of structural components. Very short impulsive dynamic loading such as impact loading and blast loading result in high strain rate of magnitudes ranging from $10 \mathrm{~s}^{-1}$ to as high as $1000 \mathrm{~s}^{-1}$ (Malvar and Crawford 1998) that can significantly affect the response of a structure. Concrete (Fu et al. 1991a; Malvar and Crawford 1998; Nard and Bailly 2000; Yan and Lin 2006) and steel (Flathau 1971; Malvar 1998) have been found to be sensitive to the rate of loading. At very high strain rates, increase in concrete and steel strength can be very significant. The dynamic increase factor (DIF) expresses the ratio of the dynamic strength to static strength (Malvar 1998). Concrete in compression has been observed to have a DIF greater than 2 (Malvar 1998). Fu et al. (1991b) presented a review of research work on strain rate effects on concrete and reported a general increase in compressive strength with increasing strain rates. The increase in compressive strength of concrete, however, can be influenced by factors such as concrete strength, aggregate sizes and moisture content. Weak concrete has been studied to be more 
sensitive to rate of loading and hence increases much more in strength under high strain-rates than high-strength concrete (Yan and Lin 2006). Wet concrete has also been studied to be much more sensitive to strain-rate effects than dry concrete (Fu et al. 1991a; Ross and Jerome 1996). Concrete in tension has also been observed to undergo increased tensile strength under high strain rates (Malvar and Crawford 1998; Yan and Lin 2006). Malvar and Ross (1998) proposed a DIF for concrete in tension as high as 7 at a strain rate of $157 \mathrm{~s}^{-1}$.

Under dynamic loading, steel reinforcing bars have also been observed to exhibit increased yield and ultimate strengths by up to $60 \%$ for higher strain rates greater than $10 \mathrm{~s}^{-1}$ (Malvar 1998).

\subsection{Column Response to seismic loading}

Maximum moments in columns with fixed ends occur at the ends when subjected to ground excitation. Columns usually bend in double curvature as shown in Figure 2-3. The double curvature deformation associated with seismic loading is accompanied by the lateral drift of the column as it is not restrained to move horizontally.
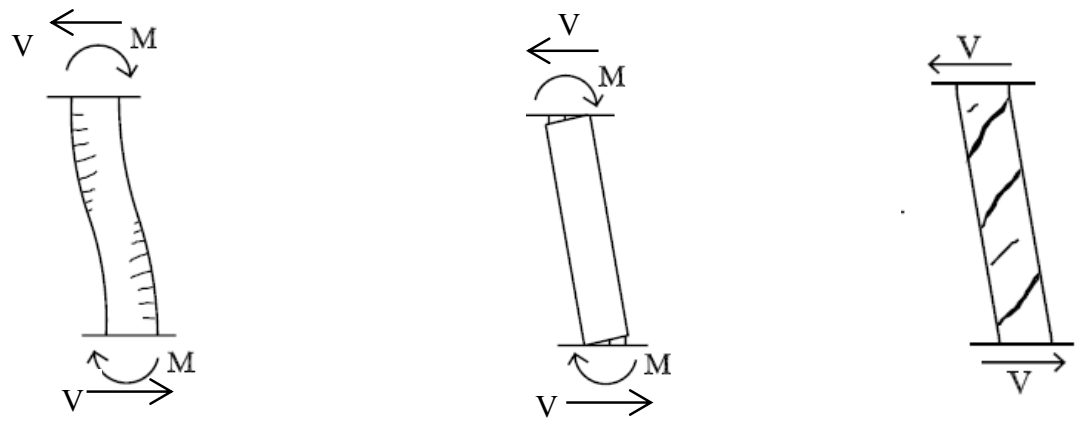

Figure 2-3: Lateral deformations due to: (a) Flexure (b) bond slip (c) shear (after Sezen 2000)

If the capacity of the column at the ends is exceeded, plastic hinges are formed. This also causes further lateral deformations. The column, as a result, loses its axial load capacity. This could lead 
to progressive collapse of other structural elements if the column is a critical load carrying element (Sezen 2000).

Sezen and Moehle (2004) conducted tests to study the effects of cyclic loading coupled with axial loading on reinforced concrete columns; $457 \times 457 \mathrm{~mm}$ concrete columns, $2947 \mathrm{~mm}$ in length, with ties spaced at approximately $300 \mathrm{~mm}$ intervals. The columns were tested under various conditions. Some of the columns in the tests were subjected to low axial loads and made to undergo incremental lateral displacements. Another set of columns were tested under constant high axial loading while another set of columns were tested under varying axial loading. Sezen and Moehle (2004) concluded that the magnitude of axial loading on the columns significantly affected the performance of the columns under cyclic loading. At high axial loading the columns failed in shear at displacements lower than the measured displacements at lower axial loading. In general, the loss of axial load carrying capacity was associated to the opening of the column ties, buckling of the main longitudinal bars and crushing of the core concrete.

Generally, in seismic design more transverse reinforcement is placed at the regions of plastic hinging, which is at the top and bottom support locations, to ensure the column is ductile enough to maintain its strength in the event of seismic loading. The mid-height region does not require as much transverse reinforcement under seismic loading. This, however, is a potential vulnerability in the event of blast loading where maximum moment is likely to occur at mid-height.

\subsection{Summary}

The chapter provided a background of the nature of explosions and the mechanism of blast wave evolution and interaction with columns. The equivalent SDOF model was also presented as a method that can be used for structural blast loading analysis to give a quick estimate of dynamic 
response parameters which can be used for informed and advanced finite element analysis of the problem.

In general, blast research work is gaining much needed impetus. The fact that blast research is still a relatively new research area coupled with the situation where a lot of blast research information still remain classified leaves an information gap deficit that blast researchers are aiming to fill. In the review of literature presented in this chapter, RC columns were identified as essential load carrying members with their subsequent collapse in blast loading often leading to catastrophic consequences.

The review presented a lot of gaps that still need to be investigated. Firstly, some research works were identified as focusing on retrofitting and hardening measures with little work on the influence on reinforcement detailing schemes on $\mathrm{RC}$ column performance. Secondly, most of the research works that investigated the effect of column detailing either ignored or did not extensively consider the effect of simultaneously loading the RC columns under both blast loading and compressive axial loading. Thirdly, little has been done in investigating scaled distance variation using different charge masses and the resulting effect on seismically detailed RC columns simultaneously subjected to blast loading and axial compression loading.

There is also very minimal work reported on the study of the performance of RC columns designed and detailed to Canadian seismic design and detailing guidelines.

The research reported in this thesis aims at addressing some of these gaps by investigating:

- The potential for mitigating explosion hazards by adapting already established seismic design and detailing techniques

- The combined effect of varying far-field blast loading and axial loading on RC columns detailed for seismic and conventional load resistance 
- The adequacy of detailing guidelines for earthquake loading in accordance with CSA A23.3-04 to enhance blast resistance of RC columns 


\section{Chapter: Detailing of Transverse Reinforcement}

\subsection{Background}

In the event of an earthquake, the response of a structure to the seismic forces acting on it is dependent on whether the structure has enough strength to behave elastically or will have to dissipate energy by undergoing non-linear plastic deformation. Reinforced concrete structures are able to resist seismic forces beyond the elastic range, provided the structure has enough ductility to undergo inelastic deformation. In seismic design, a balance is normally sought between strength and ductility. Clause (CL.) 21 of the CSA A23.3-04 (CSA 2004) proposes detailing requirements for reinforced concrete columns in accordance with the required ductility level.

CSA (2004) adopts the capacity design approach for analyzing and detailing of structures; wherein certain parts of the structure are designed to have enough ductility to undergo plastic deformation when the elastic capacity is exceeded. Special detailing is only required for a few selected parts to ensure the ductility of the structure as a whole. CSA (2004) also identifies six standard ductile systems in accordance to the National Building Code of Canada, NBCC (2005). These are outlined below.

- Ductile Moment Resisting Frames

- Moderately Ductile Moment Resisting Frames

- Ductile Coupled Walls

- Ductile Partially Coupled Walls

- Ductile Shear walls

- Moderately Ductile Shear walls 
When structural members such as shear walls are used as concrete seismic force resisting systems (SFRS), other structural members that do not form a part of the SFRS are designed to resist gravity loads as well as accommodate a significant amount of lateral deformation, depending on the level of seismicity. Reinforced concrete columns that fall under this category are the focus of this thesis.

Clause 21.12 in the CSA A23.3 (2004) seeks to provide basic detailing to ensure a minimum level of ductility and strength for all structural members that are not identified as part of the main SFRS but are subjected to seismically induced deformations in the event of an earthquake. The clause covers beams and columns not meeting the dimensional requirements of clauses 21.3.1 and 21.4.1 respectively (CSA, 2004). The minimal detailing provisions ensure that the structural elements, while undergoing seismically induced deformations, are able to carry the gravity loads they were designed for. Seismic detailing for the columns investigated in this thesis was in accordance with Clause 21 of CSA A23.3 (2004).

\subsection{Column dimensions}

Based on clause 21.4.1.1 in the CSA A23.3 (2004), the shortest cross-sectional dimension for columns should not be less than $300 \mathrm{~mm}$. The ratio of the shortest cross-sectional dimension to its perpendicular cross-sectional dimension should also exceed 0.4 or higher. A $300 \times 300 \mathrm{~mm}$ column of height $3000 \mathrm{~mm}$, meeting the clause specifications was used for the numerical simulations. 


\subsection{Column detailing}

To ensure enough ductility the column was assumed to meet the requirements of clause 21.12.2.2 of CSA A23.3-04 (CSA 2004). Plastic hinge regions were, thus, identified and detailed accordingly with transverse reinforcement detailing done according to the provisions of clause 21.4.4 of CSA A23.3-04 (CSA 2004). The computations for the transverse detailing are presented in section 3.3 .2

\subsubsection{Main reinforcement detailing}

No special code provisions are required in the selection of the longitudinal bar size as well as the number of longitudinal bars used as the main flexural and axial load resisting bars. 4-25M bars were used as the main longitudinal reinforcement bars giving a reinforcement ratio of approximately $2.2 \%$.

\subsubsection{Transverse Reinforcement}

The transverse seismic detailing was done in accordance with clause 21.4.4 of CSA A23.3-04 (CSA 2004) while the conventional RC column detailing was done in accordance to clause 7.6.5.2 of CSA A23.3-04.

Table 3-1: Parameters used for detailing of RC columns for numerical work

\begin{tabular}{|r|l|}
\hline cover & $40 \mathrm{~mm}$ \\
\hline $\mathrm{d}_{\mathrm{t}}$ & $10 \mathrm{~mm}$ \\
\hline $\mathrm{d}_{\mathrm{b}}$ & $25 \mathrm{~mm}$ \\
\hline $\mathrm{A}_{\mathrm{b}}$ & $500 \mathrm{~mm}^{2}$ \\
\hline $\mathrm{f}_{\mathrm{yh}}$ & $400 \mathrm{MPa}$ \\
\hline $\mathrm{f}_{\mathrm{c}}^{\prime}$ & $40 \mathrm{MPa}$ \\
\hline$\phi_{\mathrm{c}}$ & 0.65 \\
\hline$\phi_{\mathrm{s}}$ & 0.85 \\
\hline
\end{tabular}


Table 3-1 lists the parameters that were used for the detailing of the $300 \times 300 \times 3000 \mathrm{~mm} \mathrm{RC}$ columns used for the numerical work presented in this thesis.

The maximum transverse reinforcement spacing configuration calculated for both the seismic and conventional columns based on the above mentioned clauses are presented below:

\subsubsection{Seismic Column Detailing}

Clause 21.12.2 of CSA A23.3-04 is used for the detailing of structural members depending on the ductility demand expected. Clause 21.12.2.2 indicates that the transverse reinforcement detailing of structural members that will undergo flexural deformation with a nominal axial load ratio limit of 0.35 can be detailed in accordance to clauses 21.4.4 and 21.4.5.

\subsection{Transverse reinforcement spacing in plastic hinge length}

The spacing of the transverse reinforcement in the plastic hinge region of the RC column follows the provisions of clauses 21.4.4.2, 21.4.4.3 and 21.4.4.4.

Within the maximum spacing, s, to be provided between transverse reinforcing bars, the total effective cross-sectional area of transverse reinforcement, $A_{\text {sh }}$, is given by equation [3-1] (CL. 21.4.4.2 of CSA A23.3-04).

$A_{s h}>$ maximum of $\left\{\begin{array}{c}0.2 \cdot k_{n} \cdot k_{p} \cdot \frac{A_{g}}{A_{c h}} \cdot \frac{f_{c}^{\prime}}{f_{y h}} \cdot s \cdot h_{c} \\ 0.09 \cdot \frac{f_{c}^{\prime}}{f_{y h}} \cdot s \cdot h_{c}\end{array}\right.$

Equation [3-1] gives the total cross-sectional area of the lateral reinforcement where $k_{n}$ is the factor that accounts for the number of longitudinal bars in the column while $\mathrm{k}_{\mathrm{p}}$ factors in any compressive axial loading acting on the column. The ratio of the gross concrete cross-sectional area $\left(A_{g}\right)$ to the cross-sectional area of concrete within the transverse ties $\left(A_{c h}\right)$ is given by $\frac{A_{g}}{A_{c h}}$. 
The compressive strength of the concrete and the strength of the transverse ties are also given by $\mathrm{f}_{\mathrm{c}}^{\prime}$ and $\mathrm{f}_{\mathrm{yh}}$ respectively while $\mathrm{h}_{\mathrm{c}}$ is the dimension of the concrete core measured to the outside of the stirrups. Clause 21.4.4.2 of CSA A23.3-04 stipulates that $\mathrm{f}_{\mathrm{yh}}$ should not be greater than 500 MPa.

Rearranging equation [3-1], the required transverse spacing, in accordance with Cl. 21.4.4.2 of CSA A23.3-04, is given by equation [3-2].

$\mathbf{S} \leq$ maximum of $\left\{\begin{array}{c}\frac{A_{s h} \cdot A_{c h} \cdot f_{y h}}{0.2 \cdot k_{n} \cdot k_{p} \cdot A_{g} \cdot f_{c}^{\prime} \cdot h_{c}} \\ \frac{A_{s h} \cdot f_{y h}}{0.09 \cdot f_{c}^{\prime} \cdot h_{c}}\end{array}\right.$

Equation [3-3] and equation [3-4] are used to compute $\mathrm{k}_{\mathrm{n}}$ and $\mathrm{k}_{\mathrm{p}}$ respectively.

$\mathbf{k}_{\mathbf{n}}=\frac{\mathbf{n}_{\mathbf{l}}}{\mathbf{n}_{\mathbf{l}}-2}$

where $\mathrm{n}_{1}$ is the number of longitudinal reinforcement bars

$\mathbf{k}_{\mathbf{p}}=\frac{\mathbf{P}_{\mathbf{f}}}{\mathbf{P}_{\mathbf{o}}}$

where $\mathrm{P}_{\mathrm{f}}$ is the applied axial load on the column and $\mathrm{P}_{\mathrm{o}}$ is the axial load capacity of the column.

Using equations [3-2], [3-3] and [3-4], the maximum spacing can be computed as follows:

$$
\begin{gathered}
\mathrm{n}_{\mathrm{l}}=4 \\
\mathrm{k}_{\mathrm{n}}=\frac{4}{4-2}=2 \\
\left.\mathrm{k}_{\mathrm{p}}=0.35 \text { (Assuming the limiting axial load ratio of } 0.35\right) \\
\mathrm{A}_{\mathrm{ch}}=(300-2 \times 40-2 \times 10)^{2}=40000 \mathrm{~mm}^{2} \\
\mathrm{~A}_{\mathrm{g}}=300 \times 300=90000 \mathrm{~mm}^{2} \\
\mathrm{~h}_{\mathrm{c}}=300-2 \times 40=220 \mathrm{~mm}^{2}
\end{gathered}
$$


Case I

$$
s=\frac{200 \times 40000 \times 400}{0.2 \times 2 \times 0.35 \times 90000 \times 40 \times 220}=30 \mathrm{~mm}
$$

Also

Case II

$$
\mathrm{s}=\frac{200 \times 400}{0.09 \times 40 \times 240}=100 \mathrm{~mm}
$$

$$
\therefore s \leq 100 \mathrm{~mm}
$$

CL. 21.4.4.3 of CSA A23.3-04 also prescribes that the spacing in the plastic hinge region be computed in accordance with equation [3-5].

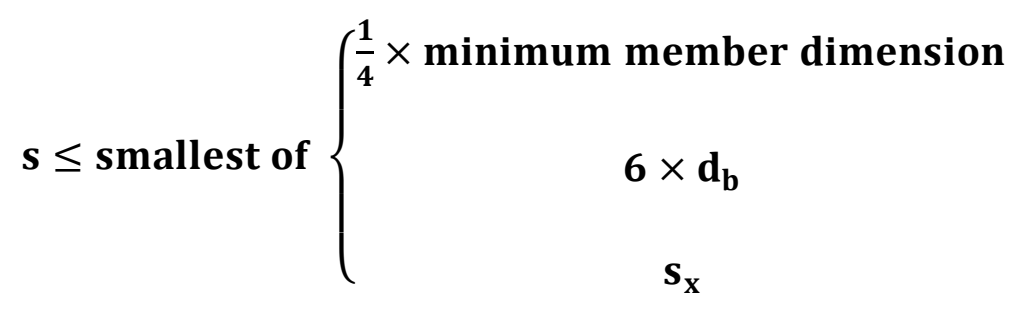

where $s_{x}$ can be computed by equation [3-6]

$\mathbf{s}_{\mathrm{x}}=100+\left(\frac{350-\mathbf{h}_{\mathrm{x}}}{3}\right)$

$\mathrm{h}_{\mathrm{x}}$ in equation [3-6] is also defined, in accordance with CL. 21.4.4.4 of CSA A23.3-04, by equation [3-7] as:

$h_{x} \leq$ greatest of $\left\{\begin{array}{c}200 \mathrm{~mm} \\ \frac{1}{3} \times \text { core dimension }\end{array}\right.$

Using equations [3-5], [3-6] and [3-7], the maximum spacing can be computed as follows: 
$h_{x} \leq$ greatest of $\left\{\begin{array}{c}200 \mathrm{~mm} \\ \frac{1}{3} \times \text { core dimension }=\frac{1}{3} \times 220=75 \mathrm{~mm}\end{array}=75 \mathrm{~mm}\right.$

Also

$\mathrm{s}_{\mathrm{x}}=100+\left(\frac{350-75}{3}\right)=190 \mathrm{~mm}$

Spacing s $\leq$ smallest of $\left\{\begin{array}{c}\frac{1}{4} \times 300=75 \mathrm{~mm} \\ 6 \times 25=150 \mathrm{~mm} \\ 190 \mathrm{~mm}\end{array}\right.$

$\rightarrow$ the actual spacing, $\mathrm{s} \leq 75 \mathrm{~mm}$

\subsection{Plastic Hinge Length}

The maximum transverse reinforcement spacing computed in section 3.3.2.1.2 in accordance with CL. 21.4.4.1 to CL. 21.4.4.3 of CSA A23.3-04 is provided over a length of the plastic hinge, $l_{o}$, from the face of the support, on both ends of the column. The plastic hinge length defines the section of the column where probable flexural yielding occurs when the column is subjected to inelastic lateral deformation in the event of an earthquake.

CL. 21.4.4.5 of CSA A.23.3-04 presents equations for determining the plastic hinge length (Equations [3-8] and [3-9]).

$\mathrm{l}_{\mathrm{o}} \geq \max \left\{\begin{array}{c}1.5 \times \text { largest member cross }- \text { section dimension } \\ \frac{1}{6} \times \text { clear span of member }\end{array}, \mathrm{P}_{\mathrm{f}} \leq 0.5 \cdot \emptyset_{\mathrm{c}} \cdot \mathbf{f}_{\mathrm{c}}^{\prime} \cdot \mathrm{A}_{\mathrm{g}}\right.$

$l_{o} \geq \max \left\{\begin{array}{c}2 \times \text { largest member cross }- \text { section dimension } \\ \frac{1}{6} \times \text { clear span of member }\end{array} \mathbf{P}_{\mathrm{f}}>0.5 \cdot \emptyset_{\mathrm{c}} \cdot \mathbf{f}_{\mathrm{c}}^{\prime} \cdot \mathbf{A}_{\mathrm{g}}[3-9]\right.$ 
The maximum factored axial load, $\mathrm{P}_{\mathrm{f}}$, is computed based on the assumed axial loading ratio on the column. Using the axial load ratio limit $(=0.35)$ (CL. 21.12.2.2 of CSA A.23.3-04), the factored axial load can be expressed in terms of the axial load capacity of the column, $\mathrm{P}_{\text {ro }}$ using equation [3-10] and equation [3-11] (CL. 10.10.4).

$P_{\mathrm{f}}=0.35 \times P_{\text {rmax }}$

$\mathbf{P}_{\text {rmax }}=0.80 \times P_{\text {ro }}$

where

$P_{\text {ro }}=\propto_{1} \cdot \emptyset_{c} \cdot f_{c}^{\prime} \cdot\left(A_{g}-A_{s t}\right)+\emptyset_{s} \cdot f_{y} \cdot A_{s t}$

In equation [3-12], $\mathrm{A}_{\mathrm{st}}$ is the total area of longitudinal bars in the RC column and $\propto_{1}$ can be computed using equation [3-13].

$$
\propto_{1}=0.85-0.0015 f_{c}^{\prime}
$$

Thus using equations [3-10], [3-11] and [3-12], $\mathrm{P}_{\mathrm{f}}$ can be calculated as follows:

$\propto_{1}=0.85-0.0015 f_{\mathrm{c}}^{\prime}=0.85-0.0015 \times 40=0.79$

$\mathrm{A}_{\mathrm{st}}=4 \times 500=2000 \mathrm{~mm}^{2}$

$A_{g}=300 \times 300=90000 \mathrm{~mm}^{2}$

$\mathrm{P}_{\text {ro }}=0.79 \times 0.65 \times 40 \times(90000-2000)+0.85 \times 400 \times 2000=2487520 \mathrm{~N}$

$\mathrm{P}_{\mathrm{ro}}=2490 \mathrm{kN}$

$\mathrm{P}_{\mathrm{rmax}}=0.8 \cdot \mathrm{P}_{\mathrm{ro}}=0.8 \times 2490=2000 \mathrm{kN}$

Since $\mathrm{P}_{\mathrm{f}}=0.35 \cdot \mathrm{P}_{\mathrm{rmax}}$

$\mathrm{P}_{\mathrm{f}}=0.35 \times 2000=700 \mathrm{kN}$

To check whether the plastic hinge length is governed by equation [3-8] or [3-9] $0.5 \cdot \emptyset_{c} \cdot f_{c}^{\prime} \cdot A_{g}$ is calculated and compared to the value of $\mathrm{P}_{\mathrm{f}}$. 
$0.5 \cdot \emptyset_{c} \cdot f_{c}^{\prime} \cdot A_{g}=0.5 \times 0.65 \times 40 \times 90000=117000 \mathrm{~N}=117 \mathrm{kN}$

$\therefore \mathrm{P}_{\mathrm{f}}(=700 \mathrm{kN})>0.5 \cdot \emptyset_{\mathrm{c}} \cdot \mathrm{f}_{\mathrm{c}}^{\prime} \cdot \mathrm{A}_{\mathrm{g}}$

From the preceding calculations, Equation [3-9] is the governing equation for the determination of the plastic hinge length. Thus, using equation [3-9], the plastic hinge length is computed as follows:

$l_{o} \geq \max \left\{\begin{array}{l}2 \times 300=600 \mathrm{~mm} \\ \frac{1}{6} \times 3000=500 \mathrm{~mm}\end{array}\right.$

$\therefore l_{o} \geq 600 \mathrm{~mm}$

\subsection{Transverse reinforcement spacing outside plastic hinge length}

For the region outside the plastic hinge lengths, $l_{o}$, CL. 21.4.4.7 of CSA A.23.3-04 specifies that the spacing of the transverse bars should be computed in accordance with equation [3-14]

$s \leq$ smaller of $\left\{\begin{array}{c}6 \cdot d_{b} \\ 150 \mathrm{~mm}\end{array}\right.$

Using equation [3-14], the region outside the plastic hinge length can be detailed with transverse reinforcement spacing computed as follows

$\mathrm{s} \leq$ smaller of $\left\{\begin{array}{c}6 \cdot \mathrm{d}_{\mathrm{b}}=6 \times 25=150 \mathrm{~mm} \\ 150 \mathrm{~mm}\end{array}\right.$

Thus for the $300 \mathrm{~mm}$ x $300 \mathrm{~mm}$ x $3000 \mathrm{~mm}$ RC columns used for the numerical analysis presented in this thesis, the minimum plastic hinge length was determined as $600 \mathrm{~mm}$. Within, this plastic hinge length, measured at both the top and bottom support regions, the maximum tie 
spacing computed was $75 \mathrm{~mm}$. Outside of the plastic hinge length, the maximum tie spacing computed was $150 \mathrm{~mm}$.

\subsubsection{Conventional Column Detailing}

The conventional RC columns used in the numerical work in later chapters were detailed in accordance to clause 7.6.5.2 of CSA A23.3-04. Clause 7.6.5.2 states that tie spacing should be determined in accordance to equation [3-15]

$s \leq$ smaller of $\left\{\begin{array}{c}16 \cdot d_{b} \\ 48 \cdot d_{t} \\ \text { least dimension of compression member }\end{array}\right.$

Using equation [3-15], the spacing for the conventionally detailed RC columns can be computed as follows:

$$
\mathrm{s} \leq \text { smaller of }\left\{\begin{array}{c}
16 \times 25=400 \mathrm{~mm} \\
48 \times 10=480 \mathrm{~mm} \\
\text { least dimension of compression member }=300 \mathrm{~mm}
\end{array}\right.
$$

Thus, the maximum spacing used for the conventional RC column is $300 \mathrm{~mm}$. 


\section{Chapter: Numerical analysis with LS-DYNA}

LS-DYNA is a high fidelity general purpose finite element code developed by Livermore Software Technology Corporation. While originally developed for highly non-linear transient dynamic analysis, using explicit time step integration, it has over the years been used in various fields of engineering (Hallquist 2006). LS-DYNA is now used in various industries such as the automobile, aerospace, military and manufacturing (Hallquist 2006).

The current code evolved from DYNA3D which was written by Dr. John O. Hallquist in the mid-seventies. The original DYNA3D code was initially limited to stress analysis of structures under various types of impact loading (Hallquist 2006).

Starting off with only a handful of material models, LS-DYNA has a rich material library with various material models for metals, plastics, concretes and soils with the capability of incorporating user-defined parametric material models based on empirical work (LSTC 2013). LS-DYNA also has a library of elements, such as beam, shell and solid elements, available for developing models in both 2-Dimensions and 3-Dimensions.

The LS-DYNA, numerical modelling and analysis tool, was used to investigate the performance of RC columns, with various reinforcement detailing schemes, under various combinations of blast and axial loading in the numerical and parametric studies presented in chapters 5 and 6 .

\subsection{Finite Element Types Available in LS-DYNA}

Selection of the appropriate element type for numerical analysis is essential in the finite element method (FEM). The selection is based on the level of accuracy desired and the time cost associated with each numerical method (Logan 2006). The compatibility of the selected element 
with the constitutive material model used in the numerical analysis procedure is also very important.

\subsubsection{Solid Element}

The 8-noded solid hexahedron element in LS-DYNA can be used for modelling 3-D finite element problems. The solid element has a total of twenty-four degrees of freedom, three per node. The formulation of this element is done by attaching an iso-parametric (natural) coordinate system to the element. Linear displacement functions are then used to define the displacement within the solid element using nodal values. The required finite element equations are then derived using appropriate strain-displacement and stress-strain relationships.

The Gaussian quadrature method is then used to solve the formulated equation of motion. LSDYNA has both a single point (under-integrated) quadrature and four point (fully-integrated) quadrature solid elements (Hallquist 2006). In the modelling of concrete, the under-integrated, constant stress solid element was used. The fully integrated solid element was not used in the models developed in this thesis because of the following disadvantages.

Firstly, the fully integrated solid element becomes overly stiff under bending. This phenomenon is commonly referred to as volumetric-locking or shear-locking and leads to inaccurate prediction of displacements and stresses (Sun 2006). Secondly, the single point under-integrated element is less computationally expensive in comparison with the fully-integrated solid element (Hallquist 2006).

However, the use of the under-integrated solid element can potentially lead to hourglassing or zero energy deformation. Hourglassing or zero energy deformation occurs when the solid element undergoes deformation with no measured corresponding strain as a result of the single integration point not undergoing any deformations (Sun 2006). Hourglassing is usually 
associated with coarse finite element meshes and non-linear materials and is often indicative of a very flexible structure. Hourglassing can lead to spurious and inaccurate numerical simulation results. Thus, there is the need to stabilize the one-point quadrature integration (Belytshko et al. 2014; Sun 2006). LS-DYNA has hourglass controlling measures incorporated in the code to prevent this unfavourable behaviour.

\subsubsection{Beam Elements}

LS-DYNA has three beam element implementations in its element library. These are:

- Belytschko beam element (Belytschko et al. 1977)

- Warped beam element (Battini 2002)

- Hughes-Liu beam element (Hughes and Liu 1981)

The Hughes-Liu beam element, a computationally efficient yet simple beam element, in LSDYNA was used in modelling both the longitudinal as well as transverse reinforcement in the RC columns for the numerical work presented later in Chapters 5 and 6. The Hughes-Liu beam element is developed based on a degenerated 8-noded iso-parametric solid element. This has the advantage of ensuring compatible node sharing between the Hughes-Liu beam elements and solid elements in a numerical simulation that uses these two types of elements (Hallquist 2006). A numerical solution using the Hughes-Liu beam element is performed with single point integration but does not result in any locking modes or zero energy deformations (Hallquist 2006). The Hughes-Liu beam element also ensures that rigid body rotations do not result in strains. The Belytschko beam element was developed for the analysis of large rotational problems. The warped beam element was developed to be used in the analysis of structural instability problems (Hallquist 2004). The development of the warped beam element is based on 
work by Battini (2002). Hallquist (2006) presents full implementation details of the Belytschko beam element as well as the warped beam element.

\subsection{Constitute Material Models}

The LS-DYNA package comes with a lot of material models that can be used to model various material behaviours that arise in dynamic analysis. Each material model has a list of applicable element types that are compatible with it.

\subsubsection{Material Constitutive Models Used}

\subsubsection{Concrete}

Concrete has peculiar characteristics that make it challenging to model perfectly in a finite element application. A good concrete model must consider the elasticity of concrete prior to cracking and the subsequent plastic states on the onset of cracking and beyond (Murray et al. 2007). Concrete, for instance, softens under cyclic loading resulting in degradation of its stiffness. In high impulse load analysis, strain rate effects become crucial to consider in selection of a concrete material model. Experiments have shown increased concrete strength with increasing strain rate (Murray 2007). A good concrete model for blast analysis ought to be able to model this behaviour of concrete. LS-DYNA has several material models that have been used by researchers to model concrete behaviour. Some of these models are the:

- plasticity based Karagozian and Case concrete damage model designated as MAT_72_R3 in LS-DYNA (Malvar et al. 1997). 
- Winfrith Concrete model designated as MAT_84 was initially developed for impact load analysis in LS-DYNA (Wu et al. 2012). This is a smeared crack and smeared rebar concrete model.

- Johnson Holmquist Concrete Model designated as MAT_111 was developed for concrete that is subjected to large strains and high pressures with corresponding high strain rates (Holmquist et al. 2011).

- Continuous Surface Cap Model designated as MAT_CSCM_159 is a visco-elastic-plastic concrete model designed initially to study impact in roadside safety structures (Murray et al. 2007).

Table 4-1 presents some properties of the concrete material models in LS-DYNA presented above that have been used by researchers to model concrete behaviour.

The LS-DYNA concrete material model chosen for this research work was the Continuous Surface Cap Model (MAT_CSCM_159). This material model assumes concrete to be isotropic and exhibits elastic behaviour prior to cracking of the concrete. Beyond the elastic phase, concrete behaves plastically with concrete yield defined by a three dimensional yield surface.

Table 4-1: Concrete Material Models in LS-DYNA (LSTC 2013)

\begin{tabular}{|c|c|c|c|c|c|c|}
\hline $\begin{array}{c}\text { Material ID } \\
\text { in LS- } \\
\text { DYNA }\end{array}$ & $\begin{array}{c}\text { Material Title } \\
\text { in LS-DYNA }\end{array}$ & $\begin{array}{c}\text { Supported } \\
\text { Element } \\
\text { Types }\end{array}$ & $\begin{array}{c}\text { Strain } \\
\text { Rate } \\
\text { Sensitivity }\end{array}$ & $\begin{array}{c}\text { Failure } \\
\text { Criteria }\end{array}$ & $\begin{array}{c}\text { Equation of } \\
\text { State } \\
\text { Requirement }\end{array}$ & $\begin{array}{c}\text { Damage } \\
\text { Effects }\end{array}$ \\
\hline 72 & Concrete Damage & Solid & Yes & Yes & Yes & Yes \\
\hline 84 & Winfrith Concrete & Solid & No & No & No & \\
\hline 111 & $\begin{array}{c}\text { Johnson Holmquist } \\
\text { Concrete }\end{array}$ & Solid & No & No & No & \\
\hline 159 & CSCM & Solid, Shell & Yes & Yes & No & \\
\hline
\end{tabular}


Figure 4-1 and Figure 4-2 show the yield surface in 3-dimensional and 2-dimensional views respectively. The stress in the concrete is computed and updated at each time step in the analysis. If the computed stress lies inside or on the yield surface the concrete behaviour is described as elastic (Murray et al. 2007). When the computed stress lies outside the yield surface, a plasticity algorithm is used to return the stress state to the yield surface. Hardening and strain rate effects can also be incorporated into the numerical analysis using the Continuous Surface Cap material model (MAT_CSCM_159) material model.

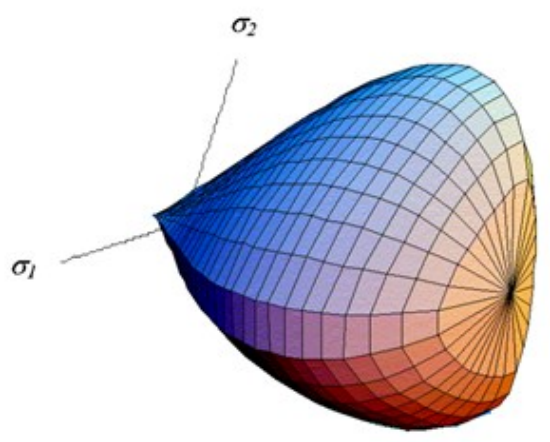

Figure 4-1: General shape of the concrete model yield surface in three dimensions (Murray et al. 2007)

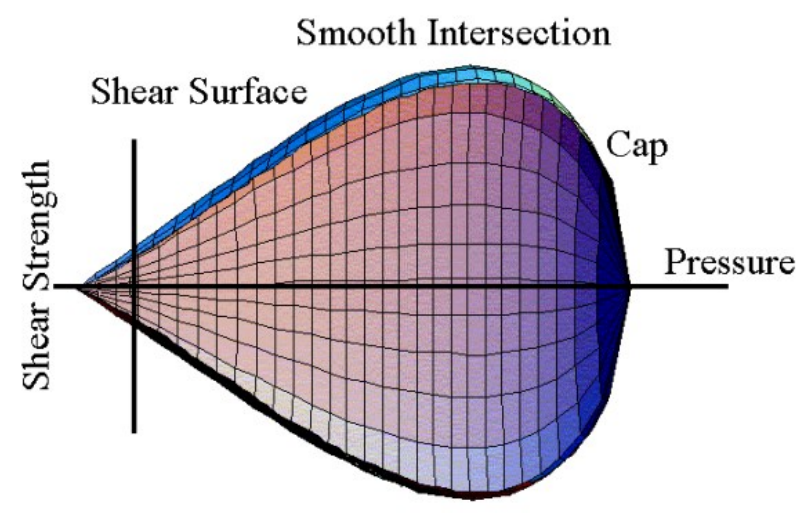

Figure 4-2: General shape of the concrete model yield surface in two dimensions in the meridonal plane (Murray et al. 2007) 
All the other concrete models mentioned do not have an in-built material erosion mechanism upon failure under loading. LS-DYNA provides a separate erosion addition technique that can be used with the material models lacking built-in material erosion capabilities. The generic MAT_ADD_EROSION parameter gives the user the option of specifying a failure criterion for element erosion upon failure (Hallquist 2006). There are, however no specific rules for setting this failure criterion (Jaime 2011). A failure criterion that tracks the material constitutive model behaviour and ensures element deletion upon failure gives a much more accurate prediction of material behaviour. The MAT_CSCM 159 has such a built-in damage prediction criterion. This makes the MAT_CSCM 159 ideal for predicting crack initiation and propagation when used as a concrete model (Jaime 2011). The damage prediction also prevents the concrete from behaving as a perfectly plastic material. The user is given the option of either making use of the element erosion formulation or disregarding it. Erosion of the elements is based on the value of the damage parameter, $d$. If $d>0.99$ and the maximum principal strain in the element exceeds the user supplied input value, the element loses all its strength and stiffness and is deleted from the numerical model (Murray et al. 2007). The concrete model also considers strain rate effects with increasing concrete strength as the strain rate increases (Murray et al. 2007).

\subsubsection{Reinforcing Bars}

Table 4-2 shows the properties of two material models in LS-DYNA that can be used to model the behaviour of steel reinforcing bars in RC structural elements. 
Table 4-2: Steel Material Models in LS-DYNA (LSTC 2013)

\begin{tabular}{|c|c|c|c|c|c|c|}
\hline $\begin{array}{c}\text { Material ID } \\
\text { in LS-DYNA }\end{array}$ & $\begin{array}{c}\text { Material Title } \\
\text { in LS-DYNA }\end{array}$ & $\begin{array}{c}\text { Supported } \\
\text { Element Types }\end{array}$ & $\begin{array}{c}\text { Strain } \\
\text { Rate } \\
\text { Sensitivity }\end{array}$ & $\begin{array}{c}\text { Failure } \\
\text { Criteria }\end{array}$ & $\begin{array}{c}\text { Equation of } \\
\text { State } \\
\text { Requirement }\end{array}$ & $\begin{array}{c}\text { Damage } \\
\text { Effects }\end{array}$ \\
\hline 3 & $\begin{array}{c}\text { Plastic } \\
\text { Kinematic/ } \\
\text { Isotropic }\end{array}$ & $\begin{array}{c}\text { Solid, Beam, } \\
\text { Shell }\end{array}$ & Yes & Yes & No & No \\
\hline 24 & $\begin{array}{c}\text { Piecewise Linear } \\
\text { Plasticity } \\
\text { (Isotropic) }\end{array}$ & $\begin{array}{c}\text { Solid, Beam, } \\
\text { Shell }\end{array}$ & Yes & Yes & No & No \\
& & & & & \\
\hline
\end{tabular}

The Material_Piecewise_Linear_Plasticity (MAT 24) is used for the longitudinal reinforcing steel bars as well as the transverse bars used in the numerical models presented in chapters 5 and 6. MAT 24 is an elasto-plastic material for which an arbitrary stress-strain curve can be defined (LSTC 2013). Up to eight plastic strains and corresponding yield stress points can be set to define realistic non-linear stress strain behaviour. The material model can also define an arbitrary strain-rate. MAT 24 can be set to fail based on the plastic strain value or a minimum time-step size.

\subsection{Time Integration}

For non-linear structural problems, numerical solutions tend to be the only practical solutions (Hallquist 2006). The response parameters of interest such as displacements, velocities and accelerations are obtained using direct integration methods at small discrete time intervals. Secondary response parameters are subsequently determined. There are two main approaches in 
using the direct integration methods: the implicit methods and the explicit methods (Humar 2012).

LS-DYNA uses the explicit central difference method (CDM) to integrate the formulated equations of motion in its dynamic analysis (Hallquist 2006). The formulation of the central difference algorithm implemented in LS-DYNA is presented by Hallquist (2006).

The CDM has the advantage of being less-sensitive to round-off errors but requires more storage space. The CDM requires a time step governed by equations [4-1] and [4-2] for undamped and damped systems respectively. As can be seen from equations [4-1] and [4-2] damping reduces the critical time step.

$$
\begin{aligned}
& \Delta t=\frac{2}{\omega_{\max }} \\
& \Delta t=\frac{2}{\omega_{\max }}\left(\sqrt{1-\xi^{2}}-\xi\right)
\end{aligned}
$$

where $\Delta t$ is the time step, $\omega_{\max }$ is the highest frequency of all individual elements in the finite element mesh and $\xi$ is the critical damping coefficient. The critical time step is limited to a single element in the finite element mesh. The smaller the mesh size, the greater the increase in time cost for analysis.

\subsection{Bonding}

In reinforced concrete, the concrete's weakness in tension is compensated for by the introduction of reinforcing bars. Effective bonding of the plain concrete and the reinforcing bars ensures transmission of the tensile forces from the concrete to the reinforcing bar. In numerical simulations involving reinforced concrete, which involves separately meshing the concrete and 
reinforcement, there are basically two ways of ensuring perfect bonding between the concrete and the reinforcing bars. The first method employed by researchers such as Fanning (2001) and Tavárez (2001) requires the meshing of the concrete and the reinforcing bars such that they share common nodes on the interface. This, however, tends to be a very laborious process. A second method in LS-DYNA allows for meshing the concrete and the reinforcement separately and later

coupling the concrete and reinforcing bars together using the CONSTRAINED_LAGRANGE_IN_SOLID command (Murray et al. 2007).

The CONSTRAINED_LAGRANGE_IN_SOLID command only requires, as input parameters, that the user specify which of the meshed parts is the master, in this case (concrete) and which of the modeled parts is the slave (reinforcing bars).

\subsection{Loading}

\subsubsection{Blast Loading}

The LOAD_BLAST_ENHANCED (LBE) keycard in LS-DYNA was used to simulate the blast loading. The LBE key produces empirical pressure loads that are applied directly to the nodes of the lagrangian, concrete column (Slavik 2012). The blast simulations produced by this keycard is very similar to the results obtained from the semi-empirical blast load calculation program Conventional Weapons Effects Program (CONWEP) (Hyde 1988). The LBE is computationally less expensive when compared to the detailed Arbitrary Lagrangian Eulerian (ALE) method and also requires fewer input parameters. The LBE keycard has been reported to produce blast loading with acceptable accuracy for numerical simulations (Slavik 2012). 


\subsubsection{Axial Loading}

The axial loads corresponding to the various axial loads ratios (ALR) are applied as pressure loads on the top face of the column. The loads are applied to the surface of the top nodes as linearly varying loads for a few milliseconds until they rise and stabilize at the maximum pressures corresponding to the axial load ratios being considered in the simulation. These static pressures are then maintained throughout the simulation even after the blast load acts on the column.

\subsection{Nodal Constraints}

In order to solve the resulting equation of motion in a dynamic finite element problem, appropriate boundary conditions are prescribed. In LS-DYNA, a group of nodes can be constrained to move together. The nodes have a common translational acceleration expressed by Equation [4-8]. The common motion can be in one or more degrees of freedom.

$$
\mathrm{a}_{\mathrm{icomm}}=\frac{\sum_{\mathrm{j}}^{\mathrm{n}} \mathrm{M}_{\mathrm{j}} \mathrm{a}_{\mathrm{i}}^{\mathrm{j}}}{\sum_{\mathrm{j}}^{\mathrm{n}} \mathrm{M}_{\mathrm{j}}}
$$

Fixed boundary conditions in a particular direction can be associated to a node group setting the DOF of the node set in that particular direction to 1 (indicating fixed). Setting the boundary condition to 1 results in $\mathrm{a}_{\mathrm{icomm}}=0$.

\subsection{Damping}

LS-DYNA considers damping in the solutions to structural dynamics problems by selecting damping coefficients that result in solutions in minimal time. The damping coefficient is approximated to generate critical damping in the system. The damping coefficients are, 
therefore, estimated based on the minimum frequency of the elements making up the structure. Hallquist (2006) presents the full details of this implementation. 


\section{Chapter: Experimental program and validation of LS-DYNA model}

Finite element analysis packages are often complex programs and thus the implementations, methods used in arriving at a solution, and assumptions made are often unknown to most users. The numerical suites (loading functions, material models, and element types) available for solving various problems of engineering statics and dynamics do not yield appropriate results under all conditions, especially where they are not applicable. Thus, there is a need to validate the results obtained from a finite element program with experimental or analytical results. The complexity associated with modelling of composite materials such as reinforced concrete makes it difficult to fully rely on the results of a numerical analysis without validation. The numerical analyses presented in this thesis, was validated with results from an experimental program conducted by Farouk (2013) on near-field blast loading on reinforced concrete columns as well as with a SDOF program that was developed.

\subsection{Description of experimental program}

As part of the experimental program by Farouk (2013), sixteen $300 \times 300 \times 3000 \mathrm{~mm}$ reinforced concrete columns were tested. The RC columns were reinforced with $4-25 \mathrm{M}$ longitudinal bars with a concrete cover to reinforcement of $40 \mathrm{~mm}$. The 28 -day concrete compressive strength of concrete was $41 \mathrm{MPa}$ while the yield strength of the steel was approximately $400 \mathrm{MPa}$.

Six of the columns were designed and detailed for a building in a region of high seismicity and had 10M transverse reinforcements spaced at $75 \mathrm{~mm}$ over a plastic hinge length of $600 \mathrm{~mm}$ close to the two supports. The transverse steel in the region between the plastic hinge lengths of the column was spaced at $150 \mathrm{~mm}$ which was reduced to $75 \mathrm{~mm}$ spacing in the mid-region. The detailing scheme for the seismically detailed reinforced columns is shown in Figure 5-1(a). The 
other ten RC columns were detailed with ties spacing of $300 \mathrm{~mm}$ throughout the entire length of the columns. The detailing scheme for the conventional columns is also presented in Figure 5-1 (b). Three of the ten detailed RC columns, with $300 \mathrm{~mm}$ tie spacing, had axial loads, corresponding to an ALR of 0.3 , acting on them. The axial loads were incorporated using a prestressing technique.

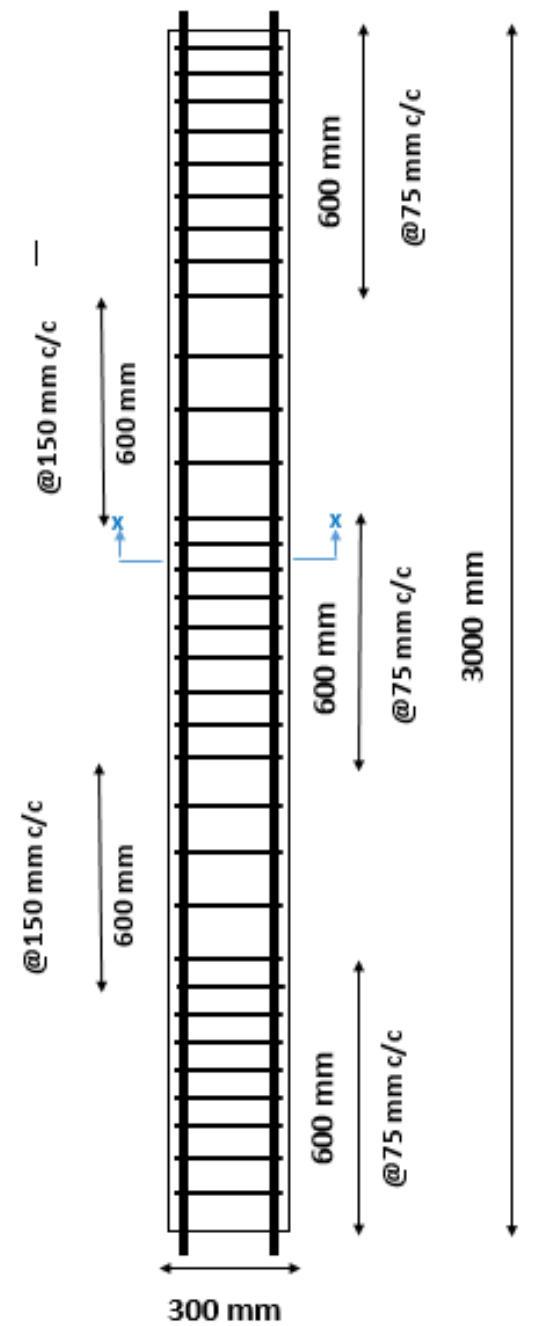

(a) Seismic Detailing

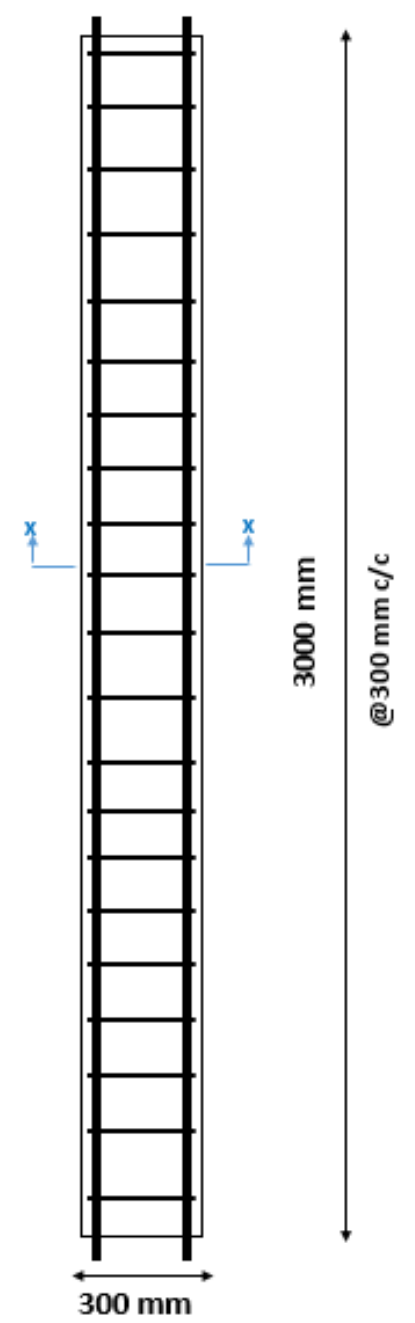

(b) Conventional Detailing

Figure 5-1: Reinforcement detailing for seismic and conventional columns used in experimental work 


\subsection{Column Testing}

The experiment was carried out at the Canadian Forces Base, Petawawa, Ontario. Figure 5-2 shows an overview of the experimental setup. Charge masses of $100 \mathrm{~kg}$ and $150 \mathrm{~kg}$ of ammonium nitrate fuel oil (ANFO), corresponding to $82 \mathrm{~kg}$ and $123 \mathrm{~kg}$ of equivalent TNT mass respectively, were detonated at scaled distances ranging from $0.26 \mathrm{~m} / \mathrm{kg}^{1 / 3}$ to $0.86 \mathrm{~m} / \mathrm{kg}^{1 / 3}$ in the tests. The charge masses were placed at a height of burst of $1 \mathrm{~m}$. Two reinforced concrete columns were tested in each test setup up.

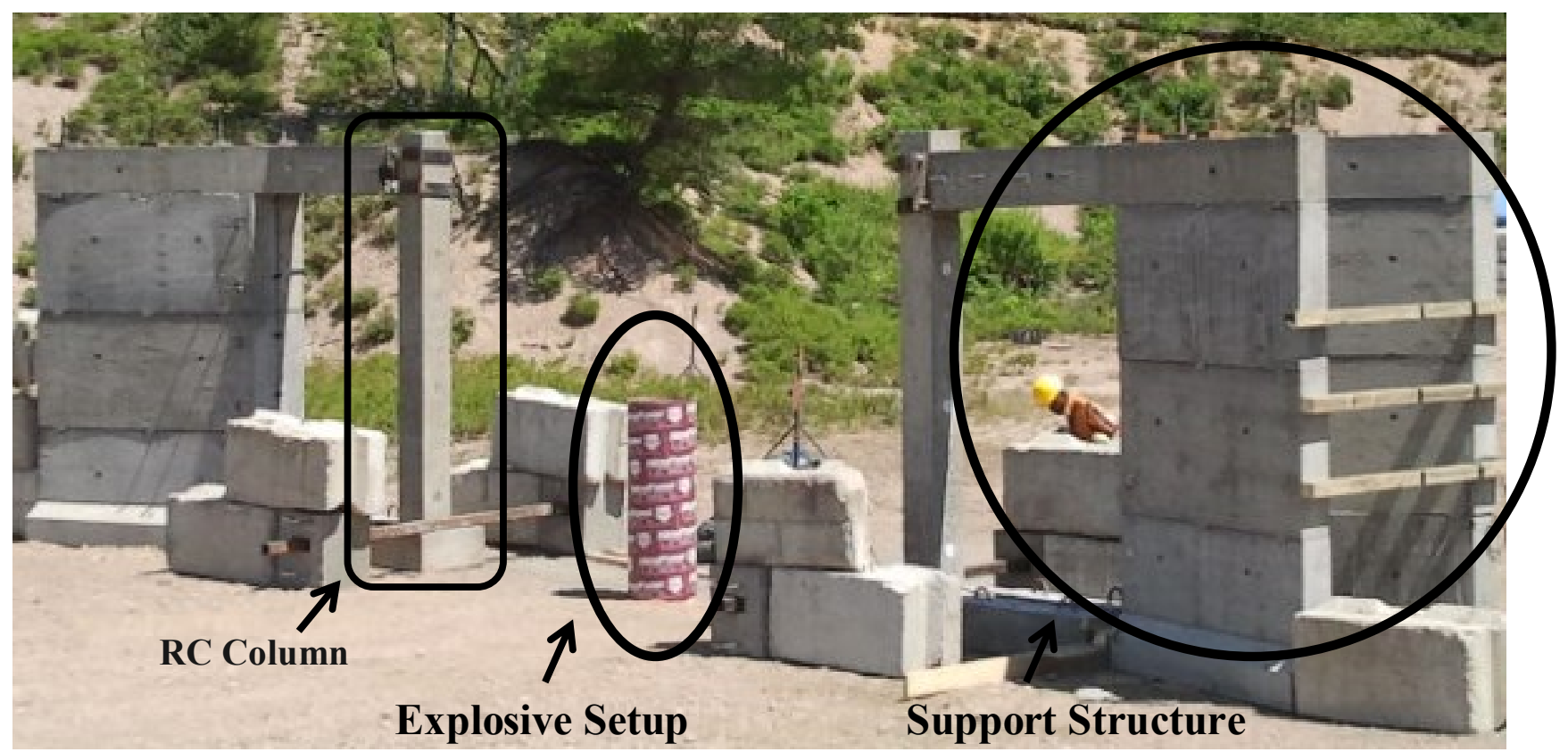

Figure 5-2: The experimental setup for blasting testing of the RC columns

\subsection{LS-DYNA Numerical modelling}

The reinforced concrete columns that were modelled, for validation, were meshed with $15 \mathrm{~mm}$ cubic solid elements. The mesh size was established in a mesh sensitivity analysis to yield accurate results with minimal computational effort. The modelled columns were representative of the columns tested by Farouk (2013) and detailed in Figure 5-1. The nodes at the base and top 
of the column were all fixed to prevent translational as well as rotational movements in three cardinal directions. In modelling the $\mathrm{RC}$ columns which were pre-stressed to simulate axial loading, the top nodes of the LS-DYNA models were allowed to translate in the vertical direction in order to transmit the axial load (strains) that was introduced in the numerical model.

\subsection{Mesh Sensitivity Analysis}

In order to optimize the accuracy of the results while minimizing high computational cost of the numerical work, a mesh sensitivity analysis was carried out. The reinforced concrete columns, detailed as shown in Figure 5-1, were modelled with mesh sizes ranging from $10 \mathrm{~mm}$ to $100 \mathrm{~mm}$. Figure 5-3 shows the modelled reinforced concrete column with the different mesh sizes.

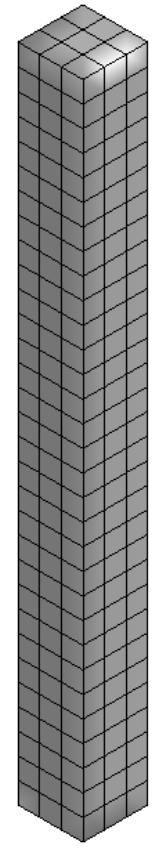

(a) $100 \mathrm{~mm}$

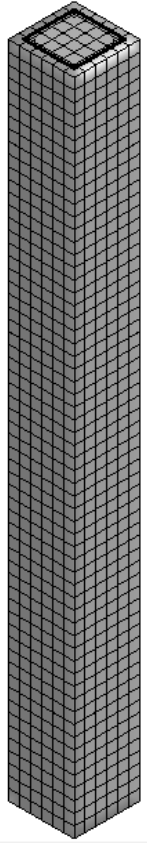

(b) $50 \mathrm{~mm}$

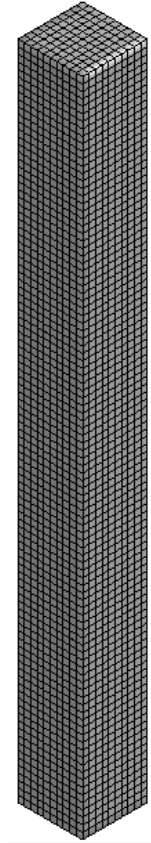

(c) $30 \mathrm{~mm}$

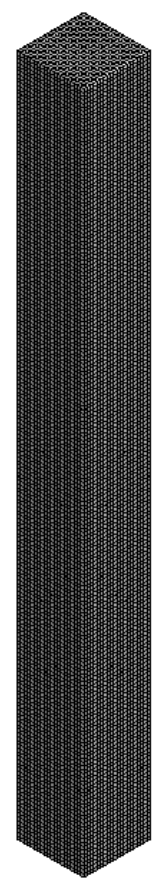

(d) $15 \mathrm{~mm}$

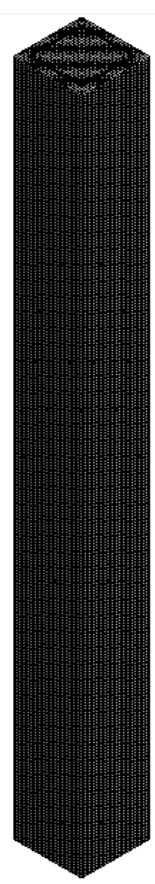

(e) $10 \mathrm{~mm}$

Figure 5-3: Finite element meshes sizes used for mesh sensitivity analysis 
For the mesh sensitivity analysis, one of the seismically detailed RC columns with the detailing scheme shown in Figure 5-1 (a) was modelled and subjected to $84 \mathrm{~kg}$ of TNT ( a TNT equivalent mass of the $100 \mathrm{~kg}$ of ANFO) used in experimental test program (Farouk 2013). The explosive was set at a stand-off distance of $2.5 \mathrm{~m}$ and a height of burst of $1 \mathrm{~m}$. Table 5-1 shows the maximum displacements from the different mesh sizes and the approximate run times associated with each of the mesh sizes. Table 5-1 also shows the number of elements associated with each mesh size and the corresponding disk space requirements. Table 5-1 presents the maximum displacement recorded from the experimental work together deflections from the numerical simulations with the different mesh sizes.

Table 5-1: Mesh Sensitivity Analysis

\begin{tabular}{|c|c|c|c|c|}
\hline $\begin{array}{c}\text { Mesh } \\
\text { Size } \\
{[\mathrm{mm}]}\end{array}$ & $\begin{array}{c}\text { Number of } \\
\text { Elements }\end{array}$ & $\begin{array}{c}\text { Maximum } \\
\text { Displacement } \\
{[\mathbf{m m}]}\end{array}$ & $\begin{array}{c}\text { Approximate } \\
\text { Run Times } \\
{[\mathbf{s}]}\end{array}$ & $\begin{array}{c}\text { Disk Space } \\
\text { Used } \\
{[\mathbf{G B}]}\end{array}$ \\
\hline $100 \mathrm{~mm}$ & 839 & 70 & 25 & 0.27 \\
\hline $50 \mathrm{~mm}$ & 2720 & 37.5 & 49 & 0.45 \\
\hline $30 \mathrm{~mm}$ & 10760 & 32.0 & 177 & 0.97 \\
\hline $15 \mathrm{~mm}$ & 82960 & 28.5 & 2796 & 22.0 \\
\hline $10 \mathrm{~mm}$ & 270560 & 25.58 & 21703 & \\
\hline \multicolumn{2}{|r|}{ Experimental } & $\mathbf{2 4 . 9 4}$ & & \\
\hline
\end{tabular}

Figure 5-4 on the other hands shows a comparison of the displacement-time histories for the various mesh sizes used and the experimental displacement-time history for a total run time of 45 milliseconds. From Figure 5-4, the maximum displacements decrease with decreasing mesh size, converging to the experimental displacement at a mesh size of $10 \mathrm{~mm}$. The total run time and the 
associated disk space requirements of mesh sizes smaller than $15 \mathrm{~mm}$, made it impractical to use mesh sizes less than $15 \mathrm{~mm}$. A $15-\mathrm{mm}$ mesh size was observed to give adequate accuracy at reasonable run times and was chosen for all subsequent analysis.

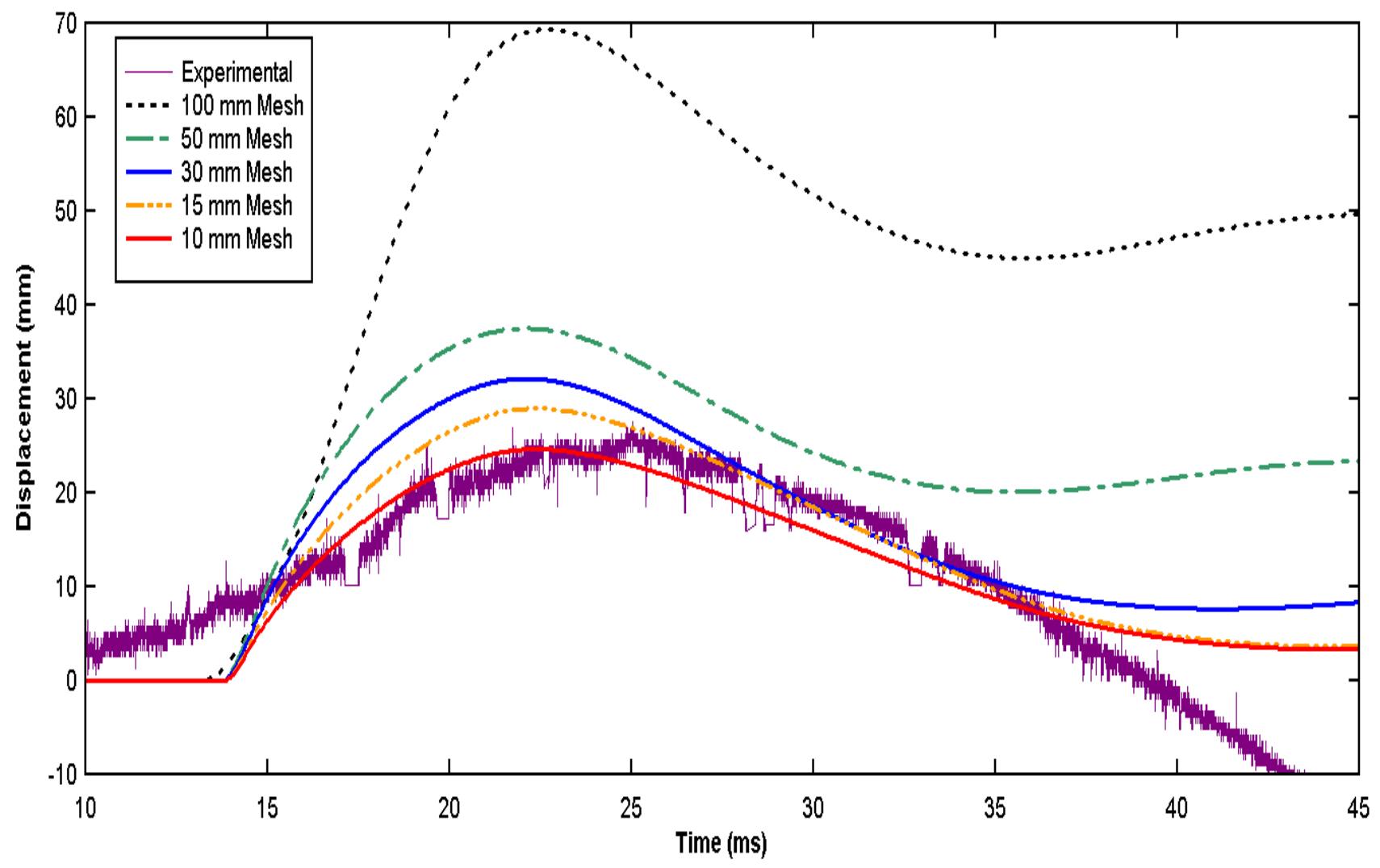

Figure 5-4: Comparison of displacement-time histories for various mesh sizes and experimental results

The experimental RC column used for the mesh sensitivity analysis did not develop extensive column damage, with only a few visible hair-line cracks while the LS-DYNA model developed some visible cracks in the tension region as can be seen in Figure 5-5. 

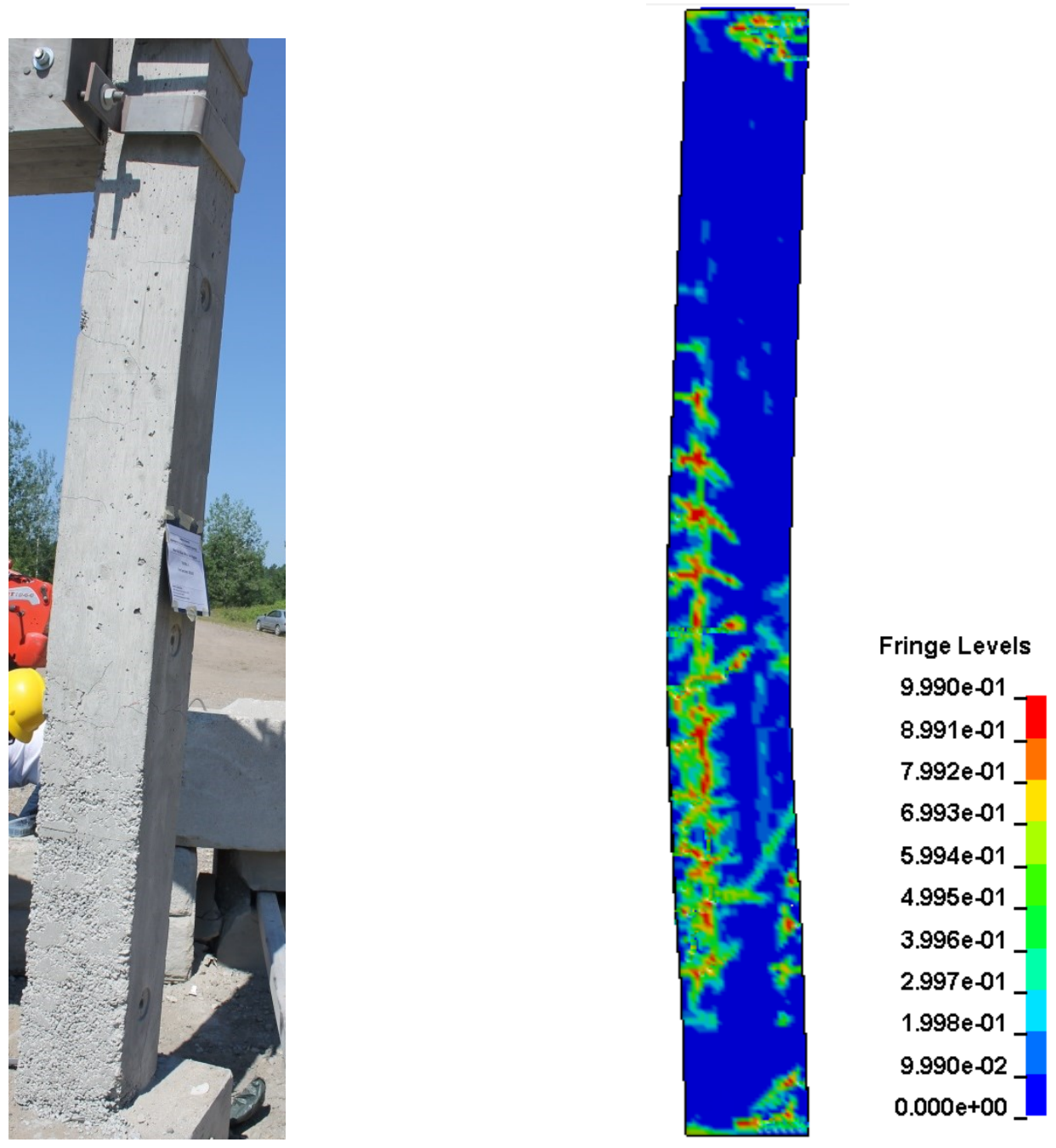

Figure 5-5: Comparison of damaged profiles of numerical and experimental RC columns for mesh sensitivity analysis

Even though the displacements from the LS-DYNA simulation compared favourably with the experimental results, it should be noted that experimental deflection measurements, especially under blast loading, are associated with various measurement errors. Firstly, excavation was not possible at the test site and so the footing of columns could not be buried. In order to develop rotation restraint at the column-footing junction concrete blocks were used to weigh down the footing (Figure 5-2). During testing, the concrete blocks were thrown and thus the level of 
rotation restraint cannot be ascertained. Secondly, perfect contact between footing and blocking beams could not be achieved in the test setup. Thus the possibility of displacement of the footing cannot be discounted. This could contribute to the overall displacements measured for the column. Thirdly, the string potentiometers used to measure column displacements were engulfed in the explosion fireball and in most tests were ruptured and retracted into the housing. The peak displacement was usually achieved before retraction but the effect of failure on measured displacement cannot be estimated.

\subsection{Comparison of experimental and numerical results}

In order to compare the damage profile in the numerical model and the experimental work, the seismically detailed RC columns subjected to blast loading from $150 \mathrm{~kg}$ of ANFO (equivalent to $123 \mathrm{~kg}$ of TNT) detonation in the live explosive testing was modelled.

Figure 5-6 presents comparison of damage to the reinforced concrete column from the numerical simulation and experimental test. The concrete crack patterns and scabbing from the numerical simulation due to blast load effects compares very well with the column subjected to live explosive testing. The fringe levels associated with the damaged profile of the reinforced concrete column represent the extent of damage. A fringe level value of 0.0 is indicative of no damage. The initiation of softening behaviour in the concrete corresponds to a fringe level value of 0.5 while fringe levels close to 1.0 represent complete loss of concrete strength and stiffness and elements exhibiting this fringe levels are removed from the analysis.

The displacement-time histories of two displacement gauges placed along the height of the reinforced concrete column at heights of $1.5 \mathrm{~m}$ and $2 \mathrm{~m}$ were compared with the displacementtime histories obtained at the same locations in the numerical model (Figure 5-7). The 
comparison shows a very good correlation between the displacement-time histories of the experimental columns and the numerical model. It should be noted that whereas experimental $\mathrm{RC}$ column show the state after testing while the numerical RC column shows the damage state at maximum response. Thus, some cracks at maximum response could be closed after the response. Also, the deflected shape in experimental is that of residual deflection.
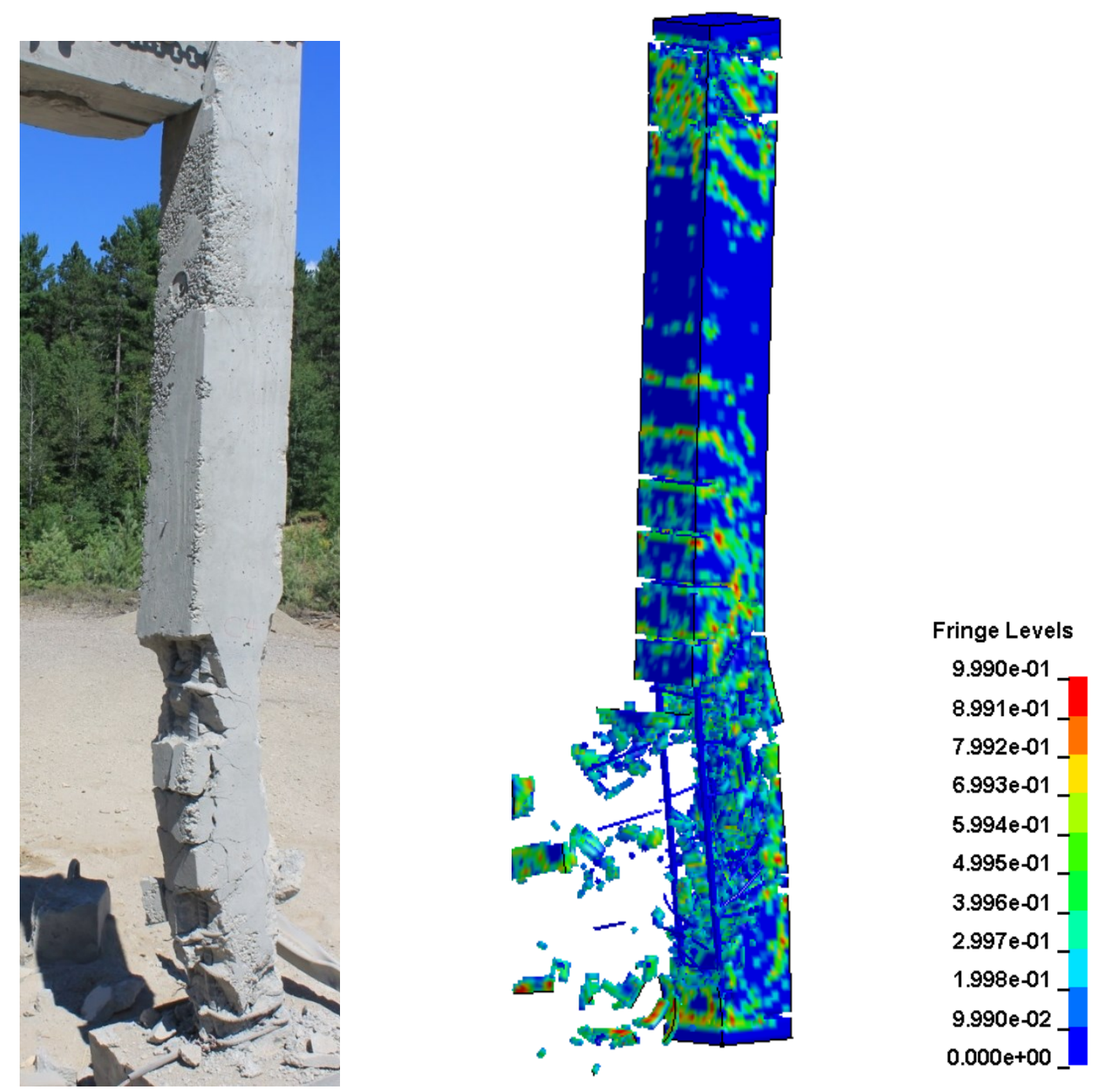

Figure 5-6: Comparison of damaged profile of seismically detailed column in numerical simulation and experimental test 


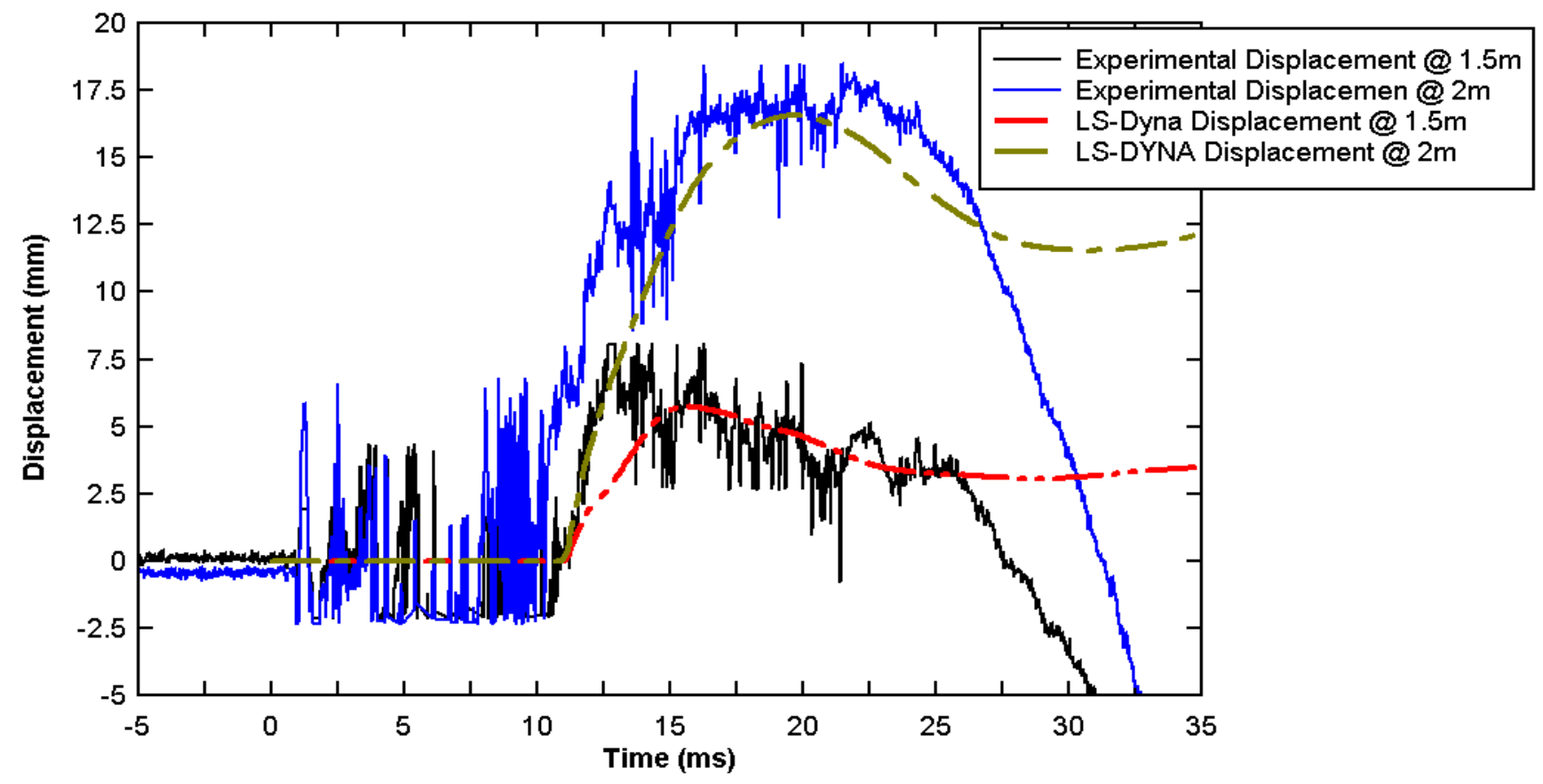

Figure 5-7: Comparison of displacement-time histories of seismically detailed experimental column and corresponding numerical models

\subsubsection{The Effect of Axial Load Ratio}

Farouk (2013) also considered the effect of axial loading in the experimental program. Three $300 \times 300 \times 3000 \mathrm{~mm}$ columns with $4-25 \mathrm{M}$ longitudinal bars and $10 \mathrm{M}$ transverse ties spaced at $300 \mathrm{~mm}$ were used to study the axial load ratio effect.

A comparison of the damage profile of one of the conventional columns with axial loading, subjected to $150 \mathrm{~kg}$ of $\mathrm{ANFO}$ (equivalent to $123 \mathrm{~kg}$ TNT) in the live explosive testing, was done with an equivalent numerical model. The blast load resulted in significant lateral deflection of the column. This resulted in loss of concrete cover and core concrete in the lower region of the $\mathrm{RC}$ column as can be seen in Figure 5-8. Under the combined axial loading and blast loading, the column failed by the crushing of the concrete in the lower-region of the column followed by the 
buckling of the longitudinal reinforcement bars in the lower region of the RC column. The 300 $\mathrm{mm}$ transverse spacing was not adequate to restrain the longitudinal bars from buckling once the surrounding concrete crushed under the blast loading from the explosion. Figure 5-8 also shows a comparison of the reinforced concrete columns under an axial load ratio of 0.3 to the numerical LS-DYNA model.
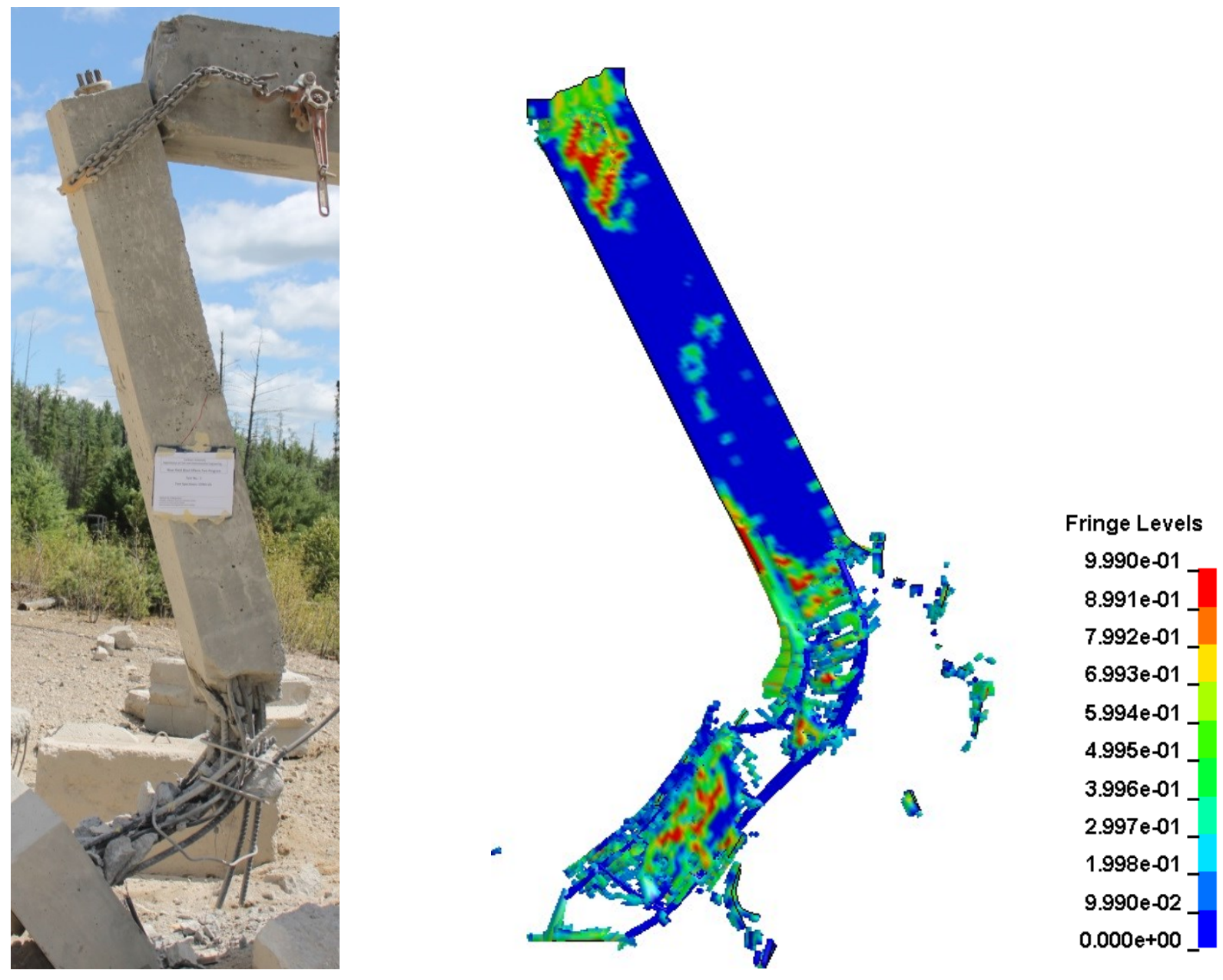

Figure 5-8: Comparison of damaged profiles of numerical and experimental RC columns 


\subsection{Development of a Single Degree of Freedom (SDOF) Model}

A SDOF model was developed which incorporated strain-rate effects (through dynamic increase factors) and material non-linearity based on the elasto-plastic material model presented in Chapter Two. Figure 5-9 shows the graphic user-interface outputting the results from the equivalent SDOF numerical code developed for a sample input using a scaled distance of $1.0 \mathrm{~m} /$ $\mathrm{kg}^{1 / 3}$. Appendix A describes the algorithm developed for the equivalent SDOF numerical model. Appendix A also gives a sample input for the SDOF numerical model with some output plots.

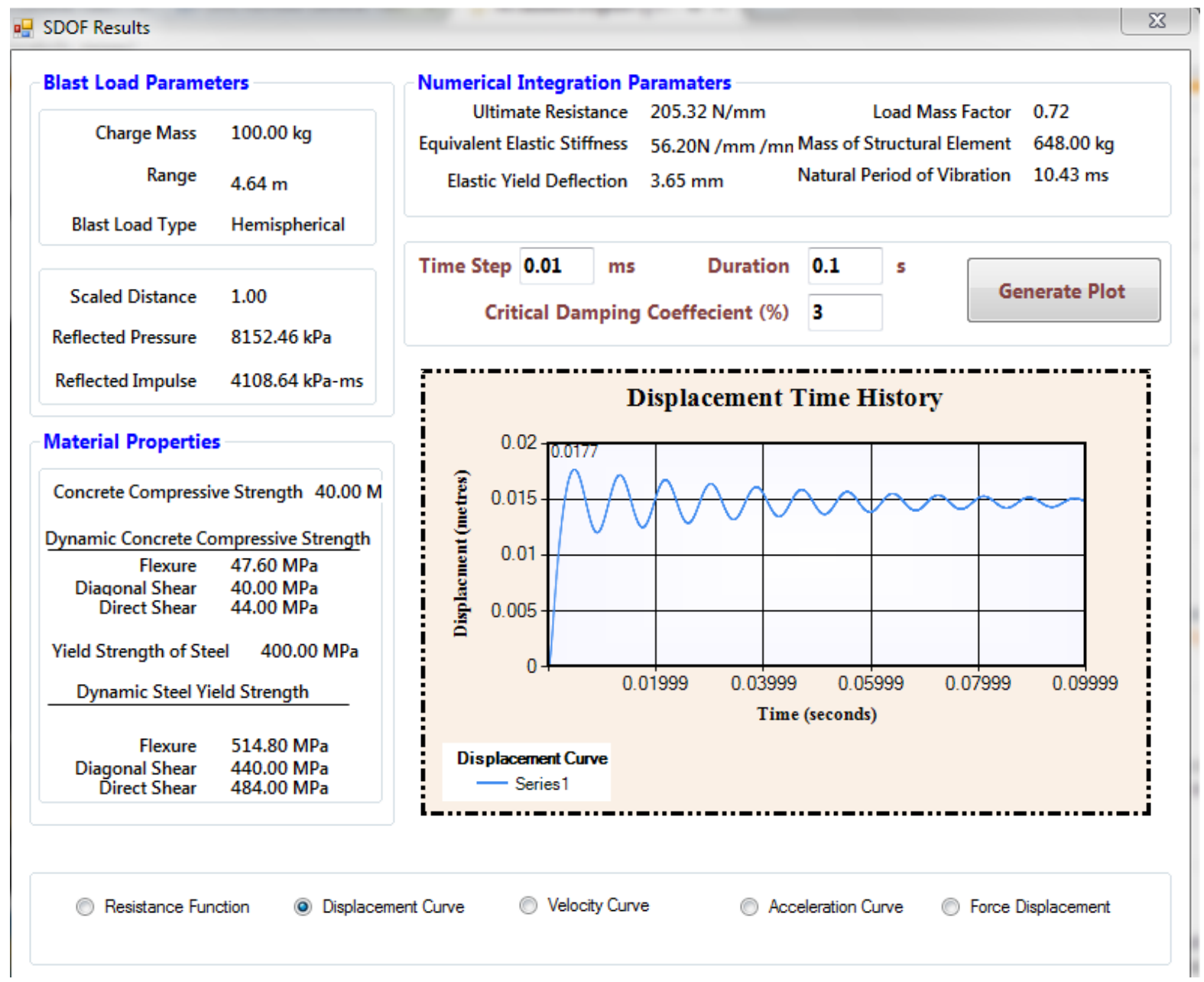

Figure 5-9: Graphic User Interface showing the output results of the developed equivalent

SDOF numerical model. 


\subsection{Comparison of SDOF and LS-DYNA results}

The equivalent SDOF model was used to determine quick and approximate displacement time histories and compared to the displacement time histories obtained from LS-DYNA using similar material and section properties of the column. Based on reviewed literature a damping ratio of 3\% was used in the SDOF (Andersson and Karlsson 2012; Carlsson and Kristensson 2012; PEC and BakerRisk 2008; Rezaei 2011). Appendix A presents an investigation into the effect of damping coefficient on the lateral displacement of the RC columns modelled with the SDOF when compared to the LS-DYNA numerical model. Damping coefficients varying from $0 \%$ to 5 $\%$ were used in the SDOF models to compare the effect of various damping ratio values to the LS-DYNA model.

Figure 5-10 and Figure 5-11 show the comparison of the SDOF model and the LS-DYNA model using a $100-\mathrm{kg}$ and $250-\mathrm{kg}$ charge at a scaled distance of $0.8 \mathrm{~m} / \mathrm{kg}^{1 / 3}$. The SDOF displacementtime histories show good comparisons with the LS-DYNA results. For the $100 \mathrm{~kg}$ charge mass, the maximum displacement in the SDOF models was $30.6 \mathrm{~mm}$ compared to $26.5 \mathrm{~mm}$ in the LSDYNA simulation (see Figure 5-10). This represents a 15\% overestimation of the displacement. The blast load from the $250-\mathrm{kg}$ charge mass also resulted in a maximum displacement of 51.8 $\mathrm{mm}$ for the SDOF model and a maximum displacement of $43.6 \mathrm{~mm}$ for the LS-DYNA model. This also represented a $19 \%$ overestimation of the displacement. The SDOF model gave much more conservative maximum displacements than the respective displacement-time history plots of the LS-DYNA models.

At the scaled distance of $1.0 \mathrm{~m} / \mathrm{kg}^{1 / 3}$, the maximum displacement in the SDOF model was 17.7 $\mathrm{mm}$ and that of the LS-DYNA model was $15.4 \mathrm{~mm}$, for the $100 \mathrm{~kg}$ charge mass, as can be seen in Figure 5-12. In Figure 5-13, the blast loading from the 250-kg charge mass also resulted in a 
29.8- $\mathrm{mm}$ maximum displacement in the SDOF model against the 27.5-mm maximum displacement recorded in the LS-DYNA model.

As the scaled distance was increased to $1.5 \mathrm{~m} / \mathrm{kg}^{1 / 3}$, the maximum displacement of the SDOF models became less conservative. For the $100-\mathrm{kg}$ charge mass, the SDOF model resulted in a maximum displacement of $6.9 \mathrm{~mm}$, approximately about a $6 \%$ under-estimation of the 7.4-mm maximum displacement resulting from the LS-DYNA model. In Figure 5-14, the displacement time histories resulting from the blast load generated by the 100-kg charge mass for both the LSDYNA and SDOF models can be observed to be almost superimposed, one on top of the other. A similar trend can be observed in the Figure 5-15 where the maximum displacement from the SDOF model was $10.6 \mathrm{~mm}$ and that of the LS-DYNA model was $9.9 \mathrm{~mm}$.

As the scaled distance increased, the RC column behaviour was more elastic with no extensive crack formations. Therefore, the SDOF models gave a closer approximation of the maximum displacements of the LS-DYNA models as the scaled distance increased.

Overall, good correlation was observed between the equivalent SDOF models and the LS-DYNA numerical models. Some of the observed discrepancies can also be attributed to the reason given below:

- The formulation of the equivalent SDOF models were based on a conservative ultimate dynamic moment capacity formulation and a simplified elasto-plastic material model (PEC and BakerRisk 2008) while the LS-DYNA constitutive material model has incorporated in the model complex formulations such as those that address softening and damage behaviour which are difficult to capture in an equivalent SDOF model. 


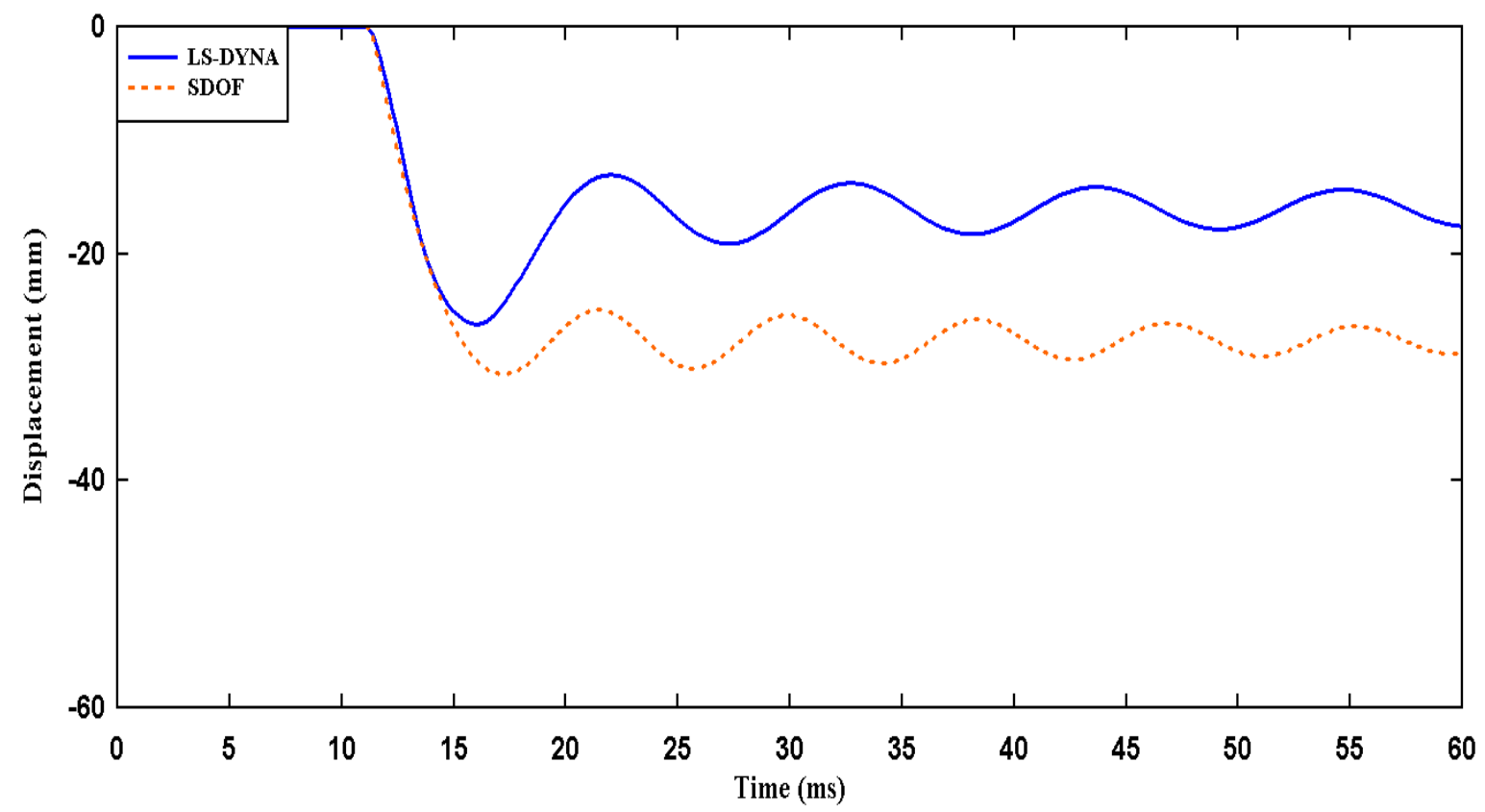

Figure 5-10: Comparison of SDOF model with LS-DYNA model at $\mathrm{z}=0.8 \mathrm{~m} / \mathrm{kg}^{1 / 3}$ using a $100 \mathrm{~kg}$ TNT charge mass

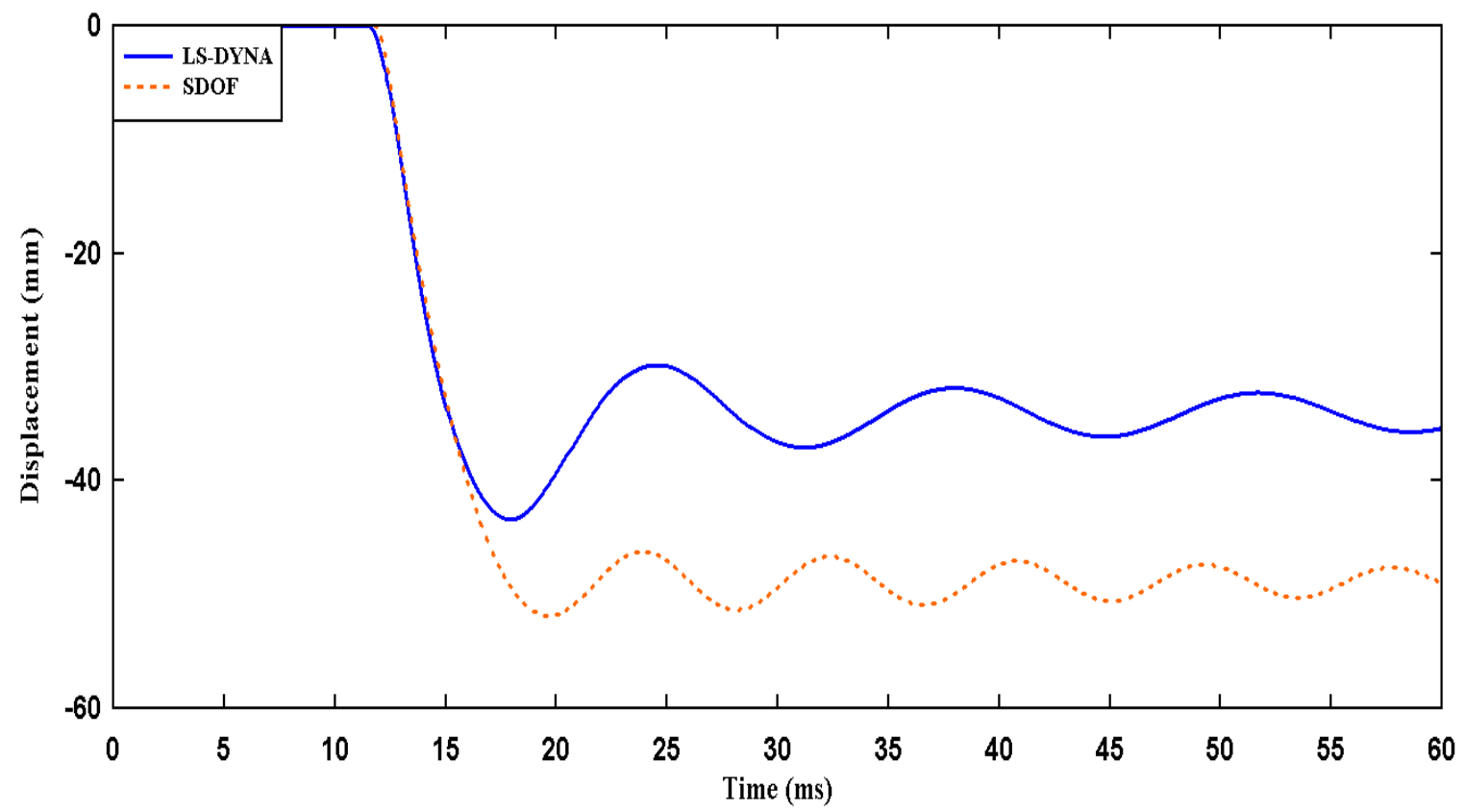

Figure 5-11: Comparison of SDOF model with LS-DYNA model at $\mathrm{z}=0.8 \mathrm{~m} / \mathrm{kg}^{1 / 3} \mathrm{using}$ a $250 \mathrm{~kg}$ TNT charge mass 


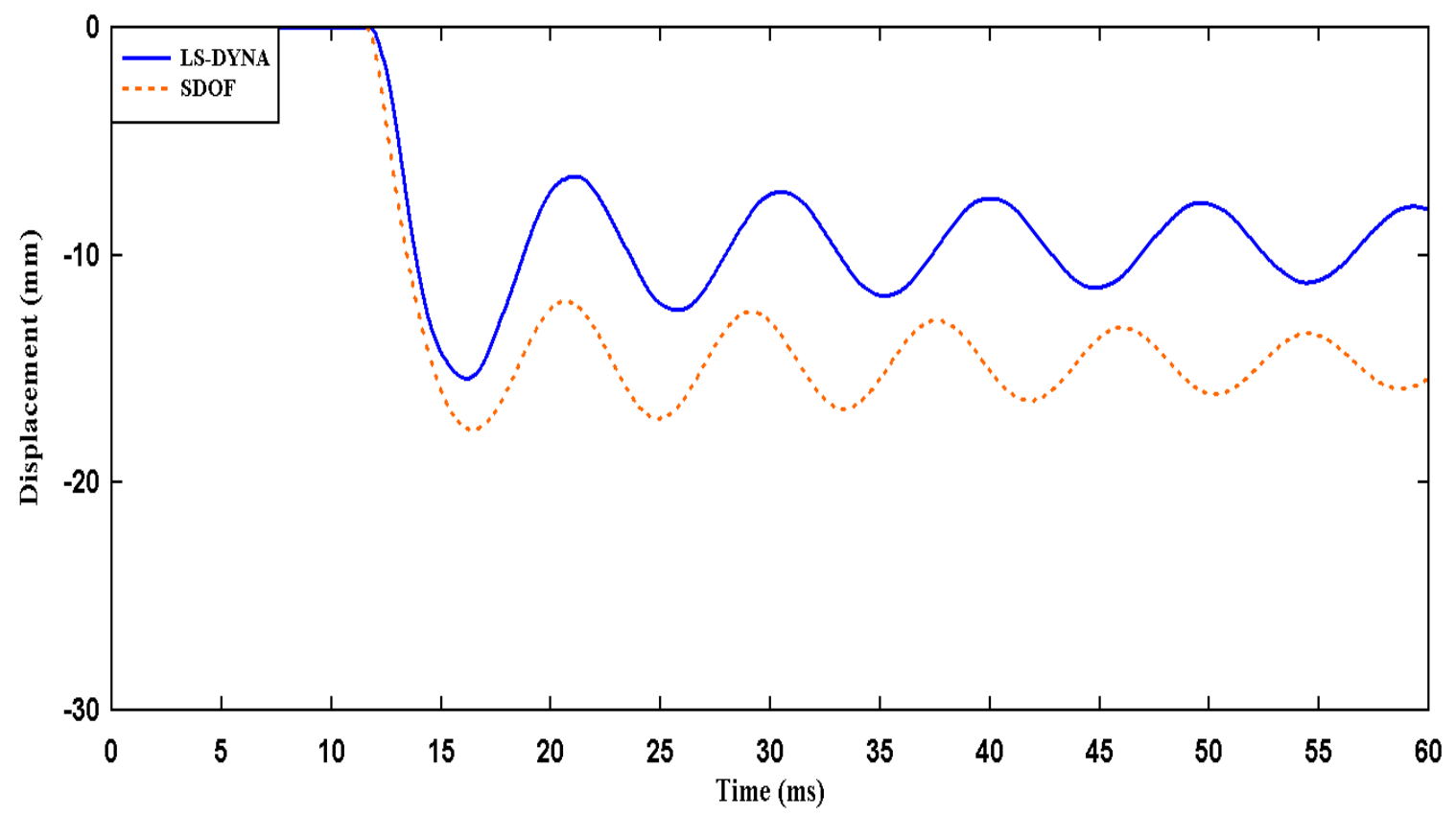

Figure 5-12: Comparison of SDOF model with LS-DYNA model at $\mathrm{z}=1.0 \mathrm{~m} / \mathrm{kg}^{1 / 3} \mathrm{using}$ a $100 \mathrm{~kg}$ TNT charge mass

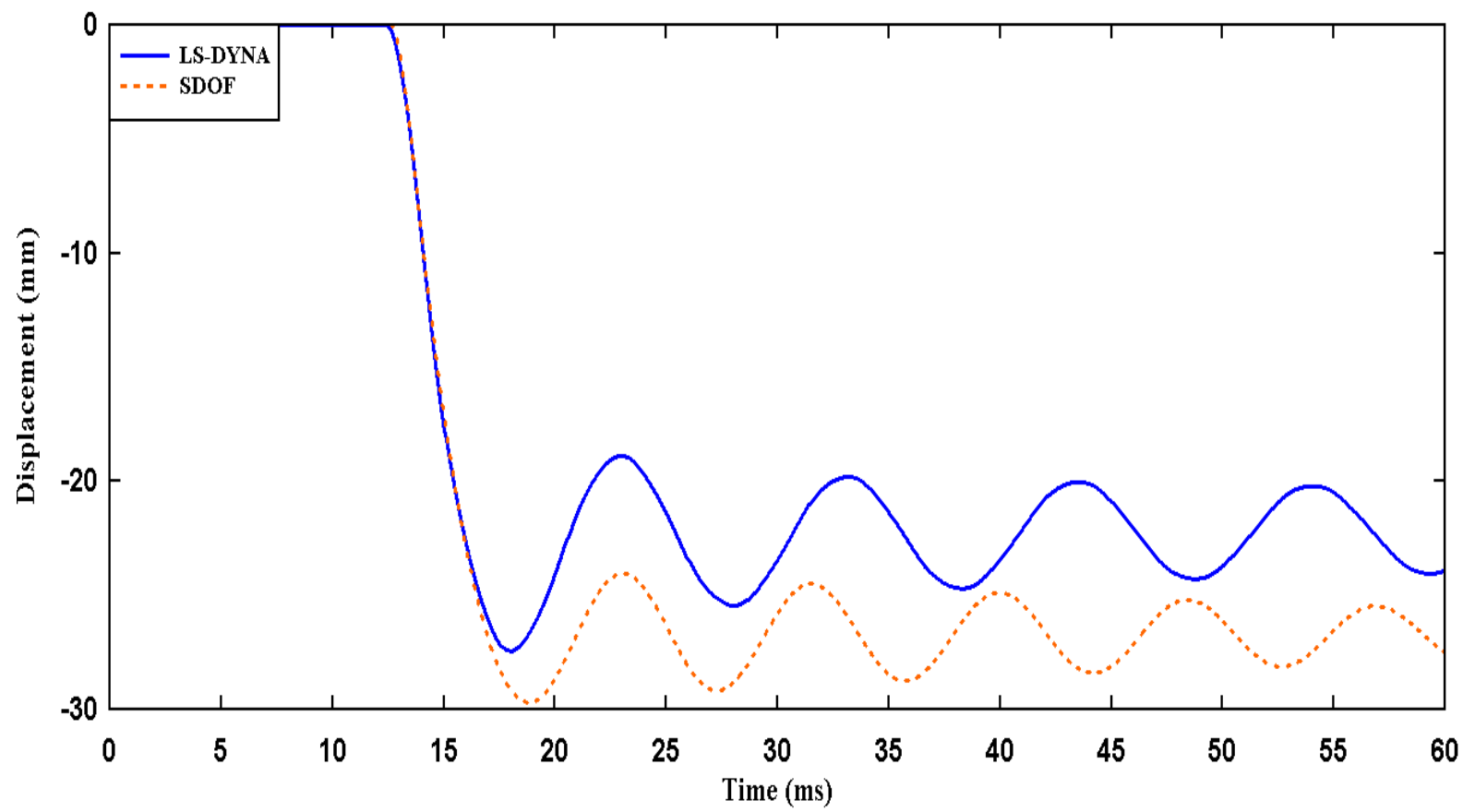

Figure 5-13: Comparison of SDOF model with LS-DYNA model at $z=1.0 \mathrm{~m} / \mathrm{kg}^{1 / 3}$ using a $250 \mathrm{~kg}$ TNT charge mass 


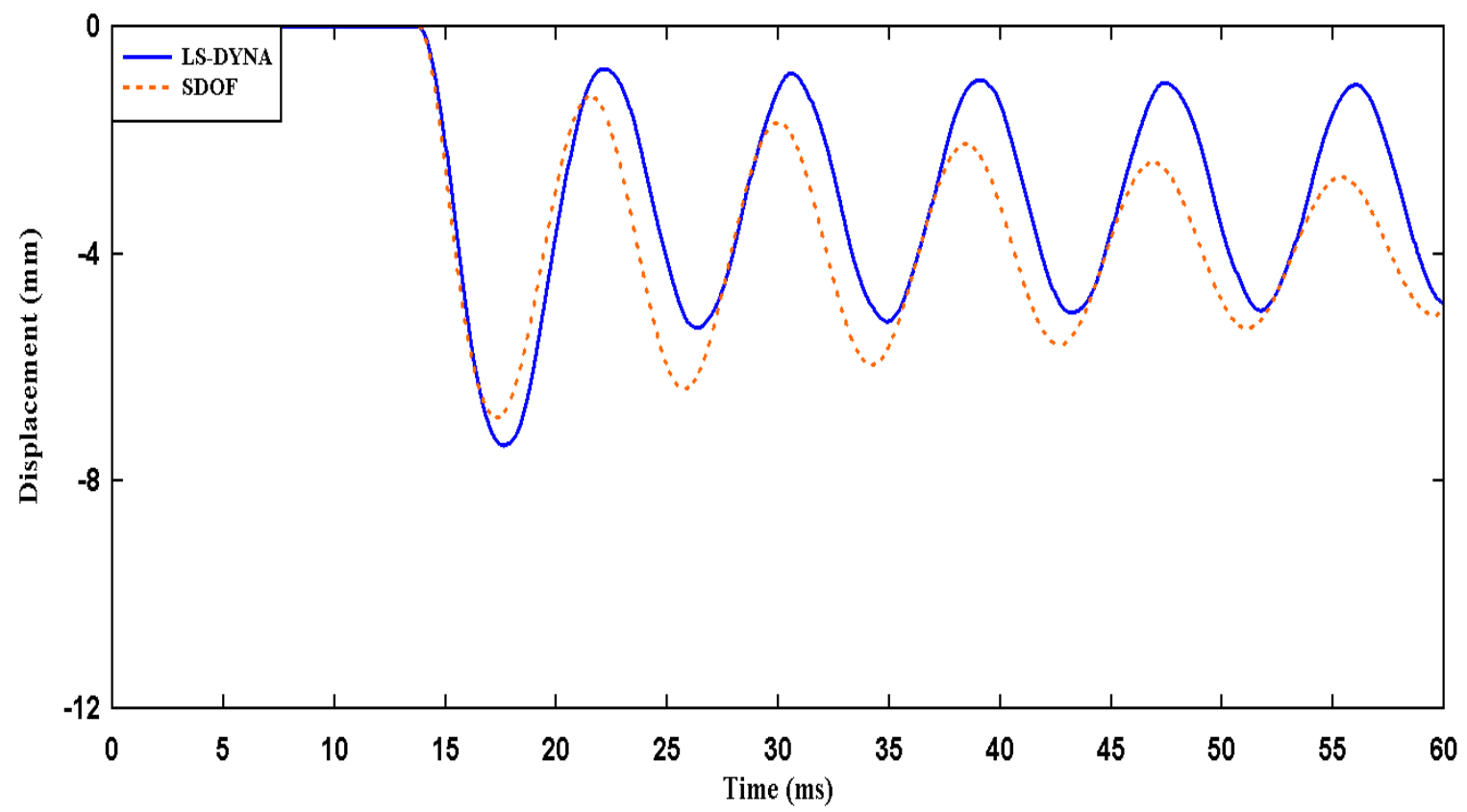

Figure 5-14: Comparison of SDOF model with LS-DYNA model at $\mathrm{z}=1.5 \mathrm{~m} / \mathrm{kg}^{1 / 3}$ using a $100 \mathrm{~kg}$ TNT charge mass

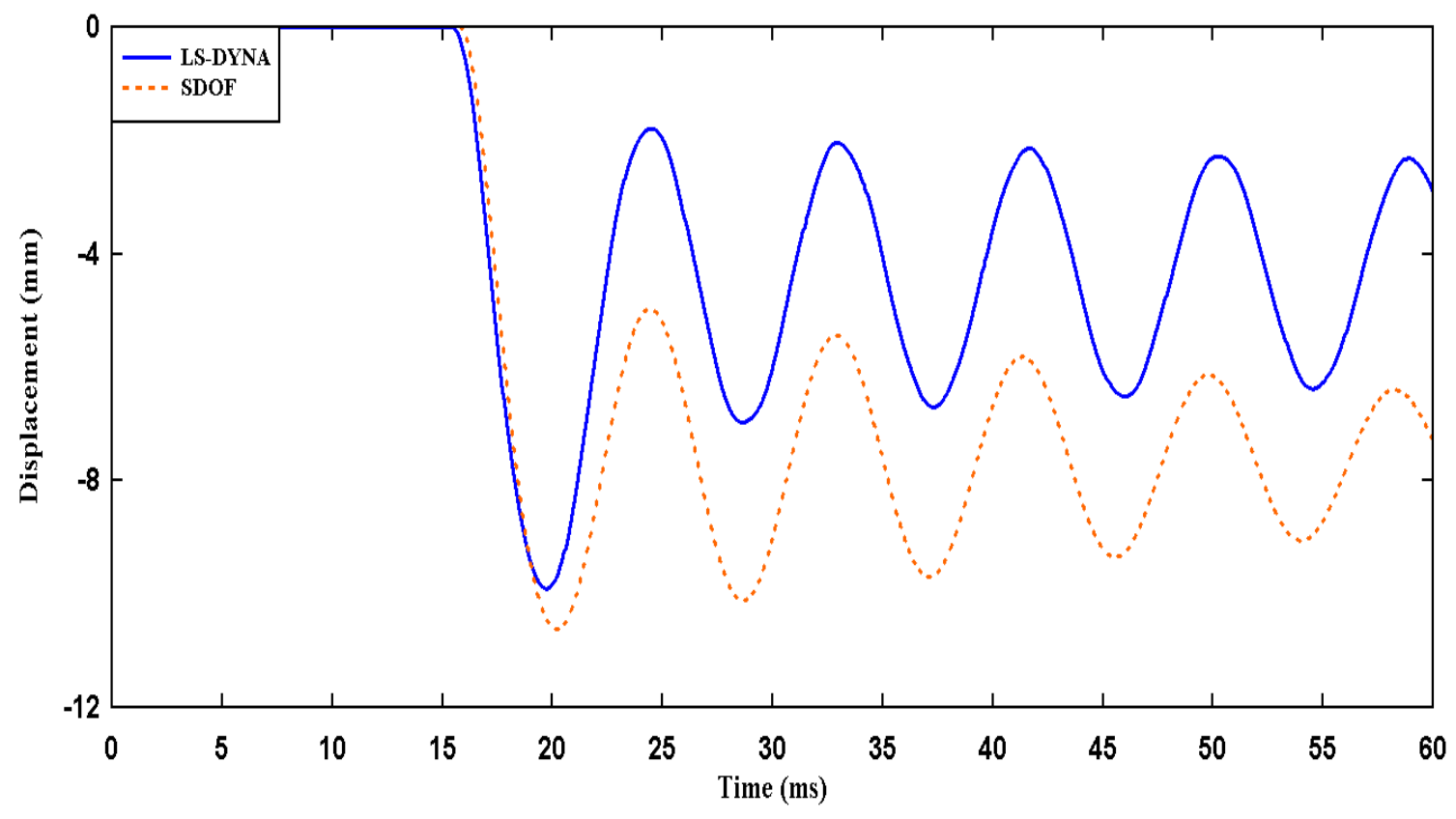

Figure 5-15: Comparison of SDOF model with LS-DYNA model at $\mathrm{z}=1.5 \mathrm{~m} / \mathrm{kg}^{1 / 3} \mathrm{using}$ a $250 \mathrm{~kg}$ TNT charge mass 


\section{Chapter: Parametric Analysis of Reinforced Concrete Columns under Blast Loading}

A parametric analysis was conducted after, the numerical models were validated with experimetal results to study the effect of other design parameters on the response of reinforced concrete columns to blast loading. The parametric study investigated the combined effect of blast loading and axial loading on RC columns detailed in accordance with clause 21 of CSA23.04. The numerical analysis was conducted with scaled distances of $0.8 \mathrm{~m} / \mathrm{kg}^{1 / 3}, 1.0 \mathrm{~m} / \mathrm{kg}^{1 / 3}$ and 1.5 $\mathrm{m} / \mathrm{kg}^{1 / 3}$. At each of these scaled distances charge masses of $100 \mathrm{~kg}, 250 \mathrm{~kg}, 500 \mathrm{~kg}$ and $1000 \mathrm{~kg}$ were used at the corresponding standoff distances. The relationship between the scaled distance, $\mathrm{z}$, range, $\mathrm{R}$, and the charge mass, $\mathrm{W}$, is given by equation [6-1].

$\mathbf{z}=\frac{\mathbf{R}}{\mathbf{W}^{\mathbf{1 / 3}}}$

Using equation [6-1], the ranges for the $\mathrm{z}$ values of $0.8 \mathrm{~m} / \mathrm{kg}^{1 / 3}, 1.0 \mathrm{~m} / \mathrm{kg}^{1 / 3}$ and $1.5 \mathrm{~m} / \mathrm{kg}^{1 / 3}$ are presented, for the different charge masses, in Table 6-1, Table 6-2 and Table 6-3 respectively.

Table 6-1: Ranges for charge masses at a scaled distance of $0.8-\mathrm{m} / \mathrm{kg}^{1 / 3}$

\begin{tabular}{|c|c|}
\hline Charge Mass (kg) & Range $(\mathrm{m})$ \\
\hline 100 & 3.71 \\
\hline 250 & 5.04 \\
\hline 500 & 6.35 \\
\hline 1000 & 8.00 \\
\hline
\end{tabular}


Table 6-2: Ranges for charge masses at a scaled distance of $1.0-\mathrm{m} / \mathrm{kg}^{1 / 3}$

\begin{tabular}{|c|c|}
\hline Charge Mass (kg) & Range (m) \\
\hline 100 & 4.64 \\
\hline 250 & 6.30 \\
\hline 500 & 7.94 \\
\hline 1000 & 10.00 \\
\hline
\end{tabular}

Table 6-3: Range for charge masses at a scaled distance of $1.5-\mathrm{m} / \mathrm{kg}^{1 / 3}$

\begin{tabular}{|c|c|}
\hline Charge Mass (kg) & Range (m) \\
\hline 100 & 6.96 \\
\hline 250 & 9.45 \\
\hline 500 & 11.91 \\
\hline 1000 & 15.00 \\
\hline
\end{tabular}

At each scaled distance, and for each charge mass at the corresponding scaled distance, ALRs of $0.0,0.1,0.2$ and 0.35 were appplied to the columns. The ALRs used were representative of gravity loading on lower storey RC columns for low-rise to mid-rise buildings as well as for bridge piers. CSA A23.04 computes axial load resistance for a concentrically loaded RC column by adding the contributions of concrete and steel reinforcement. Using equation [3-12] and the RC column properties listed in Table 3-1, the computed factored axial load resistance of the RC column, $\mathrm{P}_{\text {ro }}$, was $2490 \mathrm{kN}$. The maximum factored axial load that was used in design, $\mathrm{P}_{\text {rmax }}$ is given by

$$
\mathrm{P}_{\text {rmax }}=0.8 \times \mathrm{P}_{\text {ro }}=2000 \mathrm{kN}
$$


The axial load ratios (ALRs) used in this thesis were taken to be the ratio of the factored concentric axial load acting on the RC column, $\mathrm{P}_{\mathrm{f}}$, to the factored axial load resistance, $\mathrm{P}_{\mathrm{rmax}}$, of the RC column given by equation [6-2].

$$
\mathbf{A L R}=\frac{\mathbf{P}_{\mathbf{f}}}{\mathbf{P}_{\mathrm{rmax}}}
$$

Thus, for a given ALR, the load applied to the reinforced concrete column can then be computed using equation [6-3].

$\mathbf{P}_{\mathbf{f}}=\mathbf{A L R} \times \mathbf{P}_{\text {rmax }}$

Table 6-4 gives the axial loads applied to the RC columns corresponding to axial load ratios of $0.1,0.2$ and 0.35 .

Table 6-4: Applied axial loads for different axial load ratios

\begin{tabular}{|c|c|}
\hline Axial Load Ratio (ALR) & Applied Axial Load [kN] \\
\hline 0.1 & 200 \\
\hline 0.2 & 400 \\
\hline 0.35 & 700 \\
\hline
\end{tabular}

RC columns with three different transverse reinforcement detailing schemes were modelled to investigate the effects of transverse reinforcement on their behaviour. Figure 6-1 shows the detailing for the RC column types. All the columns were $300 \times 300 \times 3000 \mathrm{~mm}$. The detailing for the first column type, designated as conventional, for the purpose of the parametric studies is presented in Figure 6-1(a). The conventional RC columns had transverse reinforcement consisting of $10 \mathrm{M}$ ties spaced at $300 \mathrm{~mm}$ throughout the entire length of the column. The second RC column type designation, Seismic-1, had transverse reinforcements spaced at $75 \mathrm{~mm}$ at the support regions over a plastic hinge length of $600 \mathrm{~mm}$ while transverse reinforcements were spaced at $150 \mathrm{~mm}$ throughout the remainder of the column (see Figure 6-1 (b)). The third RC 
column type, designated Seismic-2, also had transverse reinforcements similar to the Seismic-1 column but in addition the transverse reinforcement spacing was reduced to $75 \mathrm{~mm}$ in the midregion (Figure 6-1 (c)).

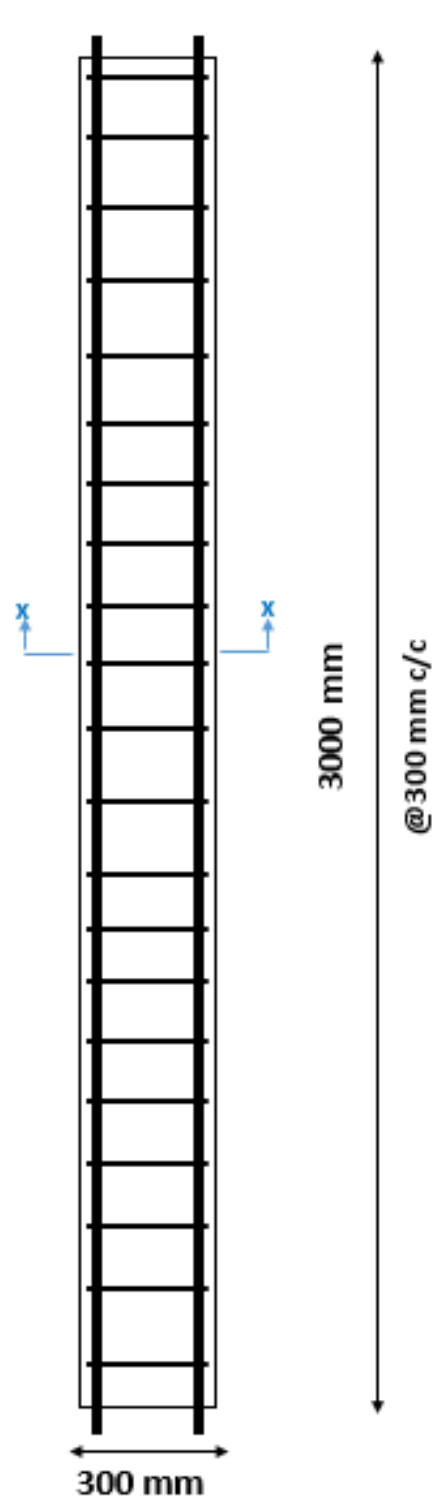

(a) Conventional

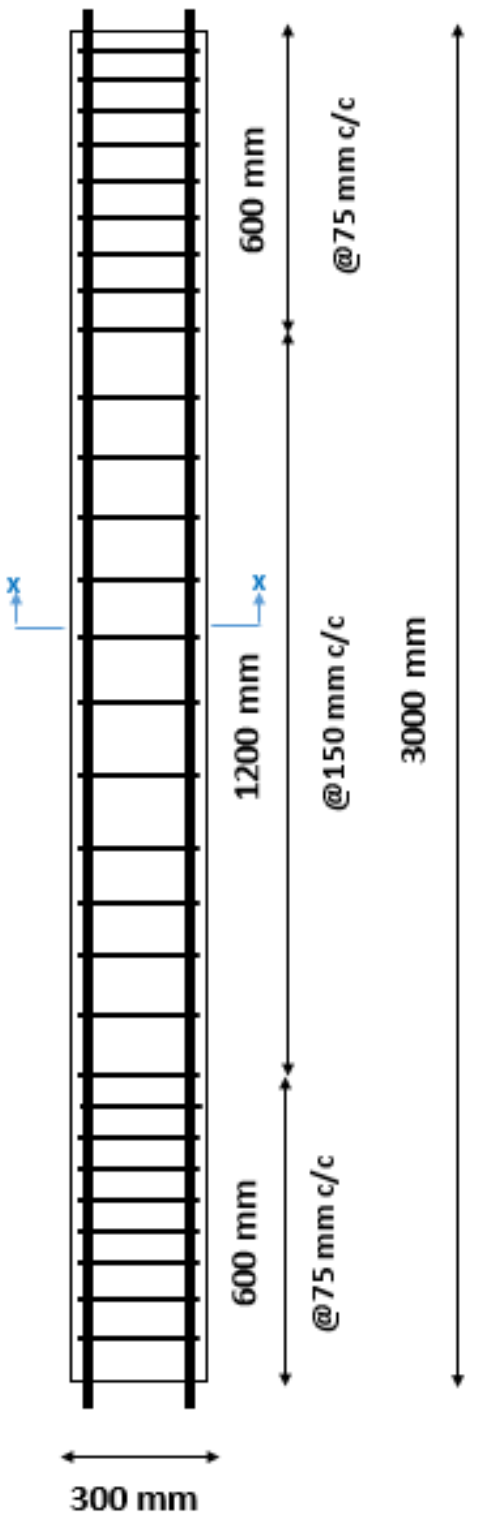

(b) Seismic 1

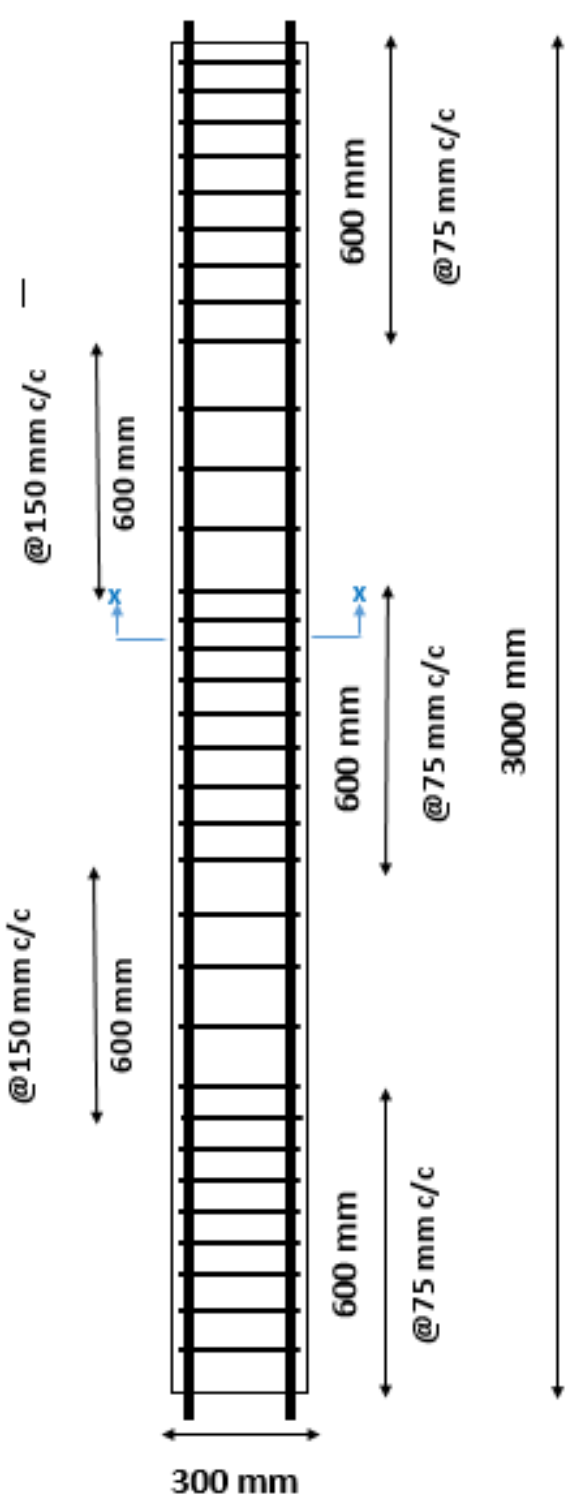

(c) Seismic 2

Figure 6-1: Three different RC column detailing used for numerical analysis 


\subsection{Effect of different charge masses at the same scaled distance}

For the different charge masses used in the parametric studies, chosen scaled distances were used to obtain the range at which the different charge masses were placed away from the target as presented in Table 6-1, Table 6-2 and Table 6-3. The Hopkinson-Cranz scaling law ensures the same peak pressure is produced by the different charge masses at a specified scaled distance. However, the duration for the blast loading, and hence the impulse, varies with charge masses at the specified scaled distance. Higher magnitude charge masses produced longer blast loading durations than lower magnitude charge masses. This means that at the same scaled distance, a charge mass of higher magnitude produced a higher impulse than the lower magnitude charge mass as indicated in Figure 6-2, even though the peak pressures are the same. Figure 6-2 shows the pressure and impulse time histories for different charges masses at a scaled distance of 1.0 $\mathrm{m} / \mathrm{kg}^{1 / 3}$

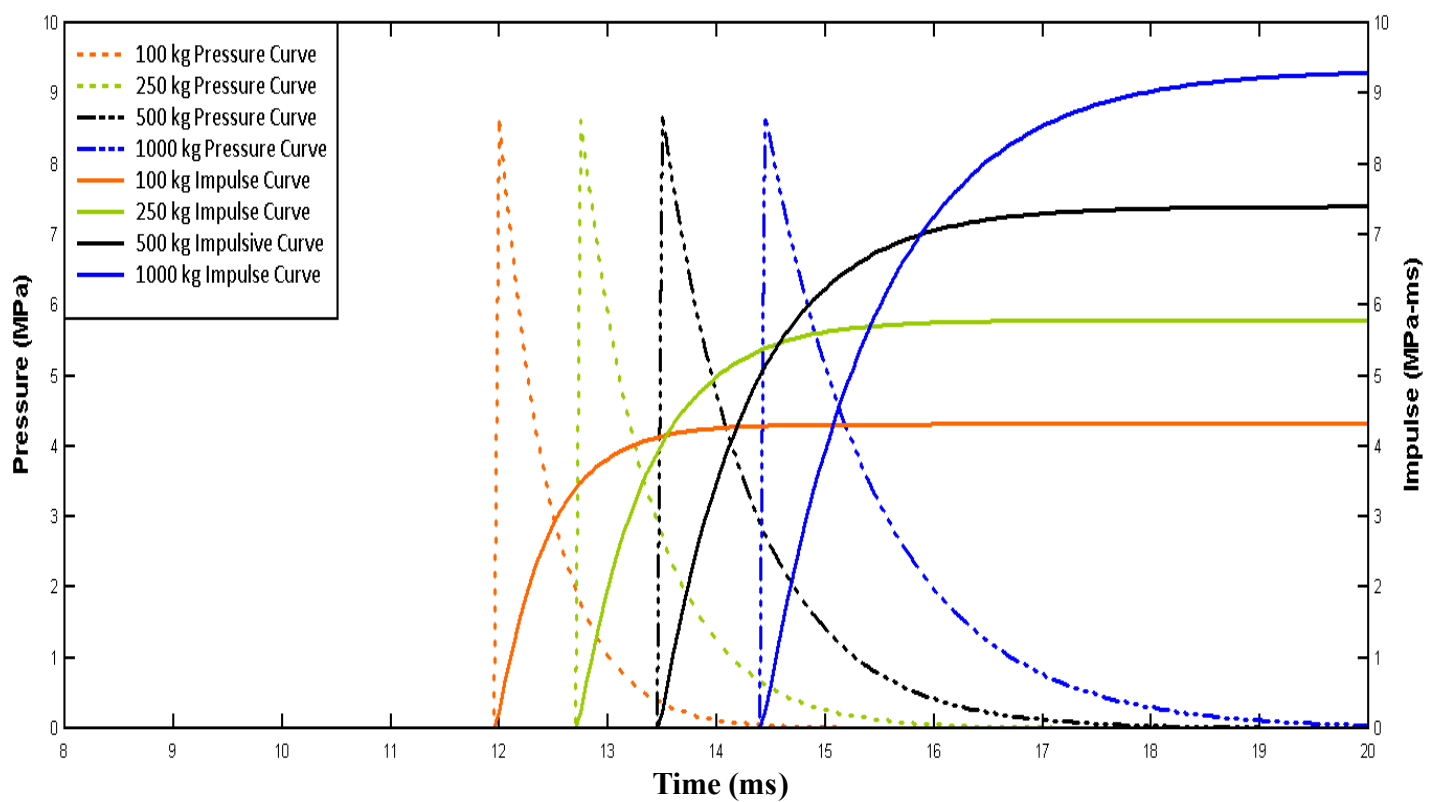

Figure 6-2: Pressure and impulse time histories for four different charges masses at $\mathrm{z}=1.0 \mathrm{~m} / \mathrm{kg}^{1 / 3}$ 
Figure 6-3 shows plots of displacement-time histories for different charge masses all placed at a scaled distance of $0.8 \mathrm{~m} / \mathrm{kg}^{1 / 3}$ for the column with seismic 1 detailing. As can be seen from Figure 6-3, the maximum recorded displacements increase from the lower charge masses to the higher charge masses due to the commensurate increase in impulse associated with higher magnitude charge masses at the scaled distance of $0.8 \mathrm{~m} / \mathrm{kg}^{1 / 3}$. Figure $6-4$ also shows the displacement-time histories for the charge masses at a scaled distance of $1.0 \mathrm{~m} / \mathrm{kg}^{1 / 3}$ using a RC column with seismic 1 detailing. Again, the maximum displacements increased with increasing charge masses. The maximum displacements were observed to be closer at the $1.0-\mathrm{m} / \mathrm{kg}^{1 / 3}$ scaled distance than at the smaller scaled distance of $0.8 \mathrm{~m} / \mathrm{kg}^{1 / 3}$. When the scaled distance was increased to $1.5 \mathrm{~m} / \mathrm{kg}^{1 / 3}$, using the same charge masses, the maximum displacements were observed to be even much closer as can be seen in Figure 6-5.

Table 6-5 presents the maximum displacements recorded for the different charge masses as the scaled distance was increased from $0.8 \mathrm{~m} / \mathrm{kg}^{1 / 3}$ through $1.0 \mathrm{~m} / \mathrm{kg}^{1 / 3}$ to $1.5 \mathrm{~m} / \mathrm{kg}^{1 / 3}$..

At the smaller scaled distance of $0.8 \mathrm{~m} / \mathrm{kg}^{1 / 3}$, for instance, the blast loading from the $1000 \mathrm{-kg}$ charge mass resulted in a maximum displacement of $320 \mathrm{~mm}$, which was observed to still be increasing after a 60 -millisecond simulation, while the blast load from the 100-kg charge mass produced a maximum displacement of $65 \mathrm{~mm}$. The maximum displacement from the $1000-\mathrm{kg}$ charge mass was more than five times larger than that recorded by the $100-\mathrm{kg}$ charge mass. At the scaled distance of $1.5 \mathrm{~m} / \mathrm{kg}^{1 / 3}$, the maximum displacement of approximately $36 \mathrm{~mm}$ resulting from the 1000-kg charge mass was only about twice as high as the $15-\mathrm{mm}$ displacement resulting from the 100-kg charge mass. A further comparison of the maximum displacements resulting from the different charge masses shows a similar trend. 


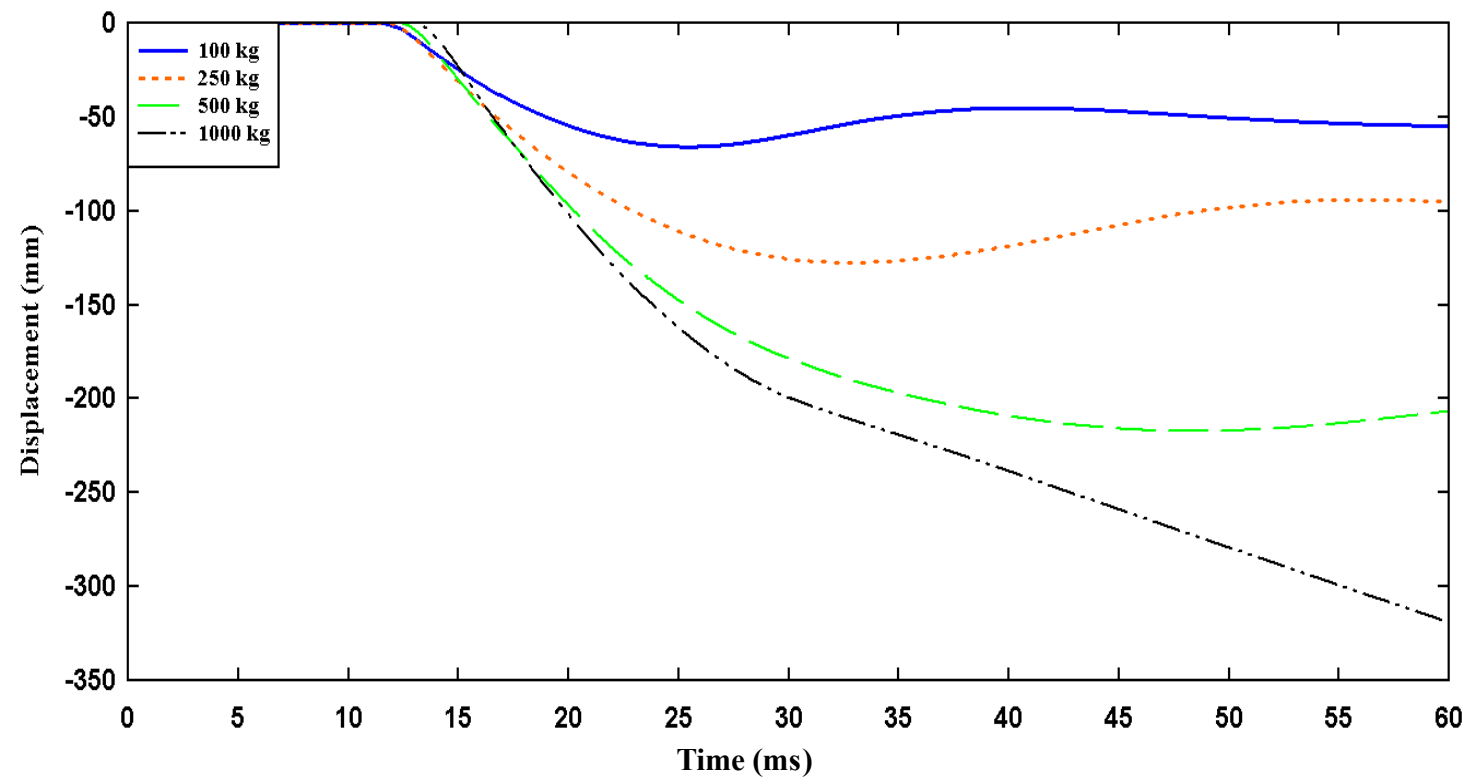

Figure 6-3: Displacement-time history plots for different charge masses at a scaled distance of 0.8

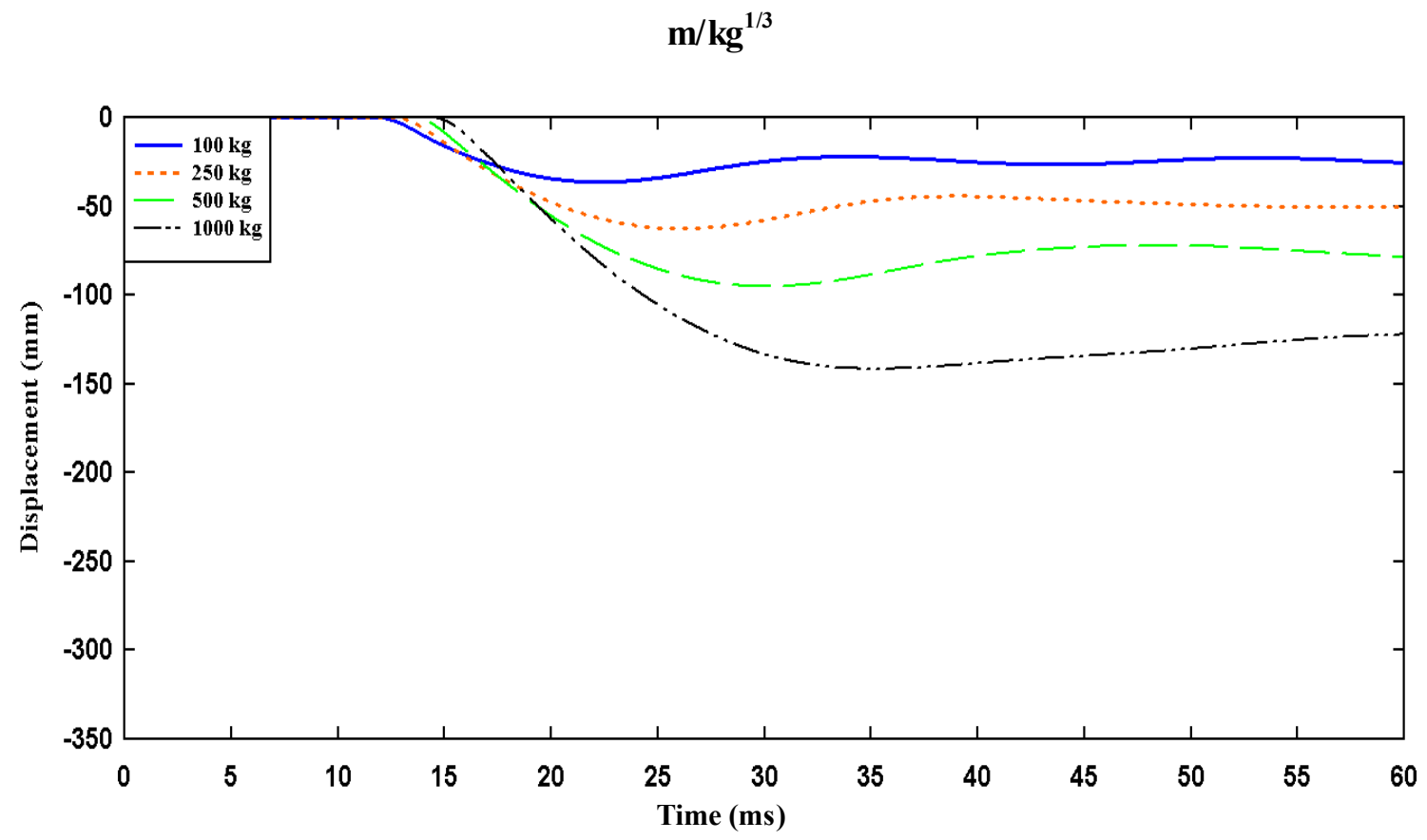

Figure 6-4: Displacement-time history plots for different charge masses at a scaled distance of $1.0 \mathrm{~m} / \mathrm{kg}^{1 / 3}$ 


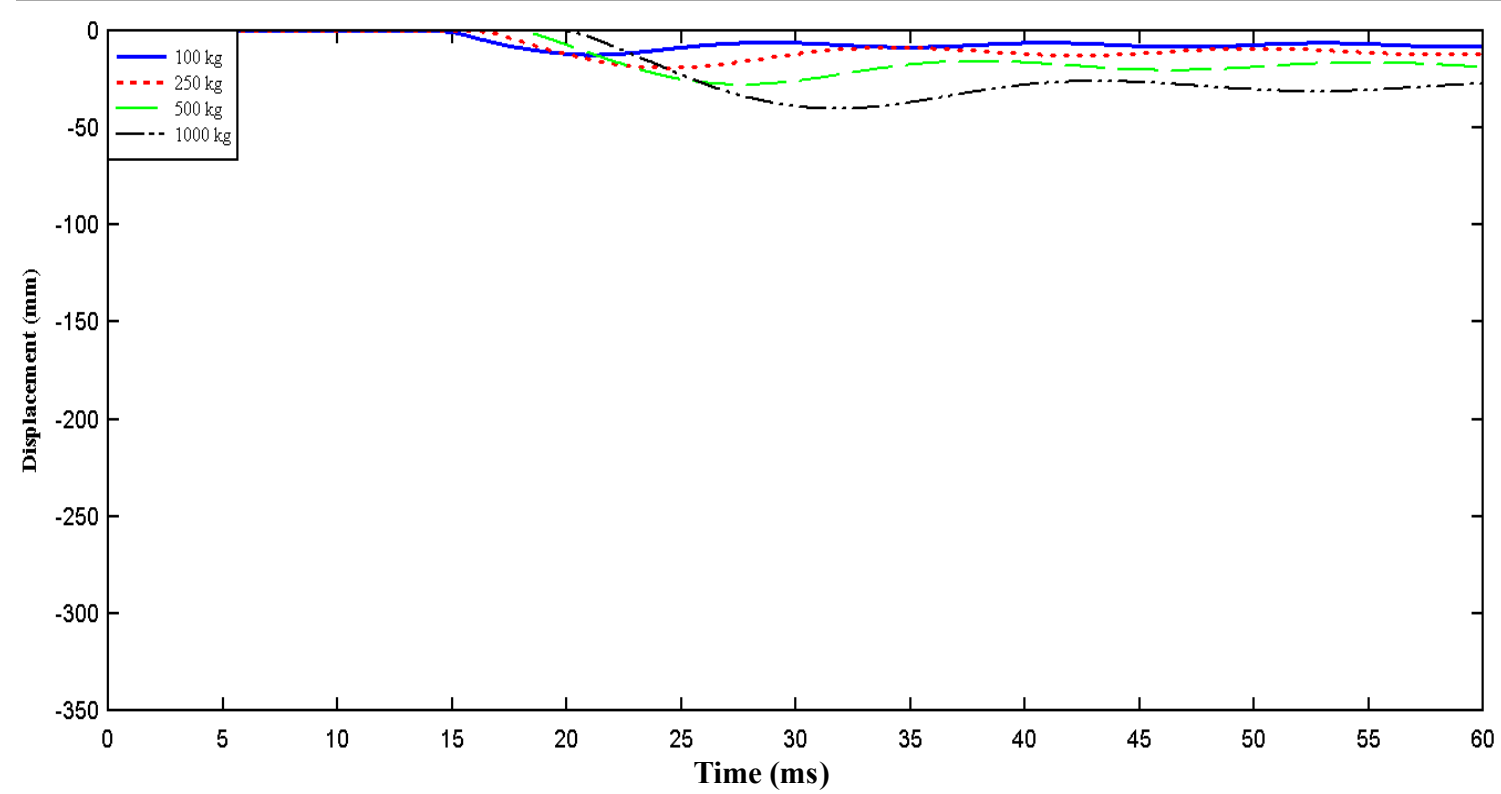

Figure 6-5: Displacement-time history plots for different charge masses at a scaled distance of $1.5 \mathrm{~m} / \mathrm{kg}^{1 / 3}$

The trend of increasing charge masses at the same scaled distance resulting in corresponding increase in maximum displacements was observed to be independent of the reinforcement detailing. That is, whether the detailing of the transverse reinforcement was widely spaced or closely spaced higher magnitude charge masses resulted in higher lateral displacements than smaller magnitude charge masses at the same scaled distance, even though the peak reflected blast pressure was the same for all charge masses at the corresponding standoff distances. However, as the scaled distance increases peak pressure becomes dominant in column response, resulting in much closer maximum displacements from the different charge masses. 
Table 6-5: Summary of maximum displacements for different charge masses with increasing scaled distance

\begin{tabular}{|c|c|c|}
\hline Scaled Distance & $\begin{array}{c}\text { Charge Mass } \\
\qquad(\mathrm{kg})\end{array}$ & $\begin{array}{c}\text { Maximum Displacement } \\
(\mathrm{mm})\end{array}$ \\
\hline \multirow{4}{*}{$0.8 \mathrm{~m} / \mathrm{kg}^{1 / 3}$} & 100 & 65 \\
\hline & 250 & 125 \\
\hline & 500 & 215 \\
\hline & 1000 & $320^{*}$ \\
\hline \multirow{4}{*}{$1.0 \mathrm{~m} / \mathrm{kg}^{1 / 3}$} & 100 & 36 \\
\hline & 250 & 62 \\
\hline & 500 & 95 \\
\hline & 1000 & 140 \\
\hline \multirow{4}{*}{$1.5 \mathrm{~m} / \mathrm{kg}^{1 / 3}$} & 100 & 15 \\
\hline & 250 & 22 \\
\hline & 500 & 28 \\
\hline & 1000 & 36 \\
\hline
\end{tabular}

* - use to denote those that are not the maximum displacement values 


\subsection{Effect of reinforcement detailing on column response}

To study the effect of reinforcement detailing on the behaviour of the modelled RC columns, three scaled distances of $0.8 \mathrm{~m} / \mathrm{kg}^{1 / 3}, 1.0 \mathrm{~m} / \mathrm{kg}^{1 / 3}$ and $1.5 \mathrm{~m} / \mathrm{kg}^{1 / 3}$ were considered. At each of these scaled distances, the RC columns, with ALR equal to 0.0 applied to them, were subjected to blast loading from detonation of $100 \mathrm{~kg}, 250 \mathrm{~kg}, 500 \mathrm{~kg}$ and $1000 \mathrm{~kg}$ charge masses.

\subsubsection{Scaled distance of $0.8 \mathrm{~m} / \mathrm{kg}^{1 / 3}$}

Using a 100-kg charge mass, the maximum displacements for all three column types were very similar as shown in Figure 6-6. The difference between the maximum displacement for the conventional column being only approximately $5 \mathrm{~mm}$ more than the maximum displacement recorded by the column disignated seismic 2 .

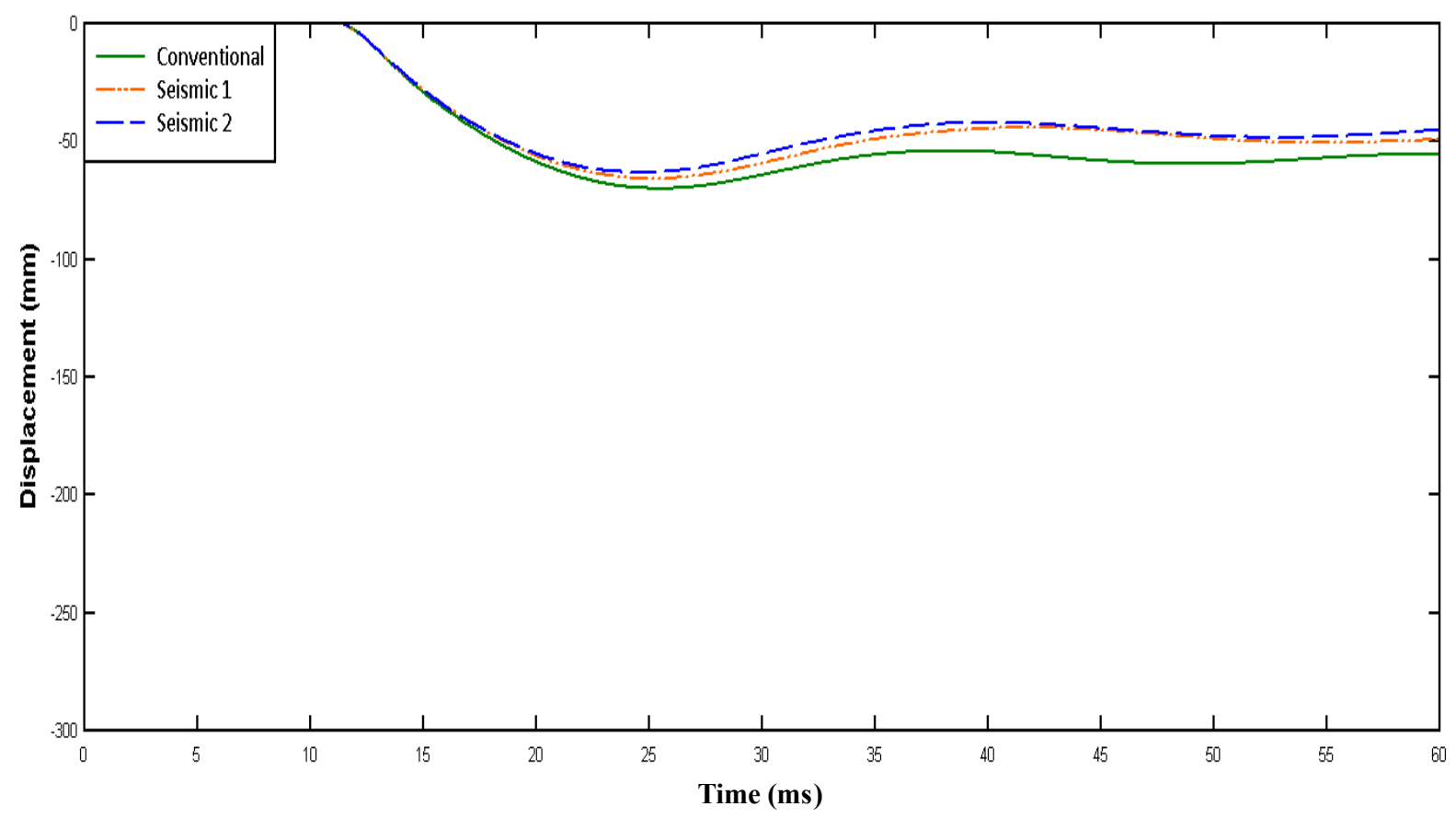

Figure 6-6: Displacement Time History at $\mathrm{z}=0.8 \mathrm{~m} / \mathrm{kg}^{1 / 3}$ using a $100 \mathrm{~kg}$ charge mass 
For the $250-\mathrm{kg}$ charge mass, the lateral displacements, shown in Figure 6-7, were much higher for all three column types, in comparison to the $100 \mathrm{~kg}$ charge mass, due to the higher impulse generated by the increased charge mass. Both the conventional column and the seismic 1 columns recorded maximum dipslacements of approximately $126 \mathrm{~mm}$ while the seismic 2 column had a maximum displacement of $127 \mathrm{~mm}$. The performance of the column types were similar to that of the columns under the $100-\mathrm{kg}$ charge mass, with no significant difference in lateral displacement between the three column types.

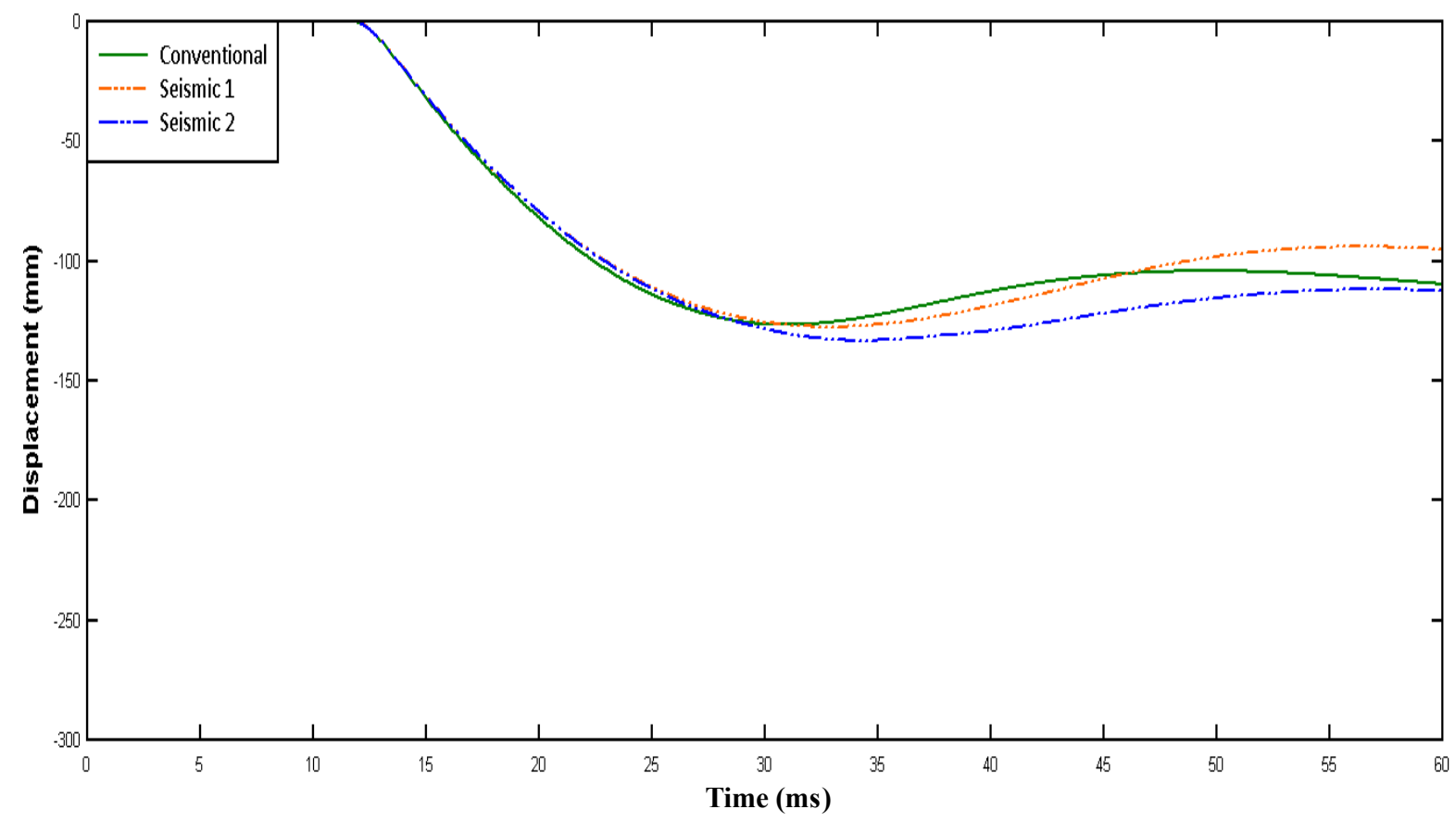

Figure 6-7: Displacement Time History at $\mathrm{z}=0.8 \mathrm{~m} / \mathrm{kg}^{1 / 3}$ using a 250-kg charge mass

Under the blast loading generated by the 500-kg charge mass however, the conventional column lost significant concrete cover on the tension region (see Figure 6-9). Figure 6-10 shows the deformation of the seismic 1 column under the $500 \mathrm{~kg}$ charge mass. The analysis was run for a 60 milliseconds duration at which time the conventional column was still moving as can be seen 
from the velocity-time plot in Figure 6-11. Figure 6-8 shows the displacement-time history for the columns under the $500 \mathrm{~kg}$ charge mass. Figure 6-8 shows a steep divergence of the displacement curve of the conventional column from the seismic columns. The displacement for the conventional column after the 60 -millisecond duration was approximately $382 \mathrm{~mm}$ which represents approximately $142 \%$ increase in the maximum lateral displacement of $158 \mathrm{~mm}$ recorded by the seismic 2 column.

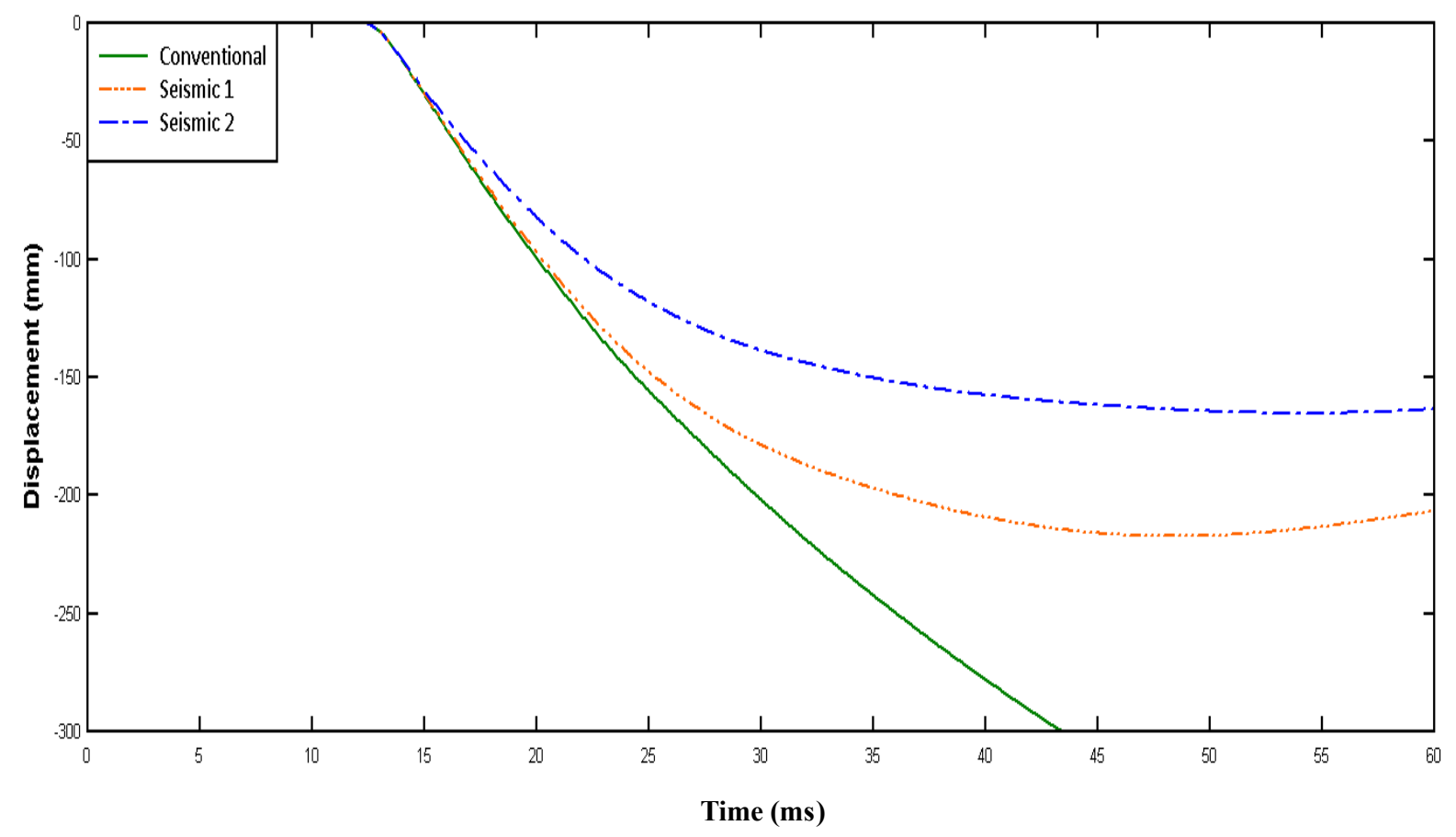

Figure 6-8: Displacement Time History at $\mathrm{z}=0.8 \mathrm{~m} / \mathrm{kg}^{1 / 3}$ using a $500 \mathrm{~kg}$ charge mass

Also, under the blast loading from 500-kg charge mass, the seismic 1 and seismic 2 columns had significantly reduced lateral displacements in comparison to the conventionally detailed RC column. The seismic columns, however, showed significant flexural cracks as can be seen in Figure 6-10. The seismic 2 column also had approximately $24 \%$ reduction in lateral deflection in comparison to the seismic 1 column. The reduction in lateral displacement can be attributed to the reduced tie spacing at mid-height for seismic column 2 . 


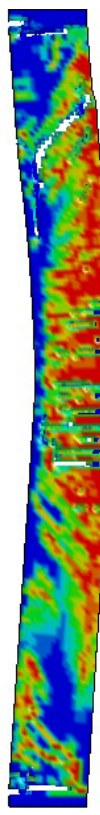

(a) $20 \mathrm{~ms}$

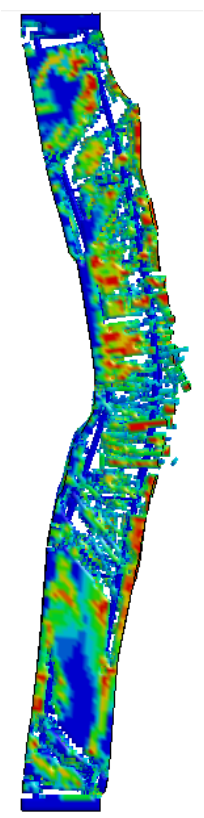

(b) $40 \mathrm{~ms}$

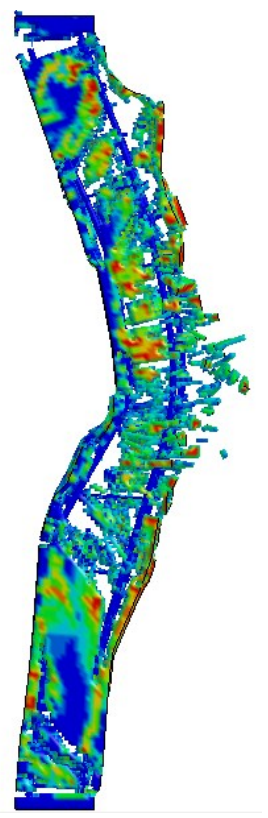

Fringe Levels $9.990 \mathrm{e}-01$ $8.991 \mathrm{e}-01$ $7.992 \mathrm{e}-01$ 6.993e-01 5.994e-01 4.995e-01 3.996e-01 $2.997 \mathrm{e}-01$ $1.998 \mathrm{e}-01$ $9.990 \mathrm{e}-02$ $0.000 \mathrm{e}+00$

(c) $60 \mathrm{~ms}$

Figure 6-9: Laterally deformed conventional columns under $500 \mathrm{~kg}$ charge mass, $\mathrm{z}=0.8 \mathrm{~m} / \mathrm{kg}^{1 / 3}$ $\mathbf{A L R}=\mathbf{0 . 0}$

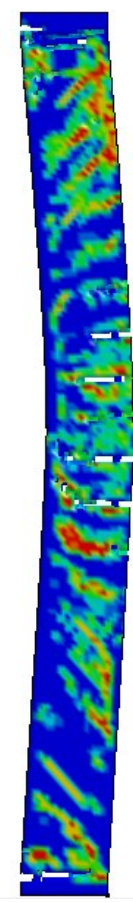

(a) $20 \mathrm{~ms}$

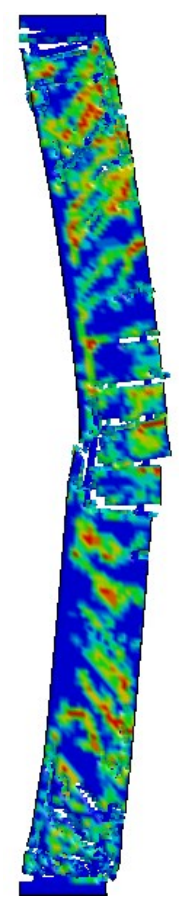

(b) $40 \mathrm{~ms}$

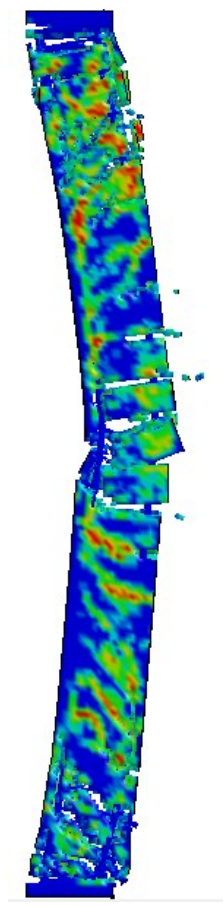

Fringe Levels $9.990 \mathrm{e}-01$ $8.991 \mathrm{e}-01$ $7.992 \mathrm{e}-01$ $6.993 e-01$ $5.994 \mathrm{e}-01$ $4.995 \mathrm{e}-01$ $3.996 \mathrm{e}-01$ 2.997e-01 $1.998 \mathrm{e}-01$ $9.990 \mathrm{e}-02$ $0.000 \mathrm{e}+00$

Figure 6-10: Laterally deformed seismic 1 column under $500 \mathrm{~kg}$ charge mass, $\mathrm{z}=0.8 \mathrm{~m} / \mathrm{kg}^{1 / 3}$ 


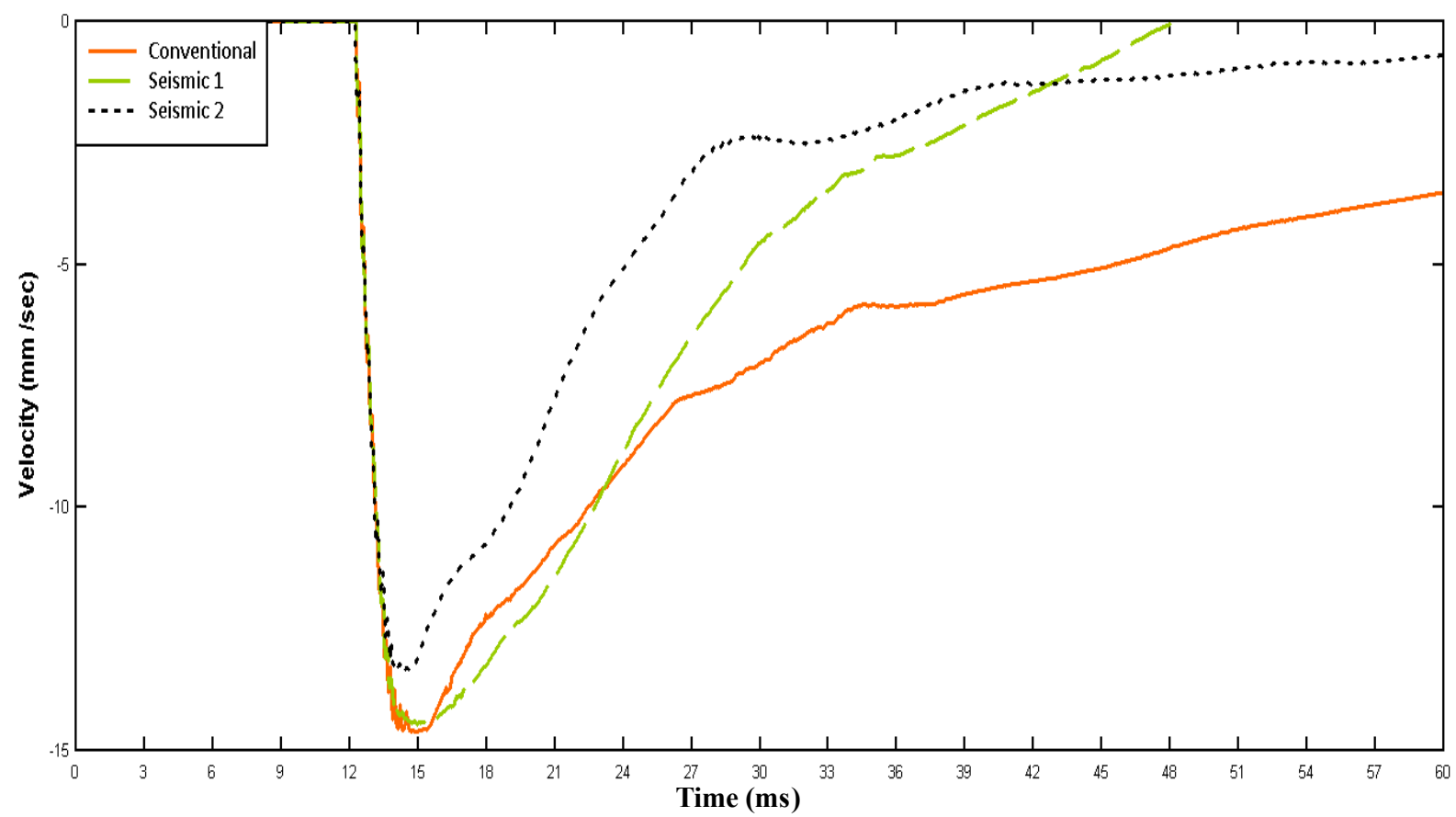

Figure 6-11: Velocity Time History for $500 \mathrm{~kg}$ charge mass on conventional column at $\mathrm{z}=0.8$

$$
\mathbf{m} / \mathbf{k g}^{1 / 3}
$$

The 1000-kg charge mass resulted in the extensive lateral displacement of the three column types (Figure 6-12). The displacements of the three column types for the 60-millisecond simulation are presented in Table 6-6 with the conventional column experiencing the highest lateral displacements. 


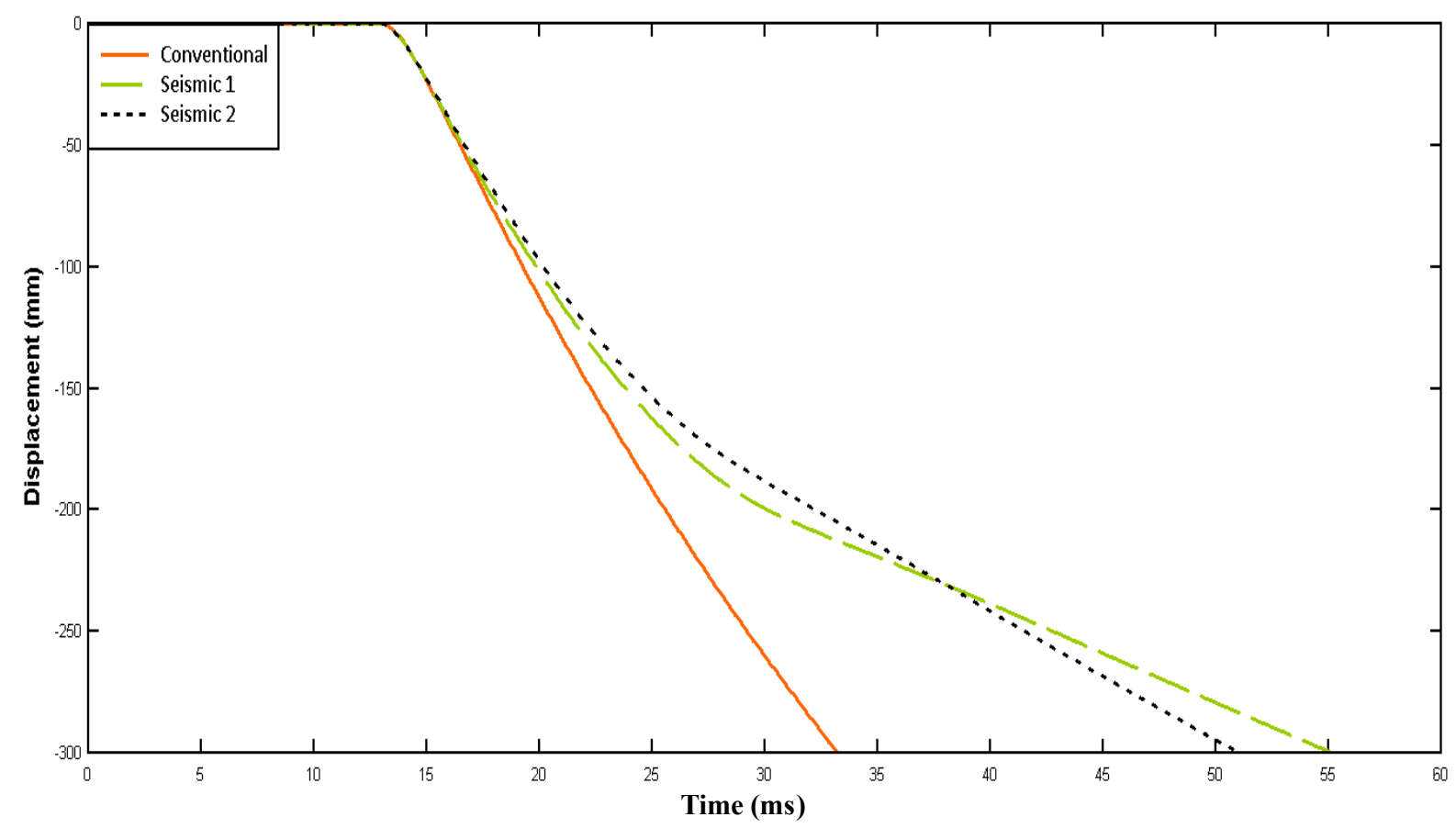

Figure 6-12: Displacement Time History at $\mathrm{z}=0.8 \mathrm{~m} / \mathrm{kg}^{1 / 3}$ using a $1000 \mathrm{~kg}$ charge mass

Table 6-6 gives a summary of the maximum displacements and support rotations recorded for the scaled distance of $0.8 \mathrm{~m} / \mathrm{kg}^{1 / 3}$. In general, all three column types experienced similar maximum lateral displacements at lower charge masses of $100 \mathrm{~kg}$ and $250 \mathrm{~kg}$. However, as the charge mass increased to $500 \mathrm{~kg}$ and then to $1000 \mathrm{~kg}$, significant increase in lateral displacement was observed for all column types with the seismically detailed columns experiencing less increase in lateral displacement in comparison to the conventionally detailed columns. The conventionally detailed columns had significant loss of the concrete cover in the mid-height region leading to loss of lateral stiffness. Conversely seismically detailed columns experienced less cracking and spalling of the concrete cover and thus experienced comparatively lower lateral displacements when compared to the conventionally detailed RC columns. 
Table 6-6: Summary of the maximum displacements and corresponding rotations for the scaled distance of $0.8 \mathrm{~m} / \mathrm{kg}^{1 / 3}$ using different charge masses.

\begin{tabular}{|c|c|c|c|c|c|c|}
\hline & \multicolumn{2}{|c|}{ Conventional } & \multicolumn{2}{c|}{ Seismic 1 } & \multicolumn{2}{c|}{ Seismic 2 } \\
\hline Charge Mass & Displacement & Rotation & Displacement & Rotation & Displacement & Rotation \\
$(\mathbf{k g})$ & $(\mathbf{m m})$ & $\left(^{\circ}\right)$ & $(\mathbf{m m})$ & $\left.{ }^{\circ}\right)$ & $(\mathbf{m m})$ & $\left(^{\circ}\right)$ \\
\hline 100 & 70.2 & 3.4 & 65.2 & 3.1 & 63.1 & 3.0 \\
\hline 250 & 125.6 & 6.0 & 125.6 & 6.0 & 128.0 & 6.1 \\
\hline 500 & $382.1^{*}$ & 17.7 & 210.6 & 10.0 & 157.1 & 7.5 \\
\hline 1000 & $553.0^{*}$ & 24.7 & $319.0^{*}$ & 14.9 & $346.0^{*}$ & 16.1 \\
\hline
\end{tabular}

*- maximum lateral displacement not attained within simulation time of 60 milliseconds.

\subsubsection{Scaled distance of $1.0 \mathrm{~m} / \mathrm{kg}^{1 / 3}$}

Figure 6-13, Figure 6-14 and Figure 6-15 show the displacement-time histories of the three column types under blast loading from charge masses of $100 \mathrm{~kg}, 250 \mathrm{~kg}$ and $500 \mathrm{~kg}$ respectively and at corresponding standoff distances for scaled distance of $1.0 \mathrm{~m} / \mathrm{kg}^{1 / 3}$.

The response of the columns is very similar with marginal differences in the recorded maximum displacement values, especially at charge masses less than $1000 \mathrm{~kg}$ (Table 6-7). Under the blast loading from the $1000 \mathrm{~kg}$ charge mass, the seismic columns were observed to have had reduced lateral displacements of $141.5 \mathrm{~mm}$ and $141.2 \mathrm{~mm}$ for seismic 1 and seismic 2 , respectively in comparison to the conventional column with a lateral displacement of $158.3 \mathrm{~mm}$ (about $12 \%$ increase over the seismic columns). The damage profiles of all three column types under the blast loading from the $1000 \mathrm{~kg}$ charge mass are shown is Figure 6-17 


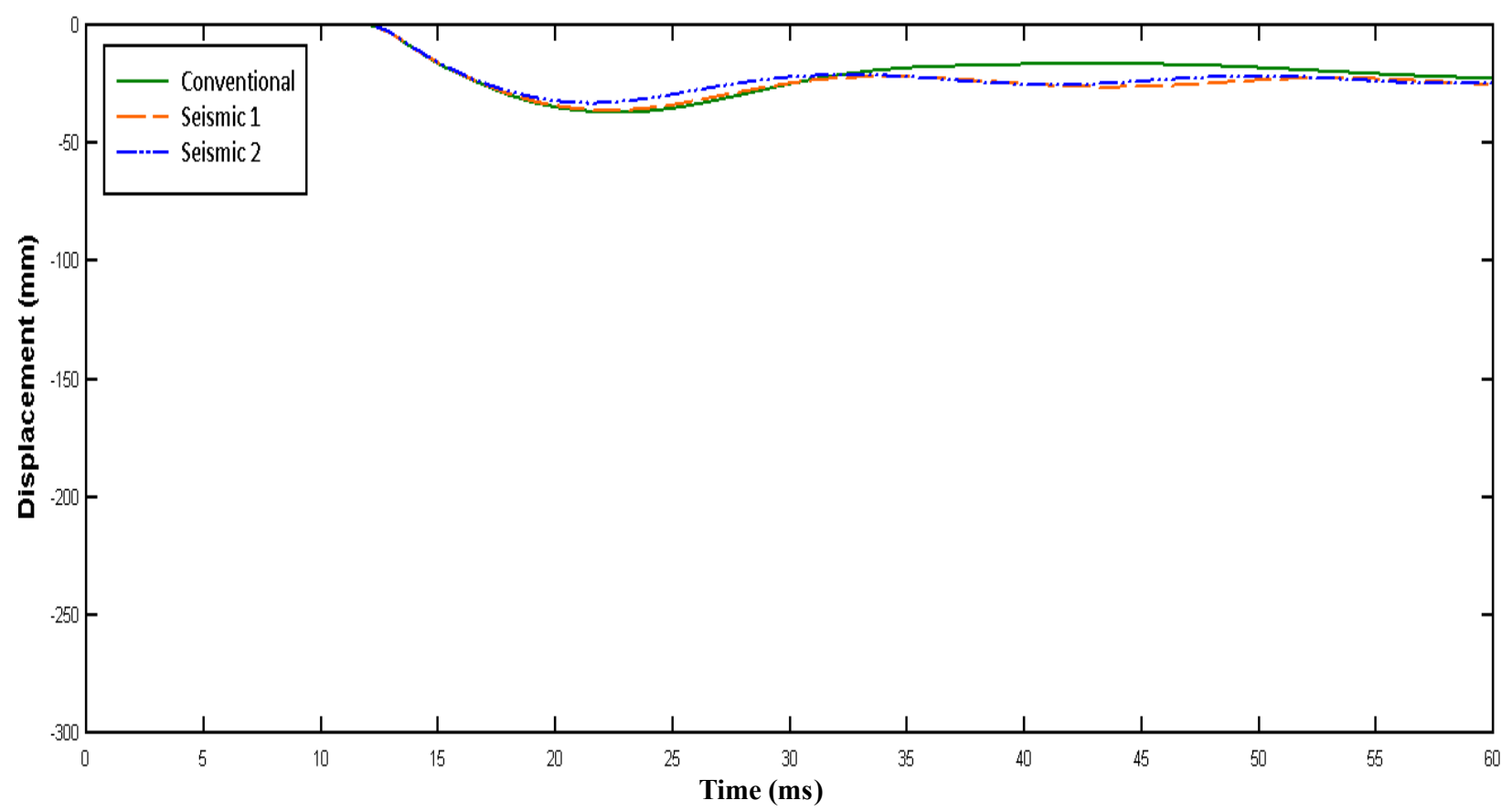

Figure 6-13: Displacement Time History at $\mathrm{z}=1.0 \mathrm{~m} / \mathrm{kg}^{1 / 3}$ using a $100 \mathrm{~kg}$ charge mass

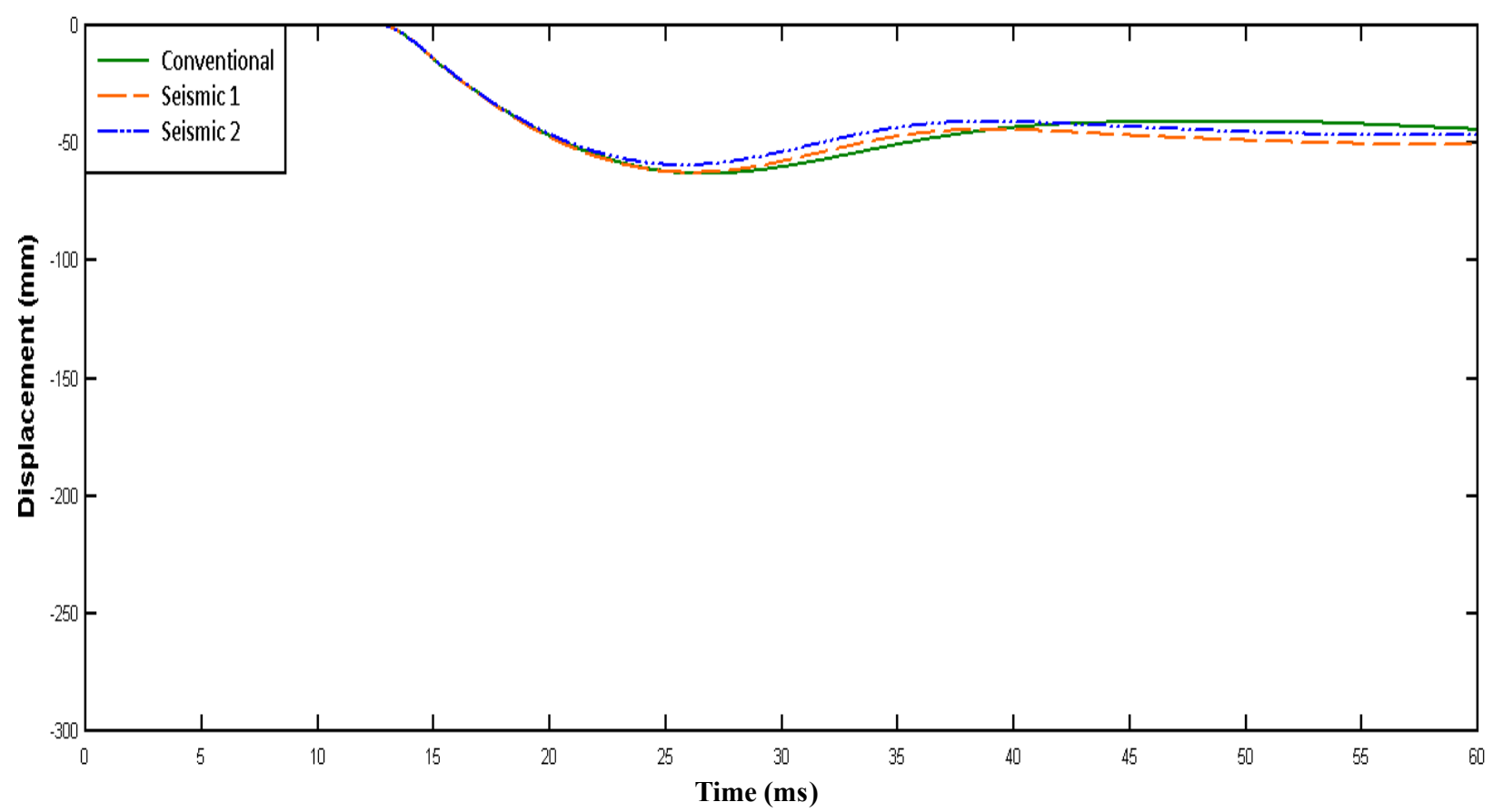

Figure 6-14: Displacement Time History at $\mathrm{z}=1.0 \mathrm{~m} / \mathrm{kg}^{1 / 3}$ using a $250 \mathrm{~kg}$ charge mass 


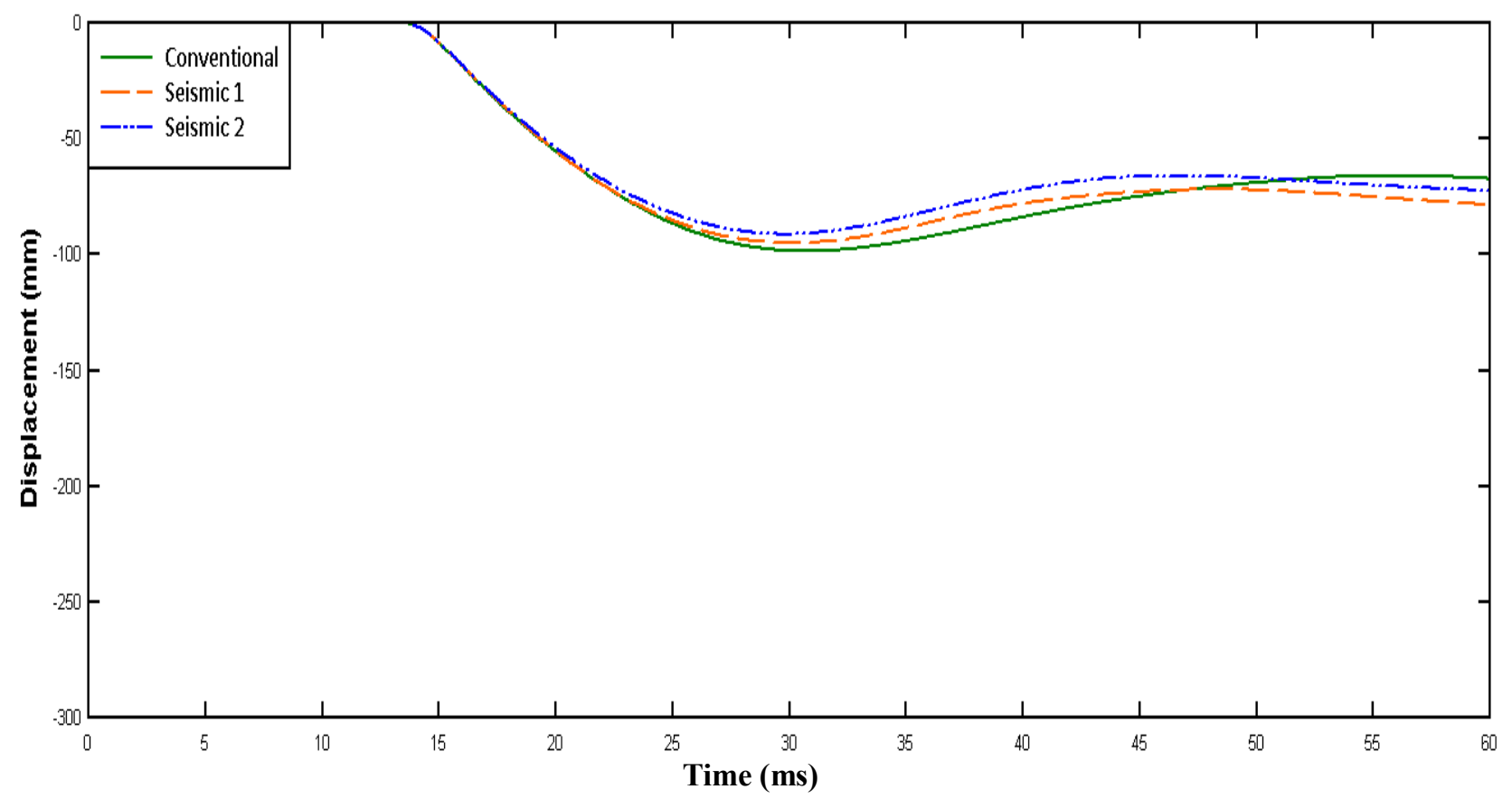

Figure 6-15: Displacement Time History at $\mathrm{z}=1.0 \mathrm{~m} / \mathrm{kg}^{1 / 3}$ using a $500 \mathrm{~kg}$ charge mass

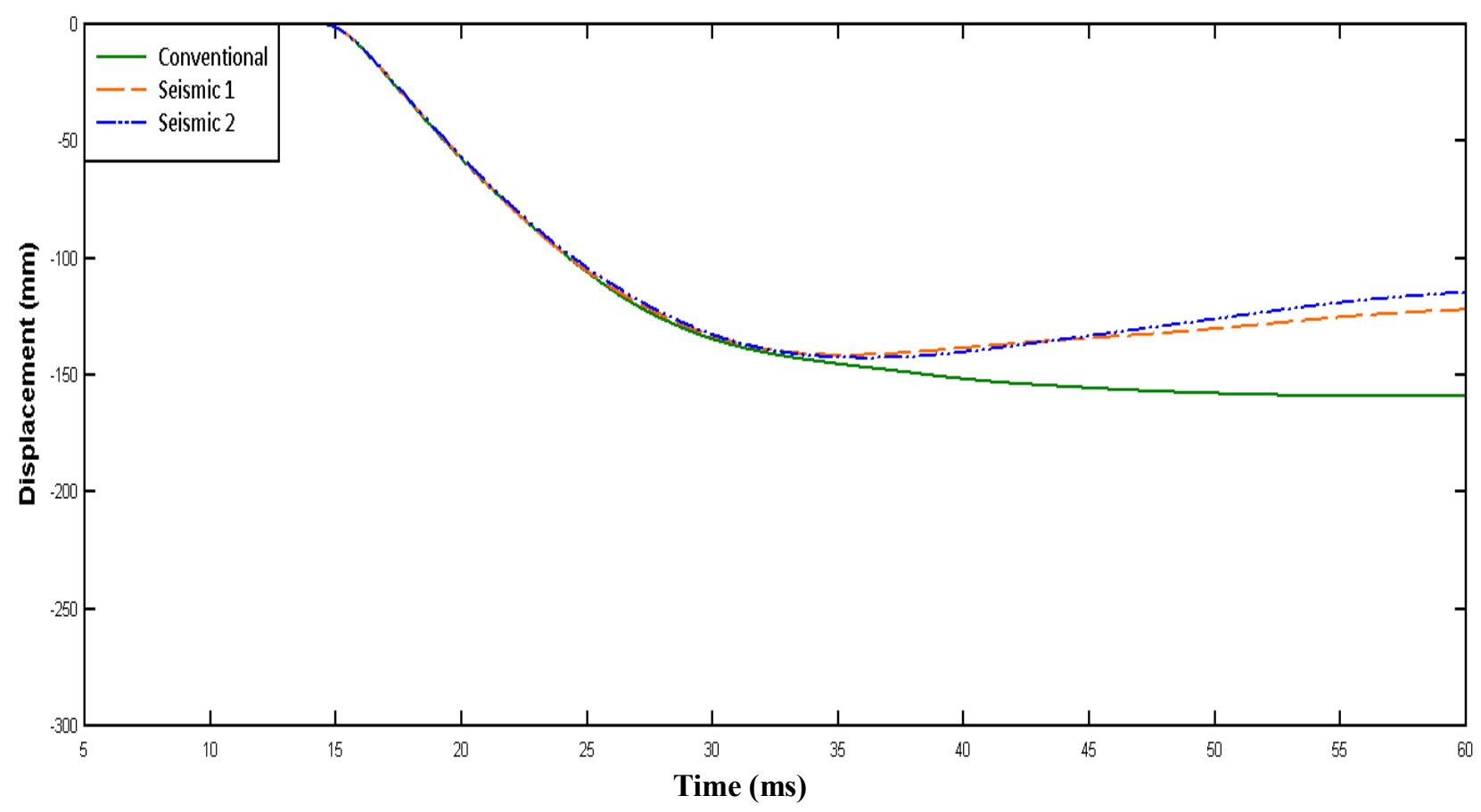

Figure 6-16: Displacement Time History at $z=1.0 \mathrm{~m} / \mathrm{kg}^{1 / 3}$ using a $1000 \mathrm{~kg}$ charge mass 


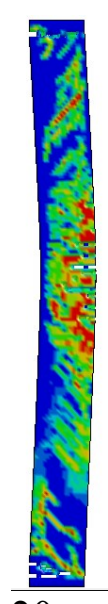

$20 \mathrm{~ms}$

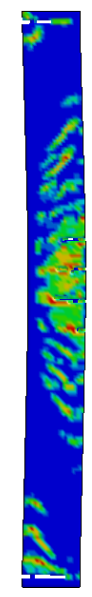

$20 \mathrm{~ms}$

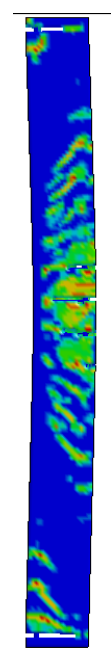

$20 \mathrm{~ms}$

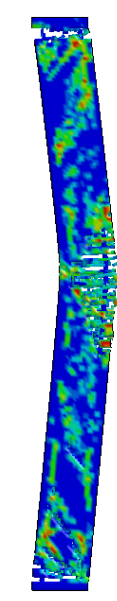

$40 \mathrm{~ms}$

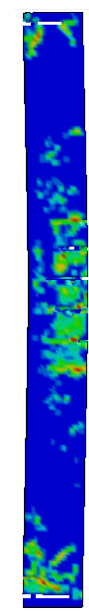

$40 \mathrm{~ms}$

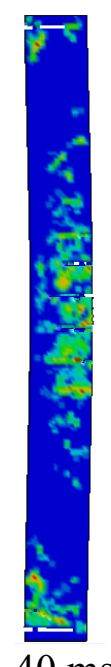

$40 \mathrm{~ms}$

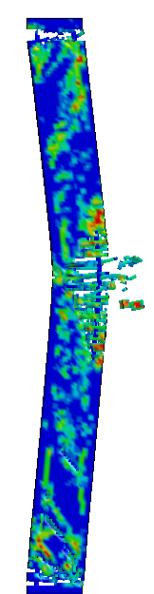

$60 \mathrm{~ms}$

(b) Seismic 1

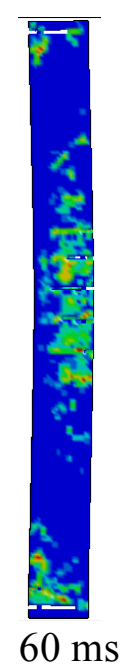

(c) Seismic 2

Figure 6-17: Damage profile columns under $1000 \mathrm{~kg}$ charge mass, $z=1.0 \mathrm{~m} / \mathrm{kg}^{1 / 3}$ 
Table 6-7: Summary of the maximum displacements and corresponding rotations for the scaled distance of $1.0 \mathrm{~m} / \mathrm{kg}^{1 / 3}$ using different charge masses

\begin{tabular}{|c|c|c|c|c|c|c|}
\hline & \multicolumn{2}{|c|}{ Conventional } & \multicolumn{2}{c|}{ Seismic 1 } & \multicolumn{2}{c|}{ Seismic 2 } \\
\hline Charge Mass & Displacement & Rotation & Displacement & Rotation & Displacement & Rotation \\
$(\mathbf{k g})$ & $(\mathbf{m m})$ & $\left(^{\circ}\right)$ & $(\mathbf{m m})$ & $\left.{ }^{\circ}\right)$ & $(\mathbf{m m})$ & $\left(^{\circ}\right)$ \\
\hline 100 & 37.1 & 1.8 & 36.0 & 1.7 & 33.0 & 1.6 \\
\hline 250 & 63.1 & 3.0 & 62.4 & 3.0 & 59.0 & 2.8 \\
\hline 500 & 98.6 & 4.7 & 94.7 & 4.5 & 90.8 & 4.3 \\
\hline 1000 & 158.3 & 7.5 & 141.5 & 6.7 & 141.2 & 6.7 \\
\hline
\end{tabular}

Table 6-7 presents the maximum displacements recorded for the three different RC column types at a scaled distance of $1.0 \mathrm{~m} / \mathrm{kg}^{1 / 3}$ and with no axial load ratios acting on the columns.

The increase in the scaled distance from 0.8 to $1.0 \mathrm{~m} / \mathrm{kg}^{1 / 3}$, showed a diminished effect of transverse reinforcement detailing on the response of the columns to blast loading. At the higher scaled distance where the response of the column is more flexural with less column spall and scabbing due to shock even at high charge mass magnitudes, as can be seen in Figure 6-17, the response is dependent on the effective stiffness of columns. The effective stiffness of the columns is dependent on the transformed section properties of the concrete column which remains the same irrespective of the transverse reinforcement detailing. When the concrete column is exposed to shock loading from close-in explosions, smaller scaled distance, the conventional concrete columns have more spalling and scabbing than the seismically detailed RC columns. Thus the closely spaced transverse reinforcements in the seismically detailed columns 
provide more confinement and thus the seismic columns have higher effective stiffness and lower lateral displacements as is observed from Table 6-6 and Table 6-7.

\subsubsection{Scaled distance of $1.5 \mathrm{~m} / \mathrm{kg}^{1 / 3}$}

Increasing the scaled distance to $1.5 \mathrm{~m} / \mathrm{kg}^{1 / 3}$ resulted in a further decrease in the maximum displacements of the three column types in comparison to the corresponding displacements of columns at the scaled distance of $1.0 \mathrm{~m} / \mathrm{kg}^{1 / 3}$. Interestingly, the effect of the transverse reinforcement detailing was almost insignificant even for the $1000-\mathrm{kg}$ charge masses as can be seen in Table 6-8 and Figure 6-18.

Table 6-8: Summary of the maximum displacements and corresponding rotations for the scaled distance of $1.5 \mathrm{~m} / \mathrm{kg}^{1 / 3}$ using different charge masses and an axial load ratio of 0.0

\begin{tabular}{|c|c|c|c|c|c|c|}
\hline & \multicolumn{2}{|c|}{ Conventional } & \multicolumn{2}{c|}{ Seismic 1 } & \multicolumn{2}{c|}{ Seismic 2 } \\
\hline Charge Mass & Displacement & Rotation & Displacement & Rotation & Displacement & Rotation \\
$(\mathbf{k g})$ & $(\mathbf{m m})$ & $\left(^{\circ}\right)$ & $(\mathbf{m m})$ & $\left.{ }^{\circ}\right)$ & $(\mathbf{m m})$ & $\left(^{\circ}\right)$ \\
\hline 100 & 12.0 & 0.6 & 12.1 & 0.6 & 11.2 & 0.5 \\
\hline 250 & 18.6 & 0.9 & 18.8 & 0.9 & 17.4 & 0.8 \\
\hline 500 & 27.9 & 1.3 & 27.8 & 1.3 & 25.1 & 1.2 \\
\hline 1000 & 41.2 & 2.0 & 40.2 & 1.9 & 35.9 & 1.7 \\
\hline
\end{tabular}

Figure 6-18 shows the damage profile of the three column types under blast loading from a 1000 $\mathrm{kg}$ charge mass at a scaled distance of $1.5 \mathrm{~m} / \mathrm{kg}^{1 / 3}$. Even at such a high magnitude charge, the tension region of the column shows minimal damage, with only a few visible flexural cracks. 

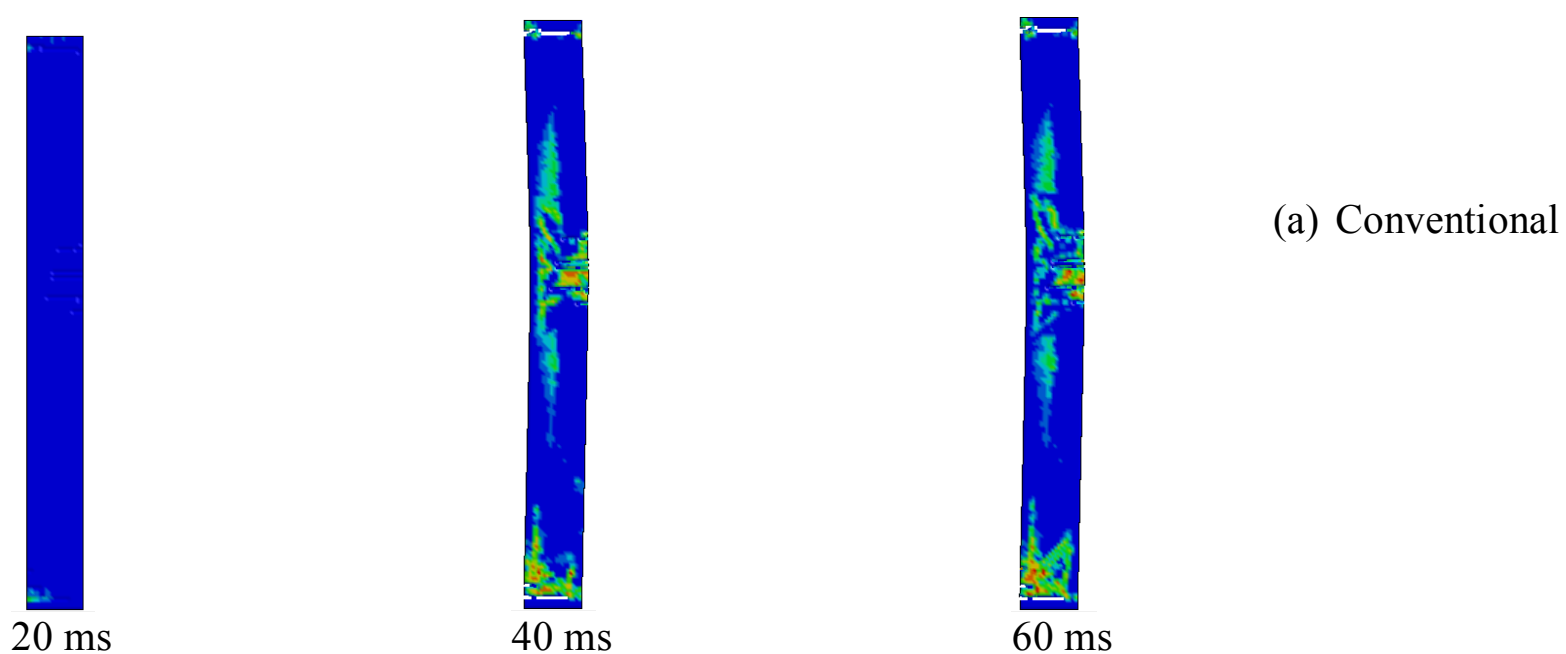

$20 \mathrm{~ms}$

$40 \mathrm{~ms}$

$60 \mathrm{~ms}$
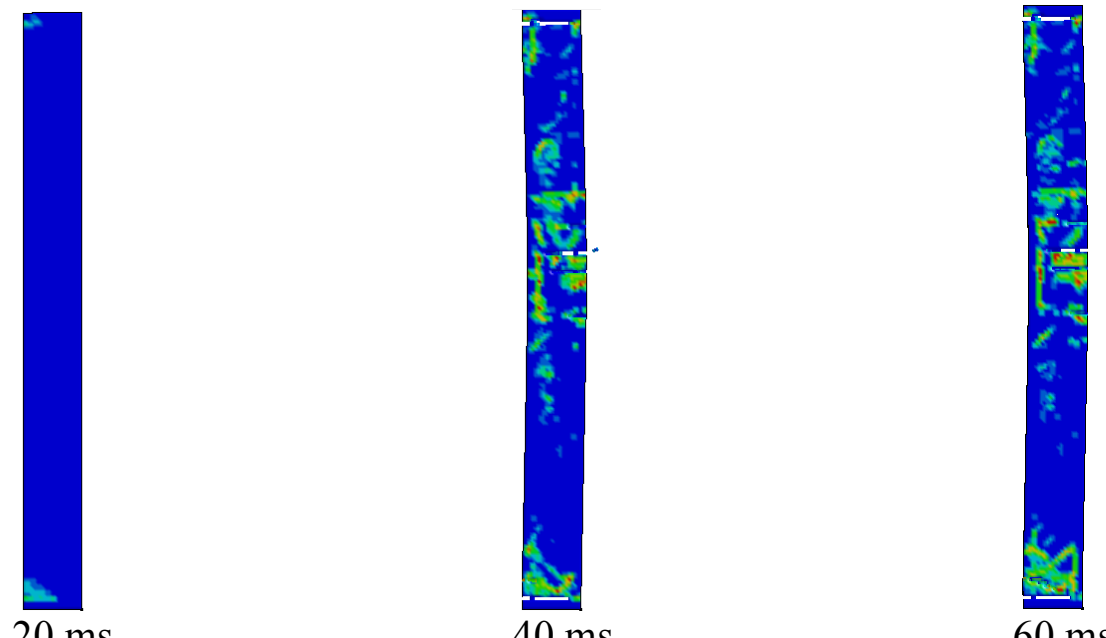

$20 \mathrm{~ms}$

$40 \mathrm{~ms}$

$60 \mathrm{~ms}$
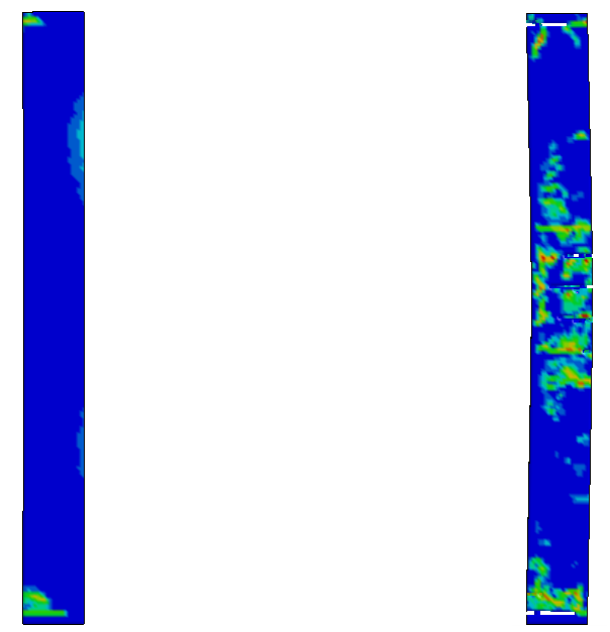

$20 \mathrm{~ms}$

$40 \mathrm{~ms}$

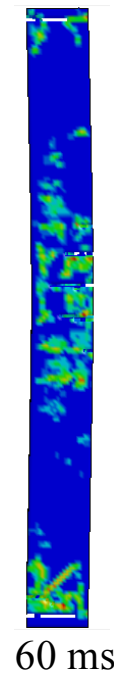

(b) Seismic 1

(c) Seismic 2

Figure 6-18: Damage profile columns under $1000 \mathrm{~kg}$ charge mass, $\mathrm{z}=1.5 \mathrm{~m} / \mathrm{kg}^{1 / 3}$ 
The effect of the transverse reinforcement on the performance of the $\mathrm{RC}$ columns under blast loading can be summarized as follows:

- At smaller scaled distances, the seismically detailed RC columns recorded much more reduced lateral displacements than the conventionally detailed columns with increasing charge mass magnitudes. The conventional columns suffer significant spalling and scabbing in comparison to the seismically detailed columns. The seismic columns are, thus, able to provide more confinement for the concrete core resulting in higher stiffness and lower lateral displacements.

- At higher scaled distances, column response tends to be more flexural for all column types. The concrete core remains much more intact with less column spall and scabbing. This resulted in the transverse detailing offering little or no significant improvement in reducing the lateral displacement in the seismically detailed columns over the conventionally detailed columns.

\subsection{Effect of axial load ratios on the performance of the RC columns}

The effect of axial loading on the RC columns was investigated at scaled distances of $0.8 \mathrm{~m} / \mathrm{kg}^{1 / 3}$ and $1.0 \mathrm{~m} / \mathrm{kg}^{1 / 3}$. The three different $\mathrm{RC}$ column types were subjected to $100-\mathrm{kg}$ and $250-\mathrm{kg}$ charge masses, at various scaled distances, while the RC columns were simultaneously subjected to different axial load ratios of $0.0,0.1,0.2$ and 0.35 . 


\subsubsection{Scaled distance of $0.8 \mathrm{~m} / \mathrm{kg}^{1 / 3}$}

\subsubsection{1 $100 \mathrm{~kg}$ Charge Mass}

\subsection{Conventionally detailed Column}

Figure 6-19 shows the displacement-time history plots for the conventionally detailed RC column subjected to blast loading from a $100-\mathrm{kg}$ charge mass at a scaled distance of $0.8 \mathrm{~m} / \mathrm{kg}^{1 / 3}$. From Figure 6-19 the maximum displacement is observed to reduce from about $70.2 \mathrm{~mm}$ to 49.7 $\mathrm{mm}$ and then to $44.5 \mathrm{~mm}$ as the ALR values increased from 0.0 through 0.1 to 0.2 respectively. At the ALR of 0.2, the conventional RC column experienced further increase in stiffness resulting in further reduction in the lateral deflection until the combined effect of the lateral blast loading and the axially applied load caused crushing of the concrete in compression and subsequent buckling of the longitudinal reinforcing bars.

Figure 6-20 shows the damage sustained by the RC column under the combined blast and axial loading on the column after 60 milliseconds. From Figure 6-20, the crushing and loss of concrete cover in the mid-region resulted in the loss of the confinement provided by the transverse reinforcing bars leading to the buckling of the longitudinal reinforcing bars. A similar damage trend was observed under an ALR of 0.35 . 


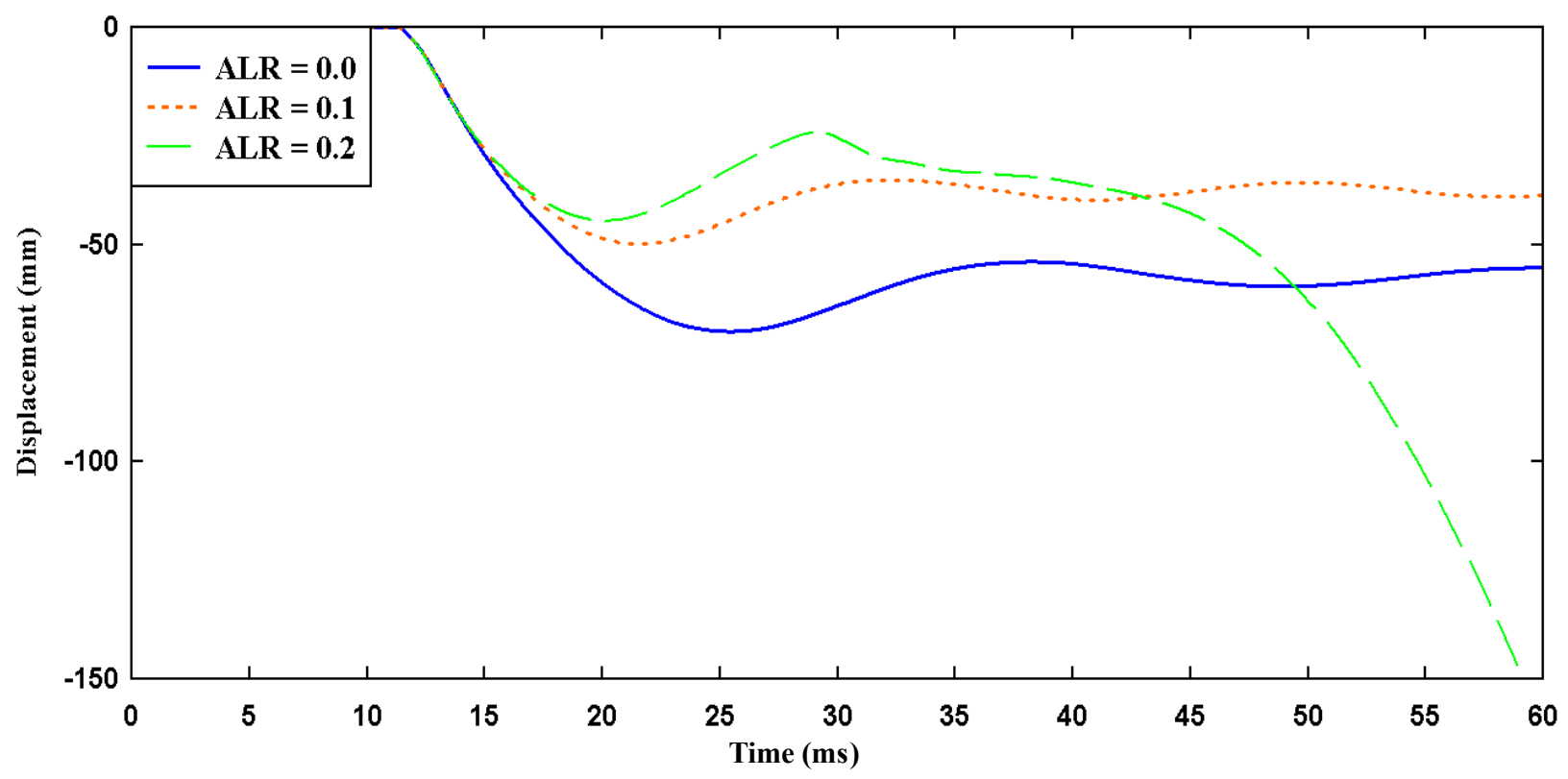

Figure 6-19: Displacement time history plot for a conventionally detailed $\mathrm{RC}$ column at $\mathrm{z}=\mathbf{0 . 8}$ $\mathrm{m} / \mathrm{kg}^{1 / 3}$ using a $100 \mathrm{~kg}$ charge mass at different ALRs

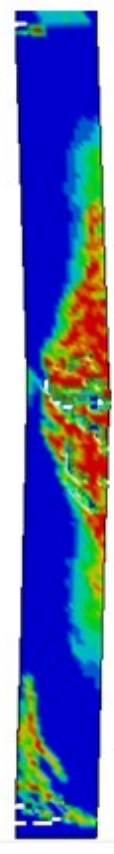

$20 \mathrm{~ms}$

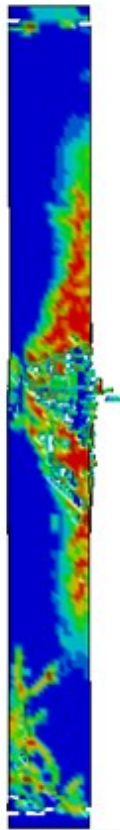

$40 \mathrm{~ms}$

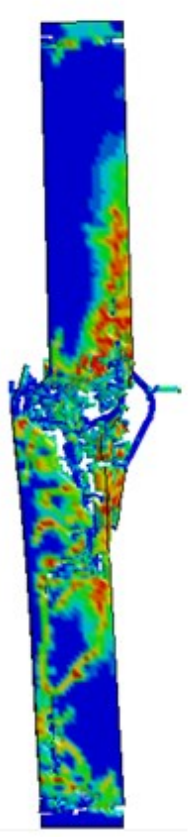

$$
\begin{gathered}
\text { Fringe Levels } \\
9.990 \mathrm{e}-01 \\
8.991 \mathrm{e}-01 \\
7.992 \mathrm{e}-01 \\
6.993 \mathrm{e}-01 \\
5.994 \mathrm{e}-01 \\
4.995 \mathrm{e}-01 \\
3.996 \mathrm{e}-01 \\
2.997 \mathrm{e}-01 \\
1.998 \mathrm{e}-01 \\
9.990 \mathrm{e}-02 \\
0.000 \mathrm{e}+00
\end{gathered}
$$

Figure 6-20 Damage profile of conventional column under a blast load from a $100 \mathrm{~kg}$ charge mass

$$
\text { at } \mathrm{z}=0.8 \mathrm{~m} / \mathrm{kg}^{1 / 3}, \mathrm{ALR}=0.2
$$




\subsection{Seismic 1 Detailing}

Figure 6-21 shows the displacement-time history plots for the RC column with seismic 1 detailing subjected to blast loading from a $100-\mathrm{kg}$ charge mass at a scaled distance of $0.8 \mathrm{~m} / \mathrm{kg}^{1 / 3}$. From Figure 6-21, an increase in the ALR results in an increased stiffness with a corresponding decrease in the lateral deflection of the RC column. The maximum displacements recorded after a 60 -millisecond simulation were $65.2 \mathrm{~mm}, 48.4 \mathrm{~mm}, 39.5 \mathrm{~mm}$ and $31.8 \mathrm{~mm}$ corresponding to the ALR values of $0.0,0.1,0.2$, and 0.35 respectively. The higher ALRs of 0.2 and 0.35 values, at which the conventionally detailed column failed by concrete crushing and buckling of longitudinal reinforcement, did not cause failure of the RC column with seismic 1 detailing as can be seen in Figure 6-22. At the higher ALR values of 0.2 and 0.35, the damage to the concrete cover was not significant to expose the concrete core. With no crushing of the concrete in compression, the transverse bars provided the needed lateral support for the longitudinal bars.

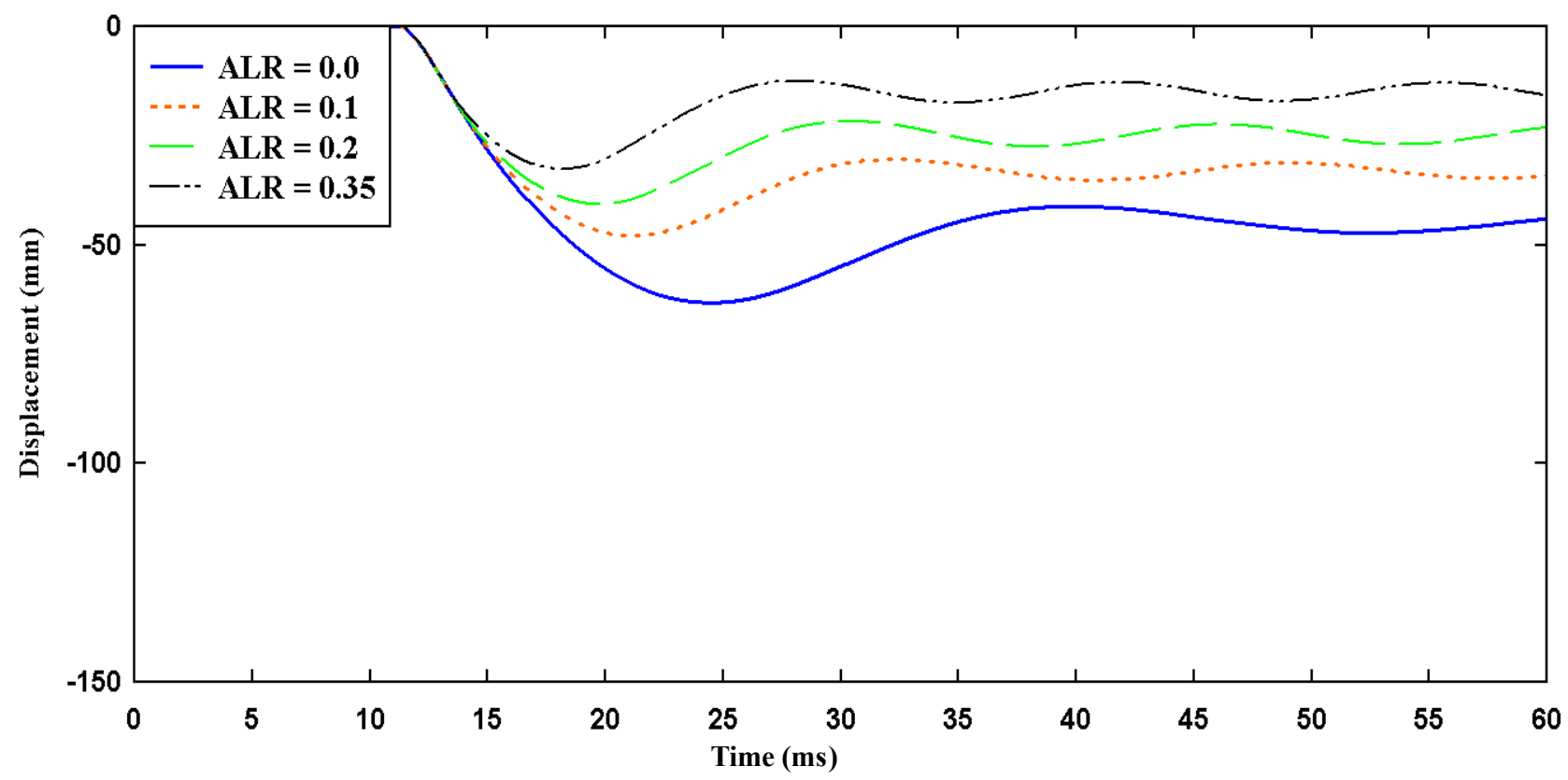

Figure 6-21: Displacement time history plot for RC column with seismic 1 detailing at $\mathrm{z}=0.8$ $\mathrm{m} / \mathrm{kg}^{1 / 3}$ using a $100 \mathrm{~kg}$ charge mass at different ALRs 


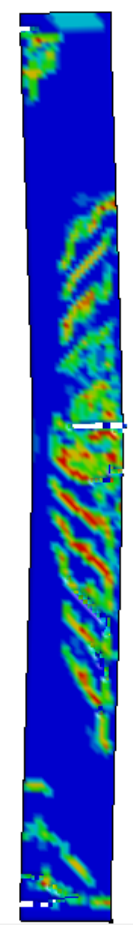

$20 \mathrm{~ms}$

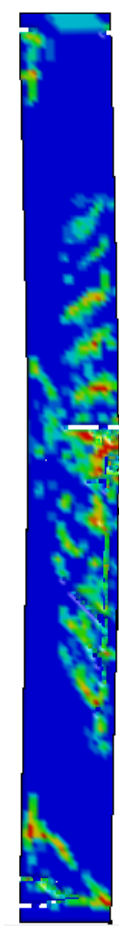

$40 \mathrm{~ms}$

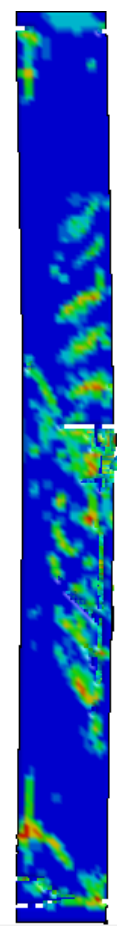

Fringe Levels 9.990e-01 $8.991 \mathrm{e}-01$ $7.992 \mathrm{e}-01$ 6.993e-01 _ 5.994e-01 4.995e-01 $3.996 \mathrm{e}-01$ $2.997 e-01$ $1.998 \mathrm{e}-01$ $9.990 \mathrm{e}-02$ $0.000 \mathrm{e}+00$

Figure 6-22: Damage profile of seismic 1 column under a blast load from a $100 \mathrm{~kg}$ charge mass at $\mathrm{z}$

$$
=0.8 \mathrm{~m} / \mathrm{kg} 1 / 3, \mathrm{ALR}=0.2
$$

\subsection{Seismic 2 Detailing}

The RC column with seismic 2 detailing behaved in a very similar manner to the RC column with seismic 1 detailing. Figure 6-23 shows the displacement-time history plots for the RC column with seismic 2 detailing subjected to blast loading from a $100-\mathrm{kg}$ charge mass at a scaled distance of $0.8 . \mathrm{m} / \mathrm{kg}^{1 / 3}$. The maximum displacements recorded were $63.1 \mathrm{~mm}, 47.8 \mathrm{~mm}, 39.7$ $\mathrm{mm}$ and $32.1 \mathrm{~mm}$ corresponding to the ALR values of $0.0,0.1,0.2$, and 0.35 respectively. 


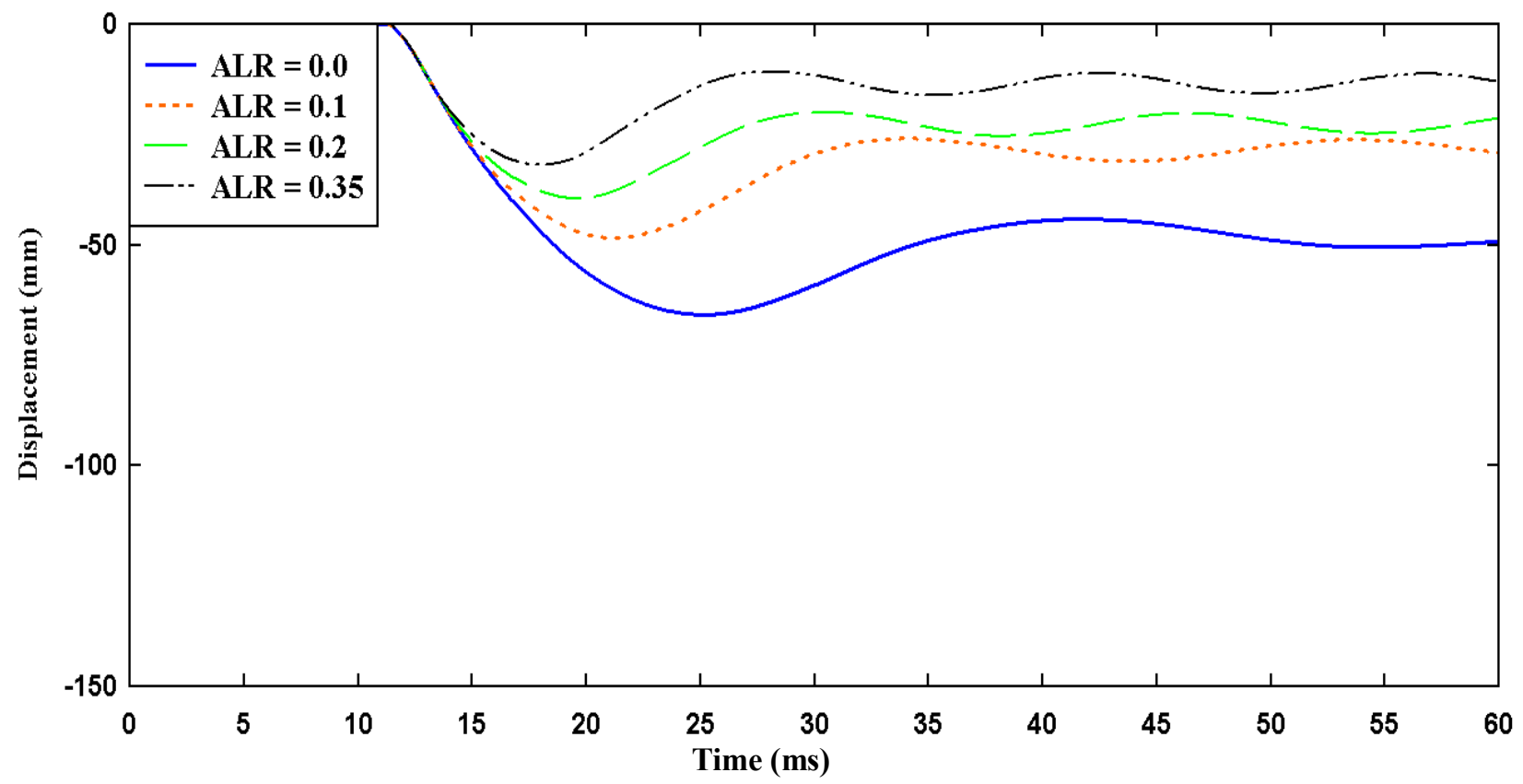

Figure 6-23: Displacement time history plot for $\mathrm{RC}$ column with seismic 2 detailing at $\mathrm{z}=0.8$ $\mathrm{m} / \mathrm{kg}^{1 / 3}$ using a $100 \mathrm{~kg}$ charge mass at different ALRs
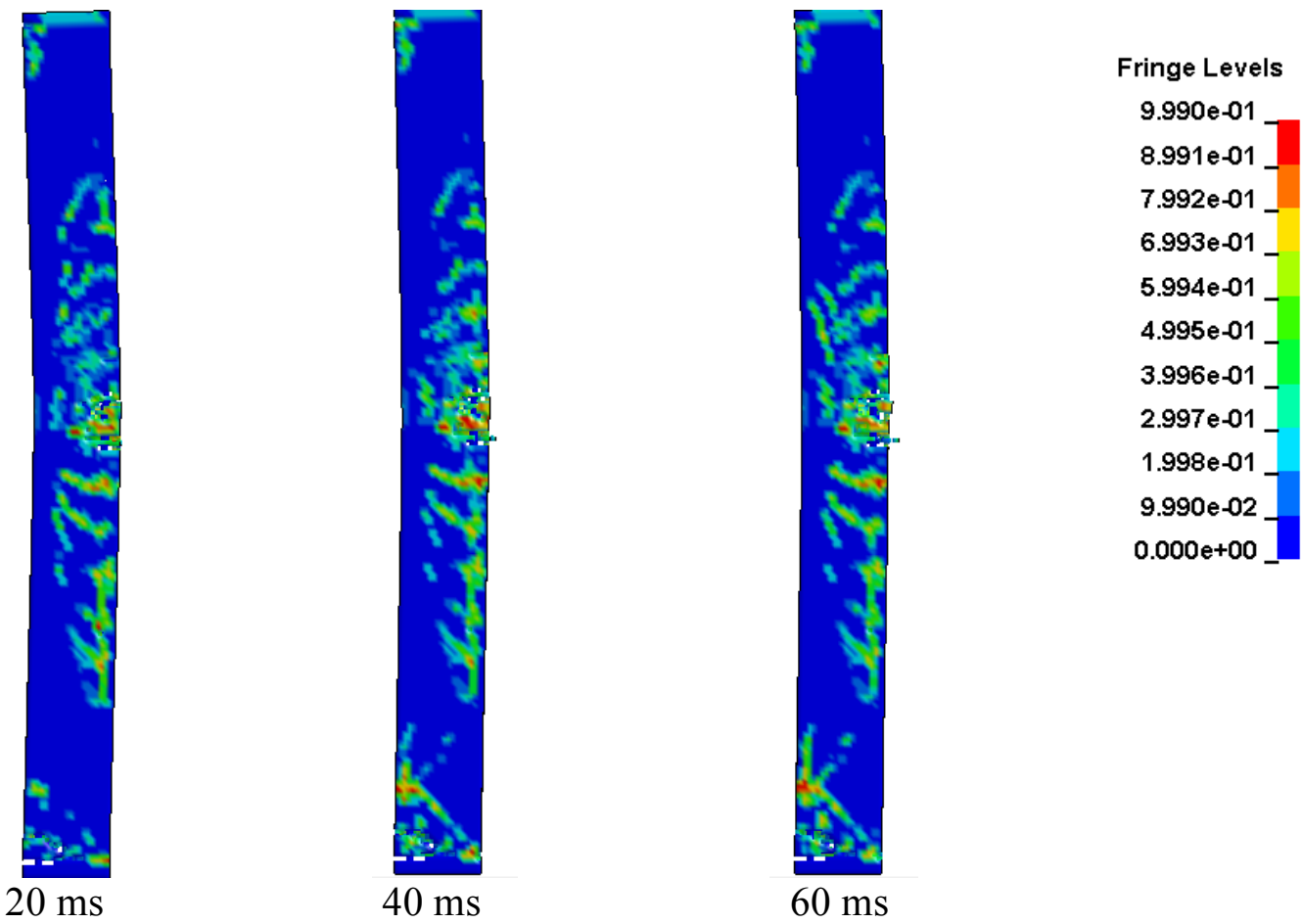

Figure 6-24: Damage profile of seismic 2 column under a blast load from a $100 \mathrm{~kg}$ charge mass at $\mathrm{z}=0.8$ $\mathrm{m} / \mathrm{kg} 1 / 3, \operatorname{ALR}=0.2$ 
Figure 6-24 shows the damage profile of the seismic 2. A comparison of damage profiles of the seismic 1 (Figure 6-22) and seismic 2 (Figure 6-24) columns show marginal or no significant differences.

\subsubsection{2 $250 \mathrm{~kg}$ Charge Mass}

\subsection{Conventionally detailed Column}

Figure 6-25 shows the displacement-time history plots for the conventionally detailed RC column subjected to blast loading from a $250-\mathrm{kg}$ charge mass as a $\mathrm{z}$ of $0.8 \mathrm{~m} / \mathrm{kg}^{1 / 3}$. Increasing the charge mass led to failure of the $\mathrm{RC}$ column by concrete crushing and buckling of the longitudinal bars at an ALR of 0.1, lower than was observed for the 100-kg charge mass. Figure 6-26 shows the damage and failure profile of the RC columns. The buckling of the longitudinal bars of the conventionally detailed RC column subjected to an axial load ratio of 0.1 is obvious.

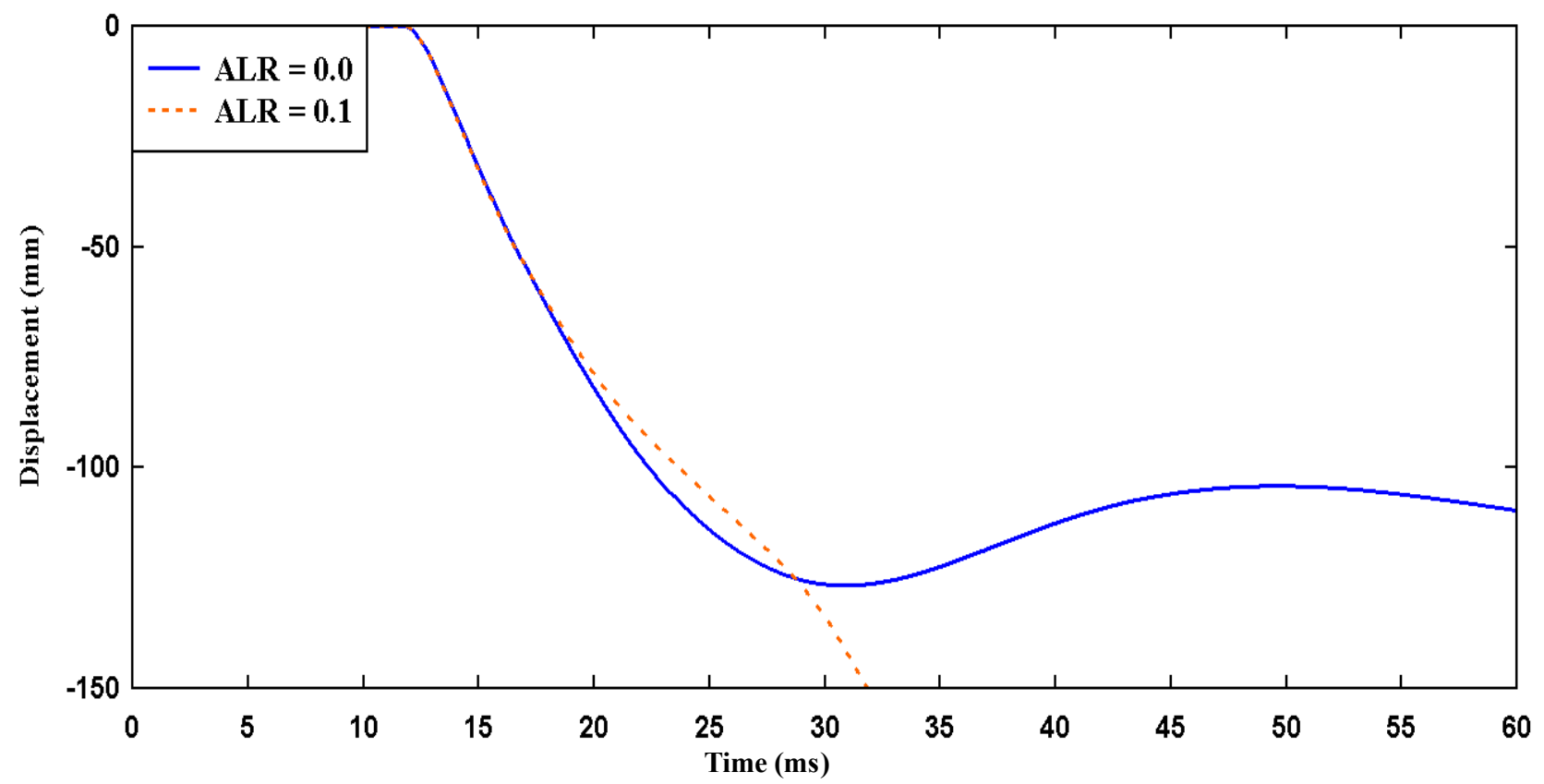

Figure 6-25: Displacement time history plot for a conventionally detailed $\mathrm{RC}$ column at $\mathrm{z}=\mathbf{0 . 8}$ $\mathrm{m} / \mathrm{kg}^{1 / 3}$ using a $250 \mathrm{~kg}$ charge mass at different ALRs 


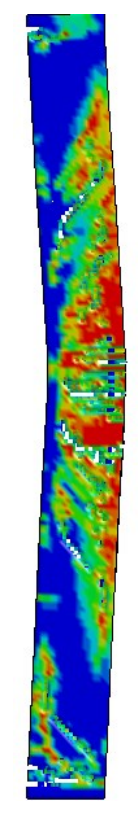

$20 \mathrm{~ms}$

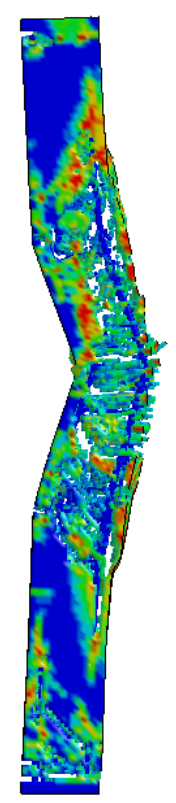

$40 \mathrm{~ms}$

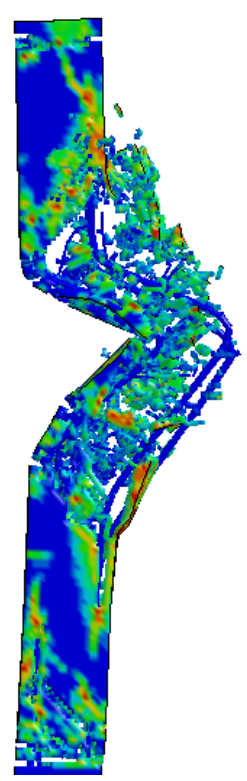

Fringe Levels 9.990e-01 8.991e-01 7.992e-01 $6.993 \mathrm{e}-01$ 5.994e-01 4.995e-01 $3.996 \mathrm{e}-01$ 2.997e-01 $1.998 \mathrm{e}-01$ $9.990 \mathrm{e}-02$ $0.000 e+00$

Figure 6-26: Damage profile for a conventional column under a blast load from a $250 \mathrm{~kg}$ charge

$$
\operatorname{mass} \text { at } \mathrm{z}=0.8 \mathrm{~m} / \mathrm{kg}^{1 / 3}, \mathrm{ALR}=0.1
$$

\subsection{Seismic 1 Detailing}

The displacement-time history plots for the RC column with seismic 1 detailing subjected to blast loading from a $250-\mathrm{kg}$ charge mass at a scaled distance of $0.8 \mathrm{~m} / \mathrm{kg}^{1 / 3}$ are shown in Figure 6-28. The introduction of increasing ALRs resulted in increased stiffness and decreased lateral displacements similar to the behaviour of the RC column under the $100-\mathrm{kg}$ charge mass as is evident in Figure 6-27 and Figure 6-28. Table 6-9 presents the maximum displacements obtained at the various ALR values. The effect of the close tie spacing in the mid-region of the RC column proved effective in providing lateral support for the longitudinal bars when compared to the conventionally detailed RC column under similar loading conditions. 

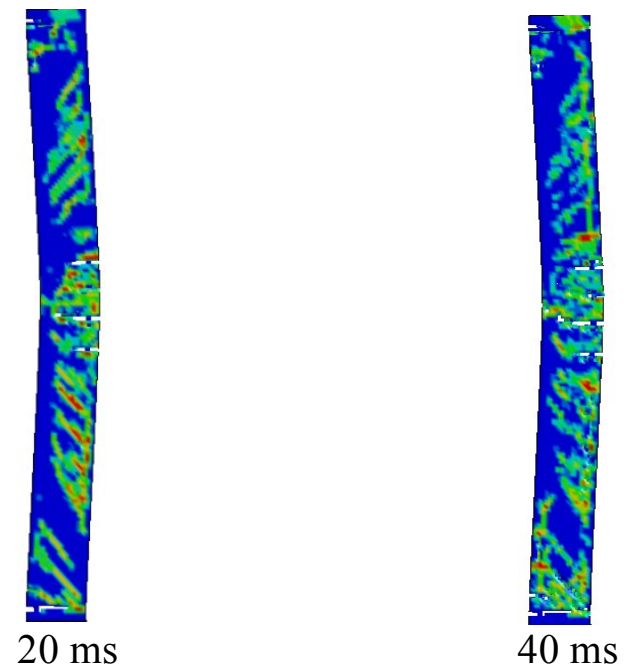

(a) $\mathrm{ALR}=0.1$

$20 \mathrm{~ms}$

$40 \mathrm{~ms}$

$60 \mathrm{~ms}$
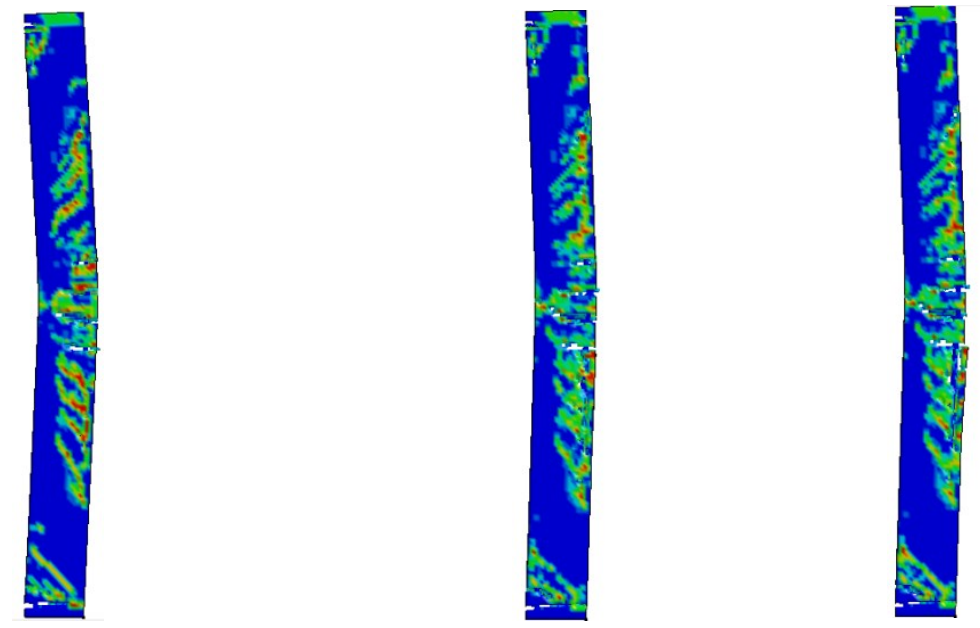

$20 \mathrm{~ms}$

$40 \mathrm{~ms}$

$60 \mathrm{~ms}$
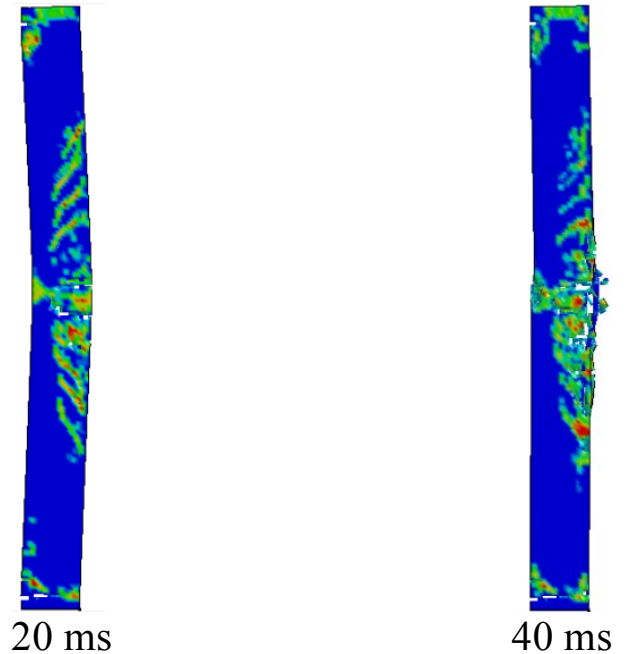

(b) $\mathrm{ALR}=0.2$

(c) $\mathrm{ALR}=0.35$

$20 \mathrm{~ms}$

$40 \mathrm{~ms}$

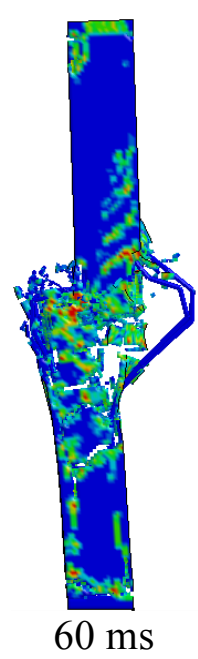

Figure 6-27: Damage profile for a seismic 1 column under a blast load from a $250 \mathrm{~kg}$ charge mass at $\mathrm{Z}=0.8 \mathrm{~m} / \mathrm{kg} 1 / 3$ with varying ALR values 
At a higher ALR of 0.35 , however, the concrete in the mid-region crushed resulting in the buckling of the longitudinal bars at such a high ALR as can be seen in Figure 6-27 (c).

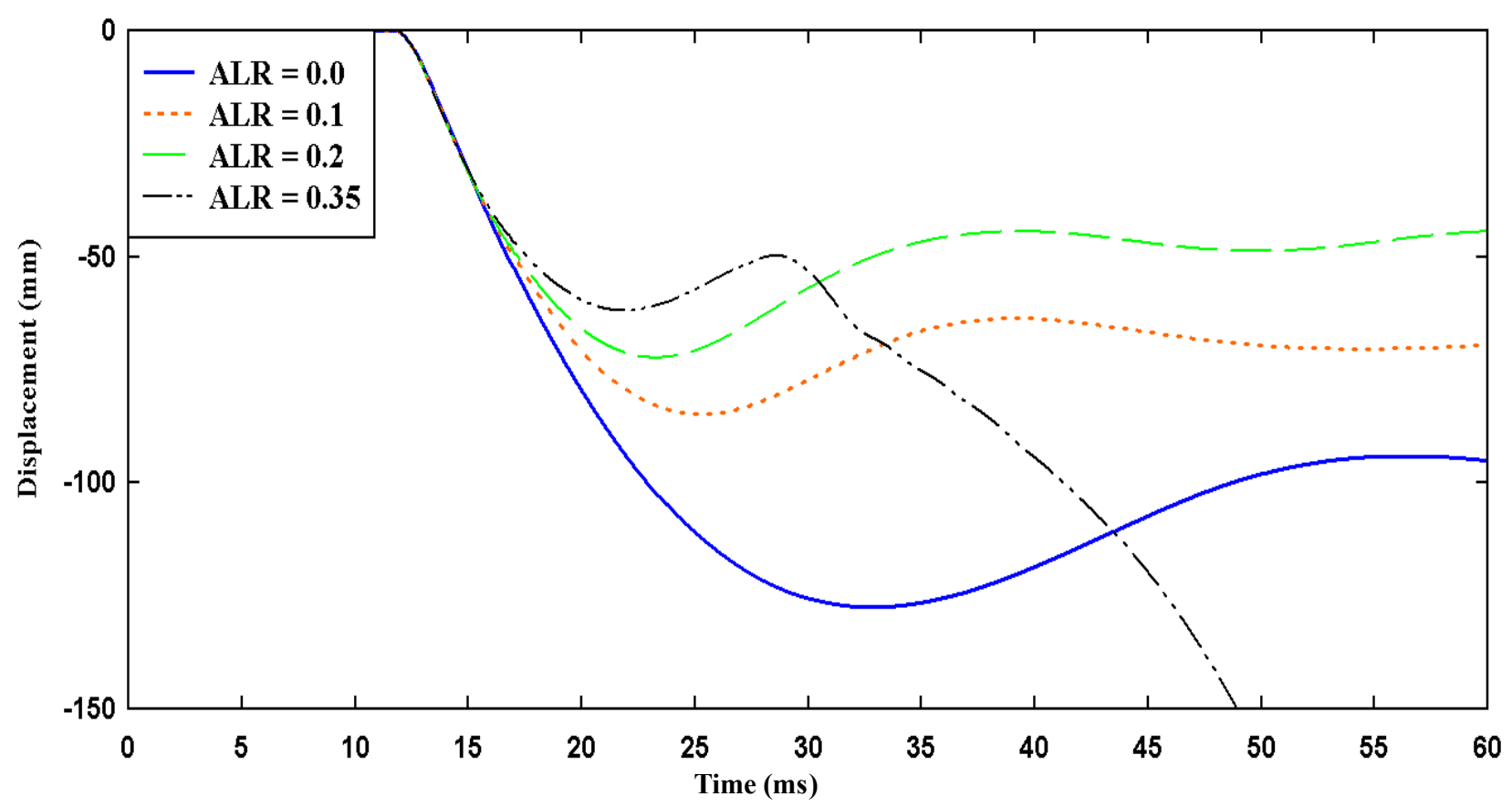

Figure 6-28: Displacement time history plot for RC column with seismic 1 detailing at $\mathrm{z}=0.8$ $\mathrm{m} / \mathrm{kg}^{1 / 3}$ using a $250 \mathrm{~kg}$ charge mass at different ALRs

\subsection{Seismic 2 Detailing}

Figure 6-30 shows the displacement-time history plots for the RC column with seismic 2 detailing subjected to blast loading from a $250-\mathrm{kg}$ charge mass at a scaled distance of $0.8 \mathrm{~m} / \mathrm{kg}^{1 / 3}$. The behaviour of the seismic 2 column was again very similar to the seismic 1 column behaviour (see Figure 6-27 and Figure 6-29). Again at the higher ALR of 0.35, the compressive loading acting on the column resulted in the crushing of compression concrete. The exposed longitudinal reinforcement buckled as the transverse bars were unable to provide the needed lateral support as shown in Figure 6-29 (c). The maximum displacements are summarized in Table 6-9. 

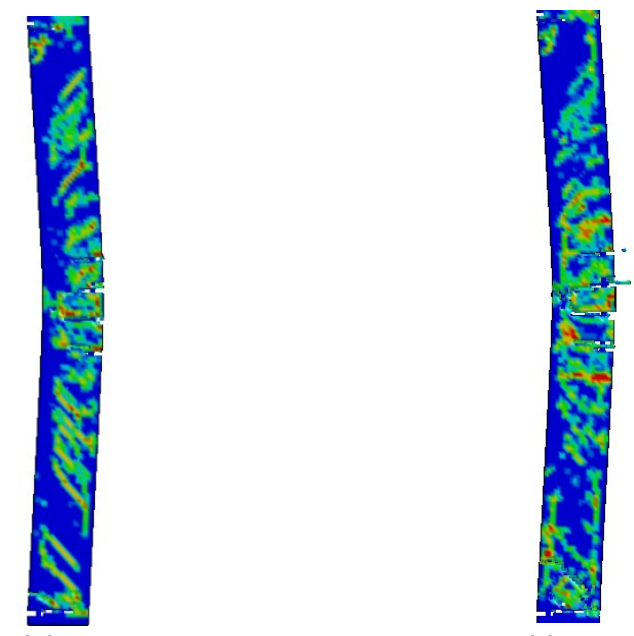

(a) $\operatorname{ALR}=0.1$

$20 \mathrm{~ms}$

$40 \mathrm{~ms}$

$60 \mathrm{~ms}$
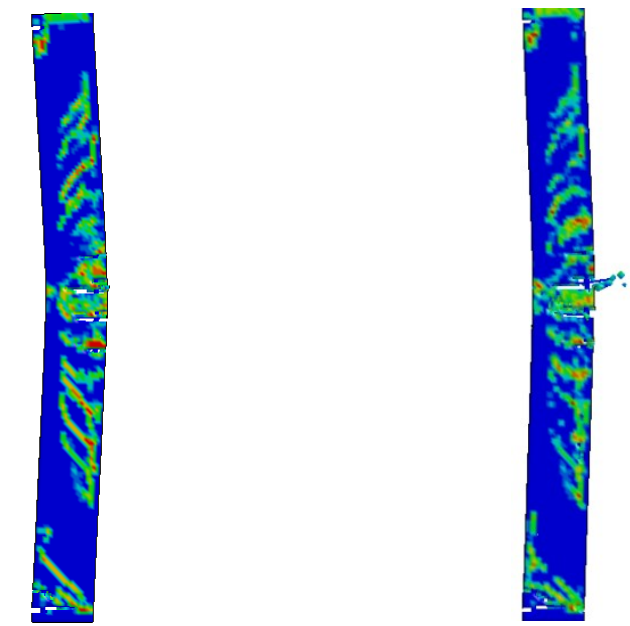

$20 \mathrm{~ms}$

$40 \mathrm{~ms}$
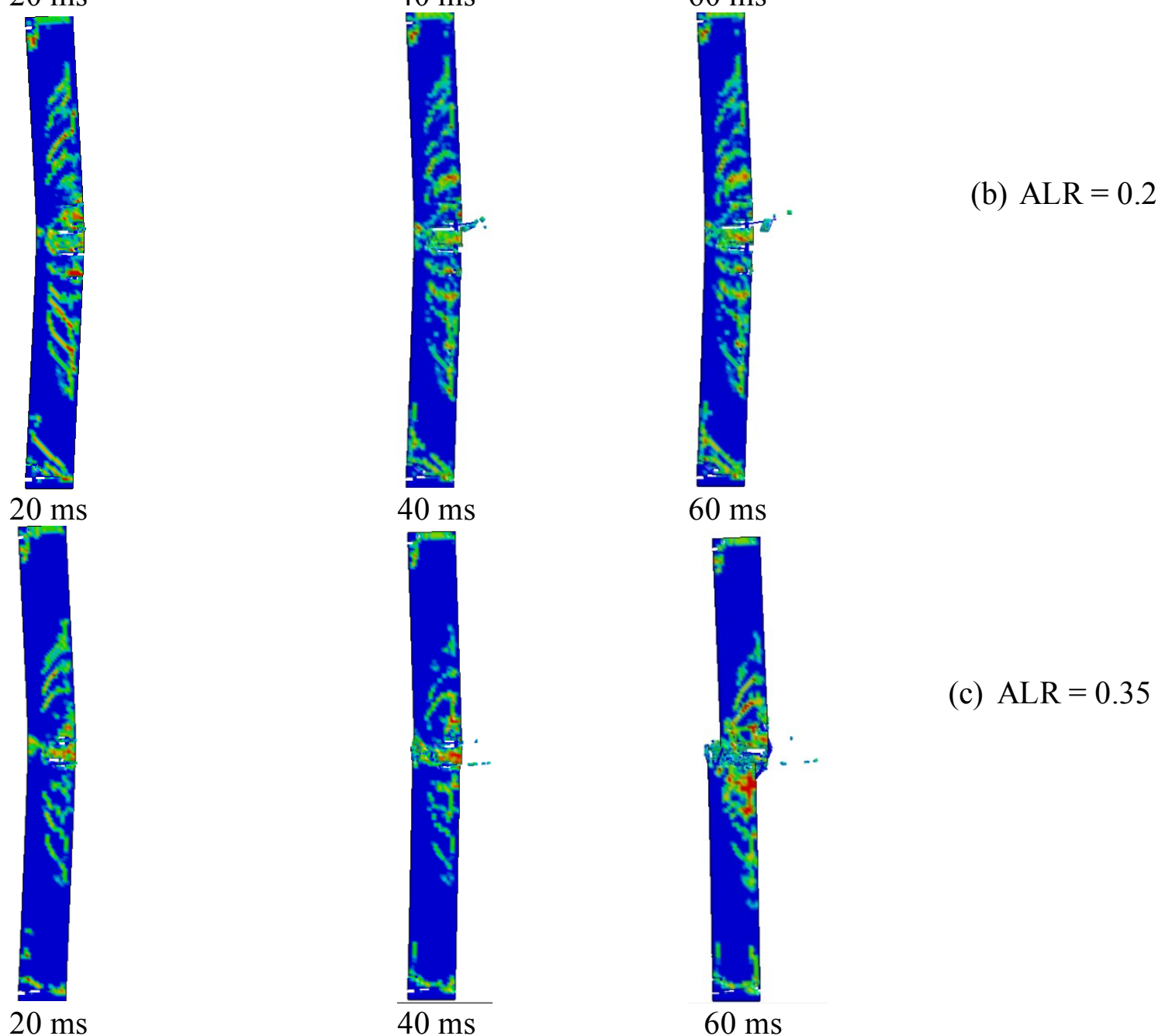

(c) $\mathrm{ALR}=0.35$

$20 \mathrm{~ms}$

$40 \mathrm{~ms}$

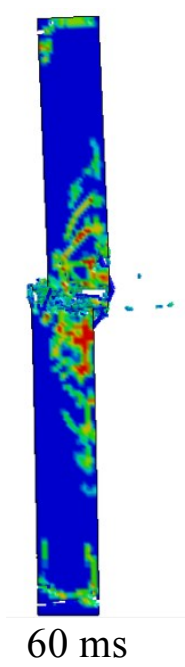

Figure 6-29: Damage profile for a seismic 2 column under a blast load from a $250 \mathrm{~kg}$ charge mass at $\mathrm{z}=0.8 \mathrm{~m} / \mathrm{kg} 1 / 3$ with varying ALR values 


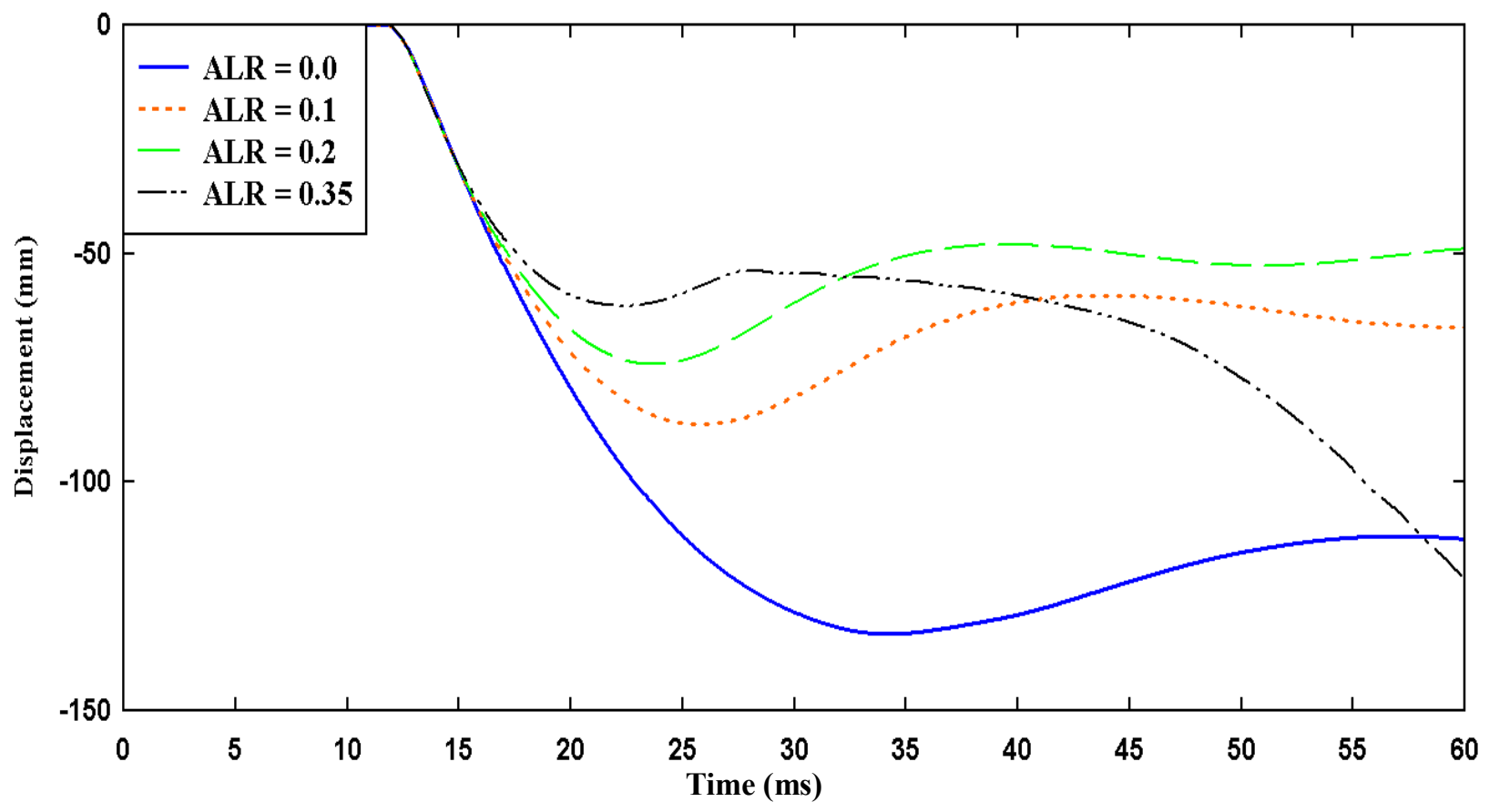

Figure 6-30: Displacement time history plot for $\mathrm{RC}$ column with seismic 2 detailing at $\mathrm{z}=0.8$ $\mathrm{m} / \mathrm{kg}^{1 / 3}$ using a $250 \mathrm{~kg}$ charge mass at different ALRs

Overall, the seismic 2 detailing resulted in reduction in lateral displacements in comparison to the seismic 1 detailing with significantly less displacement the high ALR of 0.35 .

Table 6-9: Summary of displacements for $250 \mathrm{~kg}$ charge mass at $\mathrm{z}=0.8 \mathrm{~m} / \mathrm{kg}^{1 / 3}$

\begin{tabular}{|c|c|c|c|}
\hline \multirow{2}{*}{ Axial Load } & Conventional & Seismic 1 & Seismic 2 \\
\hline 0.0 & 125.6 & 125.6 & 127 \\
\hline 0.1 & $484^{*}$ & 84.1 & 86 \\
\hline 0.2 & - & 72.3 & 74.2 \\
\hline 0.35 & - & $320.2^{*}$ & $121.4^{*}$ \\
\hline
\end{tabular}

*- maximum lateral displacement not attained within simulation time of 60 milliseconds. 


\subsubsection{Scaled distance of 1.0}

To further study the effect of ALR on the performance of the RC columns under far-field blast loading, the three RC column types were modelled for blast loading from explosives at a scaled distance of $1.0 \mathrm{~m} / \mathrm{kg}^{1 / 3}$.

\subsubsection{1 $100 \mathrm{~kg}$ Charge Mass}

All three column detailing types subjected to blast loading from a 100-kg charge mass with varying ALRs of $0.0,0.1,0.2$ and 0.35 showed decreased lateral displacements with increasing axial loading. Figure 6-31 shows the displacement-time history plot for RC column with conventional detailing at $\mathrm{z}=1.0 \mathrm{~m} / \mathrm{kg}^{1 / 3}$ using a $100 \mathrm{~kg}$ charge mass at different ALRs

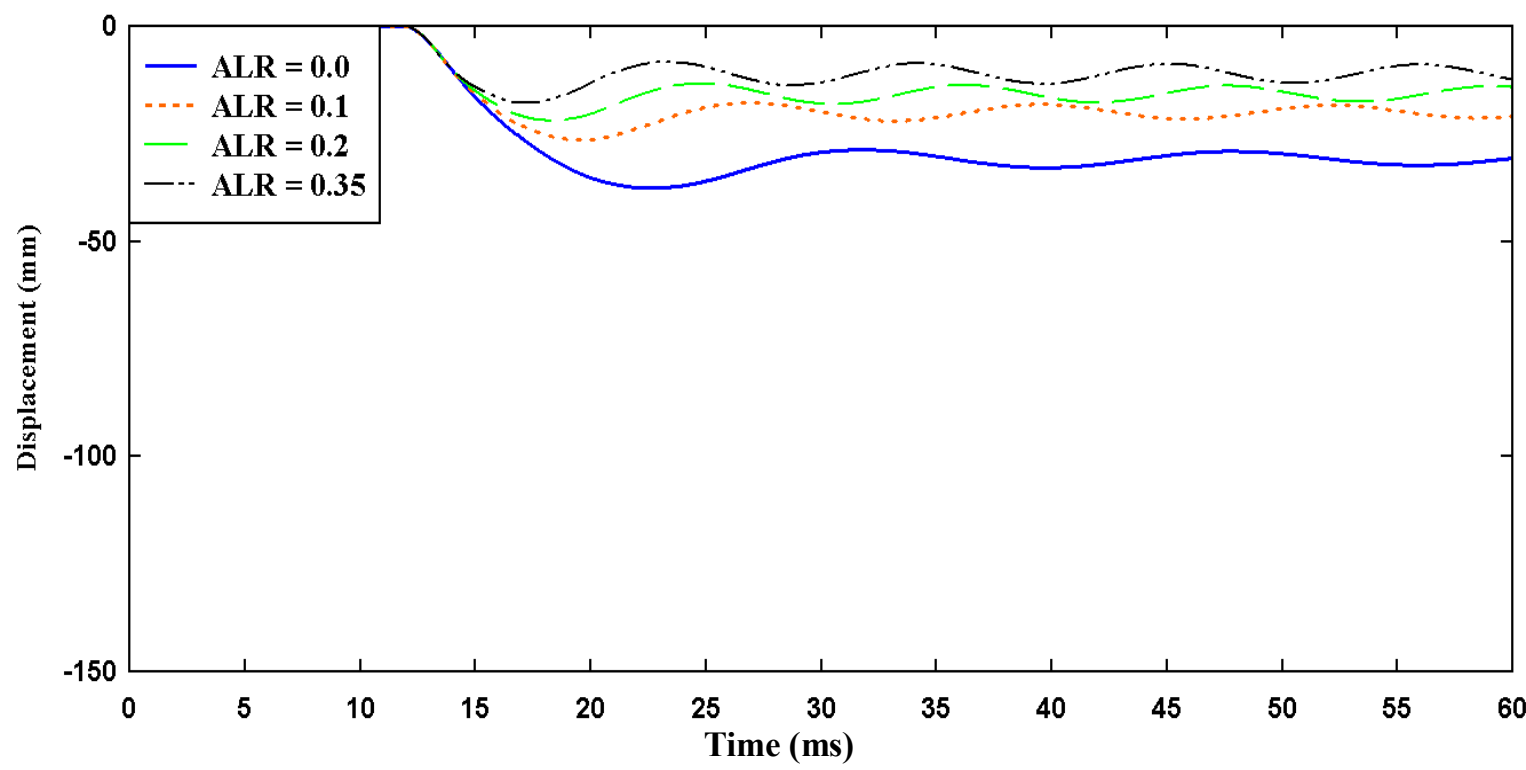

Figure 6-31: Displacement time history plot for a conventionally detailed $\mathrm{RC}$ column at $\mathrm{z}=1.0$ $\mathrm{m} / \mathrm{kg}^{1 / 3}$ using a $100 \mathrm{~kg}$ charge mass at different ALRs 


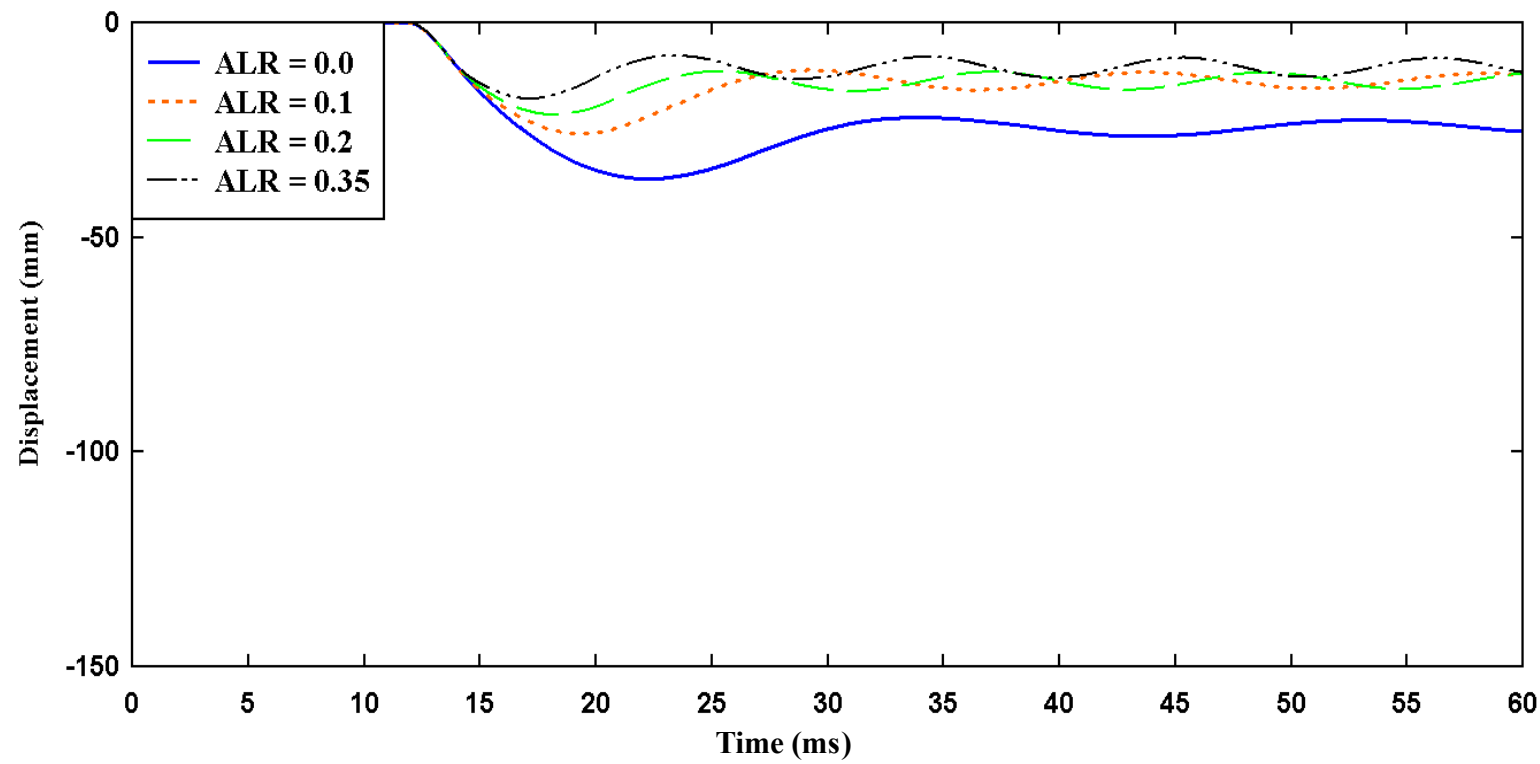

Figure 6-32: Displacement time history plot for $\mathrm{RC}$ column with seismic 1 detailing at $\mathrm{z}=1.0$ $\mathrm{m} / \mathrm{kg}^{1 / 3}$ using a $100 \mathrm{~kg}$ charge mass at different ALRs

Figure 6-32 and Figure 6-33 also show the displacement-time history plots for RC columns with seismic 1 detailing and seismic 2 detailing respectively at $\mathrm{z}=1.0 \mathrm{~m} / \mathrm{kg}^{1 / 3}$ using a $100-\mathrm{kg}$ charge mass at different ALRs. Table 6-10 gives a summary of the recorded maximum displacements for all three column types. As can be seen from Figure 6-34 the increasing ALRs did not lead to concrete crushing and subsequent buckling of the longitudinal bars in the three different detailing schemes as was seen, especially in the conventional columns, at the closer $\mathrm{z}$ of 0.8 . The seismic detailing did not offer any advantage over the conventional detailing. 


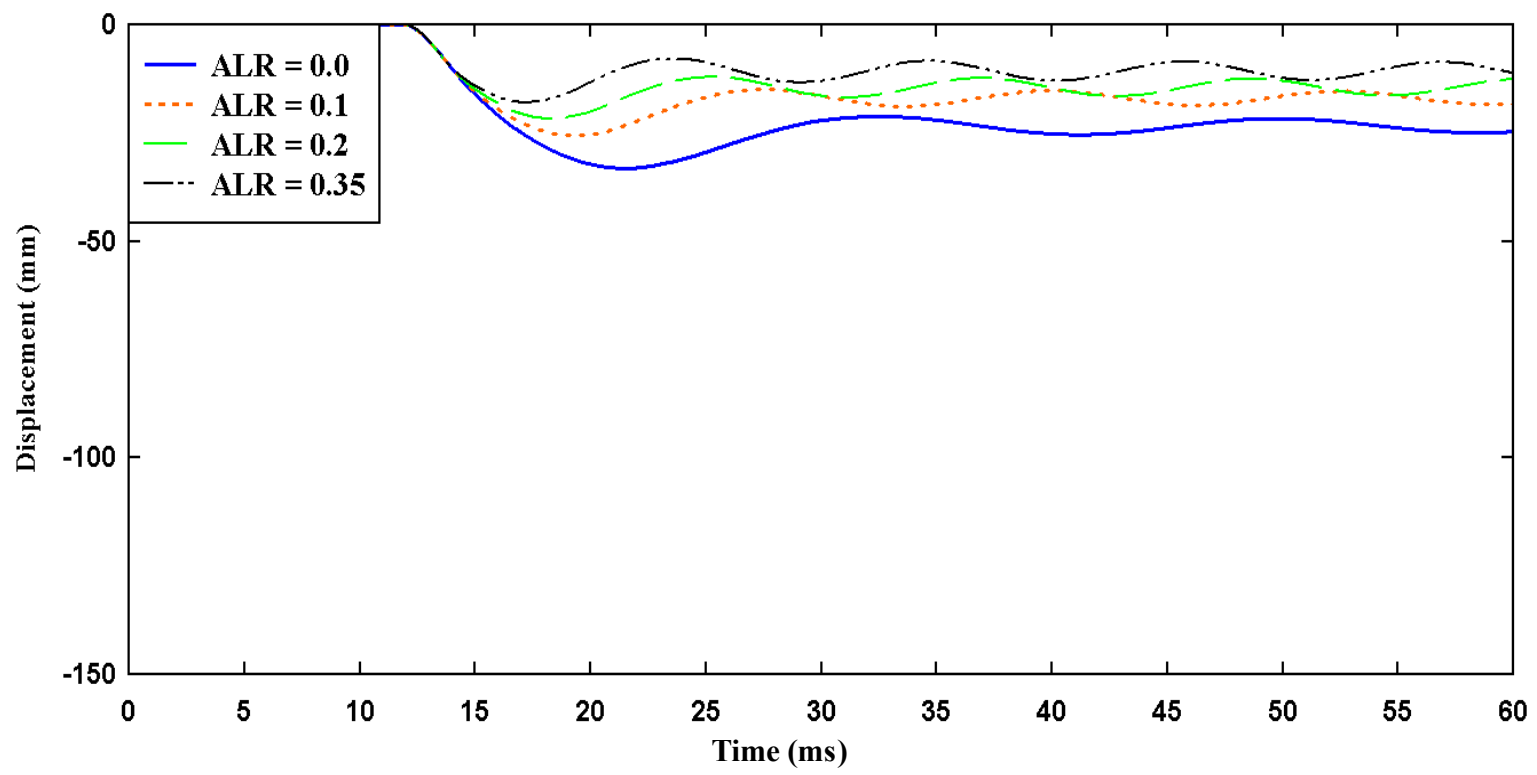

Figure 6-33: Displacement time history plot for $\mathrm{RC}$ column with seismic 2 detailing at $\mathrm{z}=1.0$ $\mathrm{m} / \mathrm{kg}^{1 / 3}$ using a $100 \mathrm{~kg}$ charge mass at different ALRs

Table 6-10: Summary of displacements for $100 \mathrm{~kg}$ charge mass at $\mathrm{z}=1.0 \mathrm{~m} / \mathrm{kg}^{1 / 3}$

\begin{tabular}{|c|c|c|c|}
\hline & Conventional & Seismic 1 & Seismic 2 \\
\hline Ratio & Displacement & Displacement & Displacement \\
\hline 0.0 & 37.6 & 36.7 & 33.1 \\
\hline 0.1 & 26.7 & 26.1 & 26.1 \\
\hline 0.2 & 21.8 & 21.8 & 21.5 \\
\hline 0.35 & 18.2 & 17.7 & 17.8 \\
\hline
\end{tabular}



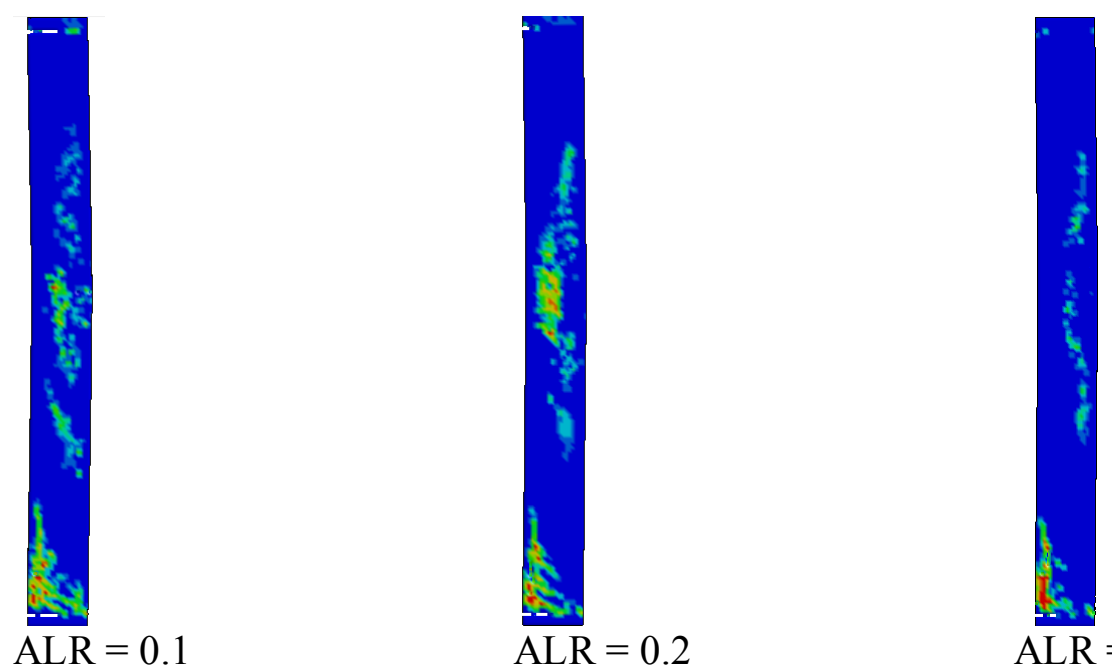

(a) Conventional

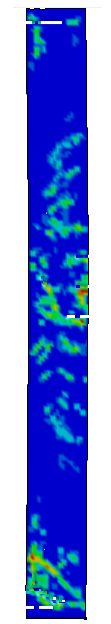

$\mathrm{ALR}=0.2$

$\mathrm{ALR}=0.35$

$\mathrm{ALR}=0.1$
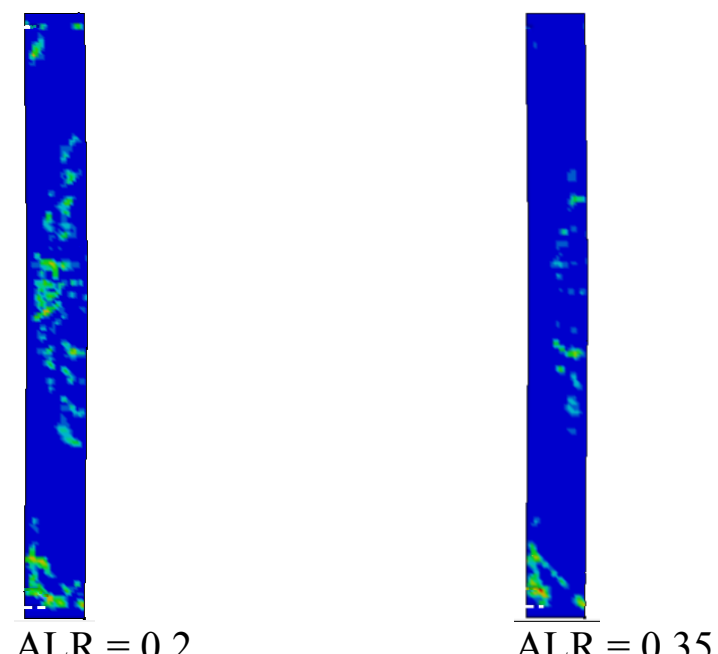

(b) Seismic 1

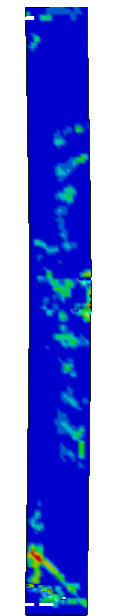

$\mathrm{ALR}=0.2$

$\overline{\mathrm{ALR}}=0.35$

$\mathrm{ALR}=0.1$
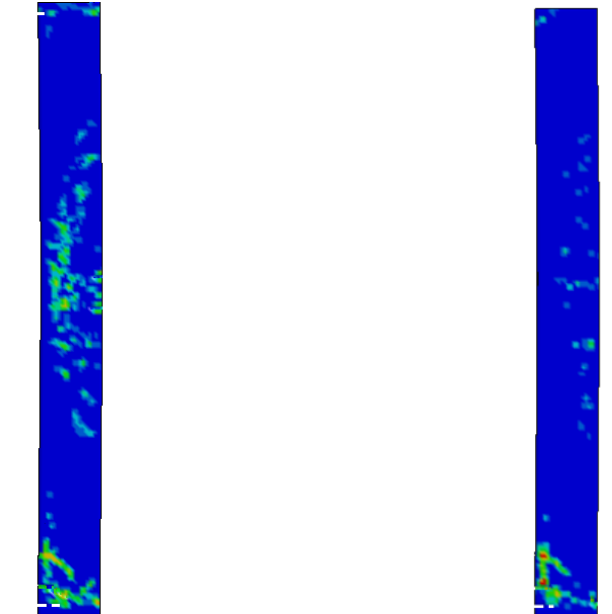

$\mathrm{ALR}=0.2$

$\mathrm{ALR}=0.35$

(c) Seismic 2

Figure 6-34: Damage profile for three column types under a blast load from a $100 \mathrm{~kg}$ charge mass at $\mathrm{z}=1.0 \mathrm{~m} / \mathrm{kg} 1 / 3$ recorded at 60 milliseconds 


\subsubsection{2 $250 \mathrm{~kg}$ Charge Mass}

Further increasing the charge mass to $250 \mathrm{~kg}$ at a $\mathrm{z}$ of $1.0 \mathrm{~m} / \mathrm{kg}^{1 / 3}$ while varying the ALRs resulted in the same pattern described in section 6.3.2.1 when the columns were subjected to the lower charge mass of $100 \mathrm{~kg}$.

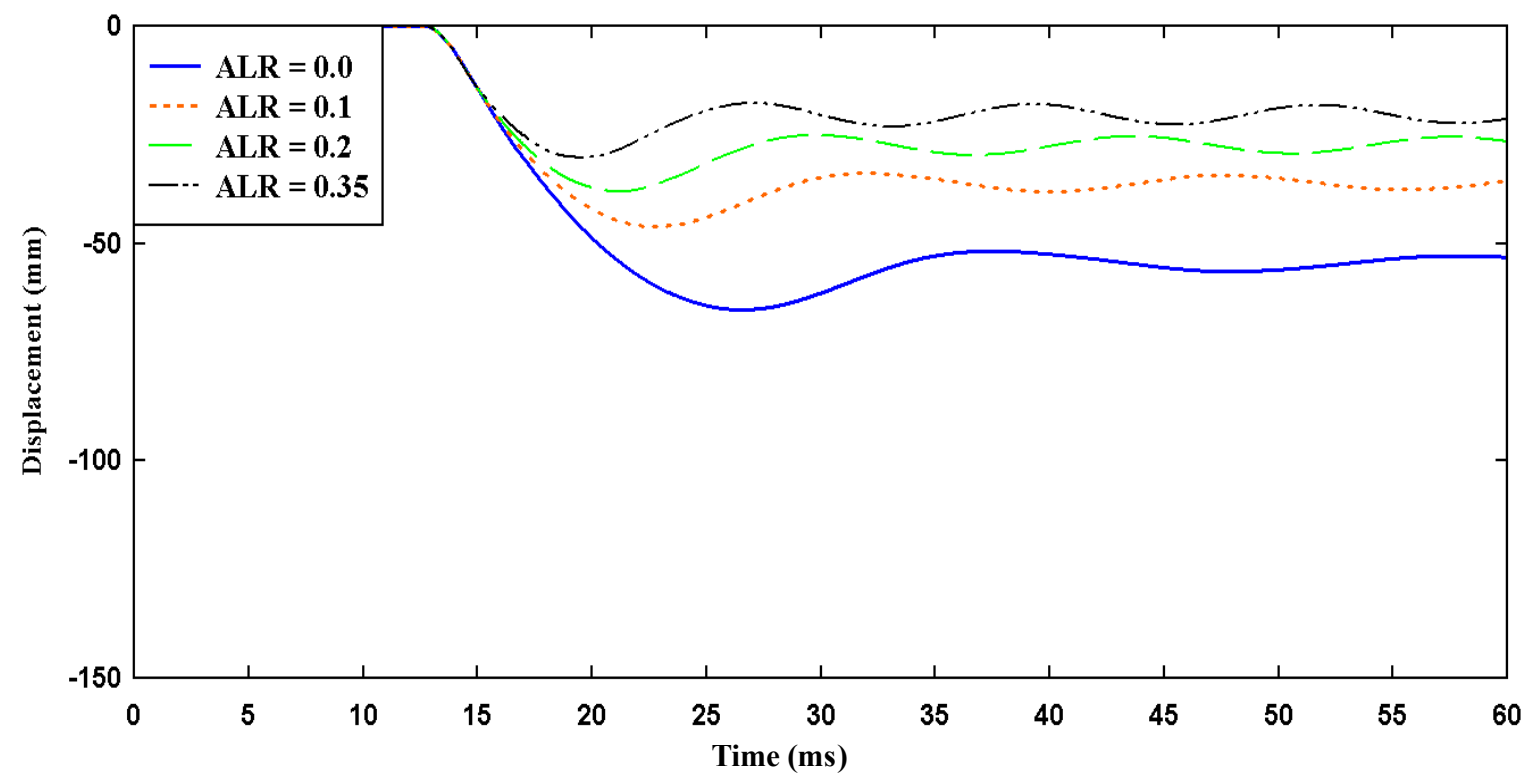

Figure 6-35: Displacement time history plot for a conventionally detailed $\mathrm{RC}$ column at $\mathrm{z}=1.0$ $\mathrm{m} / \mathrm{kg}^{1 / 3}$ using a $250 \mathrm{~kg}$ charge mass at different ALRs

Figure 6-35, Figure 6-36 and Figure 6-37 show the displacement-time history plots for the RC columns that have the conventional detailing, seismic 1 detailing and seismic 2 detailing respectively at z equals $1.0 \mathrm{using}$ a $250 \mathrm{~kg}$ charge mass with varying ALRs. The values of the maximum displacements for all three configurations at the various ALR values were observed to be very close (see Table 6-11). All column configurations also showed consistently decreasing lateral displacements with increasing axial load ratio. Again the increasing ALRs did not lead to concrete crushing and subsequent buckling of the longitudinal bars in the three different detailing schemes as was evident at the closer $\mathrm{z}$ of 0.8 (see Figure 6-38). 


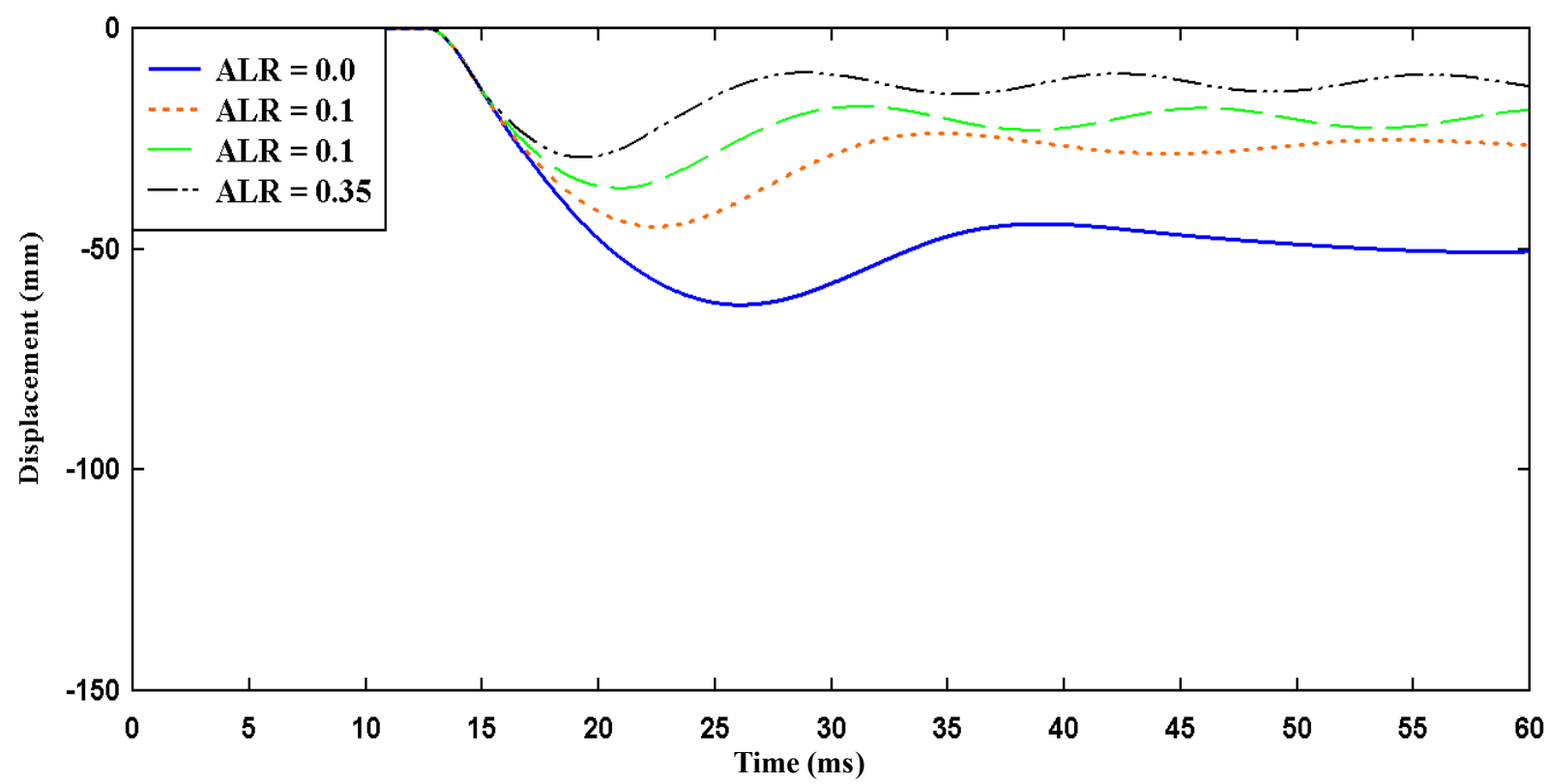

Figure 6-36: Displacement time history plot for $\mathrm{RC}$ column with seismic 1 detailing at $\mathrm{z}=1.0$ $\mathrm{m} / \mathrm{kg}^{1 / 3}$ using a $250 \mathrm{~kg}$ charge mass at different ALRs

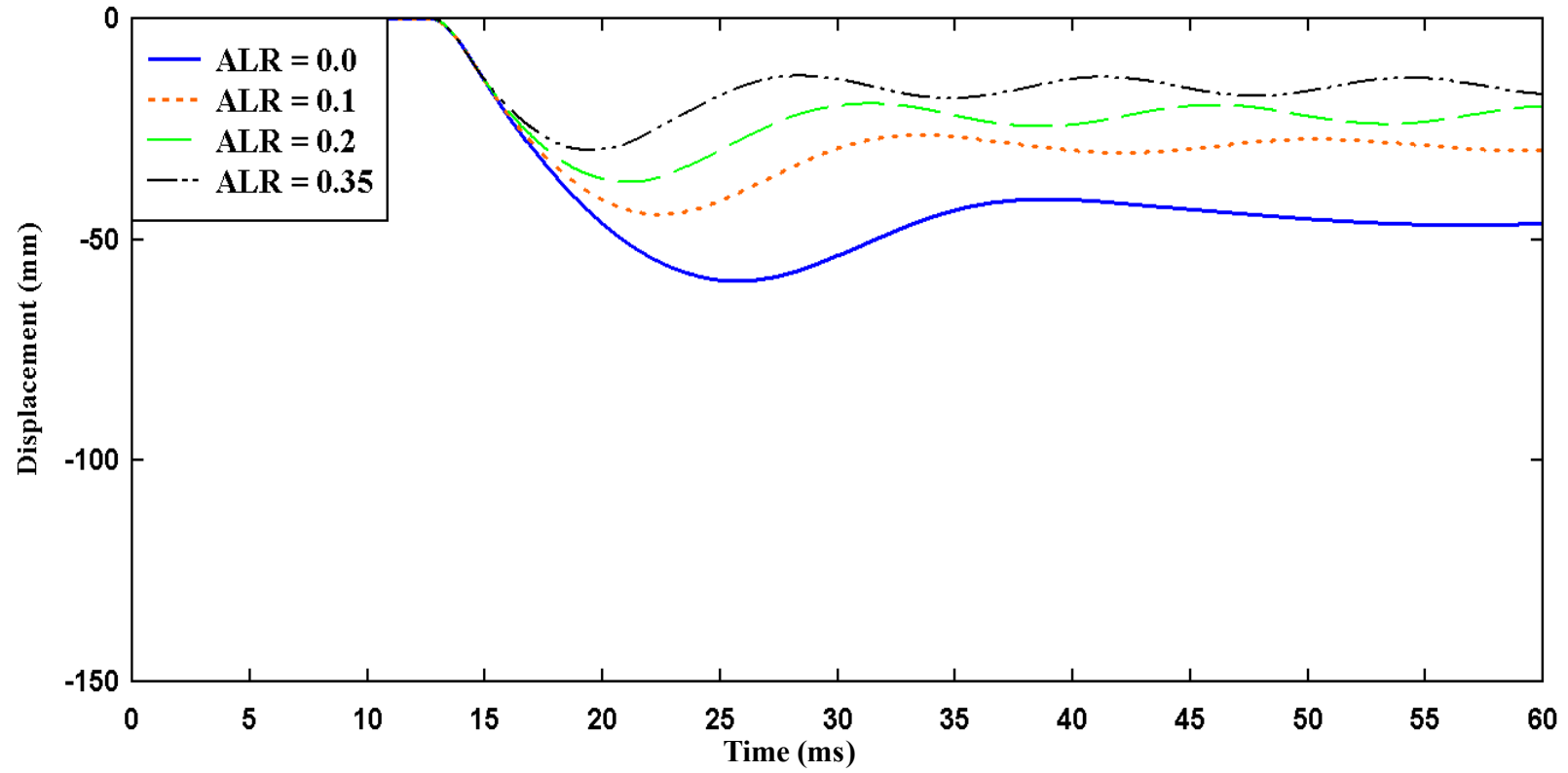

Figure 6-37: Displacement time history plot for $\mathrm{RC}$ column with seismic 2 detailing at $\mathrm{z}=1.0$ $\mathrm{m} / \mathrm{kg}^{1 / 3}$ using a $250 \mathrm{~kg}$ charge mass at different ALRs 

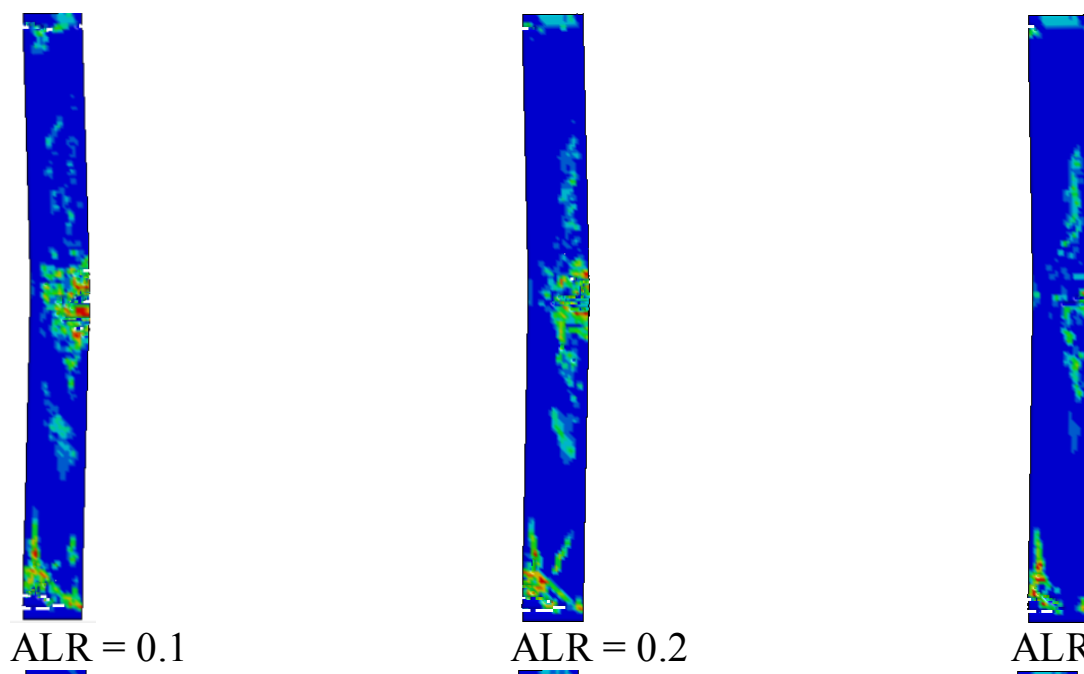

(a) Conventional

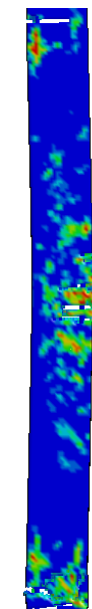

$\mathrm{ALR}=0.2$

$\mathrm{ALR}=0.35$
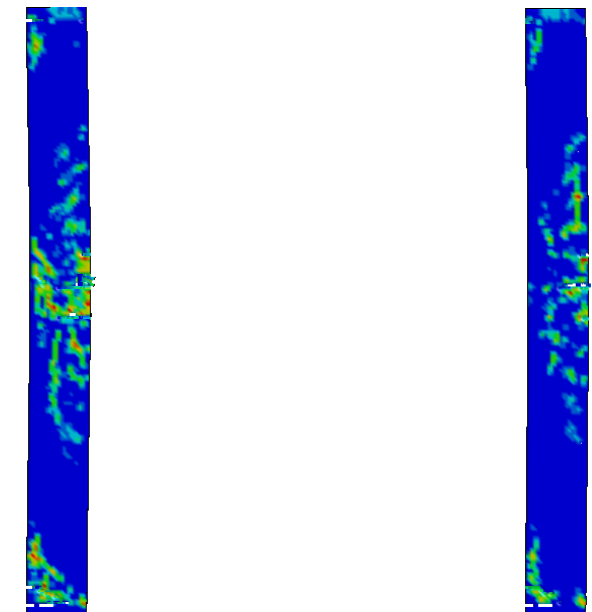

$\mathrm{ALR}=0.1$

$\mathrm{ALR}=0.2$

(b) Seismic 1
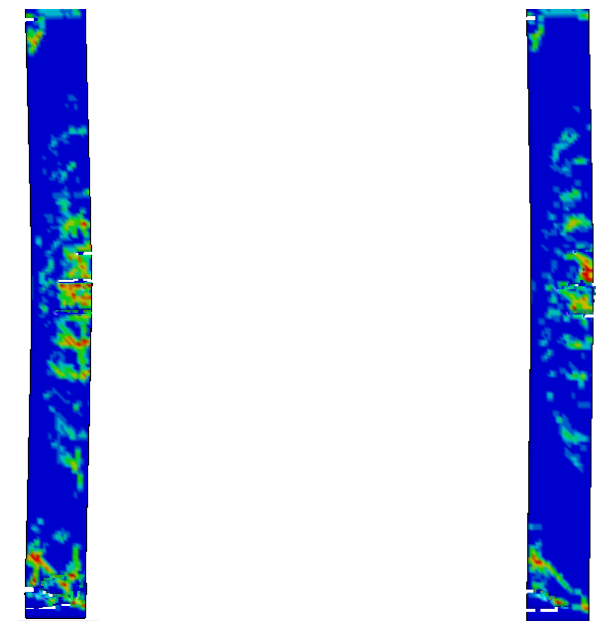

ALR $=0.35$

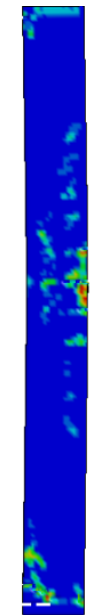

$\mathrm{ALR}=0.1$

$\mathrm{ALR}=0.2$

$\mathrm{ALR}=0.35$

(c) Seismic 2

Figure 6-38: Damage profile for three column types under a blast load from a $250 \mathrm{~kg}$ charge mass at $\mathrm{z}=1.0 \mathrm{~m} / \mathrm{kg} 1 / 3$ recorded at 60 milliseconds 
Table 6-11: Summary of displacements for $250 \mathrm{~kg}$ charge mass at $\mathrm{z}=1.0 \mathrm{~m} / \mathrm{kg} 1 / 3$

\begin{tabular}{|c|c|c|c|}
\hline & Conventional & Seismic 1 & Seismic 2 \\
\hline Ratio & Displacement & Displacement & Displacement \\
\hline 0.0 & 65.5 & 62.5 & 59.2 \\
\hline 0.1 & 46.1 & 45.2 & 45.2 \\
\hline 0.2 & 38.2 & 36.1 & 37.6 \\
\hline 0.35 & 30.7 & 29.7 & 29.7 \\
\hline
\end{tabular}

In general, at the same scaled distance increasing ALRs lead to increase in the stiffness of the columns leading to reduced lateral displacements. In the instances where the RC columns lost significant concrete cover in the mid-region sections, with accompanying crushing of the concrete in compression, the applied axial load caused the buckling of the exposed longitudinal bars as the transverse reinforcement was inadequate to provide lateral support.

At closer values of $\mathrm{z}$, the vulnerability of the conventionally detailed $\mathrm{RC}$ columns due to the widely spaced transverse reinforcement was exposed. The conventionally detailed RC columns failed at very low displacements due to the P- $\Delta$ effects caused by the simultaneous application of the lateral blast loading and the applied axial load.

The limiting axial load ratio value of 0.35 specified in CSA A.23.3-04 also becomes very significant with close in explosions. From the numerical work, it can be concluded that RC columns detailed with axial load ratios exceeding 0.35 are much more vulnerable to failure by crushing of concrete and subsequent buckling of the longitudinal bars even at much lower lateral 
displacement values than reinforced concrete columns having the lower axial load ratios acting on them, especially under close-in explosions.

At further values of $\mathrm{z}$, from $\mathrm{z}$ of 1.0 upwards, there were no significant advantages observed in the seismically detailed columns over the conventionally detailed columns even with increasing values of ALR. With less spalling and scabbing, the concrete core remained intact ensuring that the transverse bars provided the needed lateral support for the longitudinal bars 


\section{Chapter: CONCLUSION AND RECOMMENDATIONS}

\subsection{Summary}

The effect of blast loading on the performance of seismically detailed reinforced concrete columns was investigated. Current research shows various performance enhancement methods of RC columns to resist blast loading have been thoroughly investigated, yet very little has been done in studying the combined effect of lateral blast loading and axial loading on the performance of seismically detailed RC columns, specifically detailed in accordance with the National Building Code of Canada (NBCC).

The investigation was limited to the RC columns designed to predominantly resist gravity loads as well as accommodate significant amount of lateral deformation but not identified as part of the main seismic force resisting system. The minimum detailing requirements of Clause 21 of the Design of Concrete Structures code (CSA A23.3.04) were employed for the seismic detailing of the columns.

An experimental program (Farouk 2013) conducted at the Canadian Forces Base (Petawawa, Ontario) was used to validate the numerical finite element models, then parametric studies were carried out using the high fidelity physics-based finite element software package, LS-DYNA. An equivalent SDOF model was also developed to further validate the LS-DYNA numerical models.

\subsection{Conclusions}

The significant conclusions drawn from the numerical work presented in this thesis as follows:

- Reduction of transverse reinforcement spacing in $\mathrm{RC}$ columns resulted in reduced lateral displacements at lower scaled distances. The lateral displacements increased with increasing charge mass at constant scaled distance. 
- Reduction in transverse reinforcement spacing had insignificant effect on lateral displacement of RC columns at larger scaled distances.

- The gravity loads from upper stories on the behaviour of RC columns subjected to blast loading was reduced lateral displacement in general.

- At high axial load ratios, $\mathrm{RC}$ columns suffered scabbing and crushing of concrete and the subsequent buckling of longitudinal reinforcing bars in the mid-region at relatively low blast load levels, especially at low scaled distances.

- Generally, at the same scaled distance, increasing the magnitude of charge masses resulted in increased lateral displacement and much more extensive damage to the RC column, especially at smaller scaled distances. At higher scaled distance, however, the difference in the lateral displacements from different charge masses at the same scaled distance was observed to have decreased significantly.

\subsection{Recommendations}

Listed below are recommendations for future works:

- There is the need to extend the parametric studies to include different column sizes, different column shapes as well as different longitudinal reinforcement schemes.

- In the numerical works, the longitudinal bars were modelled as continuous throughout the entire length of the columns. The effect of longitudinal reinforcement lapping that usually occurs within RC column support regions needs to also be looked at in later research.

- A simple multi-degree of freedom system can also be developed to give a better estimate of RC column behaviour under blast loading. The multi-degree of freedom system can 
help predict blast loading effects involving explosives that are not located centrally with respect to the RC column.

- The research focused on RC columns that were identified as not part of the main seismic force resisting system. The structural components making up the seismic force resisting system in accordance to the NBCC can also be investigated in later research. 


\section{References}

Andersson, S., and Karlsson, H. (2012). "Structural Response of Reinforced Concrete Beams Subjected to Explosions." Masters Thesis, Chalmers University of Technology, Goteborg, Sweden.

Astarlioglu, S., Krauthammer, T., Morency, D., and Tran, T. P. (2013). "Behavior of reinforced concrete columns under combined effects of axial and blast-induced transverse loads." Engineering Structures, Elsevier Ltd, 55, 26-34.

Baker, W. E. (1973). Explosions in Air. University of Texas Press, Texas.

Bao, X., and Li, B. (2010). "Residual strength of blast damaged reinforced concrete columns." International Journal of Impact Engineering, 37(3), 295-308.

Battini, J. (2002). "Co-rotational beam elements in instability problems." PHD Thesis, Structural Engineering Department, KTH Royal Institute of Technology, Stockholm.

Belytschko, T., Schwer, L., and Klein, M. (1977). "Large displacement, transient analysis of space frames." International Journal for Numerical Methods in Engineering, 1(December 1975), 65-84.

Belytshko, T., Liu, W. K., Moran, B., and Elkhodary, K. I. (2014). Nonlinear Finite Elements for Continua and Structures. John Wiley \& Sons, Inc.

Biggs, J. M. (1964). Introduction to Structural Dynamics. McGraw-Hill College.

Byfield, M. (2006). "Behavior and design of commercial multistory buildings subjected to blast." Journal of performance of constructed facilities, (November), 324-329.

Carlsson, M., and Kristensson, R. (2012). "Structural Response with regard to explosions - Mode superposition, damping and curtailment.” Masters Thesis, Lund University, Lund, Sweden.

Carriere, M. D. (2006). "Steel reinforced polymer strengthening of reinforced concrete to resist blast loads.” Masters Thesis, Royal Military College (Canada).

Carriere, M., Heffernan, P. J., Wight, R. G., and Braimah, a. (2009). "Behaviour of steel reinforced polymer (SRP) strengthened $\mathrm{RC}$ members under blast loadThis paper is one of a selection of papers in the Special Issue on Blast Engineering." Canadian Journal of Civil Engineering, 36(8), 1356-1365.

CETS. (2000). Blast Mitigation for Structures: 1999 Status Report on the DTRA/TSWG Program. The National Academies Press, Washington, DC. 
Cooper, P. W. (1994). Comments on TNT equivalence. Sandia National Labs, Alburquerque, NM United States.

Corley, W. G., Sozen, M. A., Thornton, C. H., and Mlakar, P. F. (1996). The Oklahoma City Bombing: Improving Building Perforance Through Multi-Hazard Mitigation. Federal Emergency Management Agency Mitigation Directorate, FEMA Report 277.

Crawford, J. E. (2013). "State of the art for enhancing the blast resistance of reinforced concrete columns with fiber-reinforced plastic.” Canadian Journal of Civil Engineering, 40(11), $1023-1033$.

CSA. (2004). Design of Concrete Structures. Standard CSA A23.3-04. Canadian Standards Association, Mississauga, Ontario.

Davidson, J. S., Fisher, J. W., Hammons, M. I., and Porter, J. R. (2005). "Failure mechanisms of polymer-reinforced concrete masonry walls subjected to blast." Journal of Structural Engineering, 131(8), 1194-1205.

Davidson, J. S., Porter, J. R., Dinan, R. J., Hammons, M. I., and Connell, J. D. (2004). "Explosive Testing of Polymer Retrofit Masonry Walls." Journal of Performance of Constructed Facilities, 18(2), 100-106.

Elsanadedy, H. M., Almusallam, T. H., Abbas, H., Al-Salloum, Y. A., and Alsayed, S. H. (2011). "Effect of blast loading on CFRP-Retrofitted RC columns - a numerical study." Latin American Journal of Solids and Structures, 8(1), 55-81.

Ettouney, M., Smilowitz, R., and Rittenhouse, T. (1996). "Blast resistant design of commercial buildings.” Practice Periodical on Structural Design and Construction, 1(1), 31-39.

Fanning, P. (2001). "Nonlinear models of reinforced and post-tensioned concrete beams." Electronic Journal of Structural Engineering, 2, 111-119.

Farouk, S. (2013). "Experimental program conducted to test near-field blast loading on reinforced concrete columns.” Masters Thesis in Progress, Civil Engineering Department, Carleton University, Ottawa.

FEMA. (2003). Risk Management Series: Reference Manual to Mitigate Potential Terrorist Attack Against Buildings. Federal Emergency Management Agency.

Fitzmaurice, S. J., Salim, H., Dinan, R. J., Trawinski, E., Drive, B., and Afb, T. (2006). "Blast Retrofit Design of CMU Walls Using Polymer Sheets." University of Missouri.

Flathau, W. (1971). Dynamic tests of large reinforcing bar splices. Army Engineering Waterways experiment station, Vicksburg MS. 
Flores, L. M. (2004). "Performance of existing reinforced concrete columns under bidirectional shear and axial loading. Research Report." University of California.

Fu, H., Erki, M., and Seckin, M. (1991a). "Review of effects of loading rate on concrete in compression." Journal of structural engineering, 117(12), 3645-3659.

Fu, H., Erki, M., and Seckin, M. (1991b). "Review of effects of loading rate on reinforced concrete." Journal of structural engineering, 117(12), 3660-3679.

Fujikura, S. (2007). "Multihazard-Resistant Highway Bridge Pier-Bent." Student Research Accomplishments, University of Buffalo, New York.

Fujikura, S., and Bruneau, M. (2011). "Experimental investigation of seismically resistant bridge piers under blast loading." Journal of Bridge Engineering, 16(1), 63-71.

Fujikura, S., Bruneau, M., and Lopez-Garcia, D. (2008). "Experimental investigation of multihazard resistant bridge piers having concrete-filled steel tube under blast loading." Journal of Bridge Engineering, 13(6), 586-594.

Hallquist, J. O. (2004). "Recent developments in LS-DYNA Part II. 3rd LS-DYNA Forum 2004." Livermore Software Technology Corporation, 1-31.

Hallquist, J. O. (2006). LS-DYNA Theory Manual. Livermore Software Technology Corporation, Livermore, Carlifornia, 680.

Hargather, M. J. (2008). "Scaling, characterization, and application of Gram-Range explosive charges to blast testing of materials." PHD Thesis, Mechanical Engineering Department, Pennsylvania State University, Pennsylvania.

Hayes, J. R., Woodson, S., Pekelnicky, R. G., Poland, C. D., Corley, G., and Sozen, M. (2005). "Can strengthening for earthquake improve blast and progressive collapse resistance?" Journal of Structural Engineering, 131(8), 1157-1177.

Held, M. (1983). “TNT- Equivalent. Propellants, Explosives, Pyrotechnics.” 8(5), 158-167.

Høiset, S., Hjertager, B. H., Solberg, T., and Malo, K. A. (2000). "Flixborough revisited - an explosion simulation approach." Journal of hazardous materials, 77(1-3), 1-9.

Holmquist, T., Johnson, G., and Cook, W. (2011). "A computational constitutive model for concrete subjected to large strains, high strain rates, and high pressures." Journal of Applied Mechanics, 78(5), 591-600.

Hughes, T. J. R., and Liu, W. K. (1981). "Nonlinear finite element analysis of shells: Part I. three-dimensional shells." Computer Methods in Applied Mechanics and Engineering, 26(3), 331-362. 
Humar, J. L. (2012). Dynamics of Structures. CRC Press, Leiden, The Netherlands.

Hyde, D. W. (1988). Microcomputer Programs CONWEP and FUNPRO, Applications of TM 5855-1, "Fundamentals of Protective Design for Conventional Weapons" (User's Guide). US Army Engineer Waterways Experiment Station.

Jaime, M. (2011). "Numerical modeling of rock cutting and its associated fragmentation process using the finite element method." PHD Thesis, Civil Engineering Department, University of Pittsburgh.

Kamali, A. Z. (2012). "Shear Strength of Reinforced Concrete Beams subjected to Blast Loading." Masters Thesis, Department of Civil and Architectural Engineering, Royal Institute of Technology (KTH), Stockholm, Sweden.

Kinastowski, A. (2009). Recovery of Expenses for Propane Explosion Clean-Up. Municipal Law Legal Services, Toronto, Canada, 2-4.

Kitz, J. F. (1989). Shattered city: The Halifax explosion and the road to recovery. Nimbus Pub., Halifax, 212.

Kleine, H., Dewey, J. M., Ohashi, K., Mizukaki, T., and Takayama, K. (2003). "Studies of the TNT equivalence of silver azide charges." Shock Waves, 13(2), 123-138.

Lew, H. S. (2002). Case Study of the Alfred P. Murrah Federal Building. Gaithersburg.

Li, J., and Hao, H. (2013). "Numerical study of structural progressive collapse using substructure technique.” Engineering Structures, Elsevier Ltd, 52, 101-113.

Logan, D. L. (2006). A First Course in the Finite Element Method. Cengage Learning Engineering, Stamford, USA.

Low, H. Y., and Hao, H. (2002). "Reliability analysis of direct shear and flexural failure modes of RC slabs under explosive loading.” Engineering Structures, 24(2), 189-198.

LSTC. (2013). Keyword User's Manual: Material Models. Version, Livermore Software Technology Corporation, Livermore Carlifornia.

Luccioni, B., Ambrosini, R., and Danesi, R. (2004). "Analysis of building collapse under blast loads.” Engineering Structures, 26(1), 63-71.

MacGregor, J. G., and Bartlett, F. M. (2000). Reinforced Concrete Mechanics and Design. Pearson Education Canada Inc., Toronto. 
Magnusson, J. (2007). "Structural concrete elements subjected to air blast loading." Thesis, Civil and Architectural Engineering Department, Royal Institute of Technology, Stockholm, Sweden.

Malvar, L. (1998). "Review of static and dynamic properties of steel reinforcing bars." $A C I$ Materials Journal, (95), 609-614.

Malvar, L., and Crawford, J. (1998). "Dynamic increase factors for concrete." Naval Facilities Engineering Service center, Hueneme CA.

Malvar, L., Crawford, J., James, W., and Simons, D. (1997). "A plasticity concrete material model for DYNA3D.” International Journal of Impact Engineering, 19(9-10), 847-873.

Malvar, L., and Ross, C. (1998). "Review of strain rate effects for concrete in tension." $A C I$ Materials Journal, (95), 735-739.

Morrill, K., and Malvar, L. (2004). "Blast resistant design and retrofit of reinforced concrete columns and walls." Proc of structures ..., (818), 1-8.

Mosalam, K., and Mosallam, A. (2001). "Nonlinear transient analysis of reinforced concrete slabs subjected to blast loading and retrofitted with CFRP composites." Composites Part B: Engineering, 32, 623-636.

Murray, Y. (2007). Users manual for LS-DYNA concrete material model 159. Federal Highway Administration, Georgetown Pike, USA.

Murray, Y., Abu-Odeh, A., and Bligh, R. (2007). Evaluation of LS-DYNA Concrete Material Model 159. Federal Highway Administration, Georgetown Pike, USA.

Myers, J., Belarbi, A., and El-Domiaty, K. (2004). "Blast resistance of FRP retrofitted unreinforced masonry (URM) walls with and without arching action." The Masonry Society Journal, 22.1(2004).

Nard, H. Le, and Bailly, P. (2000). "Dynamic behaviour of concrete: the structural effects on compressive strength increase." Mechanics of Cohesive-fricitional Materials, 5(6), 491510.

Nassr, A. a., Razaqpur, a. G., Tait, M. J., Campidelli, M., and Foo, S. (2012). "Single and multi degree of freedom analysis of steel beams under blast loading." Nuclear Engineering and Design, Elsevier B.V., 242, 63-77.

Ngo, T., Mendis, P., and Krauthammer, T. (2007). "Behavior of Ultrahigh-Strength Prestressed Concrete Panels.” Journal of Structural Engineering, 133, 1582-1590. 
Norville, H. S., and Conrath, E. J. (2006). "Blast-Resistant Glazing Design.” Journal of Architectural Engineering, 12(3), 129-136.

NRC. (2005). National Building Code of Canada. National Research Council of Canada, Ottawa.

Parisi, F., and Augenti, N. (2012). "Influence of seismic design criteria on blast resistance of RC framed buildings: A case study." Engineering Structures, Elsevier Ltd, 44, 78-93.

Paultre, P. (2010). Dynamics of Structures. John Wiley \& Sons, Inc, Hoboken, USA.

PEC, and BakerRisk. (2008). U.S. Army Corps of Engineers Protective Design Center Technical Report. Methodology Manual for the Single-Degree-of- Freedom Blast Effects Design Spreadsheets.

Pritchard, D. K. (1981). "Breakage of glass windows by explosions." Journal of Occupational Accidents, 3(2), 69-85.

Remennikov, A. M. (2003). "A review of methods for predicting bomb blast effects on buidings.” Journal of Battlefield Technology, 6(3).

Rezaei, S. H. C. (2011). "Response of Reinforced Concrete Elements to High-Velocity Impact Load." PHD Thesis, Purdue University, West Lafayette, Indiana, US.

Roller, C., Mayrhofer, C., Riedel, W., and Thoma, K. (2013). "Residual load capacity of exposed and hardened concrete columns under explosion loads." Engineering Structures, Elsevier Ltd, 55, 66-72.

Ross, C., and Jerome, D. (1996). "Moisture and strain rate effects on concrete strength." $A C I$ Materials Journal, (93), 293-298.

Sachs, R. (1944). The dependence of blast on ambient pressure and temperature (Proj. 776). Ballistic Research Lab., Aberdeen Prooving Ground, Aberdeen.

Sezen, H. (2000). "Seismic Behavior and Modeling of Reinforced Concrete Building Columns." Vasa, University of California, Berkeley.

Sezen, H., and Moehle, J. (2004). "Strength and deformation capacity of reinforced concrete columns with limited ductility." Proceedings of the 13th World Conference on Earthquake Engineering.

Shi, Y., Li, Z.-X., and Hao, H. (2010). "A new method for progressive collapse analysis of RC frames under blast loading.” Engineering Structures, Elsevier Ltd, 32(6), 1691-1703.

Slavik, T. P. (2012). Blast Loading in LS-DYNA. Livermore Software Technology Corp., San Diego, USA. 
Smith, P. ., and Hetherington, J. . (1994). Blast and ballistic loading of structures. ButterworthHeinemann (Oxford and Boston).

Sochet, I. (2010). "Blast effects of external explosions." Eigth International Symposium on Hazards, Prevention, and Mitigation of Industrial Explosions, Yokohama: Japan, $(05 / 09 / 2010)$.

Stewart, M. (2006). "Terrorism risks and blast damage to built infrastructure." Natural Hazards Review, 7(3), 114-122.

Sun, E. Q. (2006). "Shear Locking and Hourglassing in MSC Nastran, ABAQUS , and ANSYS Shear Locking." MSC Software Users Conference.

Tavárez, F. (2001). "Simulation of behavior of composite grid reinforced concrete beams using explicit finite element methods."

TDPS. (2013). "Fertilizer Plant Explosion SITREP \#3.” Texas Department of Public Safety, Texas, 1-9.

U. S. Army Corps of Engineers. (2008). Structures to resist the effects of accidental explosions. United States of America Department of Defense, Washington DC, USA.

Williams, G., and Williamson, E. (2011). "Response of reinforced concrete bridge columns subjected to blast loads." Journal of Structural Engineering, 137(SPECIAL ISSUE: Commemorating 10 Years of Research since 9/11), 903-913.

Williamson, E., Bayrak, O., Daniel, W., and Carrie, D. (2010). Blast-resistant highway bridges: Design and detailing guidelines. National Cooperative Highway Research Program, Washington DC, USA.

Winget, D., Marchand, K. A., and Williamson, E. B. (2005). "Analysis and design of critical bridges subjected to blast loads." Journal of Structural Engineering, 131(8), 1243-1255.

Wu, K.-C., Li, B., and Tsai, K.-C. (2011a). "Residual axial compression capacity of localized blast-damaged RC columns.” International Journal of Impact Engineering, 38(1), 29-40.

Wu, K.-C., Li, B., and Tsai, K.-C. (2011b). "The effects of explosive mass ratio on residual compressive capacity of contact blast damaged composite columns." Journal of Constructional Steel Research, Elsevier Ltd, 67(4), 602-612.

Wu, Y., Crawford, J. E., Magallanes, J. M., and Way, N. H. (2012). "Concrete Constitutive Models." 12th International LS-DYNA Users conference, 2012, (1), 1-14.

Yan, D., and Lin, G. (2006). "Dynamic properties of concrete in direct tension." Cement and Concrete Research, 36(7), 1371-1378. 
Yusof, M., Norazman, N., Ariffin, Zain, F. M., Risby, and Ng, C. P. (2010). "Normal Strength Steel Fiber Reinforced Concrete Subjected to Explosive Loading." International Journal of Sustainable Construction Engineering and Technology, 1(2), 127-136.

Zhou, X. Q., Kuznetsov, V. a., Hao, H., and Waschl, J. (2008). "Numerical prediction of concrete slab response to blast loading." International Journal of Impact Engineering, 35(10), 1186-1200. 


\section{APPENDIX A: Implementation of the SDOF Numerical Model}

In order to perform the numerical integration on the equivalent SDOF equation of motion, input parameters have to be computed. The input parameters include the effective mass (Me), the equivalent stiffness $(\mathrm{Ke})$, the ultimate resistance $\left(\mathrm{r}_{\mathrm{u}}\right)$, the damping coefficient $(\mathrm{C})$ and the blast loading function.

\section{Effective Mass (Me)}

The effective mass is given by

$M_{e}=$ Volume of Column $\times$ Density of Concrete $\times k_{L M}$

Where $k_{L M}=$ load mass factor

The load mass factor can be obtained using the table below:

Table A 1: Load mass factors for different support types

\begin{tabular}{|l|c|c|}
\hline & \multicolumn{2}{|c|}{ Load Type } \\
\hline Support Type & Uniformly Distributed Load & Point Load \\
\hline Pinned - Pinned & 0.72 & 0.41 \\
\hline Pinned - Fixed & 0.72 & 0.395 \\
\hline Fixed - Fixed & 0.7175 & 0.35 \\
\hline Fixed - Free & 0.285 & 0.655 \\
\hline
\end{tabular}

\section{Equivalent Stiffness (Ke)}

The equivalent stiffness is also computed based on the support type and the load type.

$$
K_{e}=K E \times \text { Length of Column }
$$


The table below gives the values of the KE based on the combination of the support type and the load type.

Table A 2: Equivalent stiffness values for different support types

\begin{tabular}{|l|c|c|}
\hline & \multicolumn{2}{|c|}{ Load Type } \\
\hline Support Type & Uniformly Distributed Load & Point Load \\
\hline Pinned - Pinned & $\frac{384 \mathrm{EI}}{5 \mathrm{~L}^{4}}$ & $\frac{48 \mathrm{EI}}{\mathrm{L}^{3}}$ \\
\hline Pinned - Fixed & $\frac{160 \mathrm{EI}}{\mathrm{L}^{4}}$ & $\frac{106 \mathrm{EI}}{\mathrm{L}^{3}}$ \\
\hline Fixed - Fixed & $\frac{307 \mathrm{EI}}{\mathrm{L}^{4}}$ & $\frac{192 \mathrm{EI}}{\mathrm{L}^{3}}$ \\
\hline Fixed - Free & $\frac{8 \mathrm{EI}}{\mathrm{L}^{4}}$ & $\frac{3 \mathrm{EI}}{\mathrm{L}^{3}}$ \\
\hline
\end{tabular}

The values of $\mathrm{E}$ and I are given by

$\mathrm{E}=4500 \sqrt{\mathrm{F}_{\mathrm{dy}}}$

$\mathrm{I}=0.5\left(\mathrm{I}_{\mathrm{gt}}+\mathrm{I}_{\mathrm{cr}}\right)$

where $\mathrm{I}_{\mathrm{gt}}=$ the gross transformed moment of inertia

and $\mathrm{I}_{\mathrm{cr}}=$ the cracked moment of inertia

and $\mathrm{F}_{\mathrm{dy}}=$ dynamic flexural yield strength

Ultimate resistance $\left(\mathbf{r}_{u}\right)$

The ultimate resistance is given as a function of the maximum positive moment (Mp) and maximum negative moment $(\mathrm{Mn})$ of resistance of the $\mathrm{RC}$ cross-section.

$\mathrm{M}_{\mathrm{n}}=\mathrm{F}_{\mathrm{dy}} \mathrm{A}_{\mathrm{spos}}\left(\mathrm{d}-\frac{\mathrm{a}}{2}\right)$ 
$M_{p}=F_{d y} A_{\text {sneg }}\left(d-\frac{a}{2}\right)$

where $F_{d y}=$ dynamic flexural yield strength

$\mathrm{A}_{\text {spos }}=$ Area of steel in the compression region when column is under bending

$\mathrm{A}_{\text {sneg }}=$ Area of steel in the tension region when column is under bending

The ultimate resistance values depending on the support type and the loading type are given in the table below:

Table A 3: Ultimate resistance for different support types

\begin{tabular}{|l|c|c|}
\hline & \multicolumn{2}{|c|}{ Load Type } \\
\hline Support Type & Uniformly Distributed Load & Point Load \\
\hline Pinned - Pinned & $\frac{8 \mathrm{M}_{\mathrm{p}}}{\mathrm{L}^{2}}$ & $\frac{4 \mathrm{M}_{\mathrm{p}}}{\mathrm{L}}$ \\
\hline Pinned - Fixed & $\frac{4\left(\mathrm{M}_{\mathrm{n}}+2 \mathrm{M}_{\mathrm{p}}\right)}{\mathrm{L}^{2}}$ & $\frac{2\left(\mathrm{M}_{\mathrm{n}}+2 \mathrm{M}_{\mathrm{p}}\right)}{\mathrm{L}}$ \\
\hline Fixed - Fixed & $\frac{8\left(\mathrm{M}_{\mathrm{n}}+2 \mathrm{M}_{\mathrm{p}}\right)}{\mathrm{L}^{2}}$ & $\frac{4\left(\mathrm{M}_{\mathrm{n}}+\mathrm{M}_{\mathrm{p}}\right)}{\mathrm{L}}$ \\
\hline Fixed - Free & $\frac{2 \mathrm{M}_{\mathrm{n}}}{\mathrm{L}^{2}}$ & $\frac{\mathrm{M}_{\mathrm{n}}}{\mathrm{L}}$ \\
\hline
\end{tabular}




\section{Dynamic Increase Factors}

The dynamic increase factors used in the numerical integration are tabulated below:

Table A 4: Dynamic increase factors for concrete and steel

\begin{tabular}{|l|c|c|}
\hline & Steel Reinforcement & Concrete \\
\hline Flexure & 1.17 & 1.19 \\
\hline Direct Shear & 1.10 & 1.10 \\
\hline Diagonal Shear & 1.00 & 1.00 \\
\hline
\end{tabular}

\section{Damping (C)}

Damping is allowed into the equivalent SDOF model by incorporating a user-defined damping coefficient $(\xi)$.

$$
C=2 \sqrt{K_{e} M_{e}} \times \xi
$$

\section{Blast Load Function $(F(t))$}

The exponentially varying blast load is approximated by a triangular load pulse with a fictitious duration to simple the numerical integration solution. The fictitious duration $\left(\mathrm{t}_{\mathrm{dr}}\right)$ is given by:

$$
t_{d r f}=\frac{2 I_{r}}{P_{r}}
$$

The corresponding fictitious pressure $\left(\mathrm{P}_{\mathrm{rf}}\right)$ which is multiplied by the loading surface area and using as the load-time history is the numerical integration is given by:

$$
P_{r f}(t)=\left\{\begin{array}{cc}
P_{r}\left(1-\frac{t}{t_{d r f}}\right), & 0 \leq t \leq t_{d r f} \\
0, & t>t_{d r f}
\end{array}\right.
$$




\section{The numerical integration Procedure (Algorithm)}

For the numerical integration, the linear acceleration method was implemented though any of the other popular numerical integration methods can be implemented to give similar results.

The numerical integration procedure requires that certain initial parameters are computed. Some of the initial parameters are also computed to simplify subsequent computations.

\section{Initial Values}

$$
\begin{aligned}
& \mathrm{a}_{1}=\frac{3}{\Delta \mathrm{t}} ; \quad \mathrm{a}_{2}=\frac{6}{\Delta \mathrm{t}} ; \quad \mathrm{a}_{3}=\frac{\Delta \mathrm{t}}{2} ; \quad \mathrm{a}_{4}=\frac{6}{\Delta \mathrm{t}^{2}} \\
& \mathrm{R}_{\mathrm{t}}=\mathrm{r}_{\mathrm{u}} ; \quad \mathrm{R}_{\mathrm{c}}=-\mathrm{R}_{\mathrm{t}} \quad \mathrm{K}_{\mathrm{p}}=0 \\
& \mathrm{y}_{\mathrm{t}}=\frac{\mathrm{R}_{\mathrm{t}}}{\mathrm{K}_{\mathrm{e}}} ; \quad \mathrm{y}_{\mathrm{c}}=-\mathrm{y}_{\mathrm{t}} \\
& \mathrm{U}_{\mathrm{o}}=\dot{\mathrm{U}}_{\mathrm{o}}=0 ; \quad \ddot{\mathrm{U}}_{\mathrm{o}}=\frac{\mathrm{P}_{\mathrm{o}}}{\mathrm{M}_{\mathrm{e}}}
\end{aligned}
$$

where $\Delta \mathrm{t}=$ user - defined timeStep of numerical integration

and $\mathrm{R}_{\mathrm{t}}=$ material ultimate resistance in tension

and $\mathrm{R}_{\mathrm{c}}=$ material ultimate resistance in compression

and $\mathrm{U}_{\mathrm{o}}=$ intial displacement; $\quad \dot{\mathrm{U}}_{\mathrm{o}}=$ initial velocity; $\quad \ddot{\mathrm{U}}_{\mathrm{o}}=$ initial acceleration

$$
\mathrm{P}_{\mathrm{o}}=\text { load at initial timestep } \mathrm{t}=0
$$

The response parameters at each subsequent time step are then computed by implementing the procedure presented in the flow charts of the figures below: 


\section{Loop Through Each Time Step}

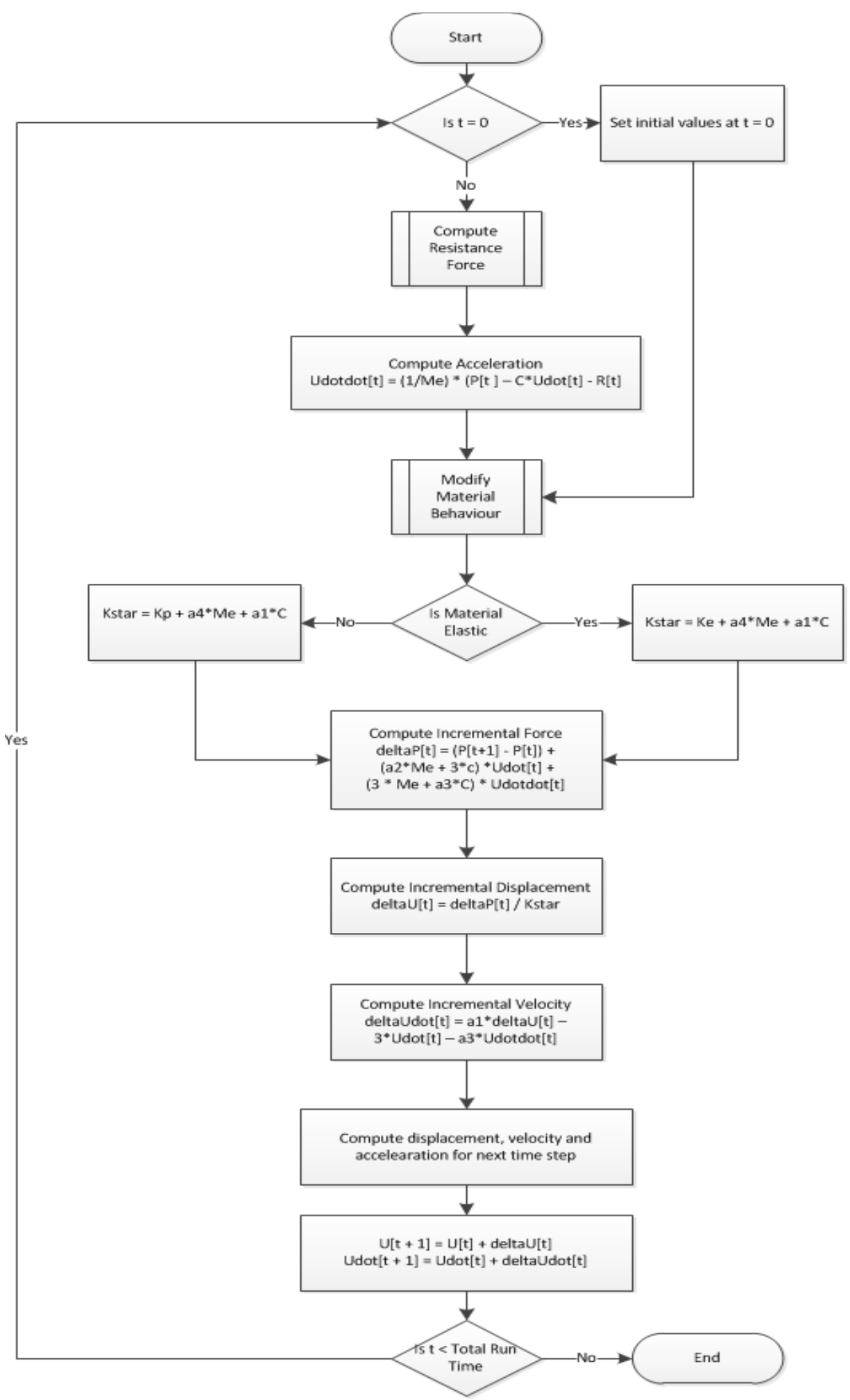

Figure A 1: Single Degree of Freedom Algorithm 


\section{Subroutine to Compute Resistance Force}

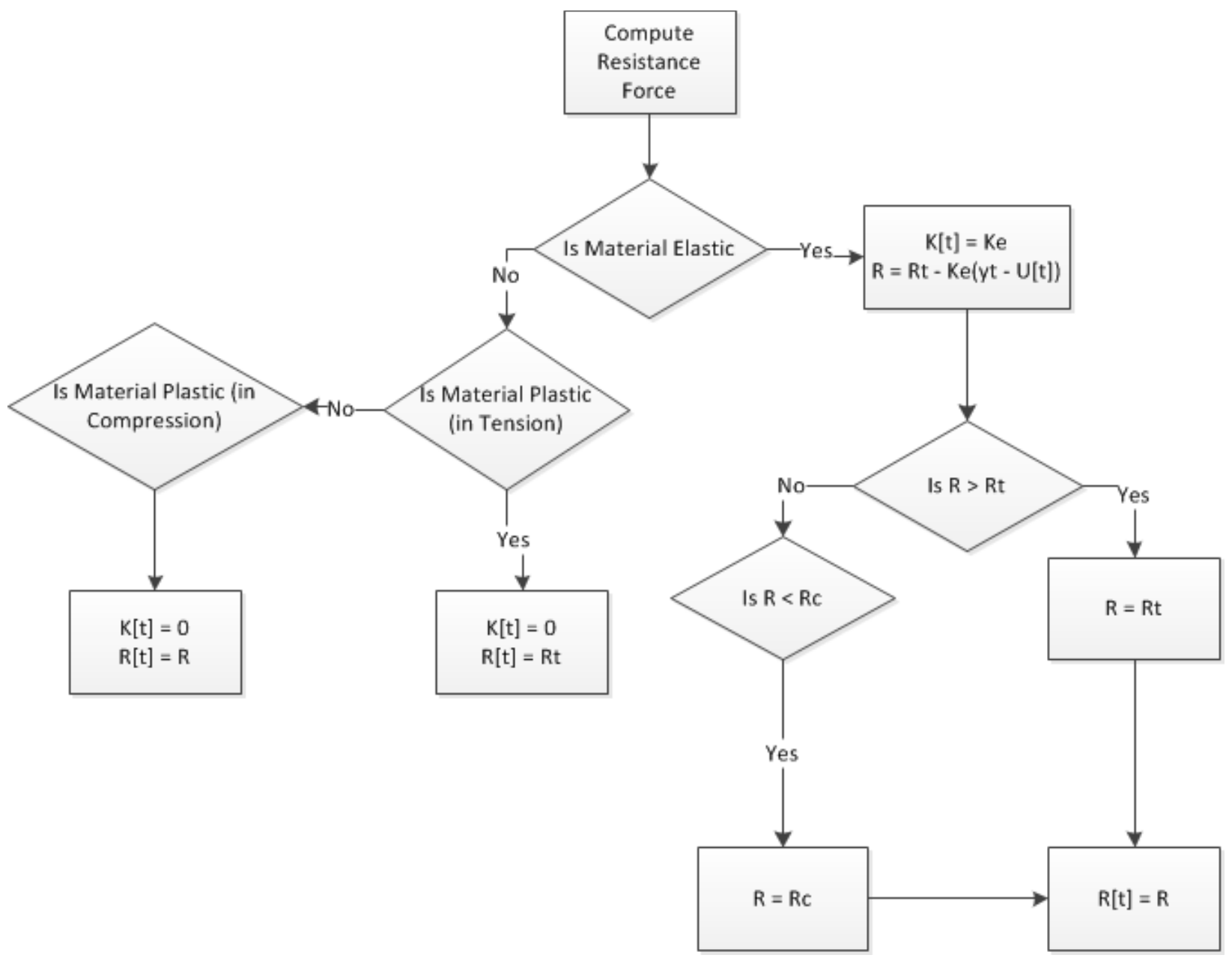

Figure A 2: Subroutine to Compute Resistance Force for SDOF model 


\section{Subroutine for modifying Material Behaviour}

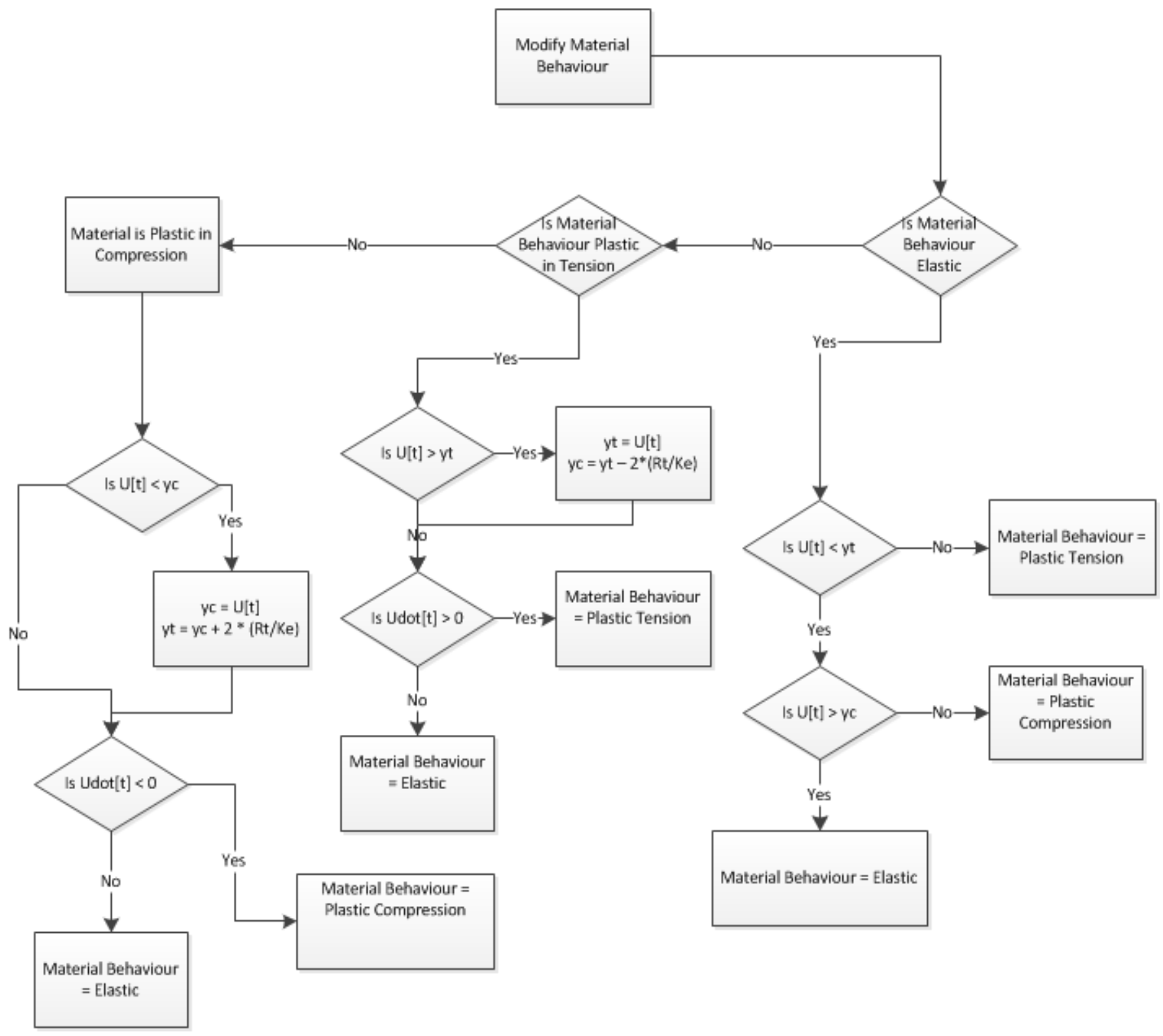

Figure A 3: Subroutine for modifying Material Behaviour for SDOF model 
Sample input parameters for the single degree of freedom (SDOF) model

The sample input values presented below were used to obtain blast loading output results for the developed SDOF model at a scaled distance of $1.0 \mathrm{~m} / \mathrm{kg}^{1 / 3}$ using a $100 \mathrm{~kg}$ charge mass.

Table A 5: Input parameters for sample SDOF model

\begin{tabular}{|c|c|}
\hline \multicolumn{2}{|l|}{ Blast Load Parameters } \\
\hline Scaled distance & $1.0 \mathrm{~m} / \mathrm{kg}^{1 / 3}$ \\
\hline Charge Mass & $100 \mathrm{~kg}$ \\
\hline Range & $4.64 \mathrm{~m}$ \\
\hline Blast Load Type & Hemispherical \\
\hline Reflected Pressure & $8152.46 \mathrm{kPa}$ \\
\hline Reflected Impulse & $4108.64 \mathrm{kPa}$ \\
\hline Positive Phase Duration & $8.05 \mathrm{~ms}$ \\
\hline \multicolumn{2}{|l|}{ Geometric Properties } \\
\hline \multicolumn{2}{|l|}{ Column Dimensions } \\
\hline Width & $300 \mathrm{~mm}$ \\
\hline Breadth & $300 \mathrm{~mm}$ \\
\hline Height & $3000 \mathrm{~mm}$ \\
\hline Support Type & Fixed - Fixed \\
\hline \multicolumn{2}{|l|}{ Material Properties } \\
\hline Area of steel & $1000 \mathrm{~mm}^{2}$ \\
\hline Young's Modulus of steel & $200000 \mathrm{MPa}$ \\
\hline Concrete compressive strength & $40 \mathrm{MPa}$ \\
\hline Concrete cover & $40 \mathrm{~mm}$ \\
\hline \multicolumn{2}{|c|}{ Dynamic concrete compressive strength } \\
\hline Flexure & $47.6 \mathrm{MPa}$ \\
\hline Diagonal shear & $40.0 \mathrm{MPa}$ \\
\hline Direct shear & $44.0 \mathrm{MPa}$ \\
\hline Yield strength of steel & $400 \mathrm{MPa}$ \\
\hline
\end{tabular}




\begin{tabular}{|l|l|}
\hline \multicolumn{2}{|l|}{ Dynamic steel compressive strength } \\
\hline Flexure & $514.8 \mathrm{MPa}$ \\
\hline Diagonal shear & $440.0 \mathrm{MPa}$ \\
\hline Direct shear & $484.0 \mathrm{MPa}$ \\
\hline Numerical Integration Parameters \\
\hline Ultimate resistance & $205.32 \mathrm{~N} / \mathrm{mm}$ \\
\hline Load mass factor & 0.72 \\
\hline Equivalent elastic stiffness & $56.2 \mathrm{~N} / \mathrm{mm}$ \\
\hline Mass of column & $648 \mathrm{~kg}$ \\
\hline Natural period & $10.43 \mathrm{~ms}$ \\
\hline Elastic yield deflection & $3.65 \mathrm{~mm}$ \\
\hline Time step & $0.01 \mathrm{~ms}$ \\
\hline Duration & $100 \mathrm{~ms}$ \\
\hline Critical damping coefficient & $3 \%$ \\
\hline
\end{tabular}

\section{Sample Output Results}

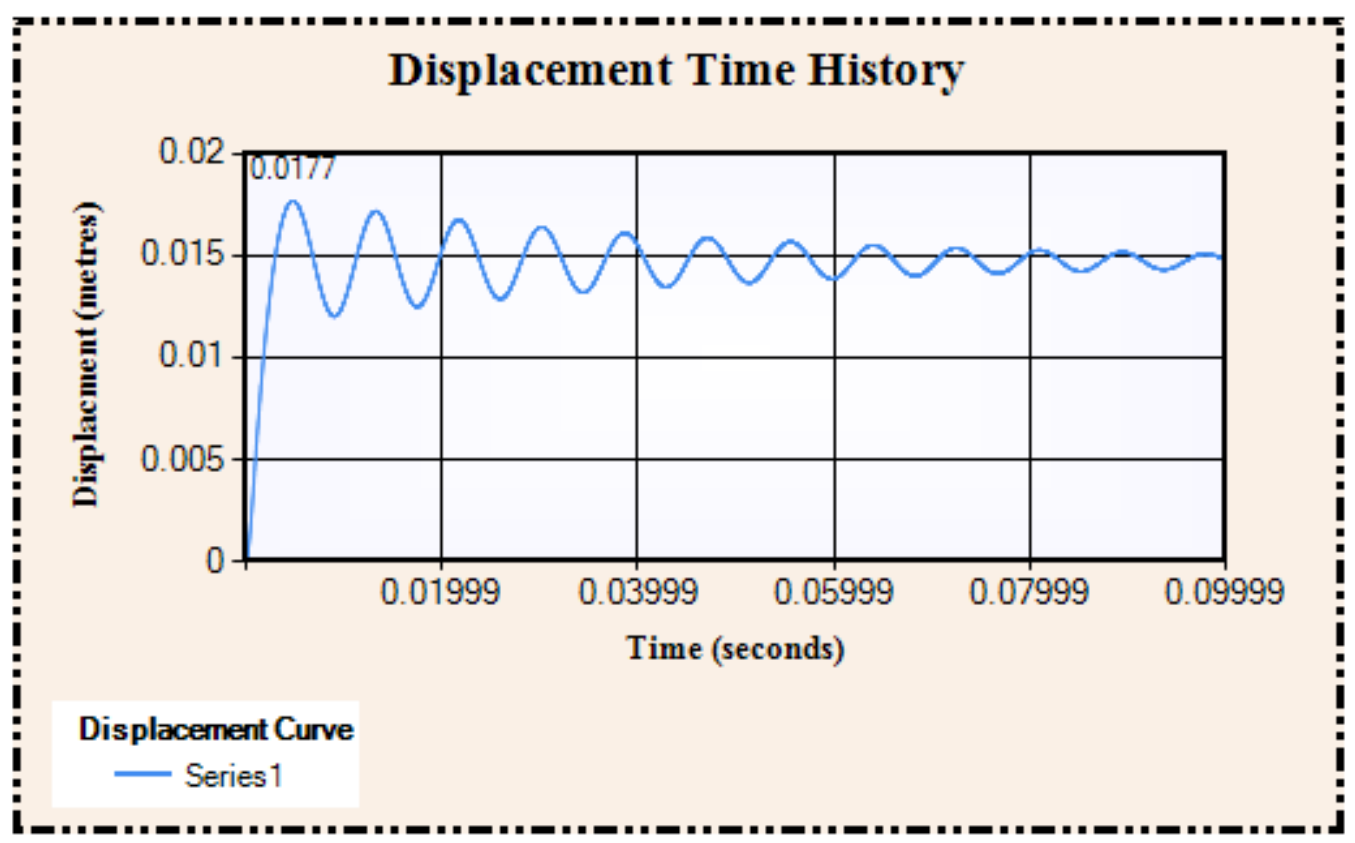

Figure A 4: Sample displacement time history plot from SDOF model 


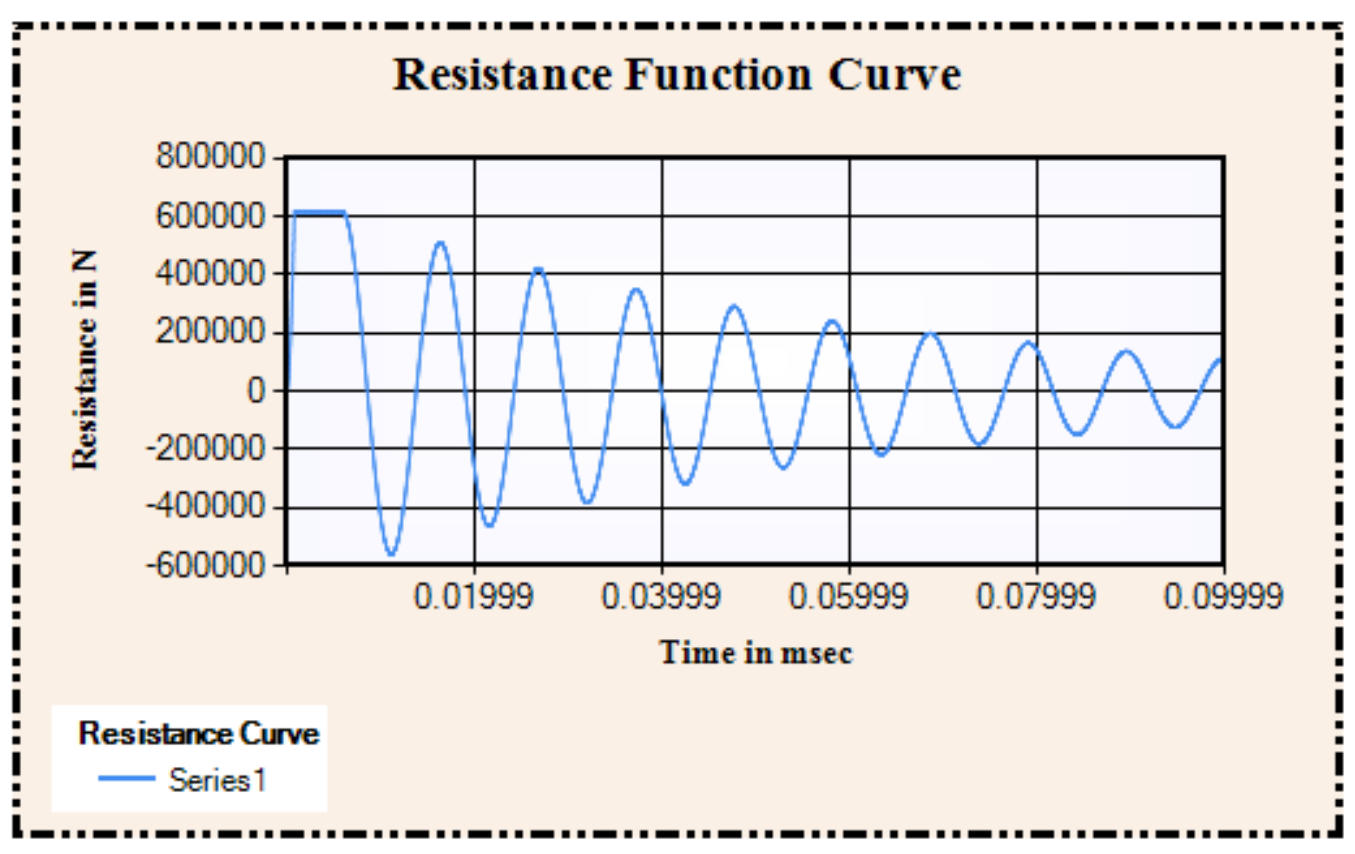

Figure A 5: Sample resistance function curve for SDOF model

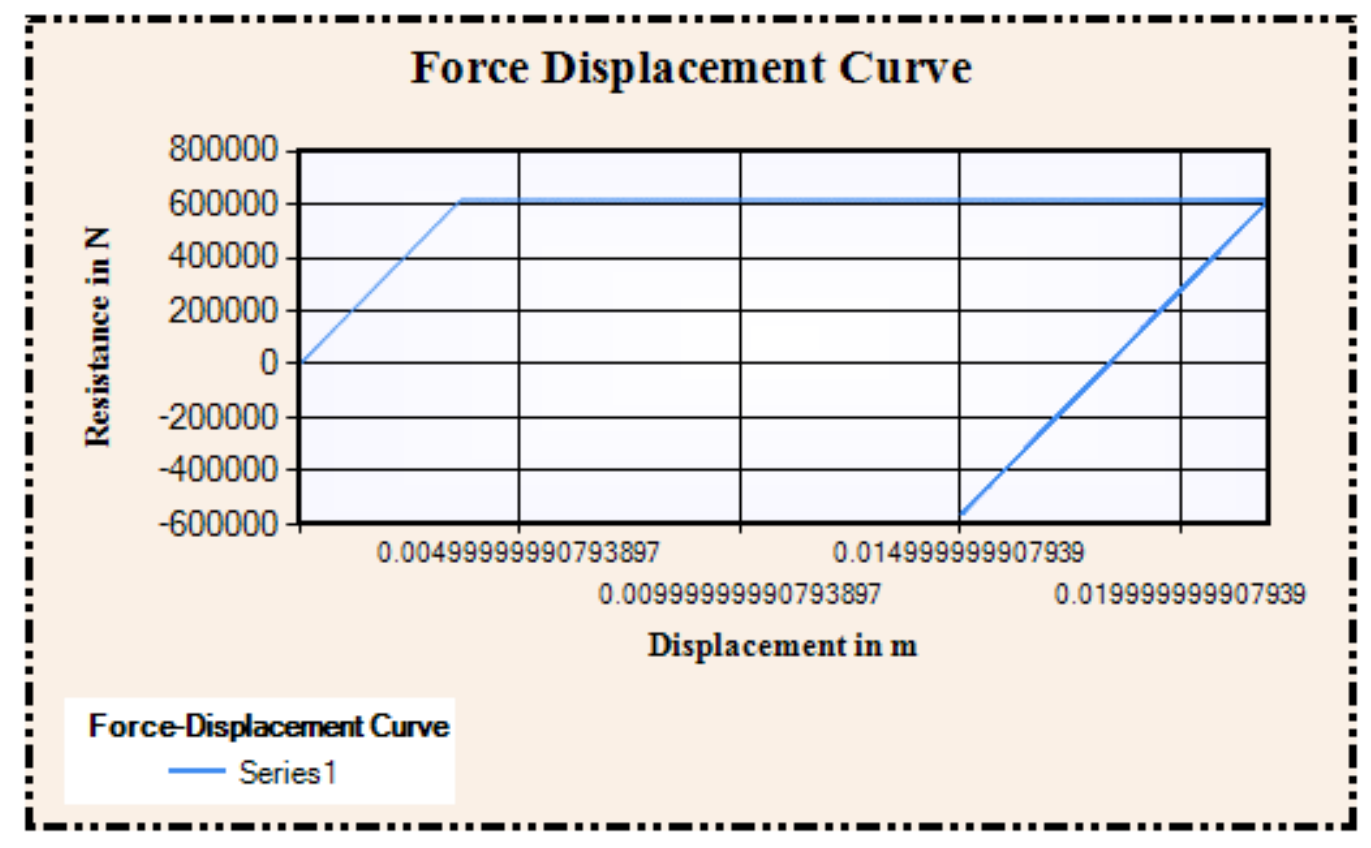

Figure A 6: Sample force displacement curve for SDOF model 


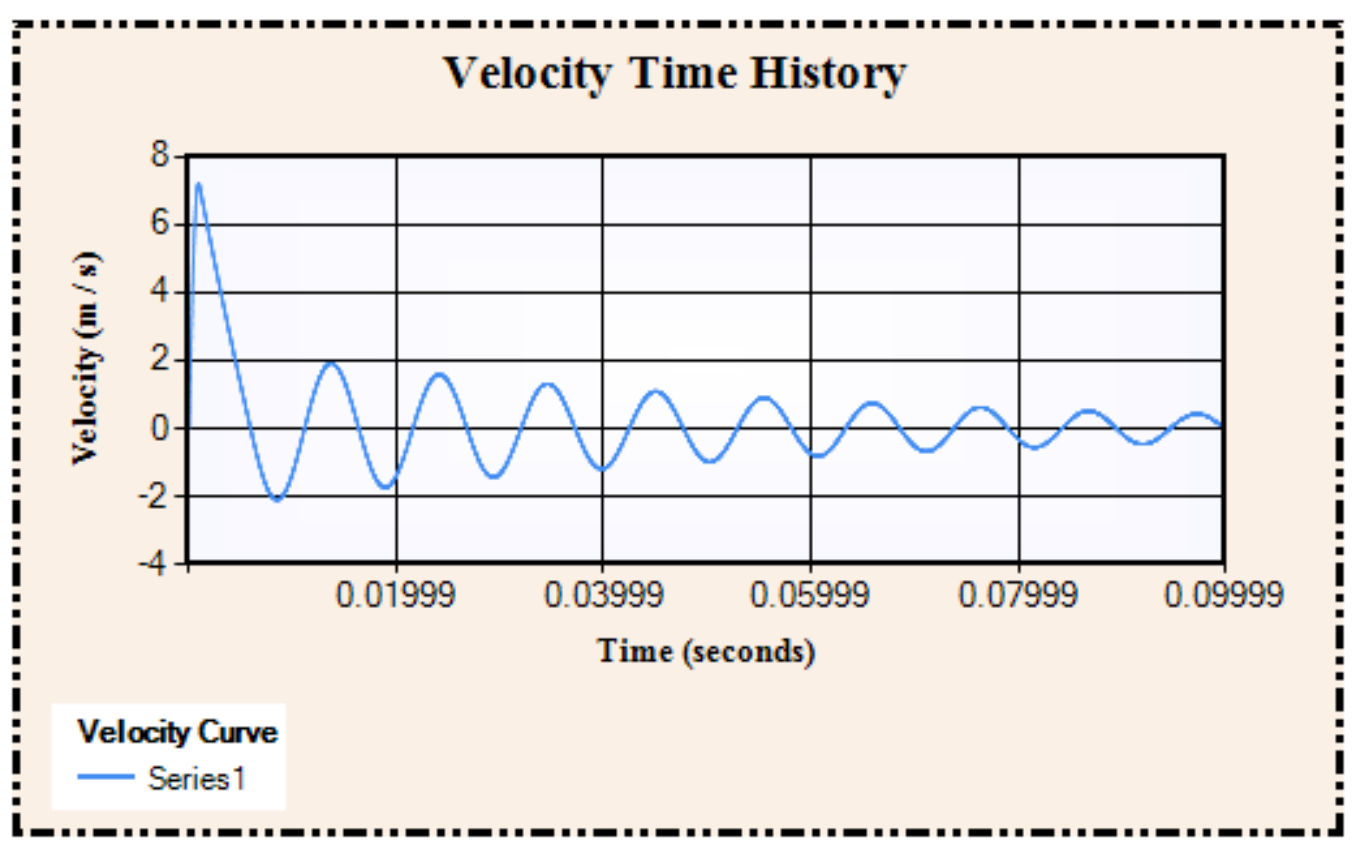

Figure A 7: Sample velocity history plot for SDOF model

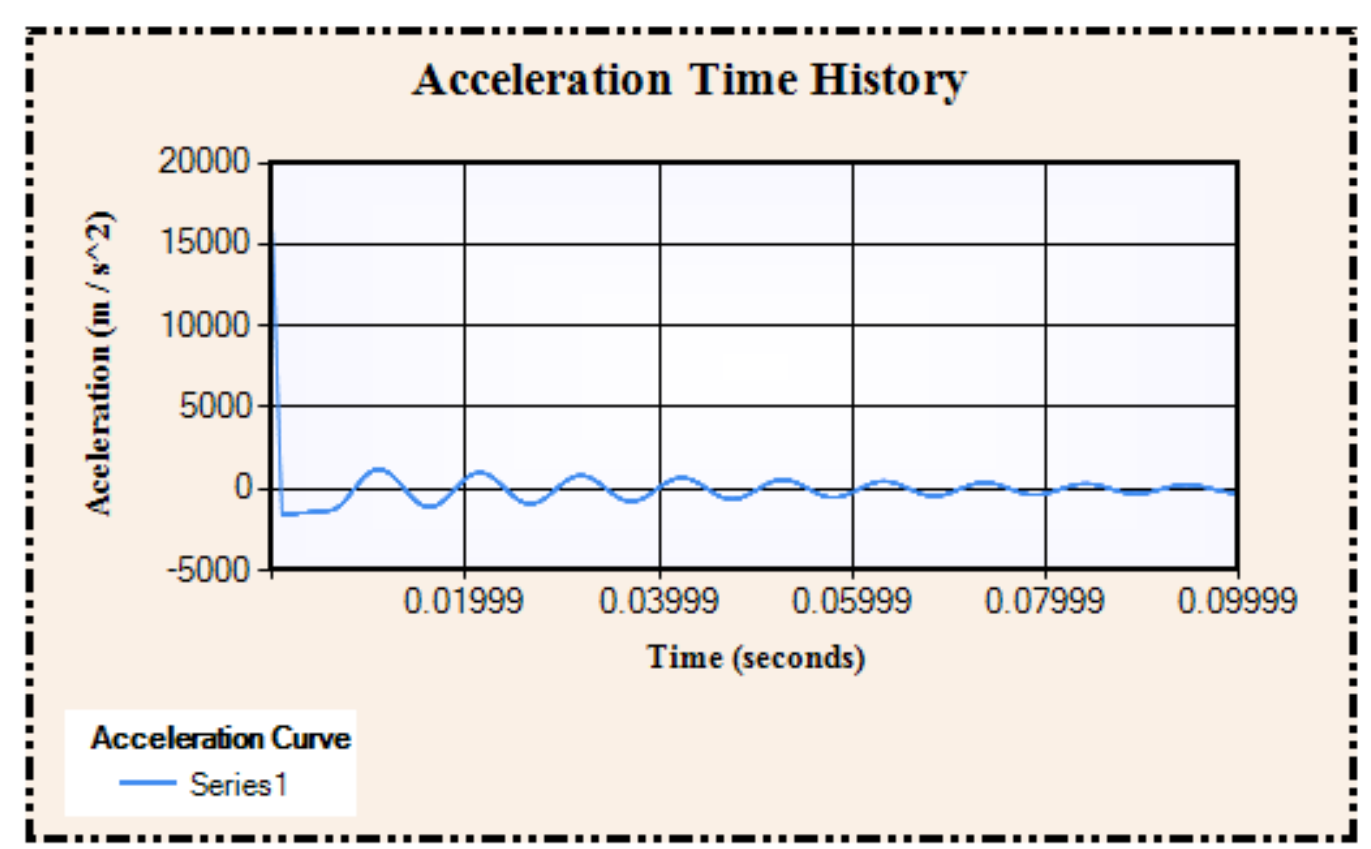

Figure A 8: Sample acceleration history plot for the SDOF model 


\section{The effect of damping coefficient on lateral deflection in SDOF analysis}

Damping coefficients varying from $0 \%$ to $5 \%$ were applied to the SDOF models to compare the effect of various critical damping ratio values to the LS-DYNA model. The Table below presents a comparison of the maximum lateral displacements of the SDOF models with the LS-DYNA numerical model at varying damping coefficients.

Table A 6: Effect of damping coefficient on lateral deflection in SDOF analysis

\begin{tabular}{|c|c|c|c|c|}
\hline $\begin{array}{c}\text { Critical damping } \\
\text { ratios }\end{array}$ & \multicolumn{4}{|c|}{ Maximum displacement values for SDOF Numerical Models } \\
& $\begin{array}{c}\text { Scaled distance of } \\
1.0 \mathrm{~m} / \mathrm{kg}\end{array}$ & $\begin{array}{c}\text { Scaled distance of } \\
1.3 \mathrm{~m} / \mathrm{kg}{ }^{1 / 3}\end{array}$ & $\begin{array}{c}\text { Scaled distance of } \\
1.5 \mathrm{~m} / \mathrm{kg}\end{array}$ & $\begin{array}{c}\text { Scaled distance of } \\
1 / 3\end{array}$ \\
\hline & $100 \mathrm{~kg}$ charge mass & $250 \mathrm{~kg}$ charge mass & $100 \mathrm{~kg}$ charge mass & $250 \mathrm{~kg}$ charge mass \\
\hline $0 \%$ & 20.2 & 35.4 & 7.5 & 11.8 \\
\hline $1 \%$ & 19.3 & 33.2 & 7.3 & 11.4 \\
\hline $\mathbf{3 \%}$ & $\mathbf{1 7 . 7}$ & $\mathbf{2 9 . 7}$ & $\mathbf{6 . 9}$ & 10.0 \\
\hline $5 \%$ & 16.3 & 26.9 & 6.5 & 9.9 \\
\hline LS-DYNA maximum & 15.4 & 27.4 & 7.4 & \\
\hline displacements & & & & \\
\hline
\end{tabular}




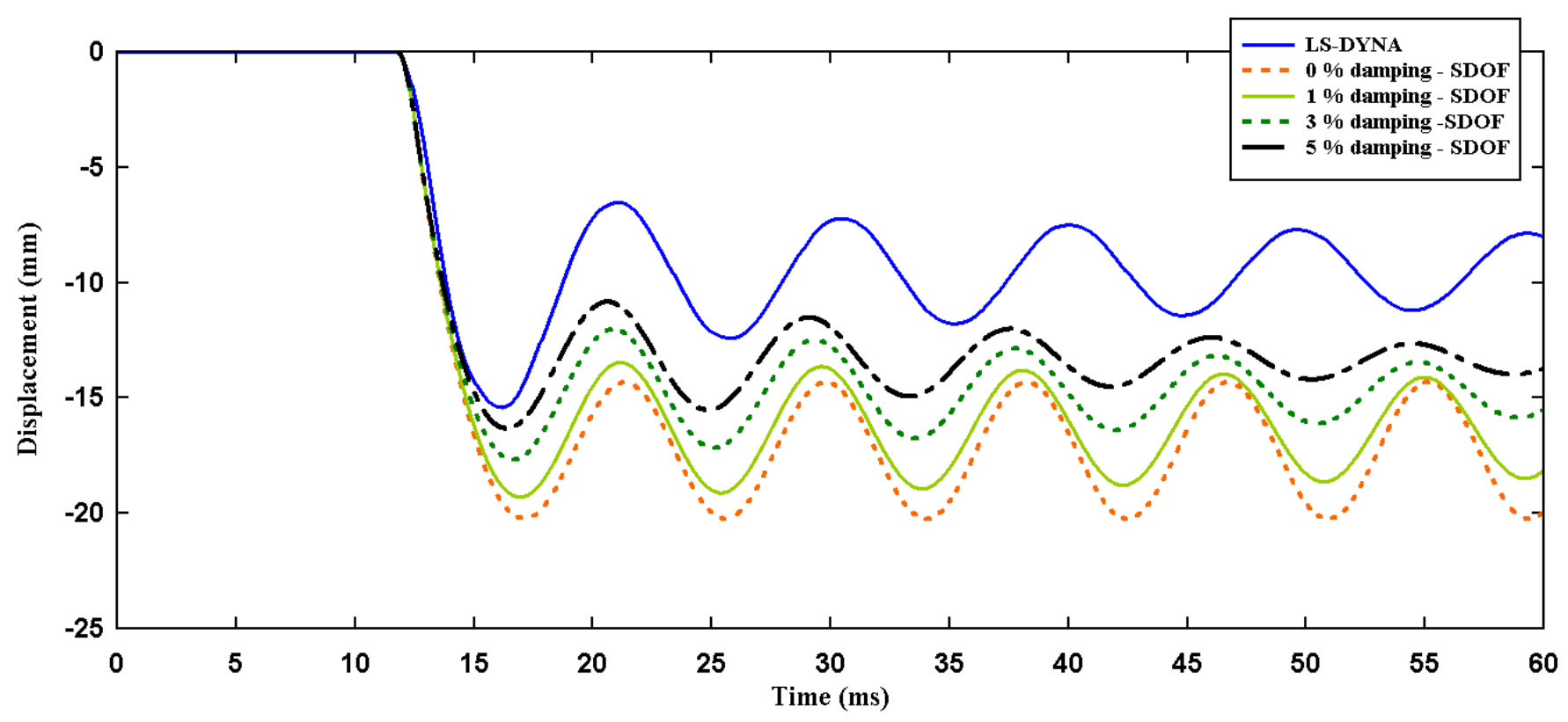

Figure A 9: Comparison of LS-DYNA and SDOF models with varying damping coefficients for a 100-kg charge mass at scaled distance of $1.0 \mathrm{~m} / \mathrm{kg}^{1 / 3}$

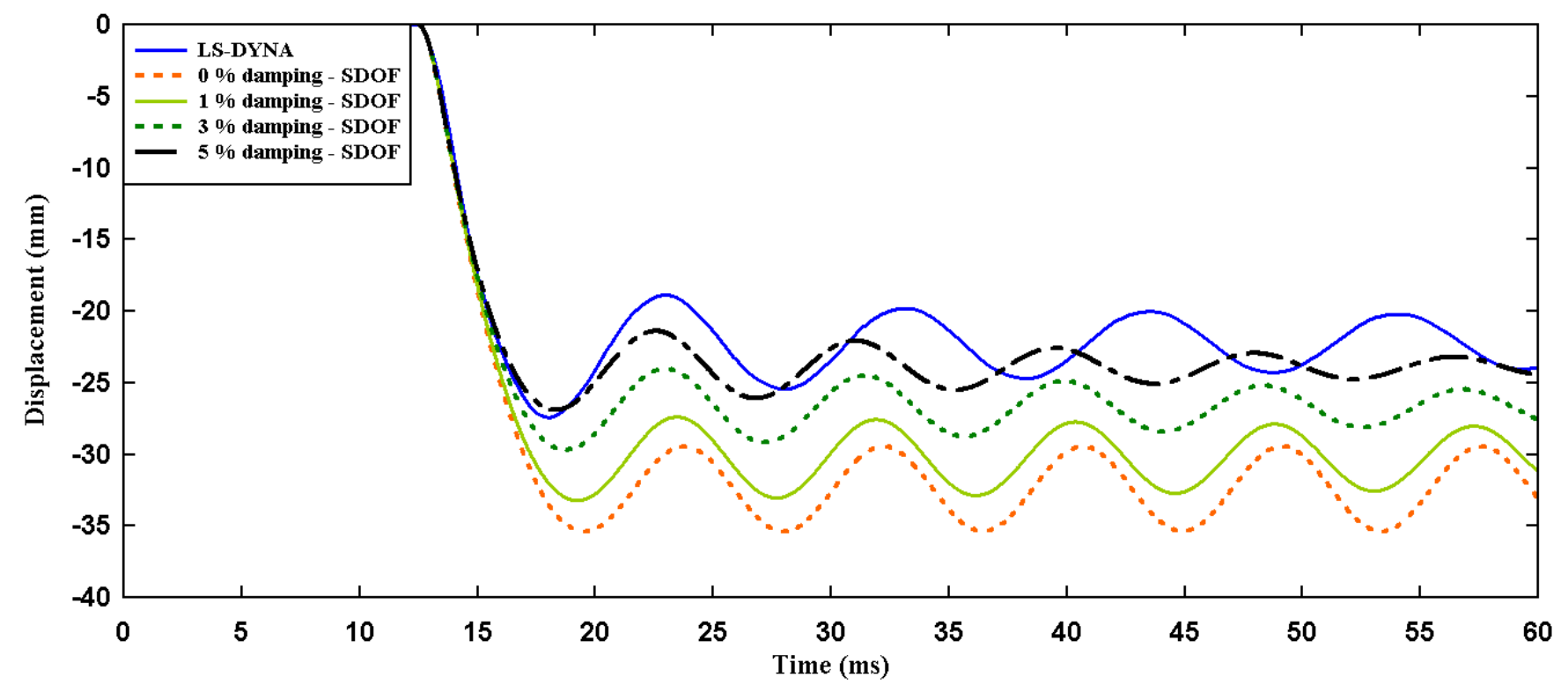

Figure A 10: Comparison of LS-DYNA and SDOF models with varying damping coefficients for a 250-kg charge mass at scaled distance of $1.0 \mathrm{~m} / \mathrm{kg}^{1 / 3}$ 


\section{APPENDIX B: Sample LS-DYNA input keycards used in numerical analysis}

Units: mass (g), distance (mm), time (ms)

PARTS OF MODEL

*PART (Concrete)

\begin{tabular}{|l|l|l|l|l|l|l|l|l|}
\hline \multicolumn{1}{|l|}{ TITLE } \\
\hline Concrete \\
\hline \multicolumn{10}{|l|}{} \\
\hline PID & SECID & MID & EOSID & HGID & GRAV & ADOPT & TMID \\
\hline 1 & 3 & 2 & 0 & 0 & 0 & 0 & 0 \\
\hline
\end{tabular}

*PART (Main Rebar)

\begin{tabular}{|c|c|c|c|c|c|c|c|}
\hline \multicolumn{8}{|c|}{ TITLE } \\
\hline \multicolumn{8}{|c|}{ Main Rebar } \\
\hline PID & SECID & MID & EOSID & HGID & GRAV & ADOPT & TMID \\
\hline 2 & 1 & 1 & 0 & 0 & 0 & 0 & 0 \\
\hline
\end{tabular}

*PART (Ties)

\section{TITLE}

\section{Ties}

\begin{tabular}{|l|l|l|l|l|l|l|l|}
\hline PID & SECID & MID & EOSID & HGID & GRAV & ADOPT & TMID \\
\hline 3 & 2 & 1 & 0 & 0 & 0 & 0 & 0 \\
\hline
\end{tabular}


*SET_PART_LIST

TITLE

\section{Reinforcement Set}

\begin{tabular}{|l|l|l|l|l|l|l|l|}
\hline SID & DA1 & DA2 & DA3 & DA4 & SOLVER & \multicolumn{2}{|l|}{} \\
\hline 1 & 0.0 & 0.0 & 0.0 & 0.0 & MECH & \multicolumn{2}{|l|}{} \\
\hline PID1 & PID2 & PID3 & PID4 & PID5 & PID6 & PID7 & PID8 \\
\hline 2 & 3 & 0 & 0 & 0 & 0 & 0 & 0 \\
\hline
\end{tabular}

\section{SECTIONS}

*SECTION_SOLID

\section{TITLE}

\section{Concrete}

\begin{tabular}{|l|l|l|}
\hline SECID & ELFORM & AET \\
\hline 3 & 1 & 0 \\
\hline
\end{tabular}

*SECTION_BEAM

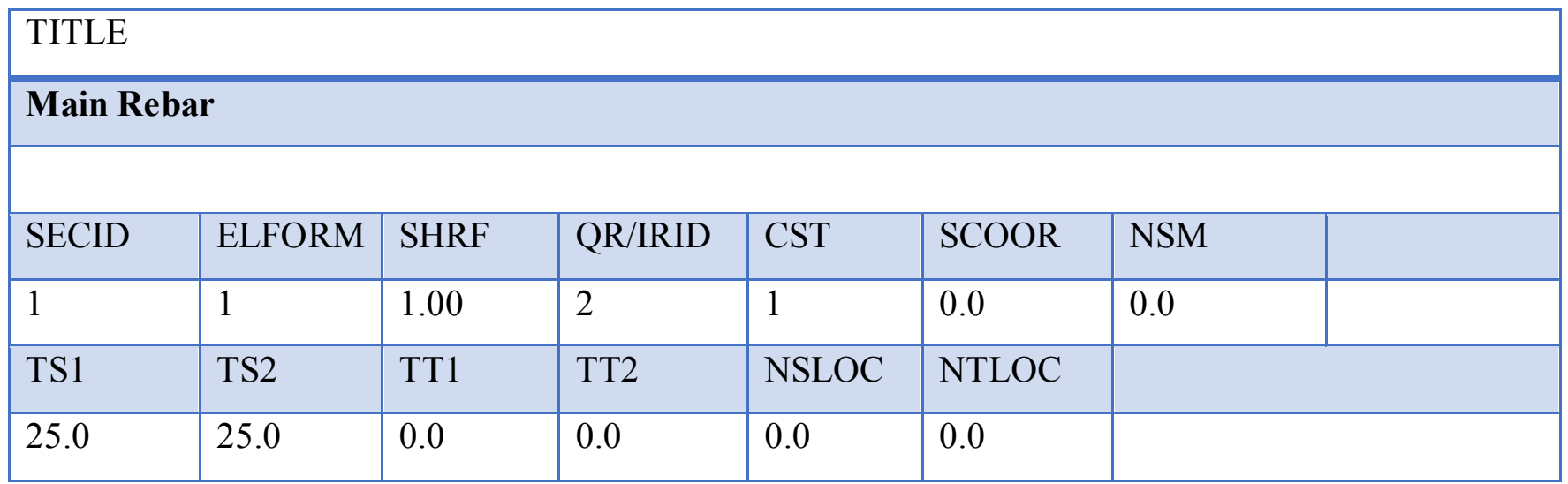


*SECTION_BEAM

\begin{tabular}{|l|l|l|l|l|l|l|l|}
\hline \multicolumn{7}{|l|}{ TITLE } \\
\hline Ties \\
\hline \multicolumn{7}{|l|}{$\mid$} \\
\hline SECID & ELFORM & SHRF & QR/IRID & CST & SCOOR & NSM & \\
\hline 2 & 1 & 1.00 & 2 & 1 & 0.0 & 0.0 & \\
\hline TS1 & TS2 & TT1 & TT2 & NSLOC & NTLOC & \\
\hline 10.0 & 10.0 & 0.0 & 0.0 & 0.0 & 0.0 & \\
\hline
\end{tabular}

MATERIAL CONSTITUTIVE MODELS

*MAT_PIECEWISE_LINEAR_PLASTICITY

TITLE

\section{Reinforcement}

\begin{tabular}{|l|l|l|l|l|l|l|l|}
\hline MID & RO & E & PR & SIGY & ETAN & FAIL & TDEL \\
\hline 1 & 0.00785 & $2.00 \mathrm{E} 5$ & 0.3 & 400 & 200 & $1.00 \mathrm{e} 21$ & 0.0 \\
\hline C & P & LCSS & LCSR & VP & \multicolumn{4}{|l|}{} \\
\hline 0.0 & 0.0 & 0 & 0 & 0.0 & \multicolumn{4}{|l|}{} \\
\hline EPS1 & EPS2 & EPS3 & EPS4 & EPS5 & EPS6 & EPS7 & EPS8 \\
\hline 0.0 & 0.0 & 0.0 & 0.0 & 0.0 & 0.0 & 0.0 & 0.0 \\
\hline ES1 & ES3 & ES3 & ES4 & ES5 & ES6 & ES7 & ES8 \\
\hline 0.0 & 0.0 & 0.0 & 0.0 & 0.0 & 0.0 & 0.0 & 0.0 \\
\hline
\end{tabular}


*MAT_CSCM_CONCRETE (159)

\begin{tabular}{|l|l|l|l|l|l|l|l|}
\hline \multicolumn{1}{|l|}{ TITLE } \\
\hline Concrete \\
\hline \multicolumn{7}{|l|}{} \\
\hline MID & RO & NPLOT & INCRE & IRATE & ERODE & RECOV & ITRETRC \\
\hline 2 & 0.0024 & 1 & 0.0 & 0 & 1.05 & 0 & 0 \\
\hline PRED & 1 & & & \\
\hline 0.0 & DPC & DAGG & UNITS & & & \\
\hline 40 & 19 & 1 & &
\end{tabular}

BONDING OF CONCRETE AND STEEL REINFORCEMENTS

*CONSTRAINED_LAGRANGE_IN_SOLID

\begin{tabular}{|l|l|l|l|l|l|l|l|}
\hline COUPID & TITLE \\
\hline 0 & $\begin{array}{l}\text { Coupling of Solid Element Concrete elements as (Master) to Beam Element } \\
\text { Reinforcement (Slave) }\end{array}$ \\
\hline SLAVE & MASTER & SSTYP & MSTYP & NQUAD & CTYPE & DIREC & MCOUP \\
\hline 1 & 1 & 0 & 1 & 0 & 2 & 1 & 0 \\
\hline START & END & PFAC & FRIC & FRCMIN & NORM & NORMTYP & DAMP \\
\hline 0.0 & $1 \mathrm{e} 10$ & 0.1 & 0.0 & 0.5 & 0 & 0 & 0.0 \\
\hline CQ & HMIN & HMAX & ILEAK & PLEAK & LCIDPOR & NVENT & BLOCKAGE \\
\hline 0.0 & 0.0 & 0.0 & 0 & 0.1 & 0 & 0 & 0 \\
\hline VENTSID & VENTYP & VTCOEF & POPPRES & COEFLC & & & \\
\hline 0 & 0 & 0 & 0 & 0 & & & \\
\hline
\end{tabular}




\section{LOADING}

*LOAD_BLAST_ENHANCED

\begin{tabular}{|l|l|l|l|l|l|l|l|}
\hline \multicolumn{7}{|l|}{ TITLE } \\
\hline \multicolumn{2}{|l|}{ Load blast Enhanced } \\
\hline BID & M & XBO & YBO & ZBO & TBO & UNIT & BLAST \\
\hline $\mathbf{1}$ & $2.00 \mathrm{e} 4$ & 1360.0 & 0.0 & 1200.0 & 10.0 & 5 & 4 \\
\hline CFM & CFL & CFT & CFP & NIDBO & DEATH & NEGPHS & \\
\hline $\mathbf{0 . 0 0 2 2 0 5}$ & 0.003281 & 1.00 & 145.0 & 0 & $1.00 \mathrm{e} 20$ & 0 & \\
\hline GNID & GVID & & & & & & \\
\hline $\mathbf{1}$ & 1 & & & & & & \\
\hline
\end{tabular}

*DEFINE_CURVE

TITLE

Axial Load Curve

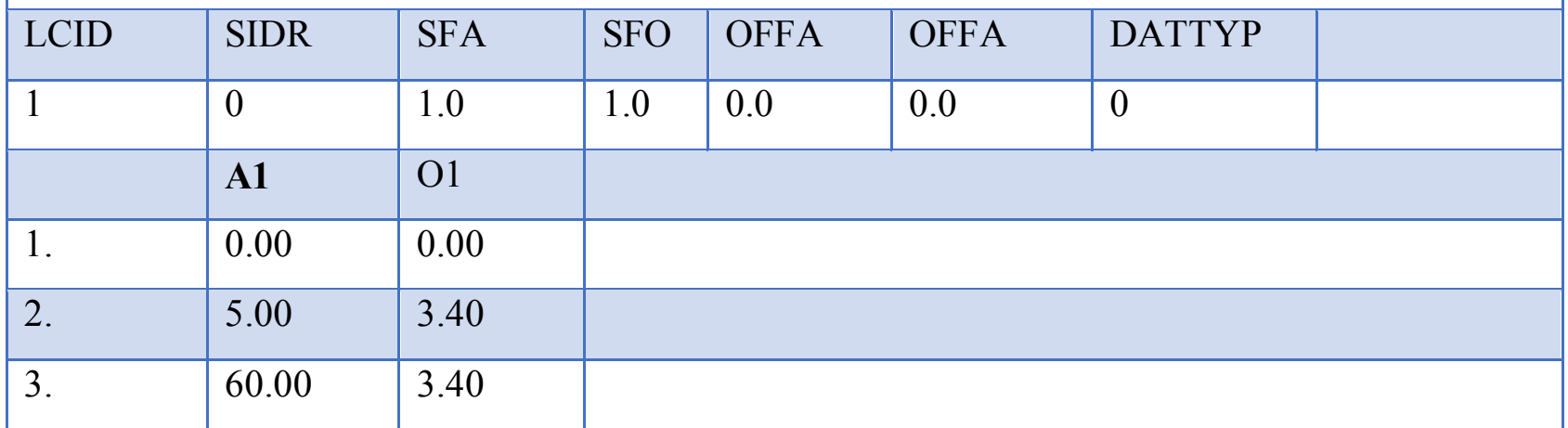

Note: This is for a sample curve for an axial load corresponding to ALR $=0.1$ 
*DEFINE_VECTOR

\section{TITLE}

Vector perpendicular to the ground surface plane

\begin{tabular}{|l|l|l|l|l|l|l|l|}
\hline \multicolumn{10}{|c|}{ VID } & XT & YT & ZT & XH & YH & ZH & CID \\
\hline 1 & 0.0 & 0.0 & 0.0 & 0.0 & 0.0 & 1.0 & 0.0 \\
\hline
\end{tabular}

\section{SOLUTION AND OUTPUT KEYCARDS}

*CONTROL_ENERGY

\begin{tabular}{|l|l|l|l|}
\hline HGEN & RWEN & SLNTEN & RYLEN \\
\hline 2 & 2 & 1 & 1 \\
\hline
\end{tabular}

*CONTROL_TERMINATION

\begin{tabular}{|l|l|l|l|l|}
\hline ENDTIM & ENDCYC & DTMIN & ENDENG & ENDMAS \\
\hline 60 & 0 & 0.05 & 0.0 & 0.0 \\
\hline
\end{tabular}

*DATABASE_BINARY_D3PLOT

\begin{tabular}{|l|l|l|l|l|}
\hline DT & LCDT & BEAM & NPLTC & PSETID \\
\hline 0.05 & 0 & 0 & 0 & 0 \\
\hline
\end{tabular}

*DATABASE_BINARY_D3HDT

\begin{tabular}{|l|l|l|l|l|}
\hline DT & LCDT & BEAM & NPLTC & PSETID \\
\hline 0.05 & 0 & 0 & 0 & 0 \\
\hline
\end{tabular}


*DATABASE_BINARY_INTFOR

\begin{tabular}{|l|l|l|l|l|}
\hline DT & LCDT & BEAM & NPLTC & PSETID \\
\hline 0.05 & 0 & 0 & 0 & 0 \\
\hline
\end{tabular}

*DATABASE_EXTENT_BINARY

\begin{tabular}{|l|l|l|l|l|}
\hline DT & LCDT & BEAM & NPLTC & PSETID \\
\hline 0.05 & 0 & 0 & 0 & 0 \\
\hline
\end{tabular}

*DATABASE_EXTENT_BLSTFOR

\begin{tabular}{|l|l|l|l|l|}
\hline DT & LCDT & BEAM & NPLTC & PSETID \\
\hline 0.05 & 0 & 0 & 0 & 0 \\
\hline
\end{tabular}

